SERVIÇO DE PÓS-GRADUAÇÃO DO ICMC-USP

Data de Depósito:

Assinatura:

\title{
Combinação de métodos de inteligência artificial para fusão de sensores
}

\author{
Katti Faceli \\ Orientador: Prof. Dr. André C. P. L. F. de Carvalho
}

Dissertação apresentada ao Instituto de Ciências Matemáticas e de Computação - ICMC-USP, como parte dos requisitos para obtenção do título de Mestre em Ciências de Computação e Matemática Computacional.

USP - São Carlos

Fevereiro/2001 
Combinação de métodos de inteligência artificial para fusão de sensores

Katti Faceli 


\title{
Combinação de Métodos de Inteligência Artificial para Fusão de Sensores
}

\author{
KATTI FACELI ${ }^{1}$ \\ Instituto de Ciências Matemáticas e de Computação \\ Universidade de São Paulo, São Carlos \\ Depto. de Ciências de Computação e Estatística
}

Orientador $^{2}$ :

Prof. Dr. André C. P. L. F. de Carvalho ${ }^{3}$

USP - São Carlos

Fevereiro/2001

\footnotetext{
${ }^{1}$ E-mail: katti@icmc.sc.usp.br

${ }^{2}$ A orientação deste trabalho conta com a co-supervisão da Profa. Dra. Solange O. Rezende

${ }^{3}$ E-mail: andre@icmc.sc.usp.br
} 


\section{Dedicatória}

Dedico este trabalho ao meu querido companheiro Jefferson. 


\section{Agradecimentos}

Muitas foram as pessoas que contribuíram de uma forma ou de outra para o sucesso deste trabalho. A todas elas agradeço sempre o apoio. Porém, há sempre um obrigada especial a ser dito.

Obrigada professor André, meu orientador, por me guiar com tanta dedicação e sabedoria durante toda a realização deste trabalho e professora Solange, cujo apoio em todos os momentos foi fundamental. A esses dois professores dedico todo o meu carinho, pois, além de professores são, principalmente, amigos.

Obrigada ao meu companheiro, Jefferson, pela ajuda constante e pela compreensão e carinho nos momentos difíceis.

Obrigada aos colegas do Labic por todo auxílio e principalmente pelo carinho e amizade.

Obrigada à minha família por todo o incentivo e compreensão.

Obrigada também à todos os professores e funcionários do ICMC/USP que direta ou indiretamente contribuíram com este trabalho.

Obrigada à FAPESP pelo apoio financeiro a este trabalho.

E, finalmente, um agradecimento especial à Vida, por todas as oportunidades que ela nos reserva. 


\section{Resumo}

Robôs móveis dependem de dados provenientes de sensores para ter uma representação do seu ambiente. Porém, os sensores geralmente fornecem informações incompletas, inconsistentes ou imprecisas. Técnicas de fusão de sensores têm sido empregadas com sucesso para aumentar a precisão de medidas obtidas com sensores. Este trabalho propõe e investiga o uso de técnicas de inteligência artificial para fusão de sensores com o objetivo de melhorar a precisão e acurácia de medidas de distância entre um robô e um objeto no seu ambiente de trabalho, obtidas com diferentes sensores. Vários algoritmos de aprendizado de máquina são investigados para fundir os dados dos sensores. O melhor modelo gerado com cada algoritmo é chamado de estimador. Neste trabalho, é mostrado que a utilização de estimadores pode melhorar significativamente a performance alcançada por cada sensor isoladamente. Mas os vários algoritmos de aprendizado de máquina empregados têm diferentes características, fazendo com que os estimadores tenham diferentes comportamentos em diferentes situações. Objetivando atingir um comportamento mais preciso e confiável, os estimadores são combinados em comitês. Os resultados obtidos sugerem que essa combinação pode melhorar a confiança e precisão das medidas de distâncias dos sensores individuais e estimadores usados para fusão de sensores. 


\section{Abstract}

Mobile robots rely on sensor data to have a representation of their environment. However, the sensors usually provide incomplete, inconsistent or inaccurate information. Sensor fusion has been successfully employed to enhance the accuracy of sensor measures. This work proposes and investigates the use of artificial intelligence techniques for sensor fusion. Its main goal is to improve the accuracy and reliability of a distance between a robot and an object in its work environment using measures obtained from different sensors. Several machine learning algorithms are investigated to fuse the sensors data. The best model generated with each algorithm are called estimator. It is shown that the employment of the estimators based on artificial intelligence can improve significantly the performance achieved by each sensor alone. The machine learning algorithms employed have different characteristics, causing the estimators to have different behaviour in different situations. Aiming to achieve more accurate and reliable behavior, the estimators are combined in committees. The results obtained suggest that this combination can improve the reliability and accuracy of the distance measures by the individual sensors and estimators used for sensor fusion. 


\section{Sumário}

1 Introdução 1

2 Sensores 6

2.1 Considerações Iniciais . . . . . . . . . . . . . . . . . . . . . 6

2.2 Características Gerais . . . . . . . . . . . . . . 7

2.3 Sensores em Robôs . . . . . . . . . . . . . . . . . . . . . . . . . . . . . . . 9

2.4 Técnicas para Medições de Distância . . . . . . . . . . . . . . . . . 10

2.5 Considerações Finais . . . . . . . . . . . . . . . . . . . . 20

3 Fusão de Sensores $\quad 21$

3.1 Considerações Iniciais . . . . . . . . . . . . . . . . . . . . . 21

3.2 Aspectos Gerais . . . . . . . . . . . . . . . . . . 21

3.3 Princípios Neurobiológicos e Cognitivos da Fusão de Sensores . . . . . . . 28

3.4 Paradigmas, Frameworks e Metodologias para Fusão de Sensores . . . . . 33 
3.5 Considerações Finais . . . . . . . . . . . . . . . . . . . . . . . . . 40

4 Algoritmos de Aprendizado de Máquina usados para Fusão de Sensores 41

4.1 Considerações Iniciais ． . . . . . . . . . . . . . . . . . . . 41

4.2 Redes Neurais . . . . . . . . . . . . . . . . . . . . 42

4.2.1 Multi-Layer Perceptron (MLP) . . . . . . . . . . . . . . 43

4.2 .2 Cascade Correlation . . . . . . . . . . . . . . . . 44

4.2 .3 Radial Basis Function $(\mathrm{RBF})$. . . . . . . . . . . . . . . 46

4.3 Support Vector Machine $(\mathrm{SVM}) \ldots \ldots \ldots \ldots$. . . . . . . . . . 47

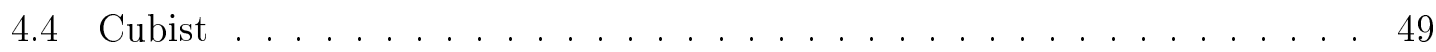

$4.5 \mathrm{M} 5 \ldots \ldots \ldots \ldots \ldots \ldots \ldots$

4.6 Combinação de Estimadores . . . . . . . . . . . . . . . . . . 50

4.7 Considerações Finais . . . . . . . . . . . . . . . . . . . 57

5 O Problema Abordado $\quad 58$

5.1 Considerações Iniciais . . . . . . . . . . . . . . . . . . 58

5.2 Descrição do Problema . . . . . . . . . . . . . . . . . 58

5.3 Descrição dos Dados . . . . . . . . . . . . . . . . 60

5.4 Preparação dos Dados . . . . . . . . . . . . . . . . . 62

5.5 Análise dos Dados . . . . . . . . . . . . . . . . . 63 
5.6 Considerações Finais . . . . . . . . . . . . . . . . . . . . . . . . 71

$\begin{array}{llr}6 & \text { Experimentos } & 72\end{array}$

6.1 Considerações Iniciais . . . . . . . . . . . . . . . . . . . . 72

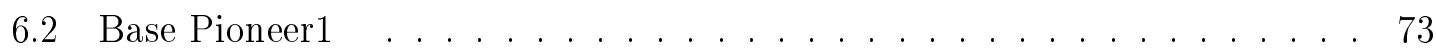

6.2 .1 Estimadores . . . . . . . . . . . . . . . 73

6.2.2 Combinação de Estimadores . . . . . . . . . . . . . . . 90

6.2.3 Comparação entre os métodos . . . . . . . . . . . . . . 96

6.2.4 Avaliação dos Resultados . . . . . . . . . . . . . . . 100

6.3 Base B14 . . . . . . . . . . . . . . . . . . . . . . . 108

6.3 .1 Estimadores . . . . . . . . . . . . . . . 108

6.3.2 Combinação de Estimadores . . . . . . . . . . . . 116

6.3.3 Comparação entre os métodos ........... 119

6.4 Considerações Finais . . . . . . . . . . . . . . . . . . . . . 122

7 Conclusões $\quad 124$

7.1 Contribuições . . . . . . . . . . . . . . . . . . . . 125

7.2 Limitações e Trabalhos Futuros . . . . . . . . . . . . . . . . . 125

$\begin{array}{ll}\text { Referências } & 127\end{array}$ 
A Exemplos de Arquivo de Entrada para o Treinamento dos diversos algoritmos

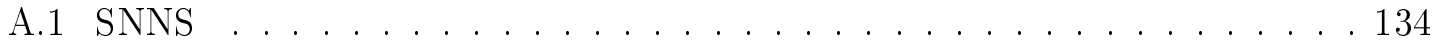

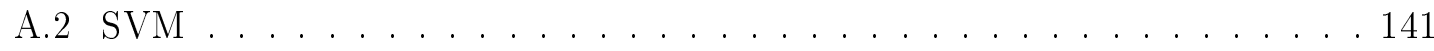

A.3 Cubist . . . . . . . . . . . . . . . . . . 144

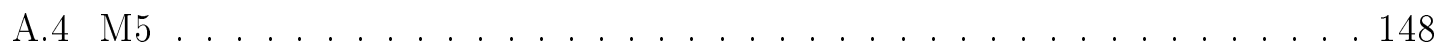

B Arquivo batch para treinamento das redes MLP 


\section{Lista de Figuras}

2.1 Princípio de funcionamento da técnica de Triangulação. . . . . . . . . . . . 12

2.2 Princípio de funcionamento da técnica baseada no efeito looming. . . . . . 19

3.1 Modelo geral para um sistema de fusão de sensores. . . . . . . . . . . . . . 34

3.2 Taxonomia dos algoritmos de fusão de Hall. . . . . . . . . . . . . . . . . 35

4.1 Arquitetura da rede Cascade Correlation. . . . . . . . . . . . . . 46

4.2 Configurações possíveis para combinação de estimadores: (a) Cascata, (b) Paralelo, (c) Hierárquico. . . . . . . . . . . . . . . . . . . . . . . . 52

4.3 Framework para combinação de estimadores (stacking). . . . . . . . . . . 56

5.1 Robô Pioneer 1. . . . . . . . . . . . . . . . . . . . . 61

5.2 Distâncias em que foram coletados os dados dos sensores do robô Pioneer 1. 62

5.3 Distância real x distâncias medidas para o ângulo de $22,5^{\circ}$. . . . . . . 65

5.4 Distância real x distâncias medidas para o ângulo de $33,75^{\circ}$. . . . . . . . 66

5.5 Distância real x distâncias medidas para o ângulo de $45^{\circ}$. . . . . . . . . 66 
5.6 Distância real x distâncias medidas para o ângulo de $56,25^{\circ}$. . . . . . . . . 66

5.7 Distância real x distâncias medidas para o ângulo de $67,5^{\circ} \ldots$. . . . . . 67

5.8 Distância real x distâncias medidas para o ângulo de $78,75^{\circ}$. . . . . . . . 67

5.9 Distância real x distâncias medidas para o ângulo de $90^{\circ}$. . . . . . . . 67

5.10 Variação das distâncias medidas para a distância real no ângulo de $90^{\circ}$. . . 69

5.11 Variação das distâncias medidas para a distância real a $61,1 \mathrm{~cm}$. . . . . . . 69

5.12 Variação das distâncias medidas para a distância real a 183,3 cm. . . . . . 70

5.13 Variação das medidas dos sensores para um mesmo ângulo e distância $\left(90^{\circ}\right.$

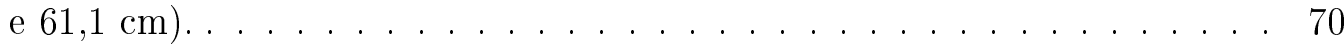

6.1 MSE para redes MLP treinadas com diferentes $\eta$. . . . . . . . . 75

6.2 MSE da melhor rede MLP treinada para cada topologia. . . . . . . . . . . 76

6.3 MSE para redes MLP treinadas com $\eta=0,6 \ldots \ldots \ldots$. . . . . . 76

6.4 MSE da rede MLP treinada com o algoritmo Rprop. . . . . . . . . . . . . 77

6.5 MSE da rede MLP treinada com o algoritmo Quickprop. . . . . . . . . . . 77

6.6 Comparação dos algoritmos de treinamento das redes MLP. . . . . . . . . . 78

6.7 MSE das redes RBF. . . . . . . . . . . . . . . . . . . . . . . 80

6.8 MSE das redes Cascade Correlation. . . . . . . . . . . . . . . 81

6.9 MSE para diferentes valores de eps. . . . . . . . . . . . . . . . 82

6.10 MSE para diferentes valores de c. . . . . . . . . . . . 83 
6.11 MSE para diferentes valores de st. . . . . . . . . . . . . 83

6.12 MSE para diferentes valores de d e s. . . . . . . . . . . . . . 84

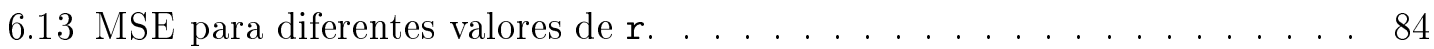

6.14 MSE para diferentes valores de s. . . . . . . . . . . . . . 85

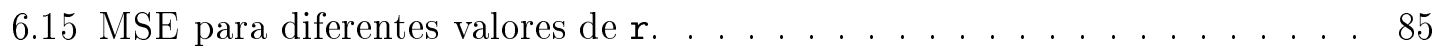

6.16 MSE para o melhor modelo gerado com cada kernel. . . . . . . . . . . . 86

6.17 MSE do algoritmo Cubist. . . . . . . . . . . . . . . . 87

6.18 MSE do algoritmo M5. . . . . . . . . . . . . . . . . . . 87

6.19 Comparação entre os melhores estimadores. . . . . . . . . . . . . . . . . 89

6.20 Rank das combinações de 3 estimadores. . . . . . . . . . . . . . . . . . . 92

6.21 Rank das combinações de 5 estimadores. . . . . . . . . . . . . . . . . 92

6.22 Rank final das combinações de 3,5 e 7 estimadores. . . . . . . . . . . . . . 94

6.23 MSE das melhores combinações de 3, 5 e 7 estimadores. . . . . . . . . . . 95

6.24 Comparação entre o MSE dos estimadores e das combinações. . . . . . . . 96

6.25 Comparação entre o MSE dos melhores estimadores e combinações. . . . . 98

6.26 Comparação entre o MSE do melhor sensor, do melhor estimador e da melhor combinação. . . . . . . . . . . . . . . . . . . . . . 98

6.27 Comparação dos erros dos sensores. . . . . . . . . . . . . . . . . . 101

6.28 Comparação dos erros dos estimadores. . . . . . . . . . . . . . . . . . . 102 
6.29 Comparação dos erros dos combinadores. . . . . . . . . . . . . . . . . . 103

6.30 Comparação entre o MSE e o desvio padrão dos melhores sensores, estimadores e combinadores. . . . . . . . . . . . . . . . . . . . . 104

6.31 Redução do erro com relação à câmera. . . . . . . . . . . . . . . . . . 105

6.32 Redução do erro com relação ao sonar 4. . . . . . . . . . . . . 106

6.33 MSE para redes MLP treinadas com diferentes $\eta$ (base B14) . . . . . . . 109

6.34 MSE da melhor rede MLP treinada para cada topologia (base B14). . . . . 110

6.35 MSE da rede MLP treinada com o algoritmo Rprop (base B14). . . . . . . 110

6.36 MSE das redes RBF (base B14) . . . . . . . . . . . . . . 111

6.37 MSE para diferentes valores de st (base B14) . . . . . . . . . . 112

6.38 MSE do algoritmo SVM (base B14). . . . . . . . . . . . . . . . 112

6.39 MSE do algoritmo Cubist (base B14) . . . . . . . . . . . . . 113

6.40 MSE do algoritmo M5 (base B14). . . . . . . . . . . . . . 114

6.41 Comparação entre os melhores estimadores (base B14) . . . . . . . . . . 115

6.42 Rank das combinações de 3 estimadores (base B14). . . . . . . . . . 116

6.43 Rank das combinações de 5 estimadores (base B14) . . . . . . . . . . 116

6.44 Rank final das combinações de 3, 5 e 7 estimadores (base B14). . . . . . . 117

6.45 MSE das melhores combinações de 3, 5 e 7 estimadores (base B14). . . . . 118

6.46 Comparação entre o MSE dos estimadores e das combinações (base B14). . 119 
6.47 Comparação entre o MSE dos melhores estimadores e combinações (base

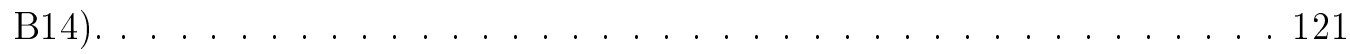

6.48 Comparação entre o MSE do melhor sensor, do melhor estimador e da melhor combinação (base B14) . . . . . . . . . . . . . . . . . . 121 


\section{Lista de Tabelas}

3.1 Resumo dos tipos de fusão. . . . . . . . . . . . . . . . . . . . . 25

5.1 Descrição da base de dados Pioneer1. . . . . . . . . . . . . . . . . . . . . . 64

5.2 Descrição da base de dados B14. . . . . . . . . . . . . . . . . . 64

6.1 MSE da melhor rede MLP treinada para cada topologia. . . . . . . . . . . 75

6.2 Comparação dos algoritmos de treinamento das redes MLP. . . . . . . . . . 78

6.3 Parâmetros do treinamento das redes RBF. . . . . . . . . . . . . . . . . . . 79

6.4 MSE das redes Cascade. . . . . . . . . . . . . . . . . . 80

6.5 Número de neurônios intermediários. . . . . . . . . . . . . . . . . . . . 81

6.6 MSE para o melhor modelo gerado com cada kernel. . . . . . . . . . . . . 86

6.7 MSE para o melhor estimador gerado com cada algoritmo investigado. . . . 88

6.8 MSE das melhores combinações de 3, 5 e 7 estimadores. . . . . . . . . . . . 95

6.9 MSE dos melhores sensor, estimadores e combinadores. . . . . . . . . . . 97

6.10 Valor de $t_{\text {calc }}$ para o teste das várias comparações. . . . . . . . . . . . . 100 
6.11 Comparação do MSE e desvio padrão do erro entre os melhores sensores, estimadores e combinadores. . . . . . . . . . . . . . . . . . . . . 104

6.12 Redução do erro com relação à câmera. . . . . . . . . . . . . . . . . . . 105

6.13 Redução do erro com relação ao sonar 4. . . . . . . . . . . . . . . 106

6.14 MSE da melhor rede MLP treinada para cada topologia (base B14). . . . . 109

6.15 Parâmetros do treinamento das redes RBF (base B14). . . . . . . . . . . . 111

6.16 MSE para o melhor estimador gerado com cada algoritmo investigado (base

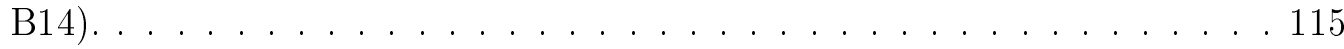

6.17 MSE das melhores combinações de 3, 5 e 7 estimadores (base B14). . . . . 118

6.18 MSE dos melhores sensor, estimadores e combinadores (base B14). . . . . 120

6.19 Valor de $\mathrm{t}_{\text {calc }}$ para o teste das várias comparações (base B14). . . . . . . . 122 


\section{Capítulo 1}

\section{Introdução}

Este trabalho se refere à utilização de técnicas de inteligência artificial como métodos para a fusão de sensores, aplicada na solução de um problema específico da área de robótica. Esse problema consiste da melhoria da precisão e acurácia das medições de distância feitas por sensores empregados nos robôs.

A motivação deste trabalho se deve a um problema bastante comum. Diversas áreas da ciência e engenharia precisam de sistemas que capturem, processem e integrem informações provenientes de várias fontes (Abidi and Gonzalez, 1992). Muitos destes sistemas interagem com o mundo real e requerem informações precisas e confiáveis do ambiente ao seu redor. As fontes de informação utilizadas por esses sistemas geralmente fornecem dados incompletos, inconsistentes ou imprecisos. Um caso específico desse tipo de sistema são os robôs móveis autônomos. Esses robôs têm como tarefa essencial navegar por um ambiente dinâmico onde devem realizar alguma atividade. Para isso, coletam informações do ambiente através de diversos tipos de sensores, utilizando-as para criar modelos do mundo a sua volta e acompanhar as mudanças que nele ocorrem (Groover et al., 1989; Goodridge, 1997).

Diferentes tipos de sensores têm sido desenvolvidos e, para selecionar o melhor sensor para uma determinada aplicação, deve-se levar em consideração suas características, tais 
como campo de visão (alcance), faixa de operação (flexibilidade), precisão e resolução, habilidade de detectar todos os objetos no ambiente, concisão e facilidade na interpretação dos dados, redundância, simplicidade (facilidade de operação, manutenção), consumo de energia, tamanho, calibração, confiabilidade e custo (Groover et al., 1989; Everett, 1995).

Muitas vezes, algumas características necessárias para uma aplicação, como boa precisão e confiabilidade (acurácia), ficam limitadas por restrições de custo ou complexidade dos sensores.

No caso específico de robôs móveis autônomos, são informações essenciais aquelas que fornecem a distância entre o robô e os diversos elementos (objetos, pessoas, paredes) que fazem parte do ambiente em que ele deve navegar. Existem vários tipos de sensores que podem ser utilizados para medição de distâncias. Alguns deles são simples, servindo somente para detectar objetos mais ou menos próximos, medir distâncias e, possivelmente, ângulos. Para medições mais complexas, outros sensores são utilizados com capacidade para detectar, por exemplo, a forma e a cor dos objetos no ambiente (além de poder medir distâncias e ângulos).

Cada tipo de sensor utiliza uma técnica diferente para medir distâncias. São várias as técnicas que podem ser empregadas, tais como Triangulação, Time of Flight (TOF), Medição de Mudança de Fase, Modulação de Freqüência, Interferometria, Varredura de Foco, Intensidade do Sinal de Retorno (Everett, 1995). Cada uma delas possui limitações técnicas, vantagens e custos.

A técnica mais comumente empregada hoje em dia para medir distâncias em robôs móveis que navegam em ambientes fechados é a TOF com ultra-som. Sua popularidade se deve a seu baixo custo e facilidade de utilização (Everett, 1995). Porém, esse tipo de sensor apresenta restrições com respeito a confiabilidade. Se forem feitas duas leituras seguidas do sensor, sem que sua posição tenha sido modificada, essas leituras provavelmente serão diferentes. Esse erro não é sistemático, mas esse tipo de sensor também está sujeito a um erro sistemático que se manifesta através de erros na leitura quando ele está inclinado em relação à sua linha de visão (quanto maior o ângulo formado entre a frente do sensor e o 
objeto a ser medido, maior tende a ser o erro na leitura). Além disso, existem superfícies que absorvem a radiação do SONAR ${ }^{1}$, fazendo com que esse tipo de sensor não as detecte.

Uma alternativa que vem se mostrando viável e promissora para a obtenção de informações de distância é a utilização de técnicas simples de processamento de sinais visuais, tais como Visual Looming (Sahin and Gaudiano, 1998; Huttenlocher et al., 1995), Visual Sonar baseado na proposta de Horswill (Horswill, 1994) e métodos que usam diversas formas de triangulação ativa ou passiva (Everett, 1995; Nguyen and Blackburn, 1995). Entretanto, sensores baseados em informações visuais também têm suas restrições. Exemplos destas restrições são: a precisão pode ser reduzida com o aumento da distância e presença de sombras de objetos e as mudanças nos padrões das superfícies podem ser confundidas com objetos.

Outras alternativas de sensores podem obter os mesmos dados, inclusive com maior precisão e acurácia, porém associadas a um custo mais elevado.

Muitas vezes, as restrições apresentadas por um tipo de sensor não se aplicam a outros e vice-versa. Nesses casos, a combinação das informações obtidas a partir desses sensores pode fornecer uma informação mais completa, precisa e confiável do ambiente.

A fusão de sensores envolve justamente a combinação de informações provenientes de diferentes sensores para captar dados do ambiente cuja obtenção está além da capacidade isolada de cada um dos sensores envolvidos, principalmente quando são considerados confiabilidade e precisão. Além disso, a fusão de sensores tanto torna o sistema mais tolerante a falhas, como também pode fornecer informações novas, que nenhum dos sensores isoladamente consegue obter. Na literatura têm sido descritos diversos paradigmas, frameworks e métodos para fusão de sensores (Abidi and Gonzalez, 1992; Luo and Kay, 1995; Brooks and Iyengar, 1998; Klein, 1999; Joshi and Sanderson, 1999; Pasika, 1999; Goodridge, 1997; Kokar et al., 1999; Murphy, 1996). Dentre os métodos mais comuns, podem ser citados (Luo and Kay, 1992; Luo and Kay, 1995; Klein, 1999; Joshi and San-

\footnotetext{
${ }^{1}$ SONAR (sound navigation and ranging): determina a distância a um alvo medindo o tempo que uma onda ultra-sônica leva para viajar até alvo e ecoar de volta a um receptor.
} 
derson, 1999; Goodridge, 1997): Técnicas de Probabilidade e Inferência Bayesiana, Teoria de Dempster-Shafer, Lógica Fuzzy e Redes Neurais Artificiais.

Porém, a área de fusão de sensores é muito vasta e tem sido empregada na solução de diversos tipos de problemas em diferentes áreas de aplicação. A área tratada neste trabalho é a robótica. Nessa área, são vários os problemas que podem ser resolvidos com a aplicação da fusão de sensores. O problema tratado aqui se refere à utilização da fusão de sensores para melhorar a precisão e acurácia (estabilidade) da informação de distância entre um robô e um alvo, medida através de diversos sensores. Melhorar a precisão diz respeito à redução do erro médio e melhorar a acurácia significa a redução da variabilidade dos erros cometidos. Assim, o que se espera da fusão de sensores neste trabalho é que se possa obter uma cooperação entre os sensores de forma que se tenha um mecanismo para corrigir as imprecisões de cada um, melhorar a repetibilidade das medições e estender a capacidade de medição para distâncias e ângulos em que as medições dos sensores são, individualmente, ruins, ou seja, em distâncias e ângulos para os quais nenhum dos sensores são adequados.

Como já citado, diferentes algoritmos têm sido empregados na fusão de sensores. Neste trabalho optou-se por investigar diferentes técnicas de Inteligência Artificial como algoritmos para fusão. Assim, diversos algoritmos de aprendizado de máquina foram implementados e tiveram seu desempenho avaliado. Essas implementações foram chamadas de estimadores. Cada estimador apresenta suas vantagens e desvantagens. Por exemplo, um dos estimadores pode apresentar melhores resultados para longas distâncias, um outro para curtas distâncias e um outro ainda, para ângulos pequenos entre o objeto e o robô. Com o objetivo de aproveitar as características intrínsecas de cada estimador, eles podem ser combinados (Gama, 1999; Sharkey, 1999; Merz, 1998; LeBlanc and Tibshirani, 1993; Tumer and Ghosh, 1996; Merz and Pazzani, 1997; Krogh and Vedelsby, 1995; Sebastiani, 1999). Assim, a baixa performance de um estimador para determinados dados pode ser compensada por uma performance superior de outro(s) estimador(es). Dessa forma, foram aplicados métodos para a combinação dos estimadores em comitês, que foram estudados como novos métodos para fusão de sensores. Tais comitês foram chamados de combina- 
dores. Os combinadores também tiveram seu desempenho avaliado e foram comparados com cada um dos estimadores implementados. A precisão das distâncias obtidas pelos métodos aplicados para a fusão foi comparada com a precisão obtida individualmente por cada sensor. Além disso, os métodos foram comparados entre si com o objetivo de avaliar cada um e verificar se a combinação de estimadores pode ser empregada com sucesso nessa aplicação.

Este trabalho está organizado em 7 capítulos. No Capítulo 2 é feita uma revisão sobre sensores, detalhando os aspectos relacionados à robótica e as técnicas comumente empregadas para medição de distâncias. Uma revisão sobre fusão de sensores é feita no Capítulo 3. O Capítulo 4 contém uma descrição sucinta dos diversos algoritmos investigados neste trabalho, incluindo um texto sobre combinação de estimadores. Os dados empregados nos experimentos com os algoritmos são descritos no Capítulo 5. No Capítulo 6 são descritos os experimentos realizados, analisados os resultados obtidos com cada algoritmo e comparados os diversos métodos aplicados para a fusão dos sensores. A conclusão deste trabalho é apresentada no Capítulo 7. 


\section{Capítulo 2}

\section{Sensores}

\subsection{Considerações Iniciais}

Diversas aplicações precisam de sistemas que capturem, processem e integrem informações provenientes de várias fontes (Abidi and Gonzalez, 1992). Atualmente, existem inúmeros dispositivos capazes de capturar algum tipo de informação a respeito do ambiente. Esses dispositivos são conhecidos como sensores.

Os robôs de forma geral, e mais especificamente os robôs móveis, são exemplos dessas aplicações. Os robôs necessitam de informações do ambiente ao seu redor para executar suas tarefas. Para obter essas informações são usados os mais diversos tipos de sensores acoplados a diversos pontos no robô (Groover et al., 1989; Iovine, 1998; Jones and Flynn, 1993). No caso de robôs móveis, sensores são utilizados para a criação automática de modelos do mundo e acompanhamento das mudanças que ocorrem no ambiente a fim de dar autonomia ao robô na realização de suas tarefas.

Neste capítulo é feita uma breve descrição das características gerais dos sensores, do seu uso na robótica e, em especial, das técnicas empregadas em sensores que medem distâncias. 


\subsection{Características Gerais}

Um sensor é um dispositivo elétrico ou mecânico que detecta algum fenômeno físico no ambiente e o mapeia em uma medida quantitativa (Brooks and Iyengar, 1998; Ferworn, 1997). Esse processo de detecção pode envolver contato físico com elementos do ambiente, captura de reflexões de alguma forma de energia emitida pelo sensor (por exemplo SONAR, RADAR, LIDAR) ou captura de alguma forma de energia presente no ambiente ou emitida pelo elemento do ambiente que está sendo medido (por exemplo, uma câmera ou termômetro) (Brooks and Iyengar, 1998).

Os sensores podem ser ativos ou passivos. Os sensores passivos obtêm informações que já estão presentes no ambiente, ou seja, contam com a energia emitida pelos vários objetos na cena que está sendo medida. Já os sensores ativos obtêm informações que resultam de uma ação iniciada pelo sensor, ou seja, o sensor irradia alguma forma de energia na região de interesse (Brooks and Iyengar, 1998; Everett, 1995). Entretanto, independentemente da sua forma de interação com o ambiente, os sensores sofrem, com o tempo, desgastes que podem levar a falhas. Essas falhas podem ser de natureza mecânica, química ou elétrica. Além disso, qualquer método de detecção que seja empregado em um sensor terá precisão

limitada (Brooks and Iyengar, 1998), estará sujeito ao efeito de algum tipo de ruído e funcionará incorretamente sob algumas condições (McKerrow, 1995). Por isso, qualquer sensor dispõe de um conjunto de características que devem ser levadas em consideração ao se avaliar qual a melhor opção para uma dada aplicação (Groover et al., 1989; Everett, 1995):

- campo de visão (alcance);

- faixa de operação (flexibilidade);

- precisão e resolução;

- habilidade de detectar todos os objetos no ambiente;

- concisão e facilidade na interpretação dos dados;

- redundância;

- simplicidade (facilidade de operação, manutenção); 
- consumo de energia;

- tamanho;

- calibração;

- confiabilidade;

- custo.

Nos sensores ativos, a qualidade da medição depende das características tanto do sensor, como do alvo (Everett, 1995). São características dos alvos:

- área cross-sectional, que se refere a quantia de energia emitida que atinge o alvo;

- reflectividade, que se refere a quantia de energia que é refletida ou absorvida pelo alvo;

- direcionalidade, que diz respeito a forma como a energia refletida é redistribuída (espalhada ou focalizada).

Existe atualmente uma grande variedade de sensores que podem ser classificados de diversas formas, tais como (McKerrow, 1995):

- quantidade física ou química que ele mede (distância, velocidade, viscosidade, cor);

- princípio físico em que se baseia (magnetostriction, memória do metal, efeito Hall);

- tecnologia que utiliza (silício, eletro-mecânica, fibra ótica);

- tipo de energia envolvida (elétrica, mecânica, solar);

- relação espacial entre o sensor e o elemento que ele está medindo (contato, sem contato, remoto).

Existem inúmeras áreas de aplicação que utilizam sensores e, mais especificamente, múltiplos sensores. Dentre estas áreas, pode-se destacar: automação doméstica (sistemas de alarme, por exemplo), medicina (desde um simples termômetro até complexos equipamentos de ressonância magnética), automação industrial, robótica, militar, pesquisas espaciais, aeronáutica, sensoriamento remoto, atividades perigosas e controle de tráfego (Luo and Kay, 1992; Brooks and Iyengar, 1998). 


\subsection{Sensores em Robôs}

Os sensores comumente empregados nos robôs podem ser divididos em internos, que medem as variáveis internas do robô, e externos, que medem informações a respeito do ambiente. Exemplos de medições feitas pelos sensores internos são: posição, movimento, limites, referências, aceleração, força e torque (McKerrow, 1995). As medições feitas pelos sensores externos podem incluir: toque, proximidade, distância, posição, som, umidade, composição de gás, pressão e temperatura.

As informações obtidas pelos sensores em um robô podem ser utilizadas para várias finalidades (McKerrow, 1995). Possíveis exemplos são:

- medir os parâmetros do robô para os loops de controle;

- localizar objetos;

- corrigir erros nos modelos que o robô possui de si mesmo e do mundo;

- detectar e evitar situações de falha;

- detectar e evitar colisões;

- monitorar a interação com o ambiente e

- monitorar mudanças no ambiente que podem afetar a tarefa a ser desenvolvida pelo robô (temperatura por exemplo).

No caso de robôs móveis, sensores são utilizados para a criação automática de modelos do mundo e acompanhamento das mudanças que ocorrem no ambiente a fim de dar autonomia ao robô na realização de suas tarefas.

O foco de interesse deste trabalho reside em uma parte da área de robótica, os robôs móveis autônomos, e, mais especificamente, em sensores capazes de medir a distância entre o robô e um objeto do ambiente.

Existem vários tipos de sensores que podem ser utilizados para medição de distâncias. Além disso, várias técnicas podem ser empregadas na implementação desses sensores. Na Seção 2.4 são apresentadas algumas dessas técnicas. 


\subsection{Técnicas para Medições de Distância}

As técnicas descritas a seguir são usadas para a medição de distâncias entre o sensor e um alvo de interesse, sem que haja contato físico direto. Existem diferentes tipos de técnicas que servem para medir distâncias. Nesta seção são apresentadas as técnicas Triangulação, Time of Flight (TOF), Medição de Mudança de Fase, Modulação de Freqüência, Interferometria, Varredura de Foco e Intensidade do Sinal de Retorno descritas por Everett (Everett, 1995) e algumas técnicas simples de processamento de sinais visuais tais como Visual Looming (Sahin and Gaudiano, 1998; Huttenlocher et al., 1995) e Visual Sonar (Horswill, 1994).

A técnica mais comum empregada hoje em dia para medir distâncias em robôs móveis que navegam em ambientes fechados é TOF com ultra-som. Sua popularidade se deve a seu baixo custo e facilidade de utilização (Everett, 1995). Porém, esse tipo de sensor apresenta restrições com respeito a confiabilidade. Se forem feitas duas leituras seguidas do sensor, sem que sua posição tenha sido modificada, essas leituras provavelmente serão diferentes. Esse erro não é sistemático, mas esse tipo de sensor também está sujeito a um erro sistemático que se manifesta através de erros na leitura quando ele está inclinado em relação à sua linha de visão (quanto maior o ângulo formado entre a frente do sensor e o objeto a ser medido, maior tende a ser o erro na leitura). Além disso, existem superfícies que absorvem a radiação do SONAR, fazendo com que esse tipo de sensor não as detecte.

As técnicas baseadas em sinais visuais tem se mostrado uma boa alternativa. Embora os sensores visuais sejam capazes de fornecer uma grande quantidade de informações, eles geralmente tem um alto custo associado, principalmente no que se refere a tempo e capacidade e processamento que eles exigem. Porém, informações simples e úteis podem ser extraídas desse tipo de sensor com a utilização de algoritmos que podem ser executados em tempo real e a um baixo custo computacional. O algoritmo Visual Looming (Sahin and Gaudiano, 1998; Huttenlocher et al., 1995) obtém distâncias através da mudança no tamanho do objeto no plano da imagem. O Visual Sonar (Horswill, 1994) obtém informações sobre a distância relativa a um objeto localizado no chão a partir da imagem de 
uma câmera. Mas essas técnicas também têm suas restrições. Exemplos destas restrições são:

- a precisão pode ser reduzida com o aumento da distância;

- sombras de objetos e mudanças nos padrões das superfícies podem ser confundidas com objetos.

Sensores mais caros podem ser mais eficientes em suas medições, porém muitas vezes restrições de custo nos projetos limitam ou impedem a sua utilização.

Uma estimativa de distância mais precisa, completa e confiável pode ser obtida através da combinação de diversos sensores simples e baratos. Técnicas de fusão de sensores, e em especial as Redes Neurais Artificiais, têm sido empregadas com sucesso para esse objetivo. Martens et al. (Martens et al., 1998) utilizaram uma rede neural do tipo fuzzy-ARTMAP para estimar distância com base em vários tipos de sensores e obtiveram informações menos vulneráveis a ruídos e outros erros dos sensores individuais. A abordagem de fusão de sensores é descrita no Capítulo 3.

A seguir são detalhadas as técnicas mais comuns para obtenção de distâncias.

\section{Triangulação}

A técnica de Triangulação é baseada na lei dos senos da trigonometria plana. Essa lei diz que: "dado o comprimento de um lado e dois ângulos de um triângulo, pode-se calcular o outro ângulo e o comprimento dos outros dois lados". Ela pode ainda ser rearranjada para representar o comprimento do lado $B$ em função do lado $A$ e dos ângulos $\theta$ e $\phi$, conforme o esquema da Figura 2.1 (Everett, 1995).

Para medidas de distância, considera-se que o objeto de interesse esteja situado no ponto P3. O comprimento do lado $B$ do triângulo é a distância desejada entre o objeto e a linha $A$, de tamanho conhecido, que separa os sensores. 


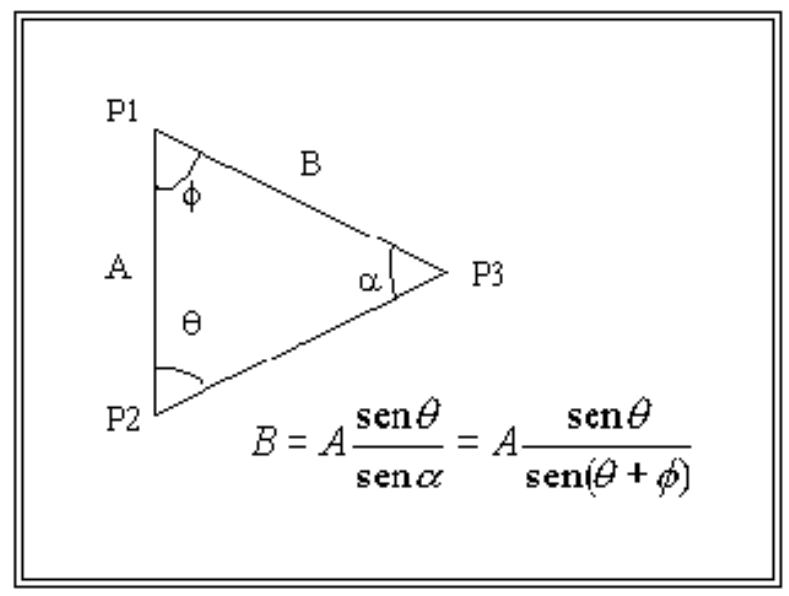

Figura 2.1: Princípio de funcionamento da técnica de Triangulação.

Os sistemas de Triangulação podem ser passivos (usam apenas a luz ambiente da cena) ou ativos (usam uma fonte de energia própria para iluminar o alvo).

Os sistemas passivos posicionam detectores direcionais nas posições $P 1$ e $P 2$, direcionados para o ponto $P 3$ onde está o objeto, formando um triângulo imaginário. A distância pode ser calculada a partir da medição dos ângulos $\theta$ e $\phi$ juntamente com a orientação e separação lateral conhecida das câmeras. Pode-se também utilizar um único detector e movê-lo entre $P 1$ e $P 2$. Em robôs móveis, muitas vezes um único sensor é empregado e a movimentação do robô provê a deteç̧ão em P1 e P2 (McKerrow, 1995).

Os sistemas ativos posicionam uma fonte de luz controlada em $P 1$ ou $P 2$ e um sensor imageador direcional no outro vértice $(P 1$ ou $P 2)$, ambos direcionados para $P 3$. Parte da luz emitida pela fonte é refletida pelo objeto e captada pelo detector. A posição lateral do ponto detectado fornece uma medida quantitativa do ângulo $\phi$ desconhecido, permitindo o cálculo da distância pela Lei dos Senos.

As limitações dos sensores que usam Triangulação em geral são:

- a redução da precisão com o aumento da distância;

- erros em medições angulares;

- o problema de partes ausentes (quando partes da cena são observadas somente em uma das posições $P 1$ ou $P 2$, causando a oclusão parcial do alvo). 
Além disso, os sistemas passivos precisam de condições especiais de iluminação e encontram dificuldades no casamento das imagens obtidas pelos dois detectores (problema de correspondência). Os sistemas ativos, por sua vez, não requerem iluminação especial e nem têm problemas de correspondência. Porém, eles têm problemas com a absorção ou reflexão especular da energia que emitem pela superfície do alvo.

Existem diversas variações da técnica de Triangulação, tais como:

- visão estéreo;

- triangulação ativa de um único ponto;

- luz estruturada;

- alvo de tamanho conhecido;

- fluxo óptico.

\section{Time of Flight}

Esses sistemas se baseiam no tempo que um pulso de energia emitida leva para viajar até um alvo e ecoar de volta a um receptor. As fontes de energia mais comumente empregadas nesse tipo de sensor são:

- ultra-sônica (por exemplo, SONAR);

- RF (freqüência de ondas de rádio);

- óptica (por exemplo, LIDAR).

Por este método, a distância é calculada de acordo com princípios da física elementar através da Equação 2.1:

$$
d=v \frac{t}{2}
$$

em que, $d=$ distância do alvo, $v=$ velocidade de propagação da energia no meio, $t=$ tempo decorrido entre a emissão do pulso e a captura do seu eco.

Essa técnica tem algumas vantagens sobre a Triangulação, tais como: 
- não requer análises complicadas para a obtenção da distância absoluta a um alvo;

- não se baseia em suposições a respeito da superfície do alvo;

- não apresenta o problema de partes ausentes;

- mantém precisão com o aumento da distância, enquanto um eco confiável puder ser detectado.

Por outro lado, essa técnica tem como potenciais fontes de erro:

- variações na velocidade de propagação do pulso de energia;

- incertezas na determinação do momento exato da chegada do pulso refletido;

- imprecisões na medição do tempo decorrido;

- interação da onda com a superfície do alvo.

Os sistemas baseados em energia acústica tendem a ser mais baratos do que os baseados em energia óptica ou RF, principalmente para aplicações de curta distância que exijam alta precisão.

\section{Medição de Mudança de Fase}

Essa técnica envolve a transmissão de uma onda contínua ou de pulsos curtos sincronizados com uma onda de referência contínua. Nessa técnica, um raio de energia é emitido para o alvo e uma pequena parte da onda é refletida e captada pelo detector. Essa energia retornada é comparada a uma referência e a distância que a onda viajou é medida através da mudança de fase relativa entre essas duas ondas.

Esse tipo de medição apresenta problemas de ambigüidade, que podem ser resolvidos tomando-se várias medidas em freqüências de modulação diferentes.

Nesse caso, também não ocorre o problema de partes ausentes. As precisões obtidas por esse método se aproximam daquelas obtidas pelos métodos que empregam TOF com laser pulsado. Essa técnica apresenta pouca vantagem com relação a TOF pulsados, já 
que o problema de medição de tempo é substituído pela necessidade de componentes sofisticados para medição de fase. Essa técnica encontra problemas quando a energia é refletida por dois alvos à distâncias diferentes do sensor.

\section{Modulação de Freqüência}

Essa técnica está intimamente relacionada à Medição de Mudança de Fase e envolve a transmissão de uma onda eletromagnética contínua modulada por um sinal triangular que ajusta a freqüência da portadora acima e abaixo da freqüência média. A freqüência do sinal transmitido varia linearmente com o tempo. Esse sinal é refletido do alvo, captado pelo receptor após um intervalo de tempo $T$ e comparado com um sinal de referência. A curva da freqüência recebida é deslocada em relação a curva da freqüência de referência ao longo do tempo, por uma quantia igual ao tempo que a onda demora para ir até o alvo e voltar. Essas freqüências são combinadas gerando uma freqüência de pulsação que é medida e usada para calcular a distância do alvo.

A precisão da medição da distância depende da linearidade da variação da freqüência sobre o intervalo de contagem.

Uma vantagem dessa técnica sobre a Medição de Mudança de Fase é que não ocorre ambigüidade nas medidas. Porém, ela apresenta desvantagens associadas com a linearidade e repetibilidade da rampa de freqüência e com a coerência do raio laser em sistemas ópticos.

\section{Interferometria}

Essa é uma das técnicas mais precisas, porém apenas recentemente tem podido ser aplicada fora de laboratórios devido aos avanços nas tecnologias ópticas.

O princípio de funcionamento dessa técnica é baseado nos padrões de interferência 
resultantes da comparação de duas ondas de energia que são levadas a viajar caminhos diferentes. Franjas de interferência destrutivas e construtivas claramente visíveis são produzidas quando dois raios interagem devido à mudança no comprimento do caminho de um deles.

Entretanto, essa técnica não mede distâncias absolutas, medindo somente a distância relativa que um objeto se moveu da sua posição anterior. Distâncias absolutas podem ser obtidas a partir do estabelecimento de um ponto de referência inicial.

As desvantagens dessa técnica dizem respeito ao custo relativamente alto, à necessidade de uma linha de visão contínua entre o alvo e o retro-refletor e à medição, exclusivamente, de distâncias relativas.

\section{Varredura de Foco}

Essa técnica se baseia na "Lei das lentes finas de Gauss", que pode ser rearranjada para fornecer a distância segundo a Equação 2.2:

$$
r=\frac{s f}{s-f}
$$

em que, $r=$ distância das lentes ao objeto observado, $s=$ distância das lentes ao plano da imagem e $f=$ distância focal das lentes.

Everett (Everett, 1995) cita como Krotov e Martin (Krotov and Martin, 1986) resumem essa técnica. Inicialmente, o sistema é calibrado com um ponto de origem para estabelecer a relação entre a posição do eixo motor do foco e a distância focal das lentes $f$. Em seguida, a nitidez do foco é maximizada variando $f$ até que o plano do detector coincida com o plano da imagem. O valor de $f$ é lido e substituído, juntamente com a constante $s$, na equação das lentes finas, que é então resolvida. O maior desafio dessa técnica é a determinação do ponto de foco ótimo. 
A vantagem dessa técnica sobre a estereoscópica é que não é necessário resolver o complicado problema de correspondência. Algumas desvantagens e limitações dessa técnica são:

- a sua aplicação a apenas um único ponto observado na cena em um dado momento;

- erros na medição associados com a quantificação de $f$ e $s$;

- quantificação espacial do detector;

- performance da função critério de foco;

- validade do modelo das lentes finas para uma composição de lentes;

- não linearidade da equação das lentes.

\section{Intensidade do Sinal de Retorno}

Essa técnica se baseia na amplitude da energia refletida da superfície do objeto. Segundo a lei do inverso do quadrado para energia emitida, conforme a distância de um ponto de origem aumenta, a intensidade da fonte diminui de acordo com o quadrado da distância. Existem vários protótipos que empregam essa técnica, mas poucos produtos comerciais.

\section{Visual Looming}

O Visual looming se baseia no fenômeno visual looming e obtém a distância a um objeto a partir da mudança no tamanho da projeção do objeto no plano da imagem que decorre de deslocamentos conhecidos da câmera. Vários pesquisadores da área de robótica têm utilizado esse fenômeno, dentre os quais estão Sahin e Gaudiano (Sahin and Gaudiano, 1998) e Huttenlocher et al. (Huttenlocher et al., 1995). Neste trabalho é descrita a abordagem de Huttenlocher et al. Essa técnica usa apenas uma câmera e apresenta como principais vantagens:

- não requerer calibração da câmera;

- utilizar apenas informações de 2D para a recuperação da imagem desejada; 
- calcular a distância do alvo utilizando a mudança no tamanho do alvo na imagem através de equações simples, permitindo que o algoritmo opere em tempo real.

O funcionamento desse algoritmo consiste das seguintes fases:

- Capturar uma imagem do campo visual atual do robô;

- Utilizar um modelo bidimensional para localizar o alvo na imagem atual;

- Computar a distância utilizando o alvo localizado e o movimento feito pelo robô desde que a imagem anterior foi obtida;

- Construir um novo modelo bidimensional que será utilizado na localização do alvo na próxima imagem;

- Comandar o robô para realizar o próximo movimento e repetir o processo.

A Figura 2.2 (Huttenlocher et al., 1995) ilustra a idéia dessa técnica, mostrando a vista da câmera conforme ela se move de uma distância $m$ na direção do eixo óptico. $L$ é o comprimento do alvo com um ponto de referência no seu centro que está a uma distância $D$ do eixo óptico.

A distância pode ser obtida a partir da Equação 2.3:

$$
r=\frac{m}{\frac{l}{l}-1}=\frac{m}{s-1}
$$

em que, $r=$ distância estimada, $l^{\prime} / l=s=$ mudança no tamanho do alvo na imagem, $m$ = distância que o robô se moveu.

A distância calculada com essa técnica não depende dos parâmetros da câmera e não requer calibração. Porém, a precisão das medidas está relacionada ao movimento na direção do objeto $(\mathrm{D}=0)$. As mudanças na perspectiva e a oclusão/aparecimento de partes dos objetos também podem causar imprecisões. 


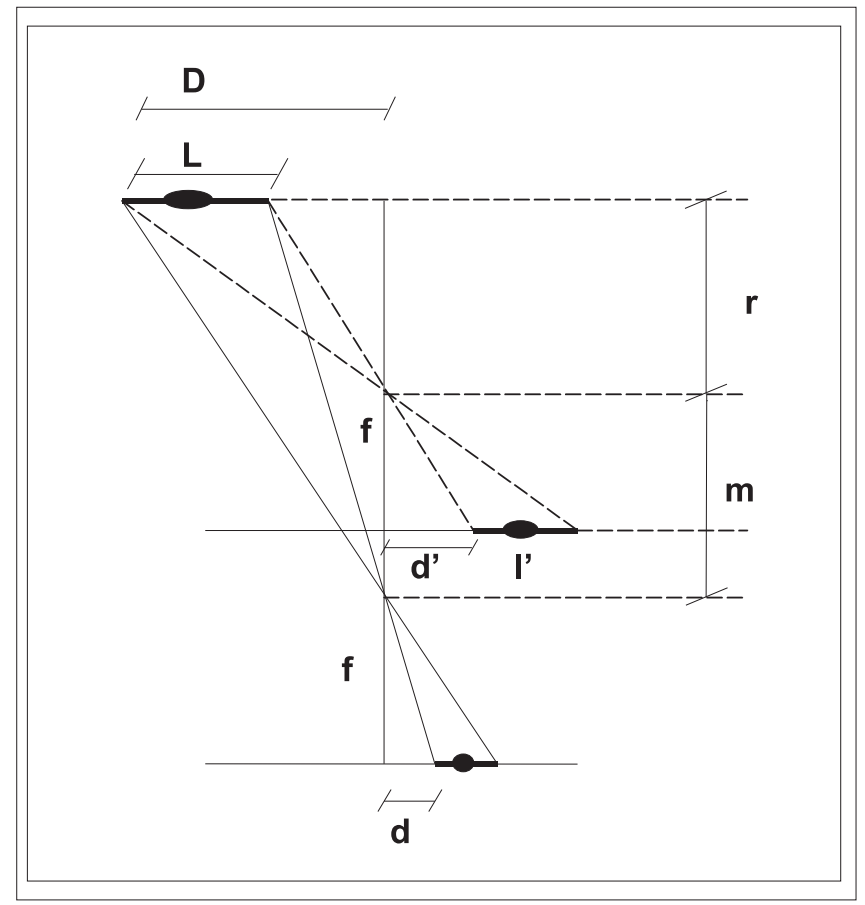

Figura 2.2: Princípio de funcionamento da técnica baseada no efeito looming.

\section{Visual Sonar}

Essa técnica extrai informações relativas à distância aos objetos localizados no chão, no campo visual do sensor (câmera), imitando a funcionalidade dos sensores ultra-sônicos a partir de imagens obtidas com câmeras (Horswill, 1994; Horswill, 1993). Para isso, uma imagem obtida a partir da câmera é dividida em colunas e é feita uma busca em cada uma delas, de baixo para cima, para localizar arestas. Assumindo que o sensor (em um robô) está operando em um ambiente fechado e que os objetos estejam no chão, a distância de um objeto é proporcional à distância da aresta correspondente a ele a partir do início da coluna.

Esse tipo de sensor encontra problemas com descontinuidades na imagem que não correspondem a objetos ou obstáculos (tapetes, marcas no chão, sombras). 


\subsection{Considerações Finais}

Neste capítulo foi feita uma descrição geral sobre sensores, detalhando as formas que podem ser empregadas na construção de sensores para medição de distâncias. Além disso, foram também ressaltadas as restrições presentes nos diversos tipos de sensores para medição de distância.

No próximo capítulo será abordado o tema fusão de sensores, que tem como um dos objetivos melhorar a precisão e acurácia das medidas dos sensores existentes. As questões tratadas envolvem alguns aspectos gerais a respeito da fusão de sensores, os princípios neurobiológicos e cognitivos relacionados ao tema e os paradigmas, frameworks e metodologias que têm sido empregados na fusão. 


\section{Capítulo 3}

\section{Fusão de Sensores}

\subsection{Considerações Iniciais}

As características de determinadas aplicações podem tornar necessária a utilização de diversos sensores. Essa necessidade pode surgir por diversos motivos e também requer alguns cuidados. Neste capítulo é abordado o problema da utilização de múltiplos sensores através da abordagem de fusão de sensores.

Primeiramente são ressaltados os aspectos gerais referentes à fusão de sensores. Em seguida são resumidos os princípios neurobiológicos e cognitivos da fusão de sensores. E, finalmente, são descritos alguns paradigmas, frameworks e metodologias que tem sido empregados com sucesso na fusão de sensores.

\subsection{Aspectos Gerais}

Como descrito no Capítulo 2, cada tipo de sensor apresenta suas limitações e tem uma precisão e custo associados. Muitas vezes, algumas características de um sensor necessárias e/ou desejáveis para uma aplicação, como por exemplo boa precisão e confiabilidade, ficam 
limitadas por restrições como custo ou complexidade dos sensores. Além disso, limitações apresentadas por um tipo de sensor podem não se aplicar a outros e vice-versa. Nesses casos, a combinação de informações obtidas a partir de alguns sensores simples e baratos pode fornecer uma informação mais completa, precisa e confiável do ambiente.

Essa é apenas uma das justificativas para a utilização de vários sensores. É grande o número de áreas que necessitam da utilização de múltiplos sensores. O seu uso nessas áreas tem como objetivo fornecer a um sistema informações mais estáveis e precisas sobre características de interesse do ambiente. Porém, para essas informações se apresentarem de forma coerente e servirem aos propósitos do sistema, elas precisam ser integradas. Esse processo de integração é realizado através da fusão de sensores.

A fusão de sensores envolve a combinação de informações provenientes de diferentes sensores para captar dados do ambiente cuja obtenção está além da capacidade isolada de cada um dos sensores envolvidos, principalmente quando são considerados confiabilidade e precisão. Além disso, a fusão de sensores tanto torna o sistema mais tolerante a falhas, como também pode fornecer informações novas, que nenhum dos sensores isoladamente consegue obter.

Cada área de aplicação tem um enfoque diferente para o problema e só recentemente têm surgido tentativas de uniformizar os conceitos e a terminologia envolvidos com a fusão de sensores (Dasarathy, 1997; Joshi and Sanderson, 1999; Luo and Kay, 1992; Luo and Kay, 1995).

Para maior clareza e compreensão do tema, pode-se fazer uma distinção entre integração e fusão de múltiplos sensores, embora essa distinção não seja padrão na literatura. A integração é uma idéia mais genérica e diz respeito ao uso sinérgico de informações provenientes de múltiplos sensores para a realização de uma tarefa. Já a noção mais restrita de fusão pode ser entendida como um estágio da integração, em que as leituras de diversos sensores são combinadas, de fato, em uma estrutura representacional (Luo and Kay, 1992; Brooks and Iyengar, 1998). Neste trabalho porém, para simplificação da terminologia, o termo fusão é empregado de uma maneira geral, englobando as idéias de 
integração e fusão.

Um modo interessante de se entender o problema da fusão de sensores é considerar a fusão como um processo inverso da fissão (Dasarathy, 1997). Quando um sensor é usado para a medição de algum fenômeno em um ambiente ele capta parte da informação disponível. Cada sensor observa uma parte diferente do ambiente, seja porque mede diferentes tipos de informações ou porque mede uma mesma informação de diferentes modos ou ângulos. Sendo assim, o fenômeno que está sendo medido pelos diversos sensores pode ser entendido como sendo decomposto por esses sensores em diversos componentes, ou seja, os sensores realizam uma fissão da informação total disponível no ambiente. Esses componentes de informação requerem uma reintegração para que o sistema possa ter a representação real do fenômeno sob observação. Essa reintegração é o processo chamado de fusão dos sensores. A fusão de sensores pode ser entendida então como um processo de recuperação ou preservação de informação e idealmente deve ser capaz de recuperar toda a informação de interesse a partir dos dados obtidos pelos sensores.

Apesar de cada sensor prover um aspecto da informação do ambiente, um grupo de sensores aplicados em conjunto pode interagir e essas interações vão determinar a forma como a fusão desses sensores deverá ser feita (Brooks and Iyengar, 1998; Joshi and Sanderson, 1999; Pasika, 1999):

- Fusão complementar;

- Fusão competitiva;

- Fusão cooperativa;

- Fusão independente.

A fusão complementar trata da fusão de informações incompletas obtidas a partir de diferentes sensores. Neste caso, diversos sensores estão medindo partes diferentes do ambiente, ou diferentes aspectos do fenômeno em questão. Isto permite uma visão mais completa do fenômeno que está sendo investigado. A informação obtida com esse tipo de fusão pode abranger uma área de cobertura maior do que a coberta com um único sensor ou agregar vários aspectos do mesmo fenômeno que são então usados para uma 
captação mais completa do fenômeno investigado. Esse tipo de fusão geralmente é fácil de ser efetuada. São exemplos desse tipo de fusão:

- diversos sensores de distâncias em um robô apontados para direções diferentes, provendo informações da localização de objetos ao seu redor;

- um sistema de radar com vários radares, cada um cobrindo uma região diferente, fornecendo informações equivalentes a um radar cobrindo toda a região;

- um velocímetro e um odômetro em um veículo, cada um medindo diferentes fenômenos, mas fornecendo informações úteis para a navegação do veículo.

A fusão competitiva, por sua vez, realiza a fusão de informações redundantes a respeito do fenômeno que está sendo investigado, com o objetivo de tornar o sistema mais confiável ou tolerante a falhas. O importante a se ressaltar a respeito deste tipo de fusão é que todos os sensores estão medindo a mesma parte do ambiente ou o mesmo aspecto do fenômeno medido. Assim, as informações são redundantes, fazendo com que se caracterize uma competição entre os sensores para se decidir qual deles contém a informação mais apropriada. As informações fundidas nesse caso, podem ser provenientes de sensores idênticos ou que usam métodos diferentes para medir um mesmo atributo físico. São exemplos desse tipo de fusão:

- a utilização de um sensor de distância laser e de um sensor acústico em um robô, apontados para um mesmo obstáculo, fornecendo a distância desse obstáculo com diferentes precisões;

- vários radares idênticos cobrindo a mesma região geográfica fazendo com que o sistema continue funcionando sem degradação, mesmo que algum dos radares pare de funcionar.

A fusão cooperativa faz a fusão de informações de sensores independentes com o objetivo de obter dados que não podem ser derivados dos sensores individualmente, ou seja, informações novas são obtidas com esse tipo de fusão. Esse tipo de fusão geralmente diminui a precisão e confiança do sistema e é feita em baixo nível (freqüentemente na fase de pré-processamento), sendo bastante dependente da aplicação. São exemplos desse tipo de fusão: 
- o uso de duas câmeras de vídeo para construir uma visão tridimensional de uma região;

- a utilização de vários termômetros dispostos em uma linha provendo, além da informação complementar de temperatura sobre a linha, informações sobre a taxa de variação da temperatura sobre essa linha.

A fusão independente trata da fusão de informações que aparentemente não estão relacionadas. Nesse caso, dados provenientes de diversos sensores e não relacionados podem ser armazenados em uma única estrutura de dados. Um exemplo desse tipo de fusão são informações de um radar e temperaturas obtidas de um mesmo local, que podem ser armazenadas conjuntamente.

Além disso, um determinado conjunto de sensores pode interagir de várias dessas formas ao mesmo tempo. A Tabela 3.1 mostra um resumo das características principais de cada forma de fusão.

\begin{tabular}{|l|l|l|}
\hline Tipo de Fusão & \multicolumn{1}{|c|}{$\begin{array}{c}\text { Região de } \\
\text { Leitura dos Sensores }\end{array}$} & \multicolumn{1}{c|}{ Objetivo } \\
\hline \hline Complementar & Diferentes (dados incompletos) & Complementar informações \\
\hline Competitiva & Diferentes (dados redundantes) & Aumentar tolerância a falhas \\
\hline Cooperativa & Mesmas & $\begin{array}{l}\text { Obter informações que não podem ser } \\
\text { obtidas de um sensor isoladamente }\end{array}$ \\
\hline Independente & Mesmas/Diferentes & $\begin{array}{l}\text { Armazenar informações vindas de sensores não } \\
\text { relacionados em uma única estrutura de dados }\end{array}$ \\
\hline
\end{tabular}

Tabela 3.1: Resumo dos tipos de fusão.

Na literatura pesquisada, os modelos de fusão de sensores têm sido caracterizados de diferentes maneiras, tais como:

- o domínio de aplicação (defesa, robótica, médica, espacial);

- o objetivo da fusão (detecção de um objeto ou condição do ambiente, reconhecimento de um objeto, classificação, tracking de um objeto);

- tipo de sensores;

- configuração dos componentes do sensor;

- nível da fusão (dados, características, decisão); 
- uma extensão do nível de fusão, descrita por Dasarathy (Dasarathy, 1997) que se baseia no par Entrada/Saída do processo de fusão.

A caracterização dos modelos de fusão mais comum, e também mais controversa, é a baseada no nível em que ocorre a fusão. O processo de fusão de sensores tem sido agrupado em níveis hierárquicos dependendo do estágio de processamento em que ela ocorre. Uma classificação muito comum na literatura divide a fusão em três níveis hierárquicos, variando a nomenclatura, mas se referindo aos mesmos conceitos (Dasarathy, 1997; Pasika, 1999). Esses três níveis são tratados neste trabalho como:

- Fusão de Dados (Data Fusion): trata de dados brutos provenientes diretamente dos sensores tais como sinais ou imagens;

- Fusão de Informações (Information Fusion): trata de informações, tais como categorias, propriedades, primitivas ou vetores de estado, que são a saída da fusão de dados;

- Fusão de Decisões (Decision Fusion): trata da união das informações que fluem pelo sistema com regras, experiência ou conceitos de mais alto nível para a tomada de uma decisão.

Outros autores apresentam outras divisões tais como nível de sinal, pixel, características e símbolos (Luo and Kay, 1992; Luo and Kay, 1995; Joshi and Sanderson, 1999) ou acrescentam outros níveis a esses já citados, tais como nível de comportamento (Goodridge, 1997) ou nível temporal (Dasarathy, 1997).

Assim como são várias as áreas que empregam a fusão de sensores, também são vários os benefícios que a sua utilização pode trazer para um sistema. Esses benefícios podem também ser entendidos como objetivos a serem atingidos com a fusão de sensores. Dentre outros possíveis objetivos, pode-se destacar (Joshi and Sanderson, 1999; Pasika, 1999; Luo and Kay, 1992; Luo and Kay, 1995):

- melhoria da precisão das medidas;

- tornar o sistema mais tolerante a falhas, através da redundância;

- obter informações em menos tempo ou a um menor custo; 
- obtenção de informações mais completas, confiáveis ou menos ambíguas;

- obter informações que não poderiam ser obtidas a partir de nenhum sensor isoladamente;

- combinação desses objetivos.

Em trabalho anterior já foram investigados alguns modelos de redes neurais, bem como um método de aprendizado simbólico para fusão de sensores aplicada ao mesmo problema descrito nesse artigo (Faceli et al., 1999). O trabalho de Martens et. al (Martens et al., 1998) também envolve a aplicação de redes neurais para fusão de sensores objetivando a melhoria da qualidade das distâncias entre um robô e um obstáculo, obtidas a partir de sensores simples e baratos. Esses trabalhos têm por objetivos a melhoria de precisão e acurácia dos sensores, tolerância a falhas e obtenção de informações a baixo custo.

Pasika (Pasika, 1999) utiliza redes neurais, comitês de redes neurais e SVM para, a partir de diferentes tipos de sensores já instalados, obter uma estimativa da altura das nuvens correspondente à dada por um LIDAR (Laser Radar), que é um dispositivo caro e que não se encontra disponível em muitas regiões. Os objetivos envolvidos com esse trabalho são, principalmente, obter informações novas a partir de um conjunto de sensores que não mede essa informação, permitindo a redução dos custos associados a obtenção dessa informação com um LIDAR.

Diversos outros trabalhos envolvem a fusão de sensores, tratando, por exemplo, da construção de mapas do ambiente em problemas de navegação de robôs e problemas em navegação em geral (Walker, 1993; Berler and Shimony, 1997; Wei et al., 1998; Nakauchi and Mori, 1998), localização e reconhecimento de objetos (Nilsson and Holmberg, 1993; Allen, 1995),

A fusão de múltiplos sensores traz diversos benefícios práticos. Porém a criação de uma metodologia geral e a sua aplicação em sistemas reais tem alguns problemas associados que precisam ser superados para que as suas vantagens sejam atingidas (Luo and Kay, 1992; Luo and Kay, 1995). 
Existem diversas abordagens para o problema de fusão de sensores. Alguns pesquisadores se baseiam nos estudos dos sistemas naturais para a criação de modelos para a fusão de sensores. Outros voltam sua atenção para os aspectos de engenharia do problema, visando, além da criação de modelos, o desenvolvimento de mecanismos práticos para executar a fusão (Pasika, 1999; Murphy, 1996). Embora muitas arquiteturas propostas na literatura não tenham como base os princípios biológicos e cognitivos envolvidos com a fusão, em geral elas são consistentes com esses princípios (Murphy, 1996). Assim, como uma motivação para a fusão de sensores, na Seção 3.3 é feita uma breve descrição dos princípios neurobiológicos e cognitivos da fusão de sensores.

O desenvolvimento de uma arquitetura para fusão de sensores envolve a consideração de diversos aspectos, tais como (Luo and Kay, 1992; Klein, 1999):

- as características individuais dos sensores envolvidos;

- a forma com que as informações devem ser integradas;

- os recursos de processamento disponíveis;

- as exigências específicas da aplicação em questão.

Com isso, torna-se difícil definir métodos e técnicas de propósito geral que englobem todos os diferentes aspectos da fusão de sensores. O que tem surgido na literatura são diferentes paradigmas, frameworks e estruturas de controle úteis para a fusão de sensores. Na Seção 3.4 é apresentado um modelo geral para o problema da fusão e brevemente descrito alguns dos paradigmas, frameworks e metodologias mais comuns que têm sido propostos.

\subsection{Princípios Neurobiológicos e Cognitivos da Fusão de Sensores}

Um sistema de percepção biológico como o dos mamíferos, por exemplo, é capaz de integrar informações dos diversos órgãos sensoriais e incorporar a elas outras informações 
previamente coletadas e armazenadas. Acredita-se que o cérebro humano constantemente forma hipóteses e as tenta validar com os dados percebidos, ou, caso não consiga, detectar uma nova classe de informações. Isso é também o que se deseja com um sistema de fusão de sensores: assimilar informações correlacionadas e formar uma opinião sobre o estado do ambiente, possivelmente fazendo uso de informações prévias (Pasika, 1999).

A fusão de informações visuais e auditivas na coruja é um bom exemplo de fusão de sensores nos animais. Na coruja, a informação acústica é colocada em uma representação bidimensional formada por características extraídas pela fase inter-auditiva e diferenças de intensidade, formando uma retina acústica. O teto óptico é alimentado com essas informações acústicas e realiza sua fusão com as informações provenientes da retina visual. Essa fusão de informações permite à coruja a deteç̧ão de alvos em condições de pouca luminosidade (Pasika, 1999).

Murphy (Murphy, 1996) descreve sucintamente alguns estudos das ciências biológica e cognitiva analisando suas contribuições como princípios para a fusão de sensores inteligentes na robótica. Ele define a fusão de sensores inteligentes como um processo que pode autonomamente reunir informações de vários sensores e combiná-las em uma percepção única e coerente, adaptar esse processo às mudanças no ambiente e aos problemas dos sensores e determinar estratégias para observar a percepção.

Como modelos biológicos, Murphy (Murphy, 1996) descreve a unidade dos sentidos de Lawrence Marks (Marks, 1978) e os estudos do colículo superior feitos por Stein e Meredith (Stein and Meredith, 1993). Esses modelos biológicos dizem respeito a como a fusão é realizada, indicando que:

- aparentemente, os sentidos usam representações específicas que são convertidas em uma representação comum na fusão;

- a saída da fusão é influenciada pelo contexto em que se insere o processo de fusão (contexto da tarefa, estado do agente, ambiente);

- as evidências dos sensores acrescem em vez de serem combinados em uma média aritmética. 
Os modelos cognitivos descritos por Murphy (Murphy, 1996) são: os modos perceptivos de Pick e Saltzman (Pick and Saltzman, 1978), a taxonomia dos modos de fusão de Bower (Bower, 1974) e o comportamento orientado de Lee (Lee, 1978). Esses modelos cognitivos enfocam porque a fusão é útil e oferecem descrições complementares de mecanismos a para fusão. Os estudos nessa área:

- enfatizam o papel do contexto na percepção e comportamento;

- sugerem uma taxonomia das alternativas de fusão que admitem a filtragem de ruídos e a recalibração de outros sensores;

- captam o aparecimento de modalidades sensoriais dominantes;

- mostram como um agente pode gerar e manter uma percepção ótima.

A seguir são apresentados, resumidamente, esses modelos descritos por Murphy (Murphy, 1996).

\section{Unidade dos Sentidos de Marks}

A teoria de Marks (Marks, 1978), segundo Murphy (Murphy, 1996), é baseada em cinco doutrinas:

- Doutrina de informações equivalentes: freqüentemente, a mesma percepção pode ser inferida de sensores individuais observando um conjunto de atributos diferentes e sem intersecção;

- Doutrina de atributos e qualidades análogos: todos os sentidos têm algum conjunto de propriedades de estímulos em comum, tais como intensidade, duração, tamanho, forma e número;

- Doutrina de propriedades psicofísicas comuns: os sentidos são processados por mecanismos similares, ou mesmo comuns;

- Doutrina de correspondência neural: existe um mecanismo neural especial para integrar informações multi-sensoriais, e, para isso existir, os diferentes sentidos usam um formato ou representação de conhecimento comum;

- Unidade dos sentidos: combinação das quatro doutrinas anteriores que sugere que para diferentes sentidos serem tão similares, eles deveriam ser interpretados como modalidades de um sentido geral. 
O aspecto principal que surge das idéias de Marks é que as representações específicas dos sensores são convertidas em uma representação comum durante a fusão (Pasika, 1999).

\section{Estudos Sobre o Colículo Superior}

Segundo Murphy (Murphy, 1996), os estudos de Stein e Meredith (Stein and Meredith, 1993) mostram que os estímulos à diferentes sentidos são inicialmente segregados ao nível neural. Os neurônios associados a diferentes sentidos não interagem entre si até que o estímulo seja transmitido para o cérebro, onde os sinais sensoriais convergem para o colículo superior (aparentemente responsável pelos comportamentos de atenção e orientação). O colículo superior aceita entradas de diferentes sentidos e também sinais do córtex cerebral que modula ou influencia o comportamento resultante. A maioria dos neurônios que entram no colículo superior são específicos a um sentido, enquanto que a maioria dos que saem são multi-sensoriais. Além disso, a saída dos neurônios é maior quando diversos estímulos fracos contribuem do que quando apenas um estímulo forte é sentido.

Desse modelo neurológico, é possível observar vários aspectos importantes para a robótica:

- a fusão de sensores acopla percepção com ação e incorpora informações contextuais;

- os sensores podem ser combinados de diferentes modos para diferentes percepções;

- as evidências dos sensores acrescem em vez de serem combinados em uma média aritmética (essa idéia suporta a noção de que vários sensores baratos e ordinários podem substituir um único sensor caro);

- os sensores usam uma representação específica até a fusão.

\section{Modos Perceptivos}

Os modos perceptivos de Pick e Saltzman (Pick and Saltzman, 1978), de acordo com Murphy (Murphy, 1996), decompõem a fusão de sensores em mecanismos gerais. A escolha 
do mecanismo a ser empregado depende da tarefa que a executada. Esse trabalho explica porque diferentes percepções podem ser obtidas a partir de um mesmo estímulo e especula que este pode ser usado tanto para integração quanto para processamento de um único sentido. Os autores argumentam ainda que podem existir mais de dois modos.

Um exemplo dos modos perceptivos é, a partir do mesmo estímulo visual de uma sala, a diferença no que se vê quando se está apenas passando ou quando se esta procurando por um objeto. A diferença entre as percepções está na tarefa: navegação, no primeiro caso, e busca focalizada, no segundo.

Essa idéia pode ser vista como base para a taxonomia descrita a seguir.

\section{Taxonomia dos Modos de Fusão}

A integração sensorial pode ser decomposta em uma taxonomia de quatro níveis, segundo Bower (Bower, 1974) citado por Murphy (Murphy, 1996):

- nível I - unidade completa dos sensores: todos os sensores que observam uma percepção são fundidos sem qualquer mecanismo para detectar discordâncias;

- nível II - unidade com conhecimento de discordâncias e possibilidade de recalibração: discordâncias entre os sensores podem ser detectadas e reconciliadas através da recalibração dos sensores que estão discordando;

- nível III - unidade com conhecimento de discordâncias e tendência à supressão: discordâncias podem ser detectadas, mas os sensores que discordam são temporariamente suprimidos, ao invés recalibrados;

- nível IV - absolutamente sem unidade: diferentes sensores observam atributos da tarefa sem correspondência espacial.

\section{Comportamento Orientado}

Segundo Murphy (Murphy, 1996), dois tipos de atividade de orientação em animais são descritas por Lee (Lee, 1978): orientação investigadora para obtenção de informações 
perceptivas importantes para a tarefa e orientação realizadora do corpo para a execução da tarefa. A possível extensão desse conceito para o processamento da percepção na robótica assumiria que o processo perceptivo é executado em duas fases: a investigadora, em que os sensores relevantes são configurados, e a realizadora, em que as observações dos sensores são coletadas, integradas e passadas adiante.

\subsection{Paradigmas, Frameworks e Metodologias para Fusão de Sensores}

Embora seja difícil derivar métodos gerais para o problema de fusão de sensores, algumas funções básicas são comuns à maioria das soluções existentes (Luo and Kay, 1992). Com base nos trabalhos de Luo (Luo and Kay, 1992; Luo and Kay, 1995) e Kokar e Tomasik (Kokar and Tomasik, 1994), Pasika (Pasika, 1999) descreve um framework geral para um sistema de fusão de sensores. Esse modelo engloba todos os níveis de fusão, apresentando quatro tipos de módulos: algoritmos de suporte auxilidores, diretrizes de orientação/controle, módulos de incorporação de conhecimento e motor de fusão propriamente dito. A Figura 3.1 (Pasika, 1999) ilustra esse modelo, que dá uma grande ênfase na estrutura de suporte, estando a fusão propriamente dita representada no motor de fusão.

Os módulos de suporte auxiliadores requerem mais poder de processamento que o coração do sistema. Existem cinco categorias básicas de algoritmos de suporte descritas por Hall (Hall, 1992) e resumidas por Pasika (Pasika, 1999). Essas categorias são: alinhamento dos dados (inscrição), pré-processamento dos dados, gerenciamento de base de dados, biblioteca numérica e interface homem/máquina. As três últimas categorias têm mais um papel de suporte do que de manipulação das informações, por isso não estão representadas no diagrama.

O módulo de orientação/controle inclui os sub-módulos seleção dos sensores, orientação/sinalização, controlador do sistema e controlador dos sensores. Esses sub-módulos 


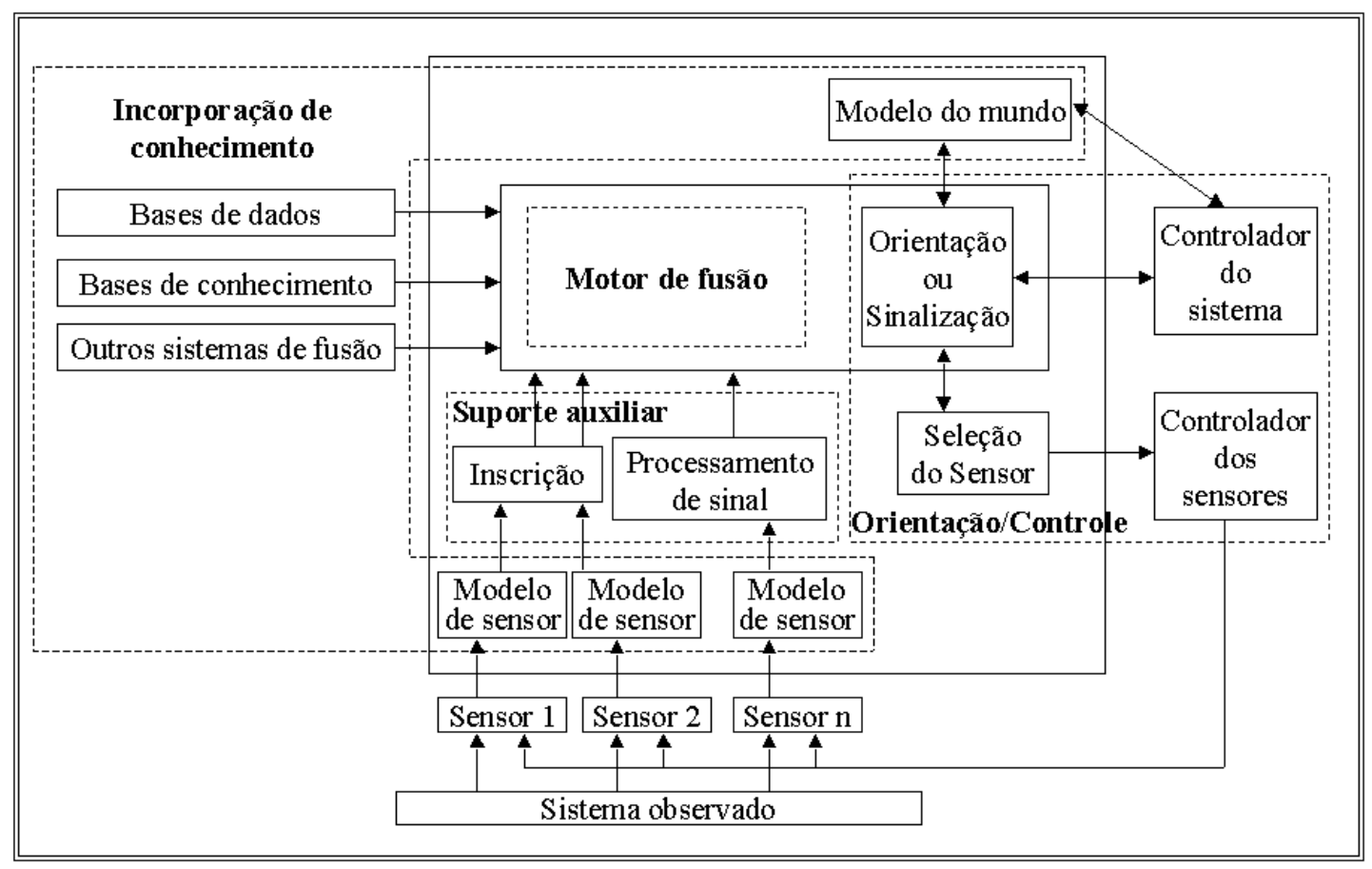

Figura 3.1: Modelo geral para um sistema de fusão de sensores.

são elementos essenciais em algoritmos de fusão fortemente acoplados. Na fusão fortemente acoplada, a operação de um sub-módulo sensorial é afetada pela saída de um outro, ou seja, as saídas dos sub-módulos não são independentes.

No módulo de incorporação de conhecimento podem ser incluídos os modelos dos sensores, o modelo do mundo e entradas externas, tais como: bases de dados, bases de conhecimento e outros sistemas de fusão. Os modelos dos sensores fornecem uma medida da qualidade da saída dos sensores e representam a incerteza e o erro desses sensores. O modelo do mundo armazena informações a respeito do estado do ambiente ao redor do sistema, contendo informações obtidas previamente ou recém adquiridas pelos sensores.

O algoritmo que realmente combina as informações está no motor de fusão. Segundo Pasika (Pasika, 1999), Hall (Hall, 1992) divide os algoritmos de fusão em:

- modelos físicos;

- técnicas de inferência baseadas em características;

- modelos baseados na cognição. 
A taxonomia para os algoritmos de fusão de Hall descrita por Pasika (Pasika, 1999) pode ser observada na Figura 3.2 (Hall, 1992). Klein faz uma breve descrição dessas categorias (Klein, 1999).

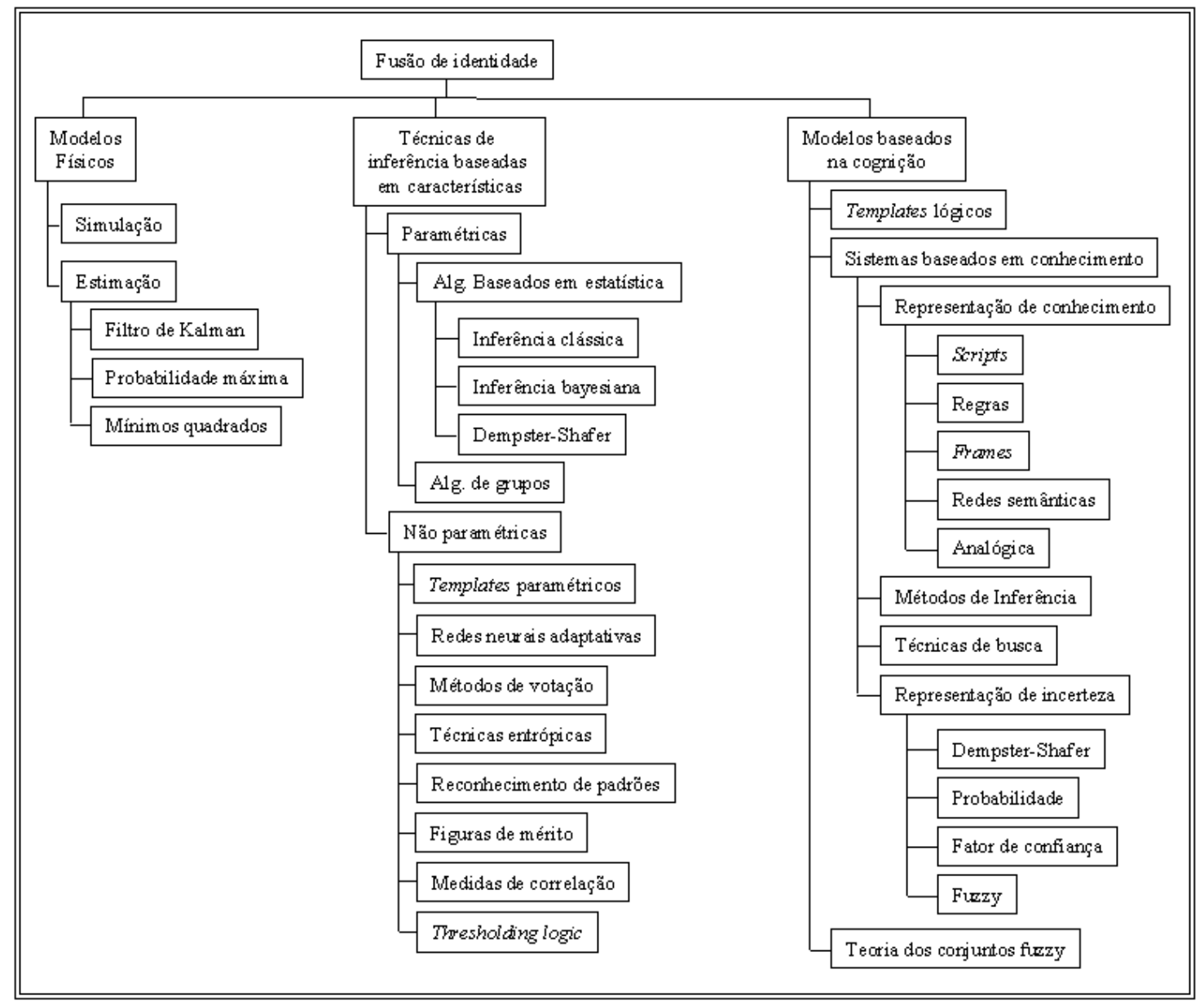

Figura 3.2: Taxonomia dos algoritmos de fusão de Hall.

Os modelos físicos replicam discriminadores de objetos que são fácil e precisamente observáveis/calculáveis e estimam a classificação e identidade de um objeto através do casamento de assinaturas do alvo modeladas ou previamente armazenadas para o dado observado. São exemplos desses modelos: simulação, estimação e métodos sintáticos.

As técnicas de inferência baseadas em características mapeiam dados em uma declaração de identidade. Técnicas paramétricas e não paramétricas são descritas nessa categoria. As técnicas paramétricas supõem que o parâmetro fundido é uma variável 
aleatória com uma função de densidade de probabilidade conhecida. Já as técnicas não paramétricas não requerem um modelo de distribuição de probabilidade. Nesse caso, nenhuma suposição é feita e os resultados são baseados exclusivamente nos dados (Pasika, 1999).

Os modelos baseados na cognição tentam emular e automatizar o processo de tomada de decisão dos analistas humanos.

Além desse framework geral, várias propostas para lidar com o problema têm sido descritas na literatura.

Luo e Kay (Luo and Kay, 1992; Luo and Kay, 1995) descrevem sucintamente diversos paradigmas e frameworks que foram empregados no desenvolvimento de sistemas de fusão de sensores:

- sensores lógicos proposto por Henderson e Shilcrat;

- paradigma fase-casamento (phase-template) hierárquico de Luo e Lin;

- Sensor de efeito cubo (sensor effect cube) de Middelhoek e Hoogerwerf;

- redes neurais artificiais;

- programação orientada a objetos;

- comportamentos lógicos de Henderson e Grupen;

- processamento de evidência generalizada;

- formalismos de Pau.

Ainda outros frameworks podem ser encontrados na literatura como a Lógica Formal e Teoria das Categorias usadas por Kokar et al. (Kokar et al., 1999) e Representação Mínima de Joshi e Sanderson (Joshi and Sanderson, 1999).

Contudo, independentemente do framework empregado, existem vários métodos e algoritmos que podem ser utilizados no processo de fusão propriamente dito, como os observados na taxonomia descrita anteriormente. A escolha do algoritmo a ser utilizado vai depender de uma série de fatores, tais como: 
- o nível das informações a serem fundidas;

- a aplicação que requer a fusão (o objetivo da fusão);

- o paradigma em que se baseia a proposta do sistema;

- a área de atuação dos pesquisadores envolvidos no desenvolvimento do sistema.

Aqui são descritos brevemente apenas alguns deles no intuito de ilustrar a enorme gama de possibilidades existentes para a aplicação na fusão de sensores. Além dos métodos já pesquisados, novos podem ser propostos. Os métodos de interesse para este trabalho são detalhados no Capítulo 4 e se referem à algoritmos de Aprendizado de Máquina (AM) e combinação de estimadores, que será avaliada como um novo método para fusão de sensores.

Uma descrição dos algoritmos mais comuns é feita por Klein (Klein, 1999), Luo e Kay (Luo and Kay, 1992; Luo and Kay, 1995) e Joshi e Sanderson (Joshi and Sanderson, 1999). Alguns desses métodos são descritos a seguir:

1. Média Ponderada (Luo and Kay, 1992; Luo and Kay, 1995; Joshi and Sanderson, 1999): É o método mais simples e intuitivo e serve para fusão de informações de baixo nível. Consiste do cálculo de uma média ponderada das informações redundantes proveniente de um conjunto de sensores.

2. Filtro de Kalman (Kalman filter) (Luo and Kay, 1992; Luo and Kay, 1995; Brooks and Iyengar, 1998; Joshi and Sanderson, 1999): Método útil para fusão de dados redundantes e dinâmicos de baixo nível em tempo real. Esse algoritmo usa características estatísticas de um modelo de medição para determinar estimativas ótimas para o dado fundido, recursivamente.

3. Inferência Clássica (Klein, 1999): Essa é uma técnica estatística que dá a probabilidade de que uma observação pode ser atribuída a presença de um objeto, dada uma hipótese. As desvantagens dessa técnica são:

- dificuldade na obtenção da função de densidade; 
- complexidades devidas a dados multivariados;

- avaliação de somente duas hipóteses de cada vez;

- não tira vantagens diretas das probabilidades a priori.

4. Inferência Bayesiana (Luo and Kay, 1995; Klein, 1999; Pasika, 1999): Essa é uma técnica estatística que se baseia na regra de Bayes. Esse método utiliza conhecimentos prévios sobre o ambiente para fazer inferências sobre o que está sendo observado. As desvantagens dessa técnica são:

- dificuldades na definição de funções de verossimilhança;

- complexidades quando existem múltiplas hipóteses e eventos condicionalmente dependentes;

- hipóteses que competem devem ser mutuamente exclusivas;

- não suporta incertezas.

5. Método de Dempster-Shafer (Luo and Kay, 1995; Klein, 1999; Joshi and Sanderson, 1999): Esse método é baseado em estatística e generaliza a teoria bayesiana para tratar incertezas. Nesse método, proposições (conhecimento dos sensores sobre eventos) são combinadas com a regra de Dempster para encontrar intersecções ou conjunções de proposições e suas probabilidades associadas. A desvantagem desse método está na necessidade de definir o processo em cada sensor.

6. Algoritmos de Agrupamentos (Clusters)(Klein, 1999): Nesses algoritmos os dados são agrupados em conjuntos ou agrupamentos naturais. Esses agrupamentos são interpretados por um analista que busca por categorias de objetos significativos. Métricas de similaridade ou medidas de associação são usadas para descrever a proximidade de dois vetores de características. Esses algoritmos selecionam dados de amostra, definem o conjunto de variáveis ou características que caracterizam as entidades na amostra, calculam as similaridades entre os dados, usam um método de análise de agrupamento criando grupos de entidades similares e validam a solução encontrada. A natureza heurística desses algoritmos pode levar a resultados tendenciosos. Os resultados podem ser afetados por diferenças de escala nos dados, escolha das métricas de similaridade e algoritmos e até pela ordem de entrada dos dados. 
7. Casamentos Paramétricos (Parametric templates) (Klein, 1999): Os dados adquiridos durante um período de tempo e de múltiplas fontes são casados com condições pré-selecionadas para determinar se as observações contém evidências para identificar uma entidade.

8. Redes Neurais Artificiais (Luo and Kay, 1995; Klein, 1999; Pasika, 1999; Brooks and Iyengar, 1998; Joshi and Sanderson, 1999): São sistemas treinados para mapear dados de entrada em categorias de saída selecionadas. Esse tipo de algoritmo é formado por um conjunto de nós altamente interconectados de forma semelhante aos neurônios no cérebro. Mais detalhes das redes neurais de interesse para este trabalho são abordados no Capítulo 4.

9. Métodos de Votação (Klein, 1999): Esses métodos combinam declarações de múltiplos sensores tratando cada declaração como um voto e usando maioria, pluralidade ou regras de árvores de decisão. Pesos nas declarações também podem ser usados.

10. Medidas de Entropia (Klein, 1999; Joshi and Sanderson, 1999): Tentam medir a importância de uma informação pela sua probabilidade de ocorrência. Dados muito freqüentes tem valor baixo enquanto dados raros tem valores mais altos e portanto a função que mede o valor da informação decresce com a probabilidade crescente de receber a informação.

11. Figuras de Mérito (Klein, 1999): São métricas que ajudam a estabelecer o grau de associação entre as observações e a identidade do objeto. Essas técnicas tentam formular um relacionamento entre diversas variáveis para melhorar a associação ou classificação dos dados.

12. Reconhecimento de Padrões (Klein, 1999): Diz respeito a descrição ou classificação dos dados. Três abordagens são comuns para o reconhecimento de padrões: estatística, sintática e redes neurais artificiais.

13. Medidas de Correlação (Klein, 1999): São derivadas de combinações ponderadas de figuras de mérito e admitem uma medida de comparação para sistemas com muitas dessas figuras. 
14. Casamentos Lógicos (Klein, 1999): Os dados observados são comparados com padrões pré-determinados e armazenados para se identificar o objeto ou avaliar uma situação. Esses casamentos paramétricos podem ser combinados com casamentos lógicos. Incertezas podem ser tratadas pela aplicação de lógica fuzzy.

15. Sistemas Baseados em Conhecimento (Klein, 1999; Joshi and Sanderson, 1999): Esses sistemas incorporam regras e conhecimentos de especialistas para automatizar o processo de identificação do objeto. Geralmente um sistema desses é composto de uma base de conhecimento que contém fatos, algoritmos e uma representação de regras heurísticas, uma base de dados global que contém dados dinâmicos, uma estrutura de controle ou motor de inferência e uma interface homem/máquina.

16. Teoria dos Conjuntos Fuzzy (Luo and Kay, 1995; Klein, 1999; Joshi and Sanderson, 1999): A lógica fuzzy se aplica em problemas nos quais os limites entre conjuntos de valores não são bem definidos, existe a ocorrência parcial de um evento ou as equações matemáticas específicas não são conhecidas. Nos conjuntos fuzzy uma proposição tem um valor de pertinência em uma classe variando de 0 (não pertence à classe) a 1 (definitivamente pertence à classe).

\subsection{Considerações Finais}

Neste capítulo foi feita uma descrição do problema de fusão de sensores, abordando os aspectos de maior interesse para este trabalho. Uma breve descrição de alguns métodos freqüentemente encontrados na literatura para a implementação da fusão também foi feita.

No capítulo seguinte será feita uma descrição mais detalhada dos métodos de Inteligência Artificial de conhecido ou potencial interesse para a aplicação no problema de fusão de sensores. Esses métodos consistem de algoritmos de aprendizado de máquina e combinação de estimadores. Alguns dos algoritmos descritos já vem sendo empregados com sucesso nessa aplicação, outros entretanto, estão sendo investigados pela primeira vez neste trabalho, como algoritmos para fusão de sensores. 


\section{Capítulo 4}

\section{Algoritmos de Aprendizado de Máquina usados para Fusão de}

Sensores

\subsection{Considerações Iniciais}

O treinamento de um modelo para resolver um problema de aproximação de função tem como objetivo a obtenção de uma representação exata, ou a melhor aproximação possível, de uma função $f: R^{N} \rightarrow R$, a partir de um conjunto de pares entrada/saída $S=$ $\left\{(x, y) \mid x \in R^{N}, y \in R\right\}$.

O problema de aproximação de funções pode ser visto como um problema de classificação de padrões ou de regressão. A classificação de padrões pode ser considerada um caso especial de aproximação de funções em que a saída $y$ é restrita a valores discretos (classes). Quando a saída y assume valores contínuos, o problema se torna de regressão. Como o objetivo da fusão de sensores, neste trabalho, é a obtenção de uma melhor estimativa de distância ente um robô e um alvo, o problema tratado nesta dissertação é claramente um problema de regressão. 
A seguir são descritas técnicas de Inteligência Artificial empregadas neste trabalho para fusão de sensores. Essas técnicas consistem de diversos algoritmos de aprendizado de máquina (AM) para regressão, englobando algoritmos dos paradigmas conexionista, simbólico e estatístico, bem como a combinação de estimadores. A idéia é que, como cada algoritmo de aprendizado possui suas características particulares, cada um podendo apresentar um melhor desempenho para uma situação diferente, a combinação desses algoritmos pode fornecer uma informação mais estável (acurada) e precisa. Os algoritmos descritos são as redes neurais do tipo MultiLayer Perceptron (MLP), Radial Basis Function (RBF) e Cascade Correlation, Support Vector Machine (SVM), Cubist e M5. As redes do tipo MLP e RBF foram escolhidas por serem as redes mais comumente utilizadas em diversas aplicações. Porém, o desempenho dessas redes depende muito da topologia empregada. Assim, a rede do tipo Cascade Correlation, cujo resultado não depende da definição inicial da topologia, também foi escolhida. O SVM foi escolhido por ser uma técnica recente, que vem apresentando bons resultados em diversas aplicações. Os algoritmos Cubist e M5, por sua vez, foram escolhidos por serem algoritmos do paradigma simbólico que se aplicam a problemas de regressão.

\subsection{Redes Neurais}

O paradigma conexionista (Redes Neurais Artificiais - RNAs) representa uma forma de computação não algorítmica, cujo funcionamento é inspirado na estrutura e funcionamento do cérebro humano. As RNAs podem ser definidas como sistemas paralelos distribuídos compostos de unidades de processamento simples, altamente interconectadas, que computam determinadas funções matemáticas. Tais unidades são dispostas em uma ou mais camadas e interligadas por um grande número de conexões, geralmente unidirecionais. Na maioria dos modelos estas conexões estão associadas à pesos, os quais armazenam o conhecimento representado no modelo e servem para ponderar a entrada recebida por cada neurônio da rede (Braga et al., 2000).

A solução de problemas através de RNAs é bastante atrativa, já que a forma como 
estes são representados internamente pela rede e o paralelismo natural inerente à arquitetura das RNAs criam a possibilidade de um desempenho superior àquele obtido por modelos convencionais. Em RNAs, o procedimento usual na solução de problemas passa inicialmente por uma fase de aprendizagem, na qual um conjunto de padrões ou exemplos é apresentado para a rede, que extrai automaticamente as características necessárias para representar a informação fornecida. Essas características são utilizadas posteriormente para gerar respostas novos padrões.

Três tipos de redes neurais são descritos nesta seção: MultiLayer Perceptron (MLP) (Rumelhart and McClelland, 1986), Cascade Correlation (Fahlman and Lebiere, 1988) e Radial Basis Function (RBF) (Broomhead and Lowe, 1988).

O software utilizado para o treinamento das redes neurais utilizadas neste trabalho foi o SNNS (Stuttgart Neural Network Simulator) (Zell et al., 1995; Diniz et al., 1997), um simulador de redes neurais constituído de quatro componentes: simulador, interface gráfica, versão batch do simulador (batchman) e compilador de rede. Para a criação das redes, alguns testes preliminares e o treinamento das redes RBF e Cascade Correlation foi utilizada a interface gráfica e para o treinamento das redes MLP foi utilizado o programa batchman.

\subsubsection{Multi-Layer Perceptron (MLP)}

A rede neural do tipo Multi-Layer Perceptron (MLP) (Rumelhart and McClelland, 1986) é o modelo de rede neural mais utilizado. Como o nome indica, nesta rede os neurônios são distribuídos em pelo menos uma camada intermediária e uma camada de saída. O algoritmo mais comumente utilizado para treinar redes do tipo MLP é o algoritmo Backpropagation. Esse algoritmo utiliza pares (entrada, saída desejada) para ajustar os pesos da rede através de um mecanismo de correção de erros. O treinamento através desse algoritmo ocorre em duas fases, cada uma percorrendo a rede em um sentido: fase forward, utilizada para definir a saída da rede para um dado padrão de entrada e fase backward, 
utilizada para atualizar os pesos das conexões da rede através da saída desejada e da saída produzida pela rede. Existem diversas variações deste algoritmo que tem como objetivo acelerar o processo de treinamento e reduzir as taxas de erros obtidas.

Dois outros algoritmos comumente usados para o treinamento das redes MLP são o RProp (Resilient backpropagation) (Riedmiller and Braun, 1993) e o Quickprop (Fahlman, 1988). O algoritmo Rprop é um esquema de aprendizado adaptativo local, que executa um aprendizado supervisionado em batch em uma rede MLP. O algoritmo Quickprop é uma forma de acelerar o aprendizado do Backpropagation utilizando informações sobre a curvatura da superfície de erro.

\subsubsection{Cascade Correlation}

As redes MLP descritas anteriormente são as redes mais comumente empregadas em problemas de aproximação de funções. O treinamento nessas redes se limita a modificações nos pesos das conexões de uma rede com topologia fixa. Contudo, é sabido que a arquitetura da rede também exerce influência no seu desempenho. Uma rede muito pequena pode não aprender bem o problema, enquanto que uma rede muito grande pode ter problemas de over-fitting e uma apresentar uma generalização pobre (Kwok and Yeung, 1995; Kwok and Yeung, 1999).

Várias abordagens têm sido empregadas na otimização da arquitetura de uma rede neural (Vargas, 1998). A abordagem mais comum é a empírica, que se baseia na tentativa e erro (o usuário, com sua experiência, sugere uma boa topologia e a partir dela vai fazendo modificações até que encontre uma que se ajuste melhor ao problema). Esta abordagem, além de ter um alto custo computacional, não garante que a arquitetura selecionada seja a melhor possível (Parekh et al., 1998). Outra abordagem é a genética, em que, a partir de um conjunto de redes candidatas, novos conjuntos são criados combinando as características das redes que tiveram melhor desempenho, até que seja obtida uma rede com desempenho satisfatório. A abordagem de pruning se baseia no treinamento de uma rede 
maior do que o necessário e posterior eliminação de pesos e neurônios redundantes. Os problemas dessa abordagem são a determinação do tamanho inicial da rede, grande gasto de recursos computacionais, possibilidade de não encontrar a menor solução possível e introdução de erros grandes (Kwok and Yeung, 1995). Uma última abordagem, a abordagem construtiva, utiliza inicialmente uma rede pequena que cresce dinamicamente com a adição e treinamento de novos neurônios até que seja obtida uma solução satisfatória.

Algoritmos construtivos têm sido propostos tanto para problemas de regressão como de classificação. Kwok e Yeung (Kwok and Yeung, 1995; Kwok and Yeung, 1999) fazem um estudo sobre algoritmos construtivos voltados ao problema de regressão, enquanto Parekh et al. (Parekh et al., 1997; Parekh et al., 1998) abordam o assunto sob a perspectiva da classificação de padrões. Algoritmos construtivos usados para regressão podem ser adaptados para problemas de classificação de padrões.

O algoritmo Cascade Correlation é um algoritmo de aprendizado supervisionado construtivo, originalmente usado para classificação de padrões (Fahlman and Lebiere, 1988; Parekh et al., 1997; Parekh et al., 1998; Vargas, 1998; Sousa, 1999). Esse algoritmo começa com uma rede de duas camadas (de entrada e saída) e adiciona unidades intermediárias durante o treinamento. A unidade que será adicionada a cada momento é selecionada de um conjunto de candidatas. A nova unidade é conectada às camadas de entrada e de saída e a todas as unidades intermediárias previamente inseridas, criando uma nova camada, gerando assim uma arquitetura em cascata. A vantagem dessas redes é a rapidez do seu treinamento. A Figura 4.1 (Kwok and Yeung, 1995) mostra um exemplo dessa arquitetura. Redes com essa estrutura são detectores de características poderosos, mesmo que empreguem funções de ativação simples nas unidades intermediárias. Porém, essas redes apresentam um longo atraso de propagação, um crescente aumento do número de entradas das unidades e podem ter problemas de generalização. 


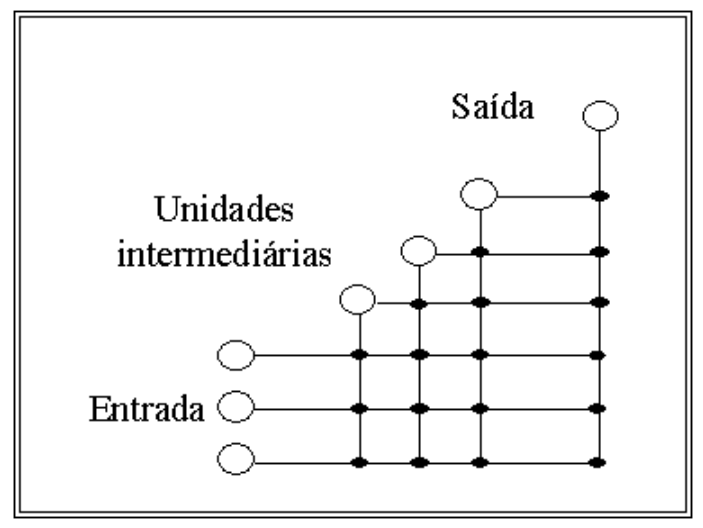

Figura 4.1: Arquitetura da rede Cascade Correlation.

\subsubsection{Radial Basis Function (RBF)}

Redes do tipo RBF (Broomhead and Lowe, 1988; Braga et al., 2000) são geralmente utilizadas em problemas de aproximação de funções e reconhecimento de padrões. Geralmente, esse tipo de rede possui uma única camada intermediária. Os neurônios da camada intermediária utilizam funções de base radial, sendo a função Gaussiana a mais comum. Essas redes são treinadas por métodos considerados híbridos, por serem divididos em dois estágios, um não supervisionado e outro supervisionado. O primeiro estágio determina o número de funções radiais e seus parâmetros através de métodos não supervisionados. $\mathrm{O}$ segundo ajusta os pesos dos neurônios de saída através de modelos lineares como a regra delta (algoritmo LMS) (Braga et al., 2000).

O algoritmo mais comum utilizado no primeiro estágio de treinamento das redes do tipo RBF é o K-Means-Clustering que, através de um aprendizado não supervisionado, posiciona os centros em regiões do espaço onde estão situados os vetores de entrada mais representativos. Esse algoritmo divide o conjunto de entradas em subconjuntos disjuntos (clusters) e posiciona os centros no ponto médio de cada um desses subconjuntos. A finalidade do algoritmo é minimizar a soma dos quadrados das distâncias entre os vetores de entrada e o correspondente centro. Já o segundo estágio de treinamento pode utilizar o algoritmo LMS para ajustar os pesos na camadas de saída, uma vez que a transformação do espaço das unidades intermediárias para o espaço de saída é linear. Porém, existem 
outras formas de se treinar uma rede RBF.

\section{$4.3 \quad$ Support Vector Machine (SVM)}

SVM (Vapnik, 1995) engloba uma classe de algoritmos de aprendizado e se baseia na teoria de aprendizado estatístico, combinando controle de generalização com uma técnica para tratar o problema da dimensionalidade. Sua formulação resulta em um problema de otimização quadrática e envolve o princípio de Minimização do Risco Estrutural (Structural Risk Minimization - SRM), em vez do princípio de Minimização do Risco Empírico (Empirical Risk Minimization - ERM) empregado pelas redes neurais convencionais. SRM minimiza o "Erro de generalização" em oposição ao ERM que minimiza o erro nos dados de treinamento, dando ao algoritmo SVM uma maior capacidade de generalização.

Esse tipo de algoritmo foi originalmente desenvolvido para reconhecimento de padrões. Nesse caso uma fronteira de decisão é representada em termos de um subconjunto dos exemplos de treinamento, tipicamente pequeno, chamado de vetores de suporte (support vectors). Para o caso de regressão, Vapnik desenvolveu uma função de perda chamada $\varepsilon$-insensitive loss function que não penaliza erros inferiores a algum $\varepsilon>0$ escolhido previamente. Esse algoritmo estima a função $f(x)=(w \cdot x)+b, w, x \in R^{N}, b \in R$, com base nos dados $\left(x_{1}, y_{1}\right), \ldots,\left(x_{l}, y_{l}\right) \in R^{N} \mathrm{x} R$, minimizando $\frac{1}{2}\|w\|^{2}+C \cdot R_{e m p}^{\varepsilon}$, em que C é uma constante que promove um balanço entre minimizar os erros do treinamento e minimizar a complexidade do modelo, e $R_{e m p}^{\varepsilon}=\frac{1}{l} \sum_{i=1}^{l} \max \left\{0,\left|y_{i}-f\left(x_{i}\right)\right|-\varepsilon\right\}$. Maiores informações sobre SVM podem ser encontradas no endereço http://www.kernel-machines.org/ que contém diversos links para artigos e softwares.

Para a utilização do algoritmo SVM foram testadas três implementações diferentes. A primeira a ser utilizada foi a SVM Software do Royal Holloway, University of London que pode ser obtida a partir do endereço http://svm.dcs.rhbnc.ac.uk/ (Saunders et al., 1998). A segunda implementação a ser testada foi a mySVM, que pode ser usada para reconhecimento de padrões e regressão, com diferentes funções de perda. mySVM po- 
de ser encontrada no endereço http://www-ai.cs.uni-dortmund.de/SOFTWARE/MYSVM/ (Rüping, 2000). Uma terceira implementação investigada para utilização foi a SVMTorch obtida no endereço http://www.idiap.ch/learning/SVMTorch.html. Essa implementação trabalha com classificação e regressão em larga escala (mais de 20000 exemplos e entradas com dimensão maior do que 100) (Collobert and Bengio, 2000).

A implementação escolhida para ser utilizada nos experimentos foi a SVMTorch que é constituída de dois programas, svm_torch e svm_test, que são executados a partir da linha de comando. Os arquivos de treinamento e teste para esses programas podem ser utilizados em diferentes formatos e são descritos em (Collobert, 2000).

O programa svm_torch é utilizado para gerar o modelo da máquina de suporte vetorial (SVM) a partir de um conjunto de dados de treinamento, podendo ser utilizado para gerar modelos para classificação ou para regressão. Quatro tipos de kernel (linear, polinomial, gaussiano e sigmoide) estão disponíveis, sendo ainda possível a utilização de um kernel definido pelo usuário. A sintaxe para execução do programa é: svm_torch [opções] $<$ arquivo de treinamento $><$ arquivo do modelo $>$.

O svm_test é utilizado para testar o modelo com os dados de um arquivo de teste. Esse programa permite a verificação do desempenho do modelo através de algumas medidas de erro, quando aplicado a um arquivo de teste que possui a resposta esperada. Também é possível utilizar esse programa para predizer o valor do atributo meta, aplicando o modelo a um arquivo de teste que não contenha a resposta esperada. A sintaxe para execução do programa é: svm_test [opções] <arquivo do modelo $><$ arquivo de teste $>$.

Schölkopf et al. (Schölkopf et al., 1996) fazem uma comparação entre as redes RBF e o SVM. 


\subsection{Cubist}

O Cubist (Rulequest-Research, 2000) consiste de uma ferramenta para geração de modelos preditivos baseados em regras que procura um balanceamento entre a necessidade de precisão em uma predição e sua intelegibilidade. Assim como as redes neurais, modelos preditivos baseados em regras se caracterizam pela facilidade e flexibilidade de uso. Esses modelos consistem em coleções de regras não-ordenadas da forma:

IF condições THEN modelo_linear.

A regra indica que, se um caso satisfaz todas as condições, o modelo linear é apropriado para prever o valor do atributo-meta (saída associada aos valores de entrada apresentados). Se duas ou mais regras são aplicadas para um caso, é calculada uma média dos valores definidos pelos respectivos modelos lineares para chegar a uma previsão final.

Os modelos gerados pelo Cubist geralmente fornecem resultados melhores que os produzidos por técnicas como regressão linear multivariada, ao mesmo tempo que são mais fáceis de entender do que as redes neurais, por exemplo.

O Cubist utiliza um método não muito comum para combinar modelos baseados em regras e baseados em instâncias (Instance Based). Inicialmente, ele encontra os cinco casos mais similares (k-vizinhos mais próximos) do atributo-meta, entre todos os casos do conjuntos de dados. Posteriormente, calcula a média utilizando estes valores. Finalmente ele ajusta estes valores usando o modelo baseado em regras.

\subsection{M5}

Uma Árvore de Decisão (Decision Tree) é uma estrutura de dados recursiva definida como: um nó folha que indica o rótulo de uma classe ou um nó de decisão que contém um teste baseado nos valores de um subconjunto dos atributos de entrada. Para cada resultado do teste existe um ramo e uma sub-árvore. Cada sub-árvore tem a mesma estrutura da 
árvore (Gama, 1999; Baranauskas and Monard, 2000). Nesse algoritmo, um problema complexo é dividido em problemas mais simples, com a mesma estratégia sendo aplicada aos subproblemas.

Para a classificação ou regressão de um padrão de entrada, uma Árvore de Decisão testa o nó raiz e, dependendo do resultado, o padrão é passado para os ramos abaixo. O processo é repetido até que seja alcançado um nó folha que contém um valor que "rotula"o padrão. Esse valor pode ser categórico (classificação) ou real (regressão), dependendo do tipo do atributo que deve ser estimado (Nagai, 1999). Quando uma árvore é empregada para regressão ela é chamada de árvore de regressão.

Árvores de regressão muitas vezes geram um grande número de nós, dificultando a interpretação dos dados. Apesar disso, sua performance para muitos problemas costuma ser melhor do que uma simples equação de regressão.

Uma model tree (Wang and Witten, 1997; Frank et al., 1998; Witten and Frank, 1999) é uma árvore que combina árvore de regressão com equações de regressão. Esse tipo de árvore funciona da mesma maneira que uma árvore de regressão, porém os nós folha contém expressões lineares em vez de valores únicos preditos. A model tree é menor e mais compreensível que uma árvore de regressão e, mesmo assim, apresenta um erro médio menor na predição.

M5 é um indutor para model tree que está disponível no sistema Weka (Waikato Environment for Knowledge Analysis) (Witten and Frank, 1999) e que é usado neste trabalho.

\subsection{Combinação de Estimadores}

Diferentes estimadores (classificadores ou regressores), com base num mesmo conjunto de treinamento, seguem diferentes princípios de funcionamento e possuem diferentes capacidades de generalização. A abordagem tradicional para se obter o melhor estimador é 
selecionar aquele que oferece o melhor resultado para o problema que está sendo tratado. Contudo, essa pode não ser a opção mais adequada, uma vez que informações valiosas descobertas pelos demais estimadores podem estar sendo ignoradas. Sendo assim, uma abordagem alternativa é combinar de alguma forma as saídas de todos os estimadores (Tumer and Ghosh, 1996).

A combinação de estimadores independentes em comitês, também chamados ensembles, é uma técnica bastante empregada nos problemas de classificação e regressão com o objetivo de melhorar a precisão e acurácia de estimadores (preditores) individuais, aproveitando as características intrínsecas de cada um (Gama, 1999; Sharkey, 1999; Merz, 1998; LeBlanc and Tibshirani, 1993; Tumer and Ghosh, 1996; Merz and Pazzani, 1997; Krogh and Vedelsby, 1995; Sebastiani, 1999). Essa combinação pode ser feita paralelamente, em cascata ou de forma hierárquica (Prampero, 1998). Em um sistema em cascata, os resultados gerados por um estimador são freqüentemente utilizados para dirigir o processo de estimação de estimadores sucessivos. Em sistemas paralelos, os estimadores trabalham independentemente e o processo de decisão integra os resultados obtidos. Já em sistemas hierárquicos, a estratégia de controle é uma combinação entre processamento em cascata e paralelo. A forma mais comum é a combinação em paralelo e essa é a forma empregada neste trabalho. Um esquema dessas formas de combinação pode ser observado na Figura 4.2 (Prampero, 1998).

Nos comitês de redes neurais, geralmente cada rede é treinada individualmente e só depois suas saídas são combinadas, em paralelo. Nos problemas de classificação, geralmente a combinação é feita por maioria (votação) e nos problemas de regressão é utilizada média simples, embora uma combinação ponderada das redes também possa ser utilizada (Krogh and Vedelsby, 1995).

Para a combinação de estimadores ser útil é preciso que as saídas dos estimadores individuais discordem para algumas entradas. Krogh e Vedelsby (Krogh and Vedelsby, 1995) discutem a discordância entre as redes, apresentando um método para aumentar a discordância entre os estimadores, mesmo que eles sejam idênticos. Merz e Pazzani (Merz 


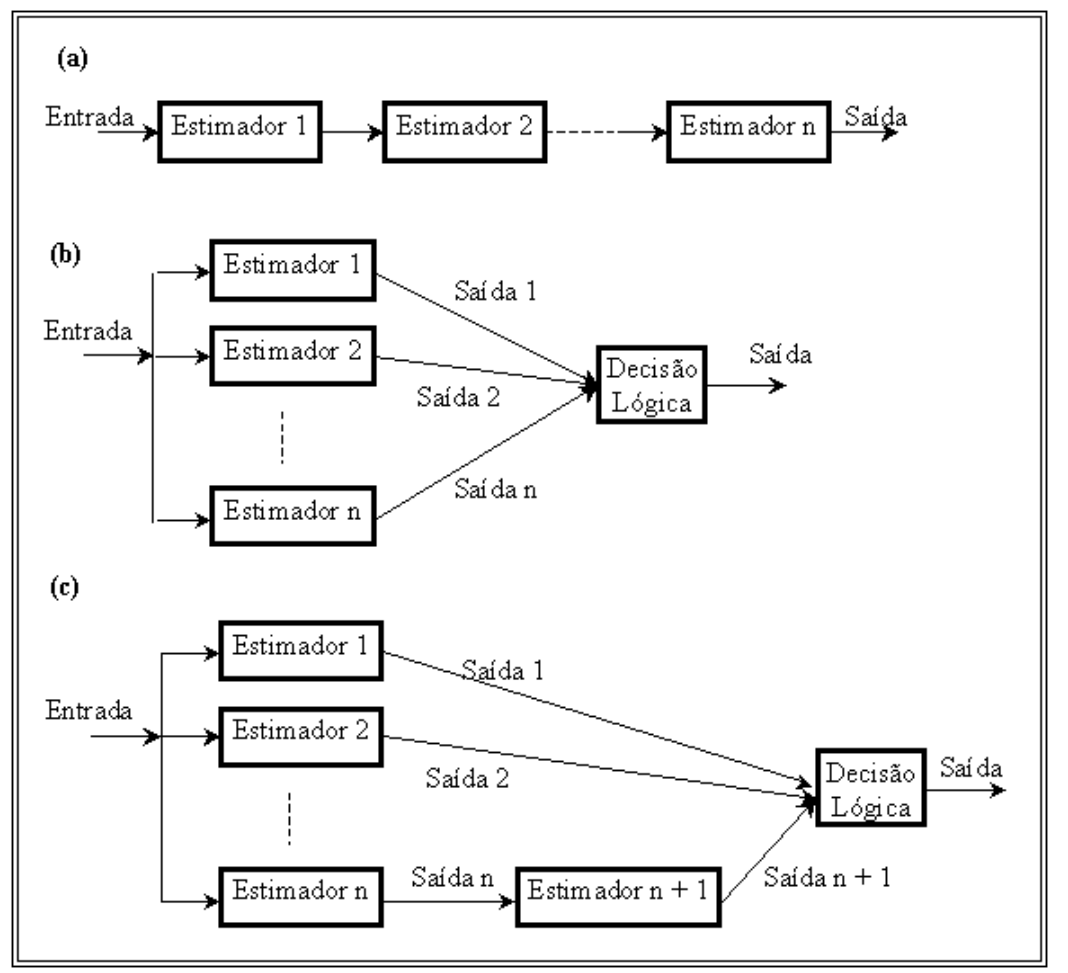

Figura 4.2: Configurações possíveis para combinação de estimadores: (a) Cascata, (b) Paralelo, (c) Hierárquico.

and Pazzani, 1997) se referem à quantidade de concordância, ou dependência linear, entre os estimadores como redundância e discutem alguns métodos para combinação existentes com respeito a essa característica, propondo um método baseado em regressão dos componentes principais (Principal Components Regression (PCR)).

Como descrito na Seção 4.1, os problemas de classificação e regressão podem ser vistos como problemas de aproximação de função, em que um estimador tem como objetivo aprender a representação exata, ou a melhor aproximação possível de uma função $f: R^{N} \rightarrow R$, a partir de um conjunto de exemplos $S=\left\{(x, y) \mid x \in R^{N}, y \in R\right\}$ no qual, $y=f(x)$. A combinação de estimadores consiste da obtenção da melhor aproximação da função $f(x)$ a partir de um conjunto de funções $F=\left\{f_{i}(x) \mid f_{i}(x)\right.$ é a função que estima $f(x)$ com base no estimador $i\}$. Existem várias formas pelas quais as saídas dos estimadores individuais podem ser combinadas: decisão aleatória, decisão pela combinação linear das saídas e decisão pela combinação não linear das saídas (Prampero, 1998). 
$\mathrm{Na}$ decisão aleatória, os estimadores individuais fornecem suas saídas e o sistema de combinação seleciona aleatoriamente uma delas para apresentar como resposta. Esse método é utilizado para medir a eficiência de outros métodos de combinação.

A maioria das abordagens atuais realiza uma combinação linear dos elementos de $F$, como mostrado na Equação 4.1 (Merz and Pazzani, 1997):

$$
\bar{f}(x)=\sum_{i=1}^{N} \alpha_{i} f_{i}(x)
$$

em que, $\alpha_{i}$ é o peso de $f_{i}(x)$ que expressa a crença no estimador $i$ e $N$ é o número de estimadores individuais.

Os métodos mais comuns dessa abordagem são a decisão por maioria (votação), aplicado a problemas de classificação e média simples, aplicado a problemas de regressão. Nesses métodos, todos os estimadores têm o mesmo peso.

No caso da decisão por maioria, um padrão é atribuído a uma classe quando a maioria dos votos dos classificadores são para esta classe, ou seja, a maioria dos classificadores classificam o padrão como pertencente à classe. Pode-se também atribuir um threshold a esse método para melhorar a confiabilidade. Por exemplo, com um threshold de 51\%, se metade dos classificadores apontarem o padrão como pertencente a uma classe, ele é atribuído a essa classe, caso contrário o padrão é considerado desconhecido.

No caso da média simples, segundo Merz e Pazzani (Merz and Pazzani, 1997), chamado por Perrone e Cooper de Basic Ensemble Method (BEM), o resultado da combinação é a média simples das saídas dos estimadores individuais, dada pela Equação 4.2, em que $\alpha_{i}$ da Equação 4.1 é igual a $\frac{1}{N}$.

$$
f_{B E M}(x)=\frac{1}{N} \sum_{i=1}^{N} f_{i}(x)
$$

Nesses métodos também podem ser associados pesos a cada um dos estimadores, permitindo um poder de voto diferenciado para os classificadores e fornecendo uma média 
ponderada no caso de regressão. Outras formas de combinação linear também podem ser aplicadas para a combinação, como as redes neurais Perceptron.

A combinação não linear é semelhante a combinação linear, com o uso de uma função não linear para combinação (estatística, lógica ou implementada por um estimador).

Os estimadores individuais a serem combinados em um comitê podem ser baseados em quaisquer técnicas usualmente empregadas para classificação ou regressão (por exemplo, Mínimos Quadrados, Projection Pursuit Regression, Redes Neurais Artificiais), uma única técnica aplicada aos dados com diferentes parâmetros, ou então, uma única técnica aplicada a diferentes conjuntos de treinamento (Krogh and Vedelsby, 1995). A utilização de um único conjunto de entrada explora a capacidade dos estimadores envolvidos na combinação. Nesse caso, todos os estimadores recebem a mesma entrada e, dessa forma, um estimador pode suprir a falha de outros, melhorando o desempenho global. Por outro lado, o particionamento do conjunto de entrada e aplicação de dados diferentes a cada estimador faz com que as amostras sejam independentes (Prampero, 1998) e permite que estimadores idênticos discordem (Krogh and Vedelsby, 1995).

Merz (Merz, 1998) faz uma revisão dos métodos existentes para a geração e combinação de estimadores (modelos) para classificação e regressão e propõe dois novos métodos para combinação de estimadores. Merz descreve ainda o framework para combinação, primeiramente proposto por Wolpert (Wolpert, 1992), chamado de stacking (ou stacked generalization) em que muitos métodos de combinação de estimadores se baseiam. Esse framework é descrito a seguir e é o framework empregado neste trabalho.

Como descrito por Merz (Merz, 1998), dois elementos são necessários para a combinação de estimadores:

- um conjunto de dados $\mathrm{L}_{0}=\left\{\left(\mathrm{x}_{m}, \mathrm{y}_{m}\right), \mathrm{m}=1, \ldots, \mathrm{M}\right\}$, em que $\mathrm{M}$ é o número de exemplos e

- uma coleção de algoritmos de aprendizado A.

A idéia básica do stacking é ver o problema da combinação como um novo problema 
de indução (como a geração dos estimadores), em que o espaço de entrada é a saída dos estimadores e o espaço de saída é o mesmo que o deles, ou seja, $\mathrm{L}_{1}=\left\{\left(\left(\mathrm{f}_{1}\left(\mathrm{x}_{m}\right), \mathrm{f}_{2}\left(\mathrm{x}_{m}\right)\right.\right.\right.$, $\left.\left.\left.\ldots, \mathrm{f}_{N}\left(\mathrm{x}_{m}\right)\right), \mathrm{y}_{m}\right), \mathrm{m}=1, \ldots, \mathrm{M}\right\}$, em que $\mathrm{N}$ é o número de estimadores combinados.

Por convenção, chama-se a camada de indução dos estimadores de nível 0 e a de indução do combinador de nível 1, assim, $\mathrm{L}_{0}$ é o conjunto de dados de nível 0 e $\mathrm{L}_{1} \mathrm{o}$ conjunto de dados de nível 1.

A Figura 4.3 (Merz, 1998) dá uma idéia geral desse framework. Inicialmente os dados de nível 0 são passados para um conjunto de algoritmos de aprendizado A e são usados para gerar um conjunto de estimadores F. Em seguida um gerador de dados gera os dados de nível 1, que são, por sua vez, utilizados na indução de nível 1, gerando o estimador final, chamado neste trabalho de combinador.

O gerador de dados pode tomar $\mathrm{L}_{1}$ como sendo simplesmente formado pelas saídas de cada de cada um dos $\mathrm{N}$ modelos para cada um dos exemplos, ou ser gerado de forma mais complexa, como sugerido por Wolpert (Wolpert, 1992). A forma de gerar os dados de nível 1 descrita por Wolpert não será apresentada aqui por não ser o foco deste trabalho, embora muitas vezes essa forma seja, sozinha, conhecida por stacking. 


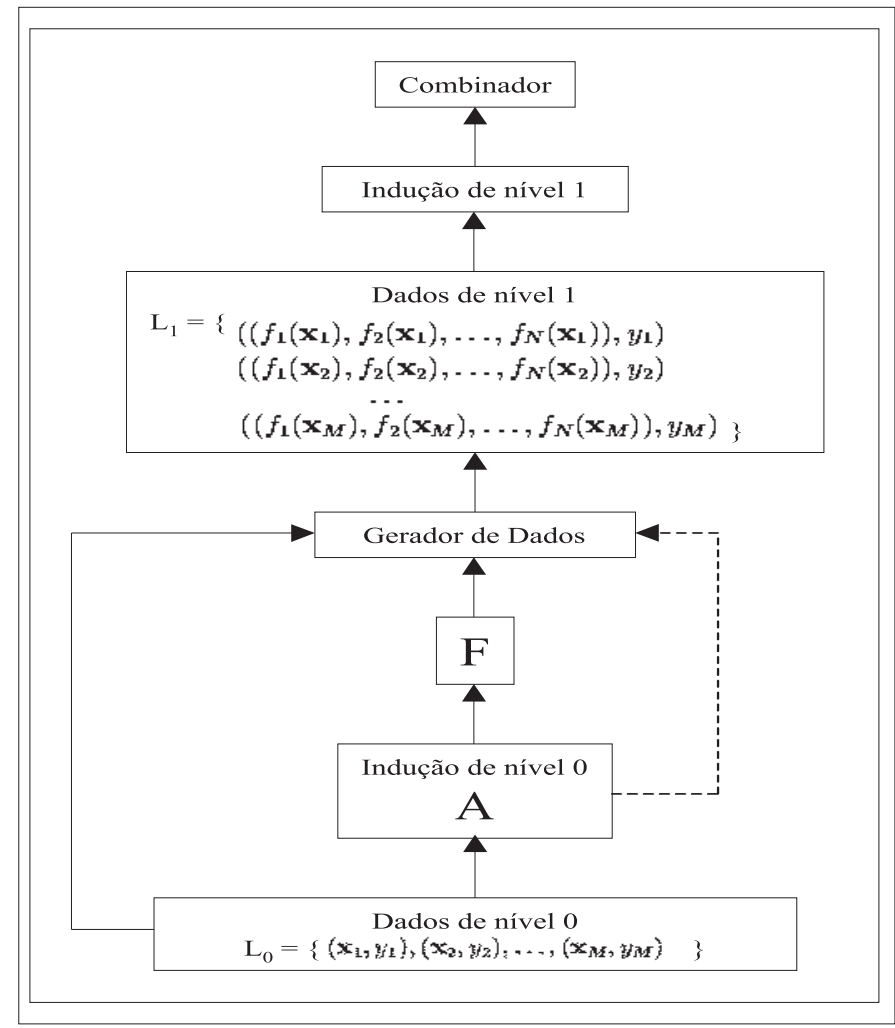

Figura 4.3: Framework para combinação de estimadores (stacking). 


\subsection{Considerações Finais}

Neste capítulo foi apresentada uma descrição dos métodos de Inteligência Artificial de interesse para esse projeto. Foi também discutido como métodos individuais podem ser combinados em comitês, de forma a melhorar o desempenho obtido.

O próximo capítulo conterá uma descrição do problema tratado neste trabalho, bem como dos dados empregados nas investigações. O processo de preparação dos dados para a utilização com os diversos softwares no treinamento dos algoritmos também será

descrito. Além disso, será feita uma análise detalhada de uma das bases, mostrando o comportamento dos sensores em diversas situações. 


\section{Capítulo 5}

\section{O Problema Abordado}

\subsection{Considerações Iniciais}

No capítulo anterior foram descritos as técnicas de inteligência artificial investigadas neste trabalho para fusão de sensores.

Neste capítulo é delimitado o problema tratado neste trabalho com a abordagem de fusão de sensores utilizando algoritmos de AM e combinação de estimadores. Além disso, também é feita uma descrição e análise das bases de dados utilizadas nos experimentos. A base Pioneer1 é analisada em detalhes com o intuito de observar o comportamento dos sensores em diversas situações. A preparação dos dados para a utilização com os diversos softwares no treinamento dos algoritmos também é descrita neste capítulo.

\subsection{Descrição do Problema}

A área de fusão de sensores abordada neste trabalho é muito vasta e tem sido empregada na solução de diversos tipos de problemas em diferentes áreas de aplicação. A área tratada neste trabalho é a de robótica. Nessa área, são vários os problemas que podem 
ser resolvidos com a aplicação da fusão de sensores. O problema tratado aqui se refere à utilização de fusão de sensores para melhorar a precisão e estabilidade da informação de distância entre o robô e um alvo, medida através de um conjunto de sensores.

Como visto no Capítulo 3, existem diferentes algoritmos que podem ser empregados com sucesso na fusão de sensores. Neste trabalho optou-se por investigar diferentes técnicas de Inteligência Artificial como algoritmos para fusão. As técnicas empregadas consistem de diversos algoritmos de Aprendizado de Máquina (AM) e combinação de estimadores já descritos no Capítulo 4.

Para a investigação das técnicas de AM e de combinação de estimadores propostas neste trabalho para fusão de sensores foram utilizadas duas bases de dados, ambas com medições de distância entre um robô e um alvo feitas a partir de diferentes sensores. A primeira delas é a base chamada, neste trabalho, de Pioneer1, que pode ser considerada como a base principal com a qual foram feitos uma análise prévia dos dados, a execução de experimentos testando os diversos algoritmos e diversas estratégias de abordagem ao problema, até se chegar à mais adequada, e uma análise detalhada dos resultados. Essa base está sendo considerada como a base principal para as análises deste trabalho por ter sido coletada pelos próprios autores em trabalho anterior. A segunda base é chamada, neste trabalho, de B14. Os nomes das bases dizem respeito aos nomes dos robôs que foram utilizados na coleta dos dados. Ambas as bases, bem como sua fonte de origem, serão descritas na Seção 5.3.

Tomando como referência a base Pioneer1, pode-se fazer uma análise mais detalhada do problema a ser abordado. A base Pioneer1, cujos dados serão melhor descritos na Seção 5.3, contém informações de dois tipos de sensores: sonar e câmera. Esses sensores empregados para a medição de distância entre o robô e o alvo utilizam diferentes técnicas para medição. Os sonares empregam a técnica de TOF com ultrasom e para a medição com a câmera foi empregada a técnica Visual Looming. Sendo assim, cada tipo de sensor tem características diferentes. A câmera tem um campo de visão maior que o sonar, porém, dentro do seu campo de visão e no melhor ângulo de aproximação, o sonar tem uma 
medição mais precisa. Além disso, cada sensor está posicionado em um lugar diferente no robô, cada um observando uma região do espaço diferente. Com isso, vê-se que, em cada momento, um sensor diferente, ou apenas alguns dos sensores está captando a informação do ambiente mais próxima da informação real de interesse.

Dessas observações surge a questão: em qual sensor confiar mais? Como saber qual sensor tem a resposta mais próxima da informação real? Ainda outro aspecto é: Se vários sensores estão captando informações sobre um mesmo ambiente com diferentes visões sobre ele, será que eles não podem contribuir de alguma forma para a medição de uma nova informação? No caso desses sensores, todos medindo a informação de distância entre o robô e um alvo, será que, por exemplo, um sonar medindo em um determinado ângulo de abordagem e fornecendo uma medida bastante diferente da real poderia contribuir com a medida feita por outro sonar ou pela câmera, dando indicação de que o robô está inclinado em relação ao alvo e permitindo que se tenha uma forma de corrigir o erro na medição?

O que se espera da fusão de sensores neste trabalho é que se possa obter uma cooperação entre os sensores de forma que se tenha um mecanismo para corrigir as imprecisões de cada um, melhorar a repetibilidade das medições e estender a capacidade de medição para distâncias e ângulos em que as medições dos sensores são, individualmente, ruins, ou seja, em distâncias e ângulos para os quais nenhum dos sensores é adequado.

\subsection{Descrição dos Dados}

A seguir são descritos os dados utilizados nos experimentos, bem como a preparação desses dados para a sua utilização com cada algoritmo. Os dados descritos se referem a duas bases de dados, Pioneer1 e B14, constituídas, respectivamente, de dados medidos com os robôs Pioneer 1 e B14, ambos da Real World Interface. Ambas as bases possuem medições de sensores e um atributo meta que corresponde à distância real em que as medições dos sensores foram feitas. O atributo meta é o valor que se deseja obter com a fusão dos 
sensores.

Os dados da base Pioneer 1 foram coletados pela autora em trabalho anterior (Faceli and Carvalho, 1998; Faceli et al., 1999). A Figura 5.1 mostra o robô Pioneer 1. Essa base consiste de medidas de distâncias obtidas de sete sonares ultra-sônicos posicionados em diferentes ângulos na frente e laterais do robô e calculados a partir de imagens obtidas com uma câmera posicionada sobre o robô. Essas distâncias foram tomadas com o robô posicionado em 7 ângulos e 9 distâncias diferentes com relação a um alvo (papel preto) afixado em uma parede branca, conforme mostra o esquema da Figura 5.2. A distância real e o ângulo foram medidos manualmente.

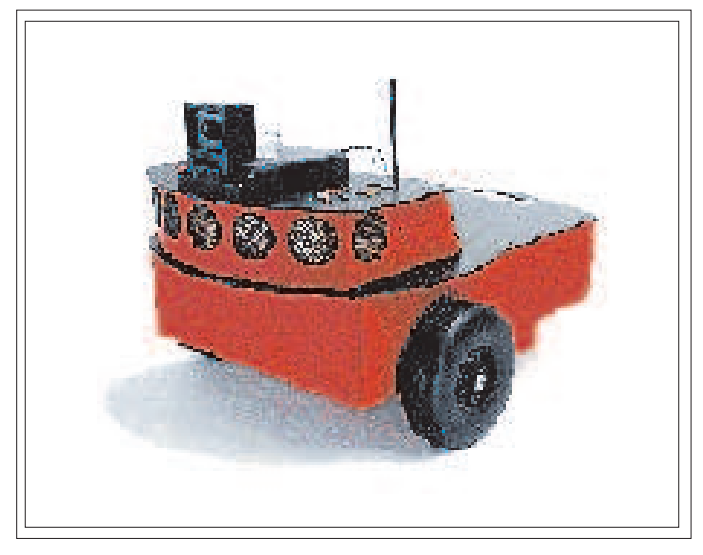

Figura 5.1: Robô Pioneer 1.

O arquivo gerado a partir dessas medidas contém as informações de ângulo (em graus), distância baseada nas imagens obtidas com a câmera, distâncias coletadas com os sonares e distância real para cada posição do esquema (cinco medidas dos sensores para cada posição). Portanto, essa base é constituída de 315 exemplos cada um com 10 atributos. Todas as distâncias foram obtidas em milímetros, porém para facilitar futuras comparações elas foram convertidas para centímetros.

A base B14 foi cedida por Martens (Martens et al., 1998) e é composta por informações de distância captadas por 8 sonares $(\mathrm{mm})$, estimativas das distâncias relativas captadas por 8 "sonares visuais", uma medida de ângulo (radianos) determinada pela leitura de 8 sensores de proximidade infravermelho e a distância desejada, obtida através de odometria. 


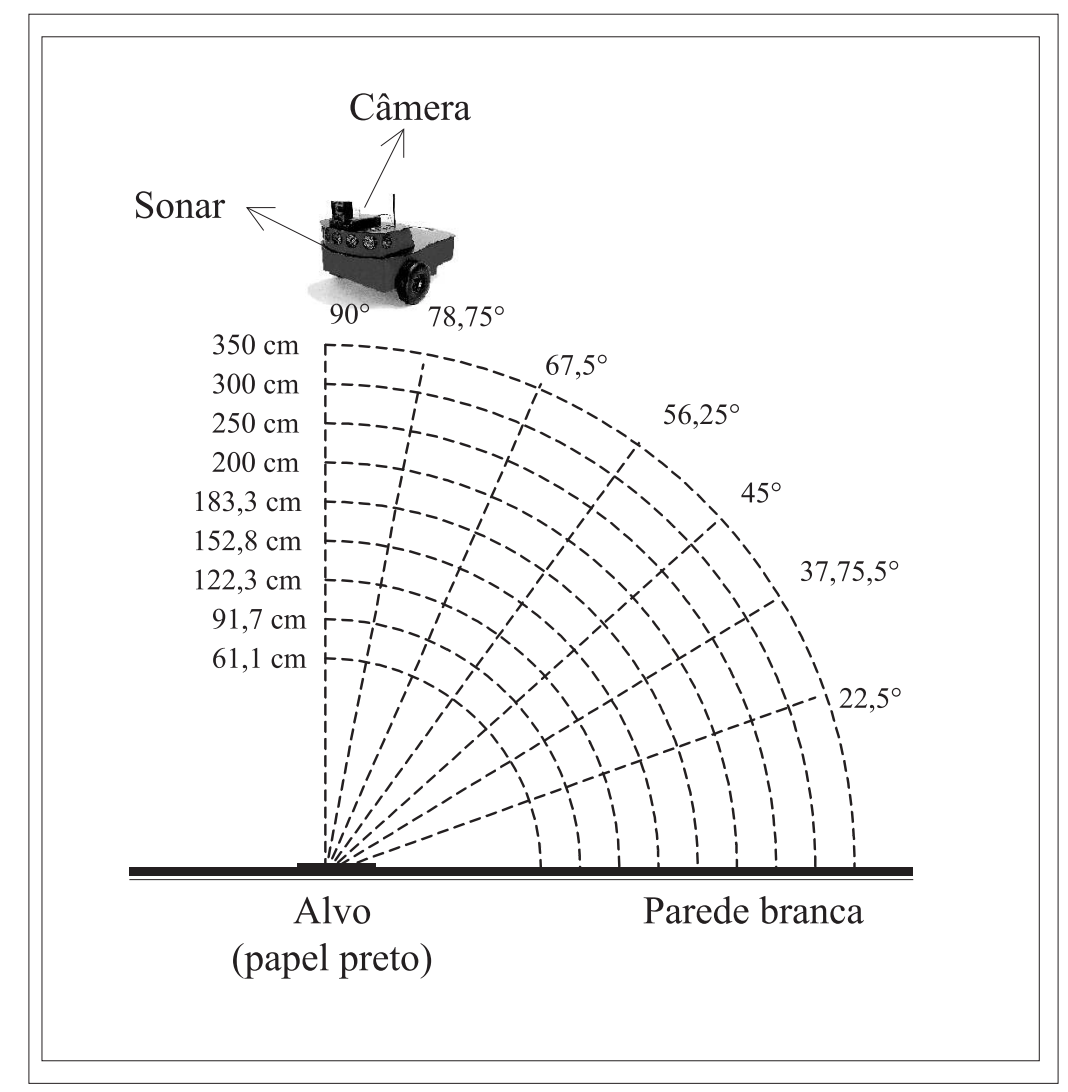

Figura 5.2: Distâncias em que foram coletados os dados dos sensores do robô Pioneer 1.

Essa base consiste, portanto, de 10.167 exemplos e 18 atributos. Mais detalhes sobre esses dados podem ser observados no artigo citado.

\subsection{Preparação dos Dados}

Antes de serem utilizados, os conjuntos de dados foram pré-processados e arquivos apropriados para o treinamento e teste dos algoritmos foram criados. Para isso um conjunto de regras de benchmark propostas para experimentos com redes neurais (Prechelt, 1994) foram seguidas.

A base Pioneerl consiste de um arquivo texto com as informações descritas anteriormente, organizadas por ângulos e distâncias em que foram feitas as medidas. A preparação 
dessa base se deu da seguinte maneira.

Inicialmente os dados foram embaralhados. Em seguida foi retirado o atributo ângulo, uma vez que essa informação não foi obtida a partir de sensores e sim manualmente. Depois foram tomados os 236 primeiros elementos para serem os dados de treinamento (75\% dos exemplos) e os 79 elementos restantes para servirem como dados de teste $(25 \%$ dos exemplos). Em seguida foi feita uma normalização dos dados fazendo com que todos os atributos tenham valores entre 0 e 1 . Esse procedimento foi repetido três vezes, gerando três partições diferentes dos dados originais.

Para a base B14, todos os 18 atributos foram utilizados, sendo realizada uma normalização para se uniformizar as medidas. O particionamento dos dados seguiu a mesma proporção descrita para a base Pioneer1, resultando em 7.624 exemplos para treinamento e 2.543 para teste. Três partições também foram geradas nesse caso.

Após essas etapas gerais do pré-processamento, uma fase de adequação dos dados às formas de entrada de cada algoritmo foi efetuada.

Para a utilização com as redes neurais, os dados de treinamento foram subdivididos, gerando um arquivo para treinamento ( $50 \%$ do total de exemplos do arquivo original) e um arquivo para validação ( $25 \%$ do total de exemplos do arquivo original).

Assim, arquivos apropriados para cada software utilizado foram gerados. Exemplos desses arquivos podem ser observados no Apêndice A.

\subsection{Análise dos Dados}

Como já foi dito, a base Pioneer1 possui 315 exemplos e 10 atributos contínuos e a base B14 possui 10.167 exemplos e 18 atributos também contínuos. Na Tabela 5.1 é apresentada uma descrição detalhada das informações da base Pioneer1 e na Tabela 5.2 são mostradas 
as informações da base B14 ${ }^{1}$.

\begin{tabular}{|l|l|c|c|c|}
\hline Medidas & Atributo & Mínimo & Máximo & Média \pm Desvio Padrão \\
\hline \hline ângulo & angulo & 22,5 & 90 & $56,25 \pm 22,5358$ \\
\hline câmera & dcamera & 0 & 17.980 & $2.194,21 \pm 1.654,76$ \\
\hline sonar 1 & ds1 & 619 & 5.201 & $4.186,61 \pm 1.339,01$ \\
\hline sonar 2 & ds2 & 482 & 5.201 & $4.096,00 \pm 1.712,86$ \\
\hline sonar 3 & ds3 & 627 & 5.201 & $4.465,00 \pm 1.429,70$ \\
\hline sonar 4 & ds4 & 691 & 5.201 & $4.465,00 \pm 1.457,99$ \\
\hline sonar 5 & ds5 & 1.303 & 5.201 & $5.086,36 \pm 523,00$ \\
\hline sonar 6 & ds6 & 1.962 & 5.201 & $4.900,26 \pm 766,74$ \\
\hline sonar 7 & ds7 & 481 & 5.201 & $3.869,59 \pm 1.766,15$ \\
\hline distância real & dreal & 611 & 3.500 & $1.901,33 \pm 906,30$ \\
\hline
\end{tabular}

Tabela 5.1: Descrição da base de dados Pioneer1.

\begin{tabular}{|l|l|c|c|c|}
\hline Medidas & Atributo & Mínimo & Máximo & Média \pm Desvio Padrão \\
\hline \hline distância real & dreal & 10 & 416,80 & $124,43 \pm 73,79$ \\
\hline ângulo & angulo & 0,2 & 3,30 & $1,67 \pm 0,64$ \\
\hline sonar 1 & s1 & -1 & $5.396,00$ & $1.574,54 \pm 803,18$ \\
\hline sonar 2 & s2 & -1 & $5.680,00$ & $1.568,83 \pm 865,33$ \\
\hline sonar 3 & s3 & -1 & $5.595,00$ & $1.490,08 \pm 789,17$ \\
\hline sonar 4 & s4 & -1 & $5.659,00$ & $1.551,25 \pm 898,58$ \\
\hline sonar 5 & s5 & -1 & $6.221,00$ & $1.636,14 \pm 1.037,96$ \\
\hline sonar 6 & s6 & -1 & $6.191,00$ & $1.771,39 \pm 1.170,73$ \\
\hline sonar 7 & s7 & -1 & $6.021,00$ & $1.676,39 \pm 955,44$ \\
\hline sonar 8 & s8 & -1 & $6.291,00$ & $1.569,58 \pm 823,52$ \\
\hline visual sonar 1 & vs1 & -1 & 0,99 & $0,39 \pm 0,41$ \\
\hline visual sonar 2 & vs2 & -1 & 0,98 & $0,42 \pm 0,40$ \\
\hline visual sonar 3 & vs3 & -1 & 0,98 & $0,44 \pm 0,39$ \\
\hline visual sonar 4 & vs4 & -1 & 0,98 & $0,46 \pm 0,38$ \\
\hline visual sonar 5 & vs5 & -1 & 0,98 & $0,46 \pm 0,38$ \\
\hline visual sonar 6 & vs6 & -1 & 0,99 & $0,46 \pm 0,38$ \\
\hline visual sonar 7 & vs7 & -1 & 0,98 & $0,44 \pm 0,39$ \\
\hline visual sonar 8 & vs8 & -1 & 0,99 & $0,41 \pm 0,40$ \\
\hline
\end{tabular}

Tabela 5.2: Descrição da base de dados B14.

Como a base Pioneer1 está sendo considerada a base principal para os experimentos deste trabalho, e devido ao tamanho da base B14, em seguida será analisado o comportamento das medidas dos sensores contidas na base Pioneer1. Essa base contém 5 medições

\footnotetext{
${ }^{1}$ Essas informações foram obtidas utilizando-se o Weka Knowledge Explorer do software WEKA (Witten and Frank, 1999).
} 
para cada distância e ângulo. Para a análise dos dados que se segue foi calculada a média dessas distâncias.

Nos gráficos das Figuras 5.3, 5.4, 5.5, 5.6, 5.7, 5.8 e 5.9 estão representadas as distâncias medidas com os diversos sensores, permitindo uma comparação das capacidades de medição dos sensores nos diferentes ângulos e distâncias. Os gráficos representam as medidas nos ângulos $22,5^{\circ}, 33,75^{\circ}, 45^{\circ}, 56,25^{\circ}, 67,5^{\circ}, 78,75^{\circ}$ e $90^{\circ}$, respectivamente. Esses ângulos são medidos entre o alvo e a frente do robô. Nesses gráficos não estão representados os sonares $5,6,7$, pois suas medidas não têm relação direta com o objeto alvo e sim com ruídos de outros elementos no ambiente na captação de dados realizada (uma vez que o posicionamento do robô de acordo com o esquema da Figura 5.2 não favorece as medições com esses sensores).

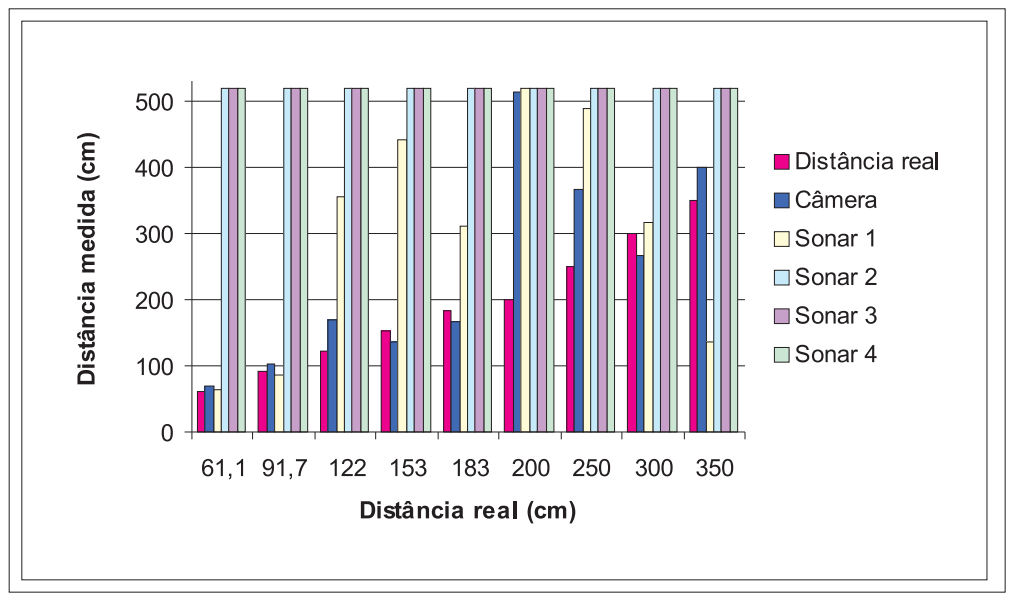

Figura 5.3: Distância real x distâncias medidas para o ângulo de 22, $5^{\circ}$. 


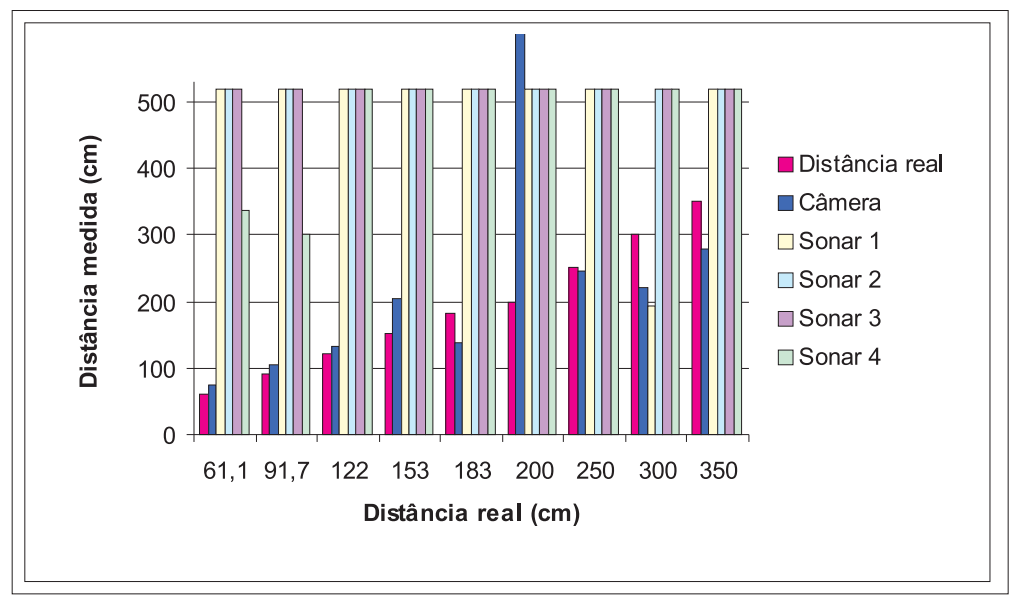

Figura 5.4: Distância real x distâncias medidas para o ângulo de $33,75^{\circ}$.

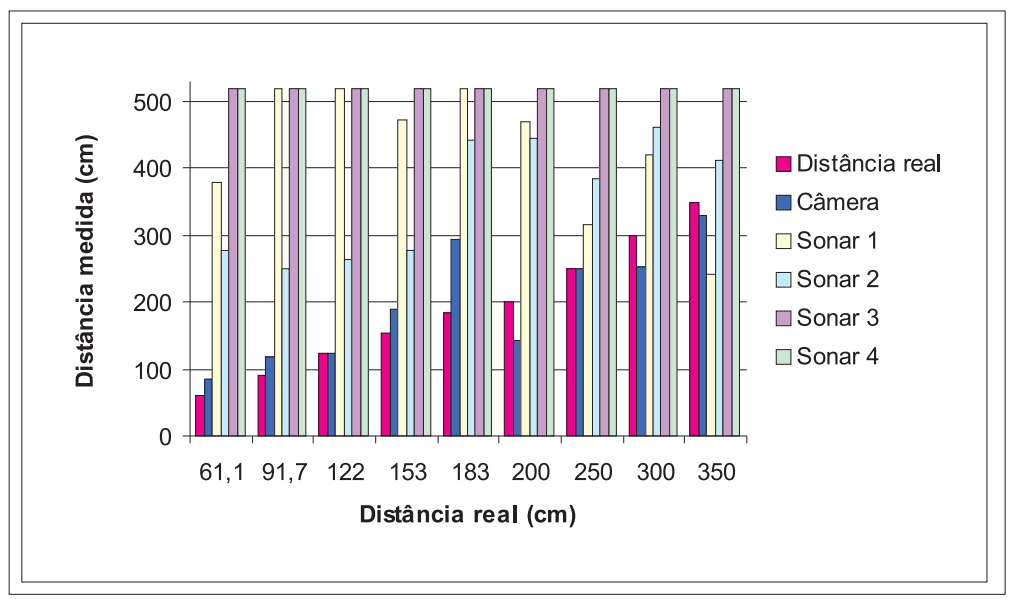

Figura 5.5: Distância real x distâncias medidas para o ângulo de $45^{\circ}$.

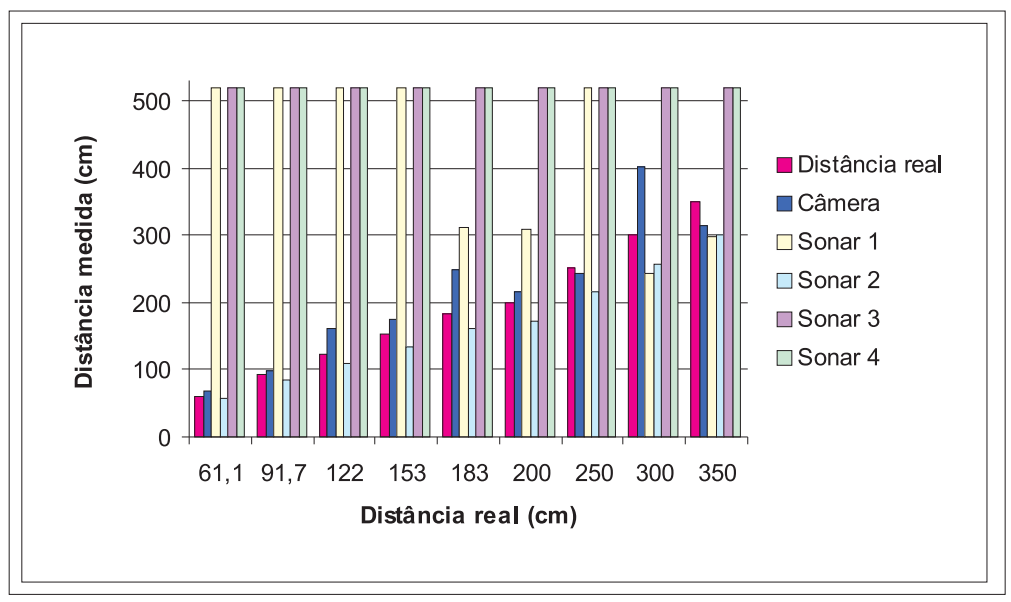

Figura 5.6: Distância real x distâncias medidas para o ângulo de 56,25․ 


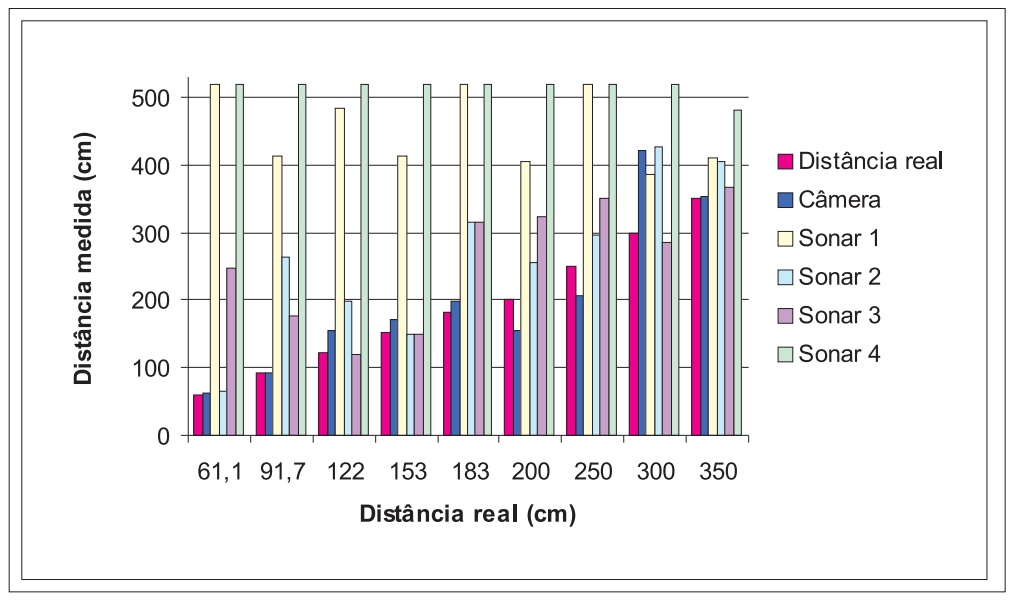

Figura 5.7: Distância real x distâncias medidas para o ângulo de $67,5^{\circ}$.

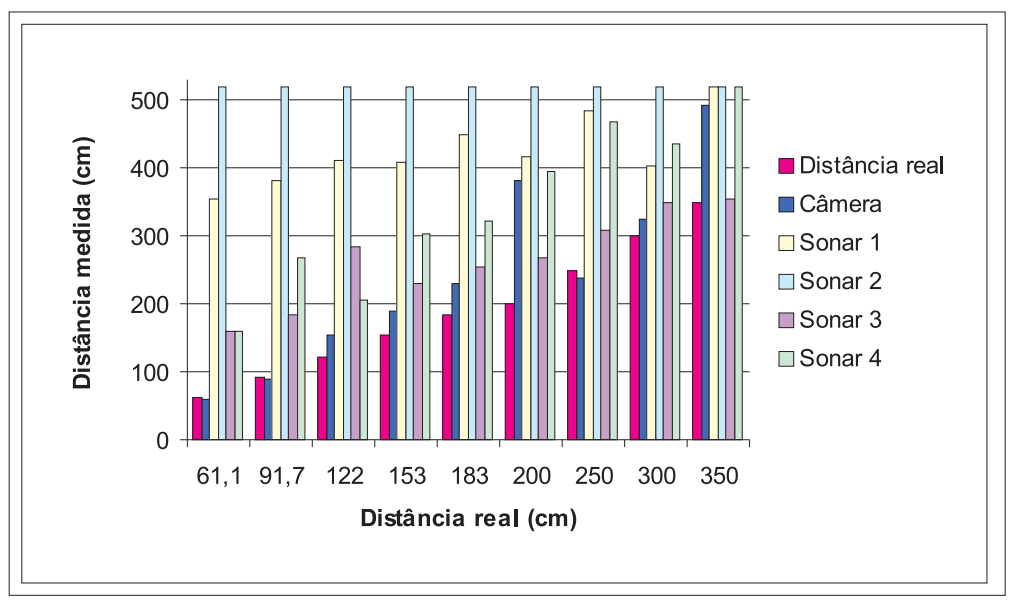

Figura 5.8: Distância real x distâncias medidas para o ângulo de 78,75º .

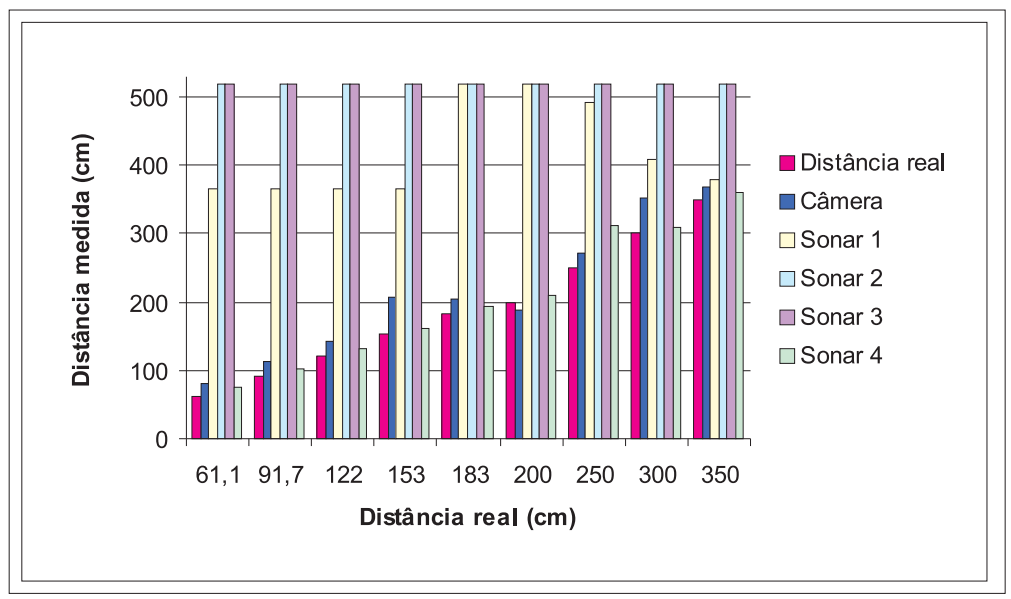

Figura 5.9: Distância real x distâncias medidas para o ângulo de $90^{\circ}$. 
A partir desses gráficos, pode-se observar o comportamento das medições dos sensores em relação à distância real, em cada ângulo. As medidas baseadas na câmera tendem a acompanhar a distância real, tendo uma diferença de até $50 \mathrm{~cm}$, salvo em alguns casos específicos, em que possivelmente algum problema com a imagem capturada ocorreu. Pode-se observar ainda que esse comportamento foi semelhante para os vários ângulos de abordagem, sendo ainda melhor com um ângulo de $90^{\circ}$ (robô indo de frente para o objeto), como pode ser visto na Figura 5.9. O comportamento também foi melhor para curtas distâncias (até $1,5 / 2 \mathrm{~m}$ ).

O sonar 1 mede bem informações a curtas distâncias (menos de 1 m) e no ângulo de 22,5 (Figura 5.9), sendo inadequado para medições nos ângulos maiores.

O sonar 2 obteve melhores resultados para o ângulo de $56,25^{\circ}$, sendo razoável para $45^{\circ}$ e $67,5^{\circ}$ e não captando nada nos demais ângulos (o valor máximo dos sonares é dado quando nenhum sinal é captado). Os resultados também foram melhores para curtas distâncias.

O sonar 3 somente captou informações nos ângulos de $67,5^{\circ}$ e $78,76^{\circ}$, obtendo melhores resultados para as distâncias maiores.

O sonar 4 somente captou informações no ângulo de $90^{\circ}$ (quando o sensor está diretamente apontado para o objeto), tendo bons resultados em quaisquer distâncias.

Essas diferenças nas respostas de cada sonar para os diferentes ângulos se explicam naturalmente pelo posicionamento dos sonares no robô: quanto mais o sonar estiver direcionado para o objeto, melhor sua resposta.

As melhores respostas dos sensores (câmera e sonar 4) foram observadas no ângulo de 90․ O gráfico da Figura 5.10 mostra o módulo da diferença entre a distância real e as distâncias medidas pela câmera e pelo sonar 4 para o ângulo de $90^{\circ}$. Pode-se observar que, para o conjunto de todos os ângulos, o sonar obteve melhores resultados tendo uma variação de cerca de $10 \mathrm{~cm}$ com relação à distância real, enquanto a câmera obteve 
uma variação em torno de $20 \mathrm{~cm}$. Em alguns casos aparecem diferenças de até $60 \mathrm{~cm}$, que se devem a ruídos ou falhas nas medições, ressaltando a falta de confiabilidade dos sensores. As mesmas informações podem ser observadas para os diversos ângulos a 61,1 e 183,3 cm nos gráficos das Figuras 5.11 e 5.12. Nesses gráficos pode-se observar que, com o aumento da distância, alguns sensores começam a ter desempenho inferior (câmera), enquanto outros começam a captar mais informações (sonar 1). Também pode-se notar que, embora a $90^{\circ}$ o sonar 4 tenha apresentado a melhor resposta, no conjunto de todos os ângulos, o sensor que melhor se comportou foi a câmera. Isso possivelmente se deve ao campo de visão desse sensor ser maior que o dos sonares e ao tipo de medição que ele realiza.

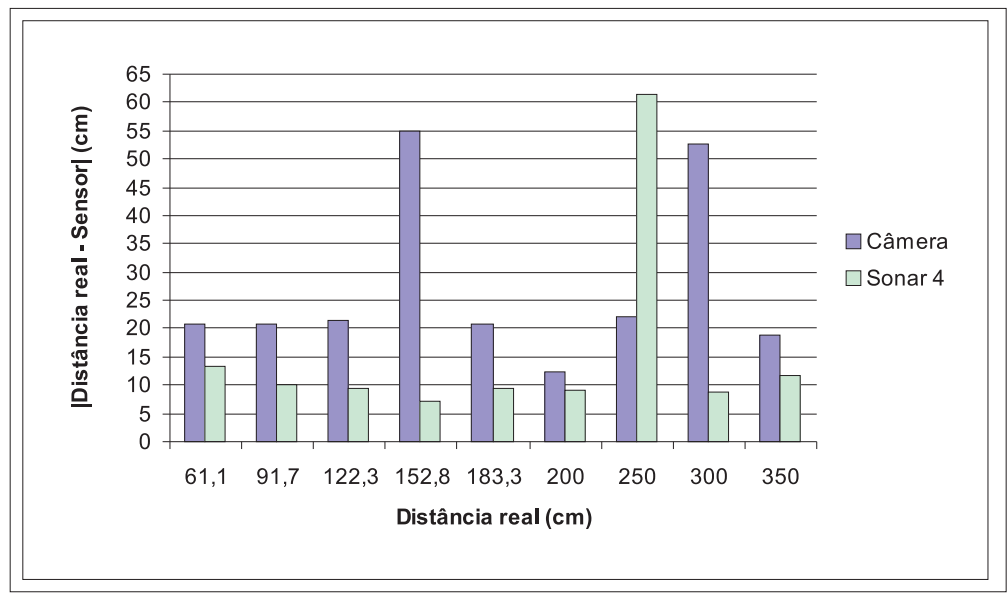

Figura 5.10: Variação das distâncias medidas para a distância real no ângulo de $90^{\circ}$.

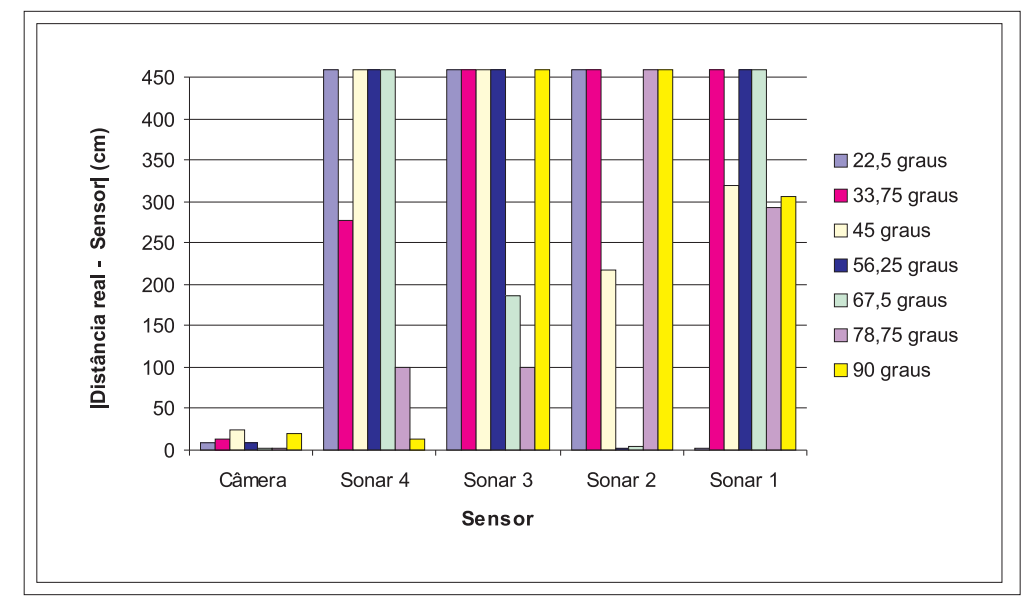

Figura 5.11: Variação das distâncias medidas para a distância real a $61,1 \mathrm{~cm}$. 


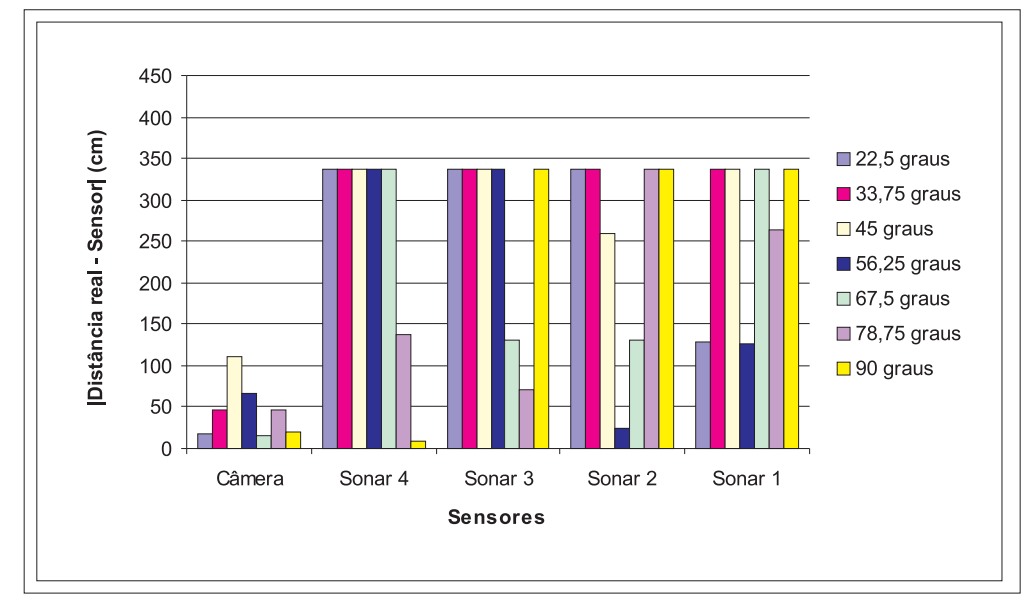

Figura 5.12: Variação das distâncias medidas para a distância real a $183,3 \mathrm{~cm}$.

Pelo gráfico da Figura 5.13 pode-se observar a instabilidade das medições feitas pela câmera e pelo sonar 4 no ângulo de $90^{\circ}$ e $61,1 \mathrm{~cm}$. No caso da câmera a medida tomada em uma mesma posição variou até $9 \mathrm{~cm}$ e no caso do sonar 4 somente $3 \mathrm{~cm}$. Esse gráfico serve para ilustrar a repetibilidade da medição fornecida pelos sensores.

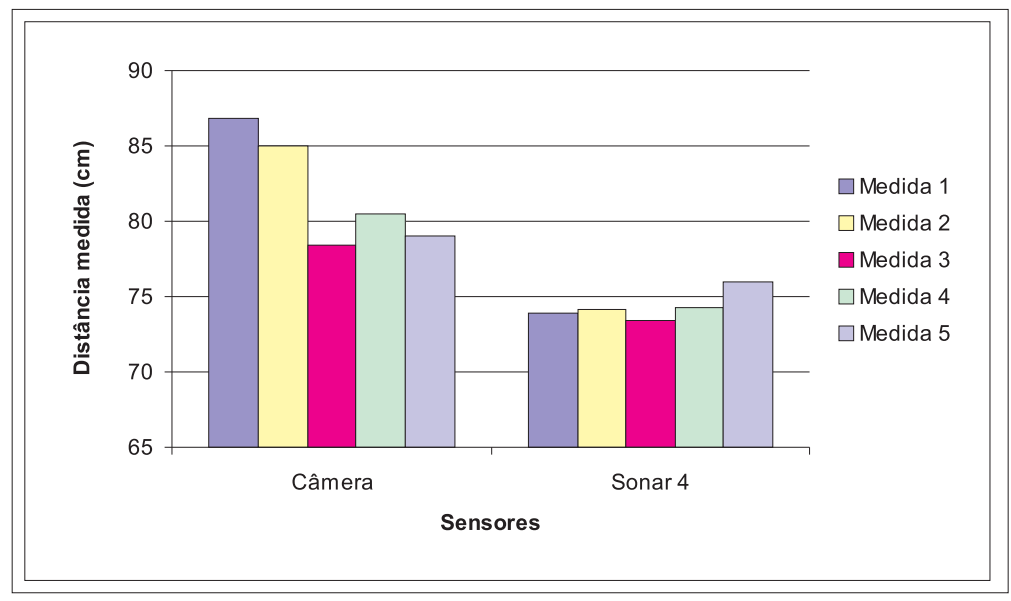

Figura 5.13: Variação das medidas dos sensores para um mesmo ângulo e distância $\left(90^{\circ}\right.$ e $61,1 \mathrm{~cm})$. 


\subsection{Considerações Finais}

Neste capítulo foi feita uma descrição geral do problema que está sendo abordado neste trabalho, bem como das duas bases de dados que foram utilizadas (Pioneer1 e B14). A preparação dos dados para a utilização no treinamento dos diversos algoritmos também se encontra descrita neste capítulo. Além disso, para ilustrar os problemas apresentados pelas medições feitas por sensores, foi feita também uma análise mais detalhada da base Pioneer1, considerada a base principal, ressaltando o comportamento de cada sensor em cada ângulo e distância real em que foram coletados os dados dessa base.

No próximo capítulo serão descritos detalhadamente os experimentos realizados e os resultados obtidos com cada método empregado para a geração dos estimadores. A combinação dos estimadores também será descrita, ressaltando-se o processo de escolha de quantos e quais estimadores têm um maior potencial para a geração de um bom combinador. Os resultados obtidos com os melhores combinadores gerados serão apresentados. Além disso, será feita uma comparação entre os diversos métodos empregados, tanto nos estimadores como nos combinadores. Os resultados obtidos com os estimadores e combinadores também serão comparados com os dados originais, obtidos com os sensores. Por fim, uma análise mais detalhada do comportamento dos algoritmos será realizada, avaliando a precisão e acurácia das medidas obtidas com cada método e verificando a melhora dessas informações com a utilização de um estimador e, em seguida de, de um combinador. 


\section{Capítulo 6}

\section{Experimentos}

\subsection{Considerações Iniciais}

No Capítulo 5 foi detalhado o problema tratado neste trabalho e, principalmente, os dados empregados na análise dos métodos que estão investigados para fusão de sensores.

Este capítulo contém uma descrição do processo de treinamento dos algoritmos com os dados das bases Pioneer1 e B14 descritas na Seção 5.3 e uma análise dos resultados obtidos com esses algoritmos. Neste capítulo também é apresentado o processo de combinação dos estimadores, abordando as questões de determinação de quantos e quais estimadores têm um maior potencial para fornecer uma boa combinação, como é feita a combinação e os resultados obtidos com as melhores combinações. Os resultados obtidos com os melhores sensores, estimadores e combinadores também são analisados juntamente com o comportamento dos métodos, ressaltando a melhoria da precisão e acurácia das medidas, atingida por cada método, com relação aos sensores isoladamente e entre alguns métodos.

O treinamento dos algoritmos foi realizado com as três partições descritas na Seção 5.4. Para a avaliação dos resultados dos experimentos, foram obtidos a média e desvio padrão do MSE (Mean Squared Error) obtido nessas três partições, para os dados de treinamento, 
validação (somente para as redes MLP e Cascade Correlation) e teste. Todos os erros MSE descritos nas seções seguintes se referem à média para as três partições. Vale notar que para avaliar e comparar os resultados está sendo considerado o MSE obtido com os dados de teste. Além disso, para se comparar os diversos métodos investigados, está sendo utilizado um teste estatístico, com o objetivo de verificar se as reduções nos erros são realmente significativas.

O processo de treinamento dos algoritmos e combinadores é descrito em detalhes apenas para a base principal, Pioneer1. Para a base B14, somente os erros dos melhores casos são apresentados para cada algoritmo. Uma avaliação detalhada dos resultados, mostrando o comportamento dos diversos métodos nos diversos ângulos, também se restringirá à base Pioneer1.

\subsection{Base Pioneer 1}

Nesta seção serão apresentados os resultados obtidos com a base Pioneer1. Neste caso, todo o processo de treinamento é descrito. Uma análise detalhada dos resultados obtidos com os melhores métodos também é apresentada, destacando o comportamento de cada método em alguns dos ângulos de abordagem.

\subsubsection{Estimadores}

Neste trabalho foram empregados os diversos algoritmos de AM descritos no Capítulo 4, como métodos para a fusão de sensores. Esses algoritmos treinados são chamados de estimadores. Esta seção descreve detalhadamente todos os passos de treinamento de cada algoritmo. Os estimadores, daqui em diante, serão chamados pelos nomes dos algoritmos com os quais foram treinados e, no caso das redes neurais, pelo tipo da rede. 


\section{MLP}

Para as redes neurais do tipo MLP, foram feitos experimentos com várias topologias e várias taxas de aprendizado $(\eta)$ utilizando o algoritmo de aprendizado Backpropagation padrão. O treinamento das redes foi feito em batch utilizando o programa batchman. Um exemplo do arquivo utilizado para o treinamento em batch pode ser observado no Apêndice B.

O treinamento foi feito em 5000 ciclos, com validação a cada 10 ciclos. A rede considerada melhor em cada etapa de treinamento foi a que apresentava o menor MSE na fase de validação.

Para cada topologia testada, foram utilizadas taxas de aprendizado variando de 0,1 a 1,0. As topologias testadas apresentavam todas uma camada intermediária, 8 neurônios de entrada e 1 neurônio de saída, variando apenas o número de neurônios na camada intermediária. Na camada intermediária foram colocados 1, 10, 50, 100 e 150 neurônios. Uma rede perceptron (sem camadas intermediárias) também foi treinada com esses mesmos parâmetros.

O gráfico da Figura 6.1 mostra o MSE para as diversas topologias treinadas com a variação de $\eta$. Nesse caso, cada grupo de barras representa os erros obtidos com diferentes taxas de aprendizado para uma topologia (cada cor representa uma taxa). De acordo com esse gráfico, pode-se perceber que a rede que teve o melhor desempenho para cada topologia foi treinada com uma taxa de aprendizado diferente. Também pode-se notar que a rede que apresentou melhor desempenho possuía 10 neurônios na camada intermediária (8-10-1) e foi treinada $\operatorname{com} \eta=0,6$.

Os resultados podem ser melhor visualizados na Tabela 6.1 e no gráfico da Figura 6.2. A Tabela 6.1 mostra o MSE no treinamento, validação e teste da melhor rede treinada para cada topologia, bem como a taxa de aprendizado com que foi treinada essa rede. Essas mesmas informações estão representadas no gráfico da Figura 6.2. Nesse gráfico, as barras representam a média do MSE das três partições e as linhas sobre as barras 


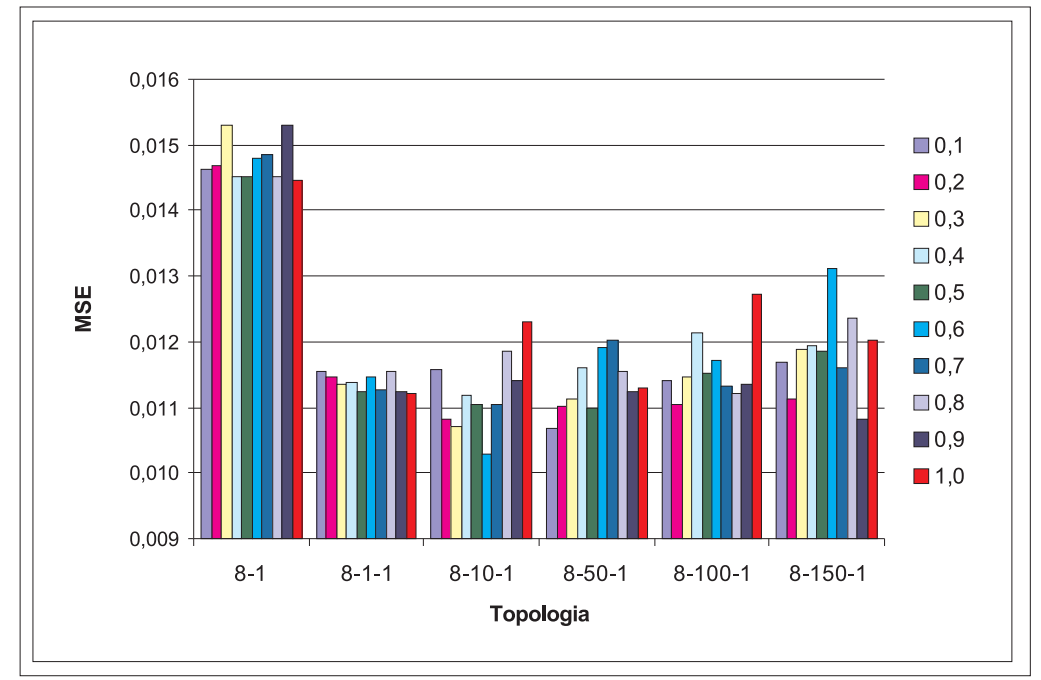

Figura 6.1: MSE para redes MLP treinadas com diferentes $\eta$.

representam o desvio padrão.

\begin{tabular}{|l|c|c|c|c|}
\hline Topologia & $\eta$ & Treinamento & Validação & Teste \\
\hline \hline $8-1$ & 1,0 & $0,01718 \pm 0,00067$ & $0,01284 \pm 0,00388$ & $0,01445 \pm 0,00040$ \\
\hline $8-1-1$ & 1,0 & $0,01164 \pm 0,00049$ & $0,00879 \pm 0,00152$ & $0,01120 \pm 0,00059$ \\
\hline $\mathbf{8 - 1 0 - 1}$ & $\mathbf{0 , 6}$ & $\mathbf{0 , 0 0 7 5 0} \pm \mathbf{0 , 0 0 2 9 2}$ & $\mathbf{0 , 0 0 7 2 4} \pm \mathbf{0 , 0 0 1 4 8}$ & $\mathbf{0 , 0 1 0 2 9} \pm \mathbf{0 , 0 0 2 0 3}$ \\
\hline $8-50-1$ & 0,1 & $0,00743 \pm 0,00182$ & $0,00765 \pm 0,00133$ & $0,01069 \pm 0,00168$ \\
\hline $8-100-1$ & 0,2 & $0,00747 \pm 0,00283$ & $0,00699 \pm 0,00130$ & $0,01104 \pm 0,00152$ \\
\hline $8-150-1$ & 0,9 & $0,00679 \pm 0,00386$ & $0,00634 \pm 0,00182$ & $0,01082 \pm 0,00155$ \\
\hline
\end{tabular}

Tabela 6.1: MSE da melhor rede MLP treinada para cada topologia.

Além do melhor resultado, esse gráfico permite uma comparação dos erros obtidos nas fases de treinamento, validação e teste, e também o quão parecido foi o treinamento das três partições (desvio padrão).

No gráfico da Figura 6.3 é apresentada uma comparação entre as redes treinadas com uma taxa de aprendizado de 0,6.

Além do treinamento com o algoritmo Backpropagation padrão, foram realizados também treinamentos com os algoritmos Rprop e Quickprop. Esses treinamentos foram realizados apenas com a topologia que apresentou o melhor resultado com o algoritmo Backpropagation padrão (8-10-1). Os valores dos parâmetros usados foram os valores 


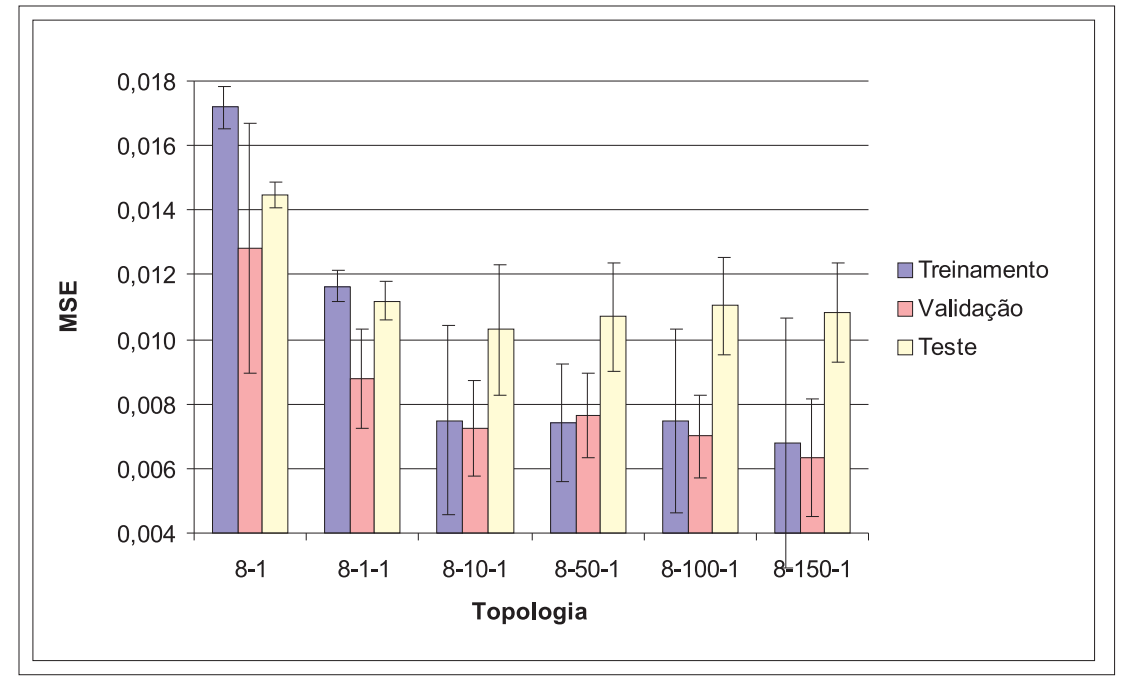

Figura 6.2: MSE da melhor rede MLP treinada para cada topologia.

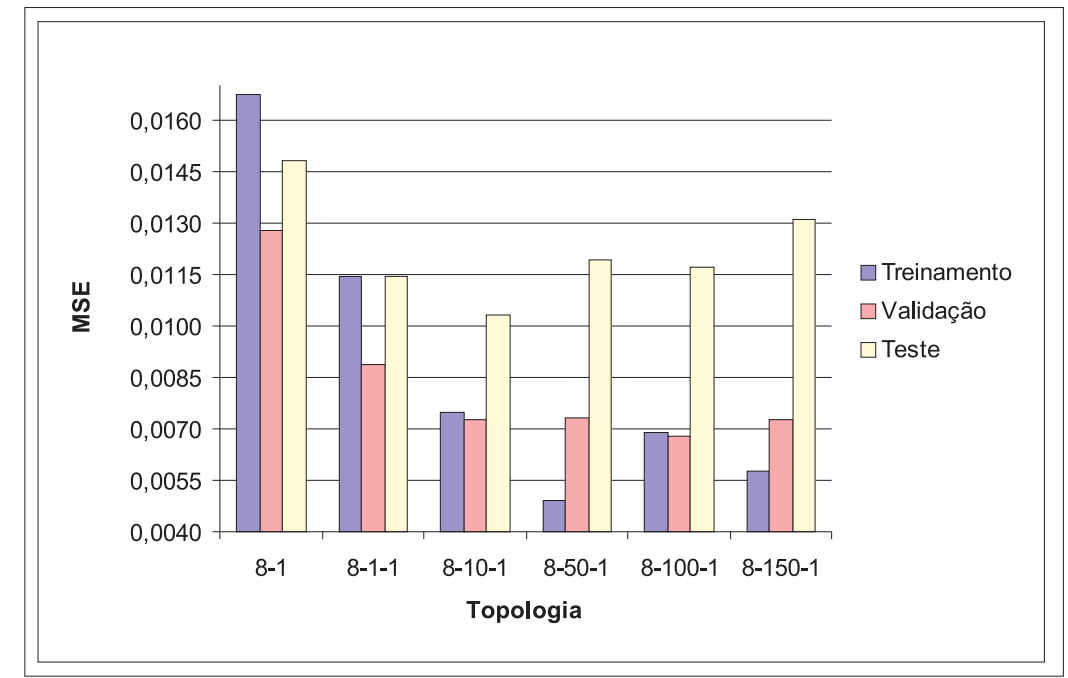

Figura 6.3: MSE para redes MLP treinadas $\operatorname{com} \eta=0,6$.

default.

O gráfico da Figura 6.4 mostra o MSE obtido no treinamento com o algoritmo Rprop e o gráfico da Figura 6.5 mostra o MSE obtido no treinamento com o algoritmo Quickprop. O treinamento com o Rprop produziu um erro médio de 0,00650, a validação de 0,00767 e o teste de 0,00841. O treinamento com o Quickprop produziu um erro médio de 0,00834, a validação de 0,00848 e o teste de 0,01132. As barras nos gráficos representam a média do MSE para as três partições e as linhas sobre as barras representam o desvio padrão. 


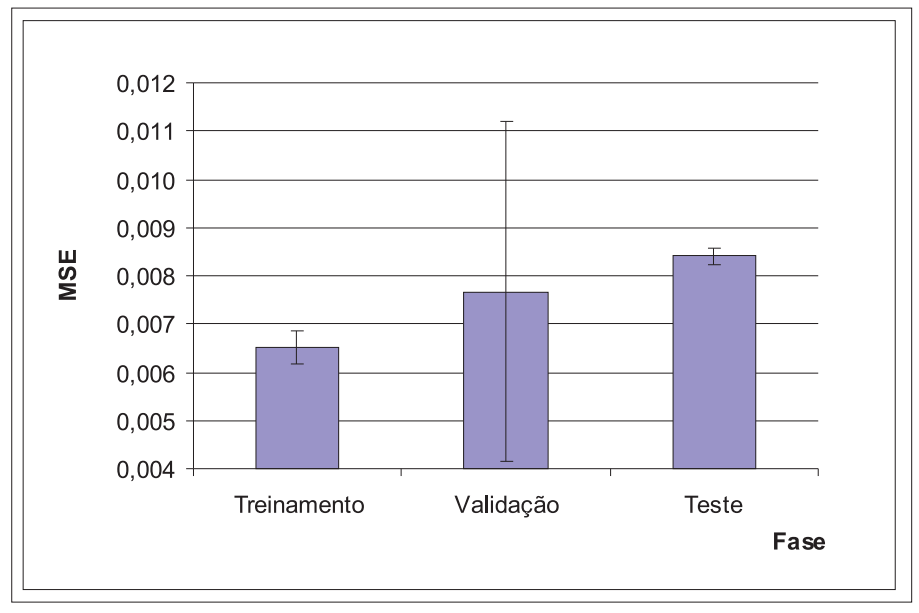

Figura 6.4: MSE da rede MLP treinada com o algoritmo Rprop.

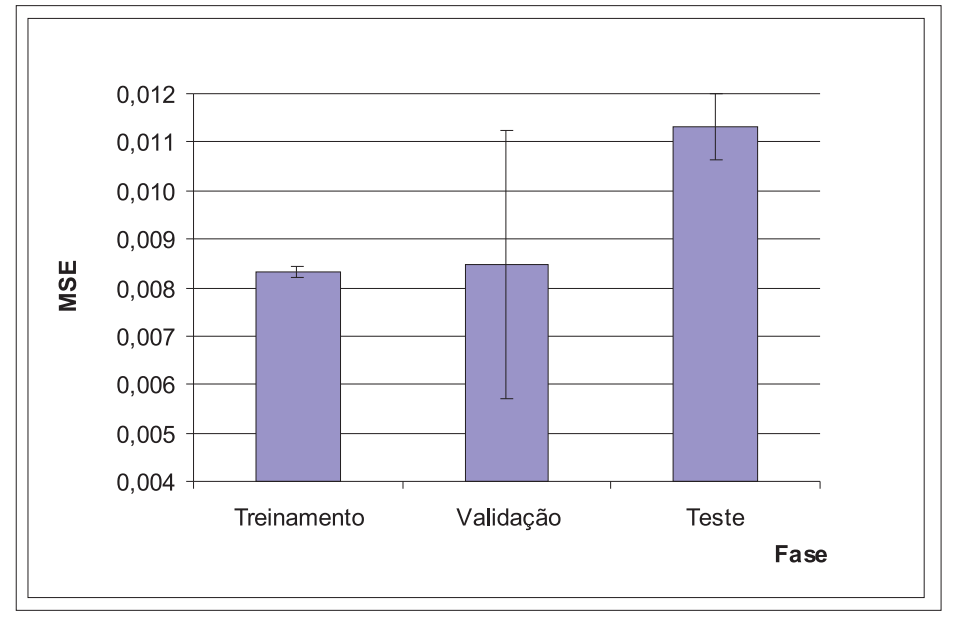

Figura 6.5: MSE da rede MLP treinada com o algoritmo Quickprop. 
O gráfico da Figura 6.6 e a Tabela 6.2 mostram uma comparação entre os erros obtidos no treinamento de redes com a topologia 8-10-1 com os três algoritmos de aprendizado utilizados. Pode-se observar que a rede que obteve o menor erro na fase de teste foi aquela treinada com o algoritmo Rprop, seguida pela rede treinada com o Backpropagation padrão. Assim, essas duas redes foram escolhidas para serem utilizadas como estimadores. O estimador que corresponde à rede treinada com o algoritmo Backpropagation padrão será chamado de MLP e o estimador que corresponde à rede treinada com o algoritmo Rprop será chamado MLPRprop.

\begin{tabular}{|l|c|c|c|}
\hline Algoritmo & Treinamento & Validação & Teste \\
\hline \hline Rprop & $\mathbf{0 , 0 0 6 5 0} \pm \mathbf{0 , 0 0 0 3 4}$ & $\mathbf{0 , 0 0 7 6 7} \pm \mathbf{0 , 0 0 3 5 3}$ & $\mathbf{0 , 0 0 8 4 1} \pm \mathbf{0 , 0 0 0 1 7}$ \\
\hline Backpropagation & $0,00750 \pm 0,00292$ & $0,00724 \pm 0,00148$ & $0,01029 \pm 0,00203$ \\
\hline Quickprop & $0,00834 \pm 0,00011$ & $0,00848 \pm 0,00275$ & $0,01132 \pm 0,00067$ \\
\hline
\end{tabular}

Tabela 6.2: Comparação dos algoritmos de treinamento das redes MLP.

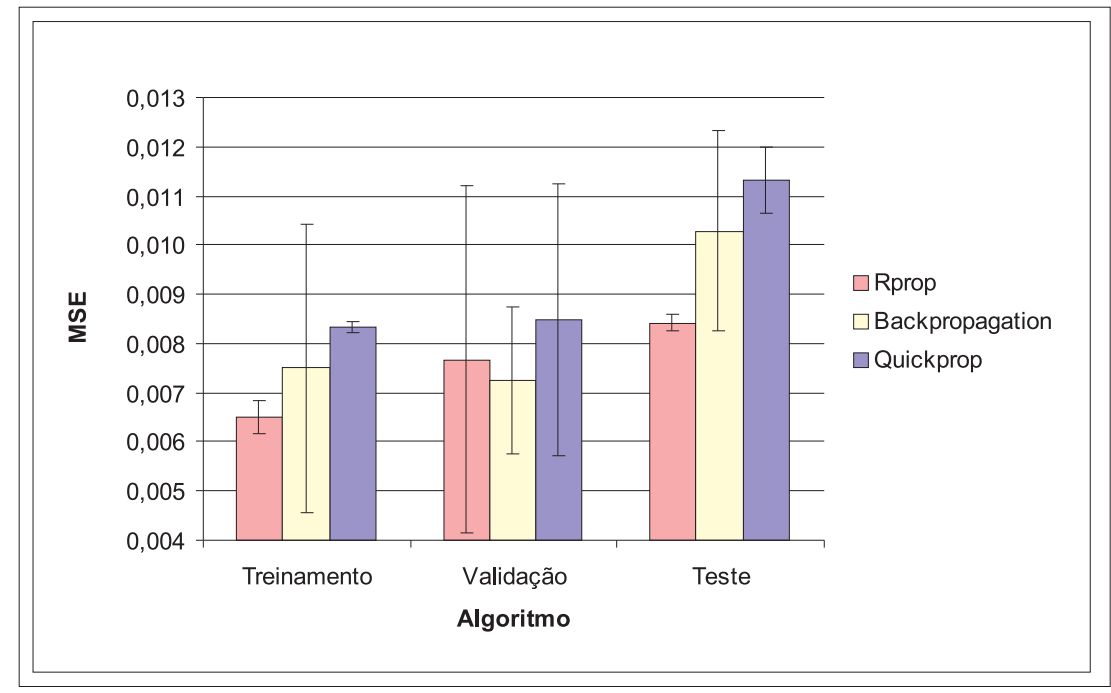

Figura 6.6: Comparação dos algoritmos de treinamento das redes MLP. 


\section{RBF}

Para as redes neurais do tipo RBF, a topologia empregada consistiu de 8 neurônios na camada de entrada, 10 na camada intermediária e 1 na de saída. O treinamento foi feito variando-se os diversos parâmetros de treinamento. A função de ativação utilizada nas unidades intermediárias foi a Act-RBF-Gaussian e na unidade de saída a Act-Logistic. O primeiro passo do treinamento da rede RBF consistiu de uma determinação preliminar do bias. Em seguida, passou-se a inicialização da rede com a função de inicialização RBF-Weights. Como parâmetros de inicialização foram utilizados os seguintes valores:

- O_scale: -4 ,

-1_scale: 4 ,

- smoothness: 0,

- bias: 0.5 (previamente determinado),

- deviation: 0 e 0.1 .

Seguindo a inicialização, um pequeno ajuste da rede foi realizado através de um treinamento com 50 ciclos para ajustar o bias, os pesos e os centros da rede. Inicialmente foi determinado o melhor valor para o parâmetro momentum $(0,09)$. O parâmetro delta Max foi fixado em 0 . Em seguida foram ajustados os valores das taxas de aprendizado $(\eta)$ para os pesos, centros e bias, nessa ordem. Diversos valores entre 0 e 1 foram testados para esses parâmetros. Esse processo foi feito para as três partições. A Tabela 6.3 mostra os valores de cada parâmetro que forneceu o melhor resultado em cada partição.

\begin{tabular}{|c|c|c|c|c|}
\hline Partição & Deviation & $\eta_{1}$ (centros) & $\eta_{2}$ (bias) & $\eta_{3}$ (pesos) \\
\hline \hline 1 & 0,1 & 0,0004 & 0,0001 & 0,05 \\
\hline 2 & 0,1 & 0,0001 & 0,00003 & 0,05 \\
\hline 3 & 0 & 0,001 & 0,0003 & 0,06 \\
\hline
\end{tabular}

Tabela 6.3: Parâmetros do treinamento das redes RBF.

O gráfico da Figura 6.7 mostra o MSE obtido no treinamento das redes RBF. O treinamento produziu um erro médio de 0,01049 e o teste de 0,01022 (para esse tipo de rede, o software empregado não requer a fase de validação. As barras no gráfico 
representam a média do MSE para as três partições e as linhas sobre as barras representam o desvio padrão.

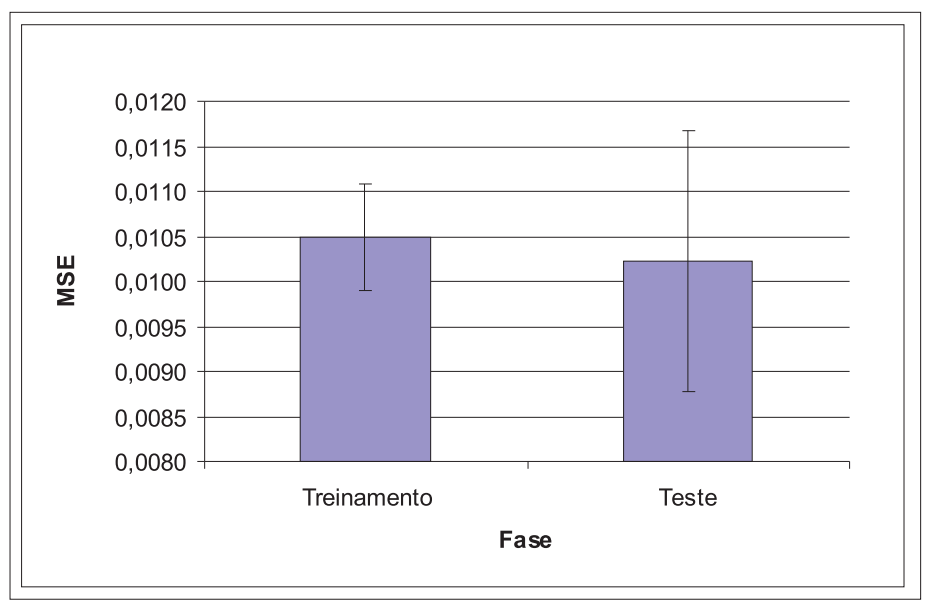

Figura 6.7: MSE das redes RBF.

\section{Cascade Correlation}

Para o treinamento das redes Cascade Correlation foi inicialmente criada uma rede com topologia mínima, ou seja 8 neurônios na camada de entrada e 1 na camada de saída. Em seguida foi realizado o treinamento com dois algoritmos: Rprop e QuickProp. Os parâmetros utilizados foram os valores sugeridos no manual do software SNNS utilizado. A Tabela 6.4 e o gráfico da Figura 6.8 mostram os resultados obtidos. Pode-se observar que a rede treinada com o algoritmo Rprop forneceu o melhor resultado na fase de teste, sendo essa rede utilizada como estimador.

\begin{tabular}{|c|c|c|c|}
\hline Algoritmo & Treinamento & Validação & Teste \\
\hline \hline Rprop & $\mathbf{0 , 0 0 2 7 5} \pm \mathbf{0 , 0 0 0 7 9}$ & $\mathbf{0 , 0 1 0 6 6} \pm \mathbf{0 , 0 0 1 8 0}$ & $\mathbf{0 , 0 0 8 8 6} \pm \mathbf{0 , 0 0 1 9 9}$ \\
\hline Quickprop & $0,00177 \pm 0,00050$ & $0,01373 \pm 0,00520$ & $0,01238 \pm 0,00279$ \\
\hline
\end{tabular}

Tabela 6.4: MSE das redes Cascade.

A Tabela 6.5 mostra o número de neurônios intermediários gerados no treinamento das redes Cascade Correlation para cada partição e algoritmo de aprendizado utilizados. Pode-se observar que o número de neurônios intermediários gerados em cada caso foi 


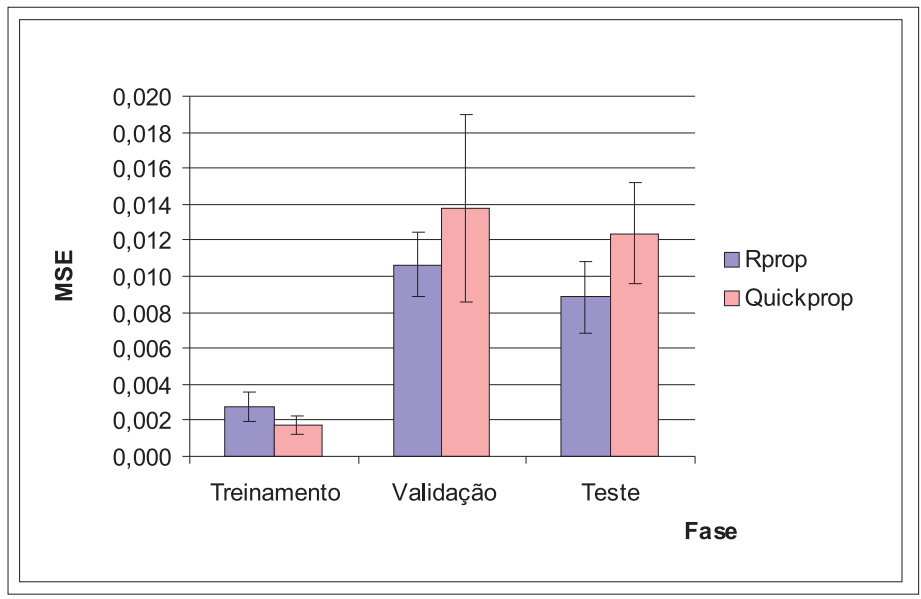

Figura 6.8: MSE das redes Cascade Correlation.

próximo ao número de neurônios na camada intermediária da topologia das redes MLP que forneceu o melhor resultado.

\begin{tabular}{|c|c|c|c|}
\hline Algoritmo & Partição 1 & Partição 2 & Partição 3 \\
\hline \hline Rprop & 8 & 12 & 10 \\
\hline Quickprop & 11 & 11 & 15 \\
\hline
\end{tabular}

Tabela 6.5: Número de neurônios intermediários.

\section{SVM}

Para o treinamento do algoritmo SVM, foram seguidas várias etapas. A primeira delas consistiu do treinamento com os quatro tipos de kernel disponíveis, o parâmetro eps com os valores 0,1 e 0,2 e utilização dos valores default para todos os demais parâmetros ajustáveis. Outros valores para eps foram também testados preliminarmente, bem como os parâmetros c e e. Essa etapa permitiu um primeiro contato com o algoritmo e ajudou a determinar os demais passos a serem seguidos para se obter melhores resultados.

A partir desses passos preliminares, pôde-se observar que o treinamento com o kernel gaussiano apresentou menor erro em todos os casos. A partir disso, estabeleceu-se que os demais parâmetros seriam determinados através de treinamentos com esse kernel. Nesse ponto, testes mais sistemáticos passaram a ser realizados. 
Inicialmente, foi determinado o melhor valor do parâmetro eps, utilizando um kernel gaussiano e demais parâmetros default. Os valores testados para eps foram 0,001, 0,005, 0,01, 0,05, 0,1, 0,5, 1, 5, 10, 25, 50 e 100. No gráfico da Figura 6.9 pode-se observar o MSE obtido com os valores testados para o parâmetro eps que forneceram os melhores resultados. Os demais valores resultaram em um erro maior do que 0,1. O melhor valor encontrado para eps foi 0,05 .

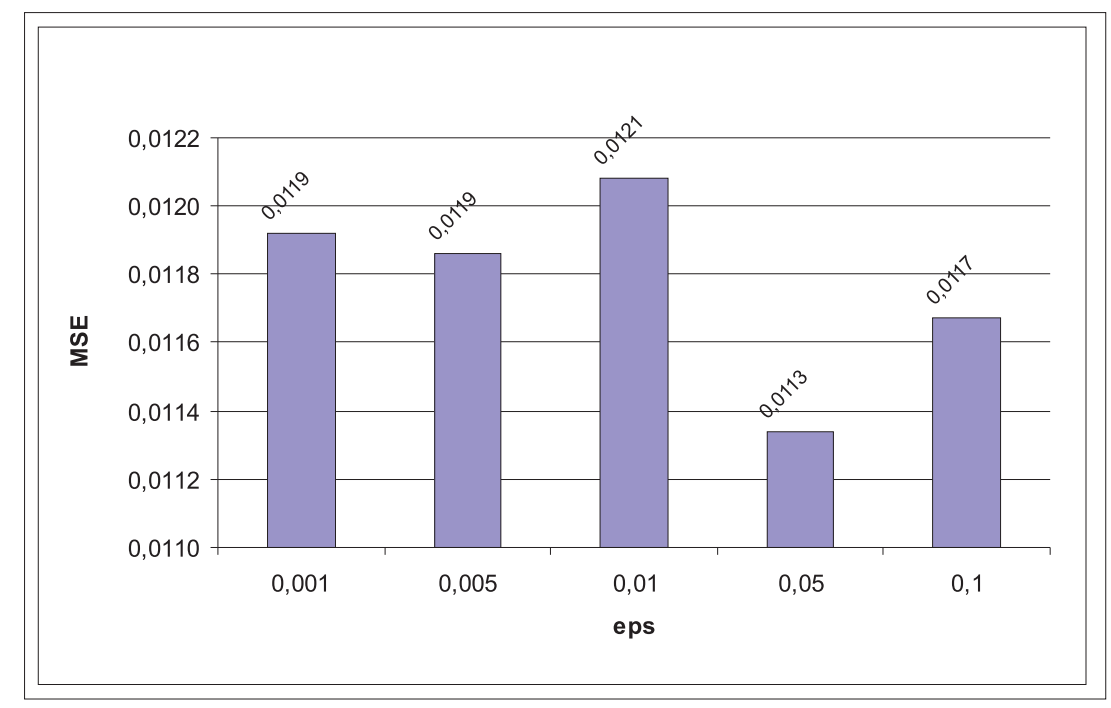

Figura 6.9: MSE para diferentes valores de eps.

A partir do melhor valor de eps, fixou-se esse parâmetro e passou-se a determinação do parâmetro c. Os valores testados para c foram 1, 10, 50, 100, 250, 500, 750 e 1000. No gráfico da Figura 6.10 pode-se observar o MSE com a utilização de um kernel gaussiano, eps $=0,05$, demais parâmetros default e variação do parâmetro c. Nesse caso, o melhor valor encontrado para c foi 500.

Com o parâmetro eps $=0,05$ e $\mathrm{c}=500$, pode-se observar a influência dos parâmetros específicos de cada kernel.

Para o kernel gaussiano, foram realizados testes com o parâmetro st assumindo os valores $0,001,0,005,0,01,0,05,0,1,0,5,1,3,5,7,10,50,100$ e 500. No gráfico da Figura 6.11 pode-se observar que o melhor valor do parâmetro st do kernel gaussiano foi 3 .

Para o kernel polinomial, testou-se d com os valores 1 e 2, uma vez que valores mai- 


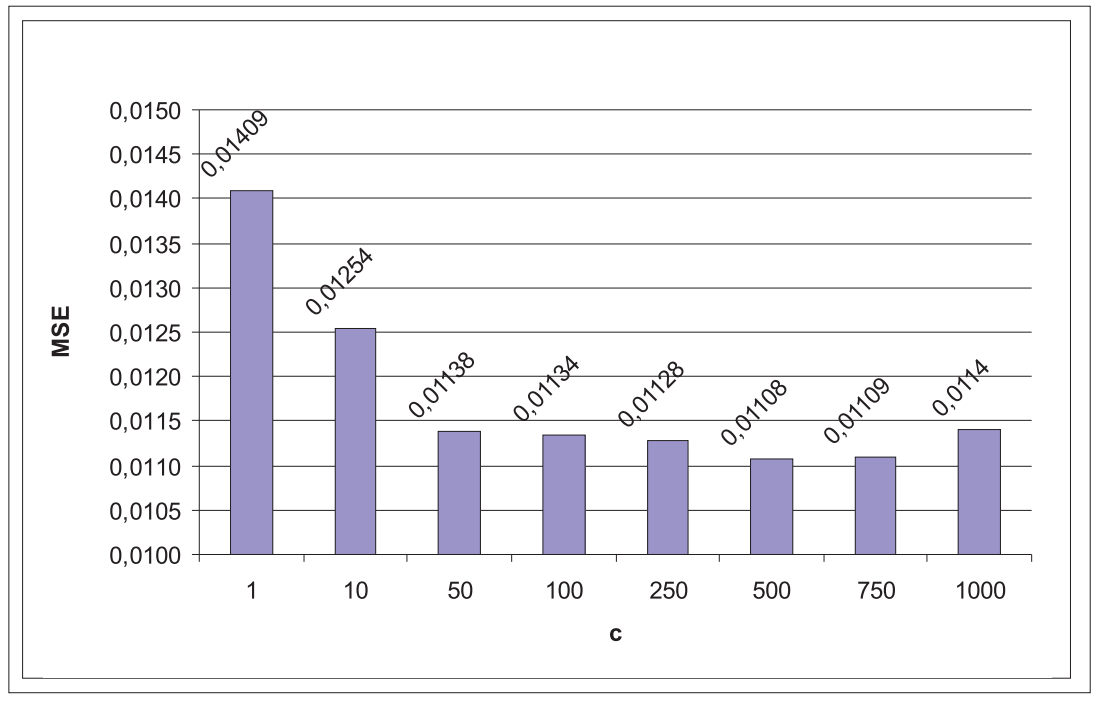

Figura 6.10: MSE para diferentes valores de c.

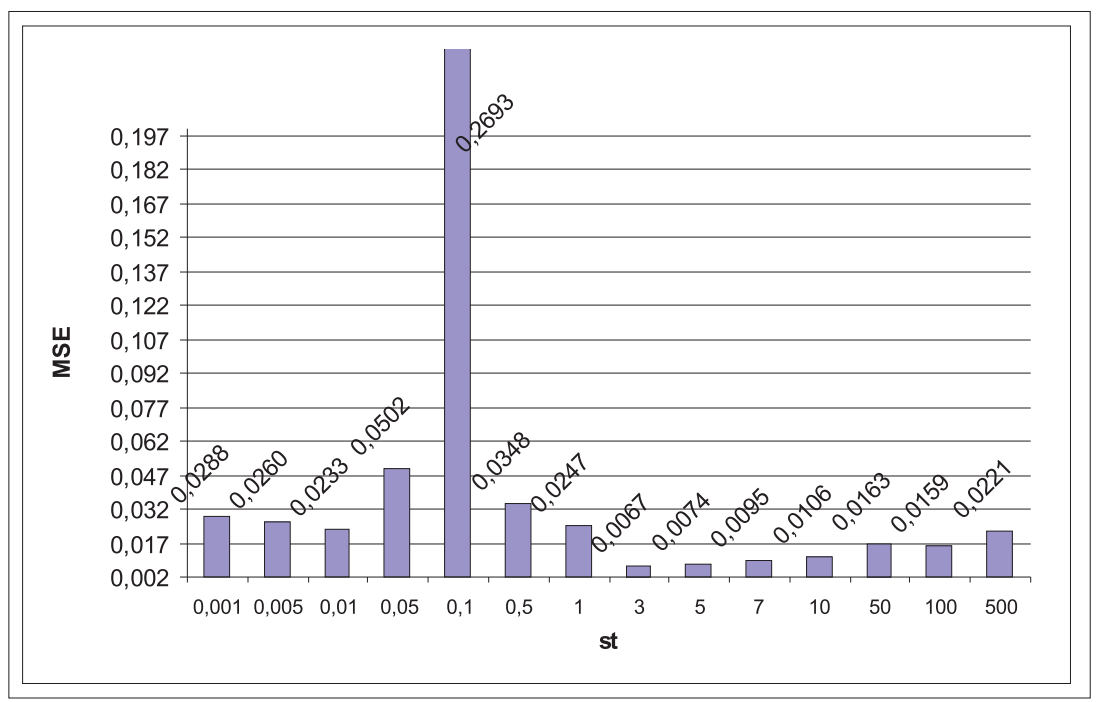

Figura 6.11: MSE para diferentes valores de st.

ores aumentavam muito o tempo de processamento. Com esses dois valores de $\mathrm{d}$ foram executados testes para a determinação do parâmetro s. Foram testados os valores 0,001 , $0,005,0,01,0,05,0,1,0,5$ e 1 . Com o melhor valor de d e s foi determinado o valor de $r$, testando-se os valores $0,001,0,01,0,1,1,10$ e 100 . Nas figuras 6.12 e 6.13 pode-se observar os melhores valores para d, s e $\mathrm{r}$ do kernel polinomial (respectivamente 2, 0,1 e $0,01)$. 


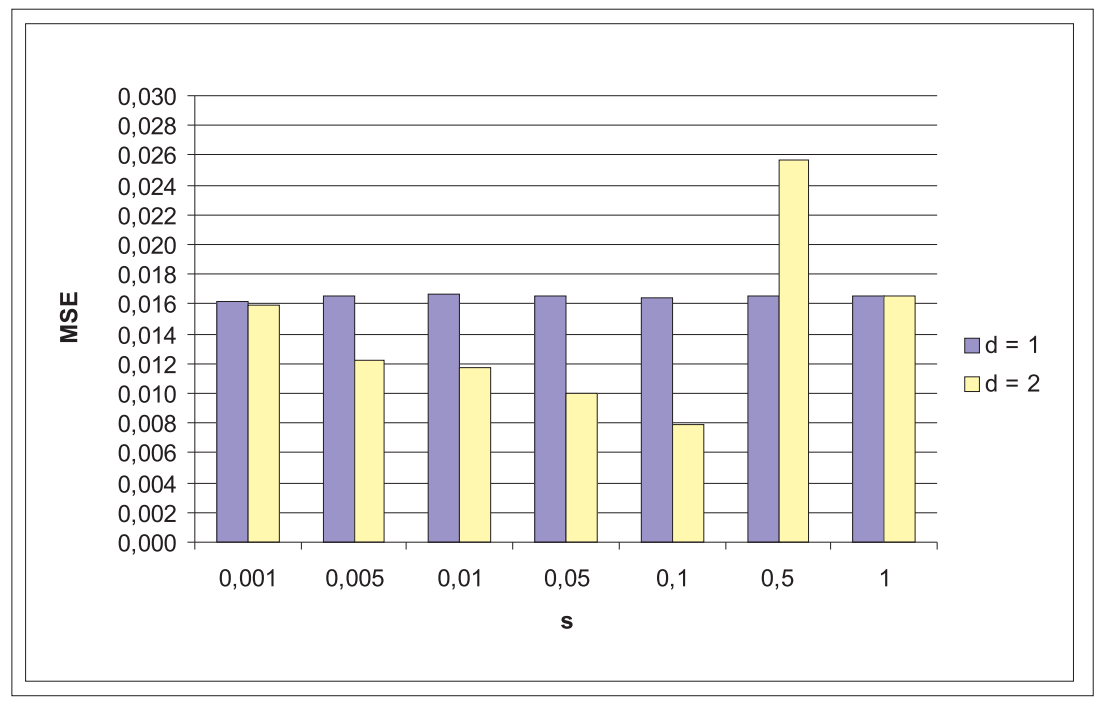

Figura 6.12: MSE para diferentes valores de d e s.

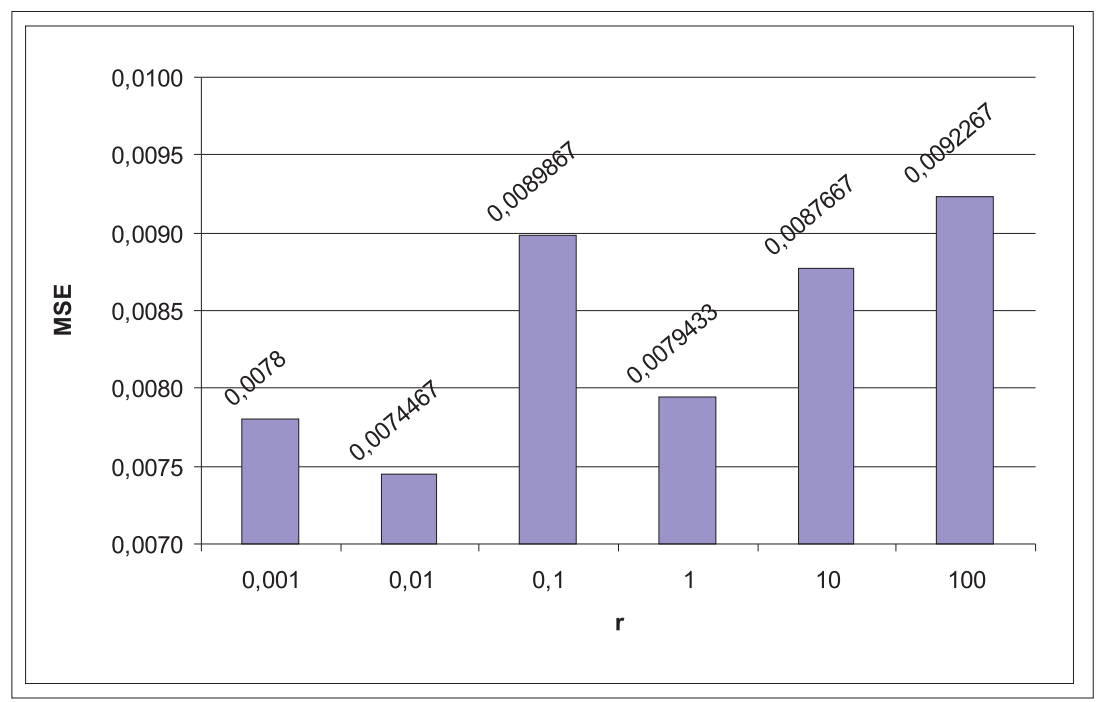

Figura 6.13: MSE para diferentes valores de $r$.

Para o kernel sigmóide o parâmetro s foi testado com os valores $0,001,0,005,0,01$, $0,05,0,1,1,5$ e 10 . Com o melhor valor de $\mathbf{s}$ foi determinado o melhor valor de $r$, testando-se os valores $0,001,0,01,0,1,1,5$ e 10 . Nas figuras 6.14 e 6.15 pode-se observar os melhores valores para s e $r$ do kernel sigmóide (respectivamente 0,001 e 1).

Finalmente, para o kernel linear foi executado um teste com os melhores valores dos parâmetros eps e c, uma vez que esse kernel não possui parâmetros específicos a serem 


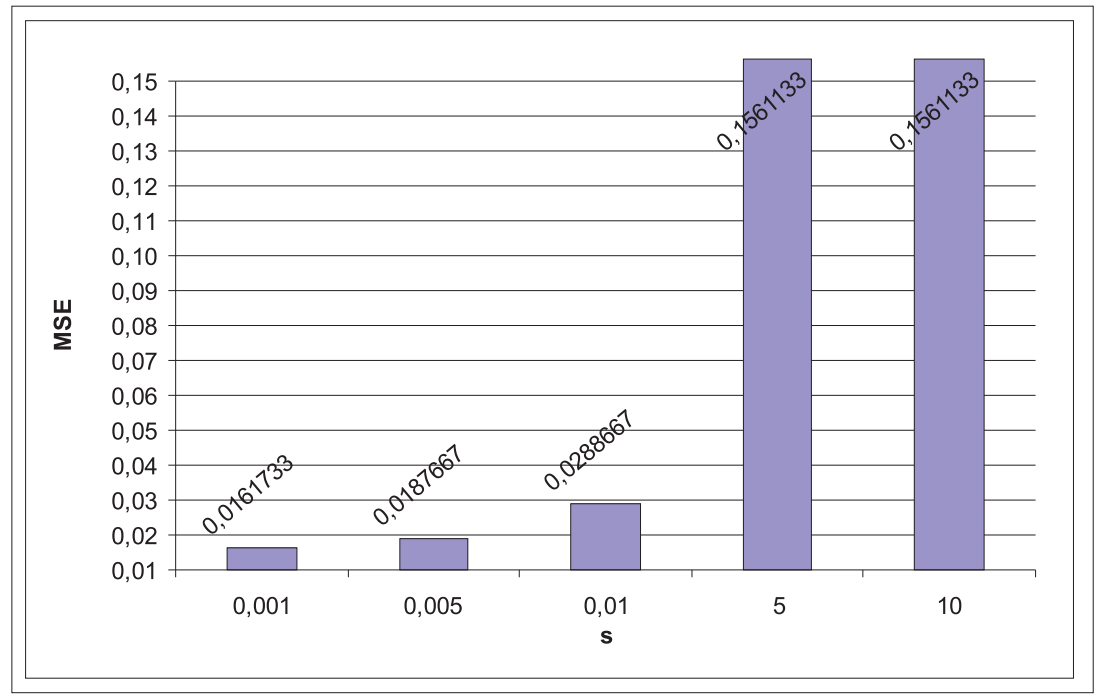

Figura 6.14: MSE para diferentes valores de s.

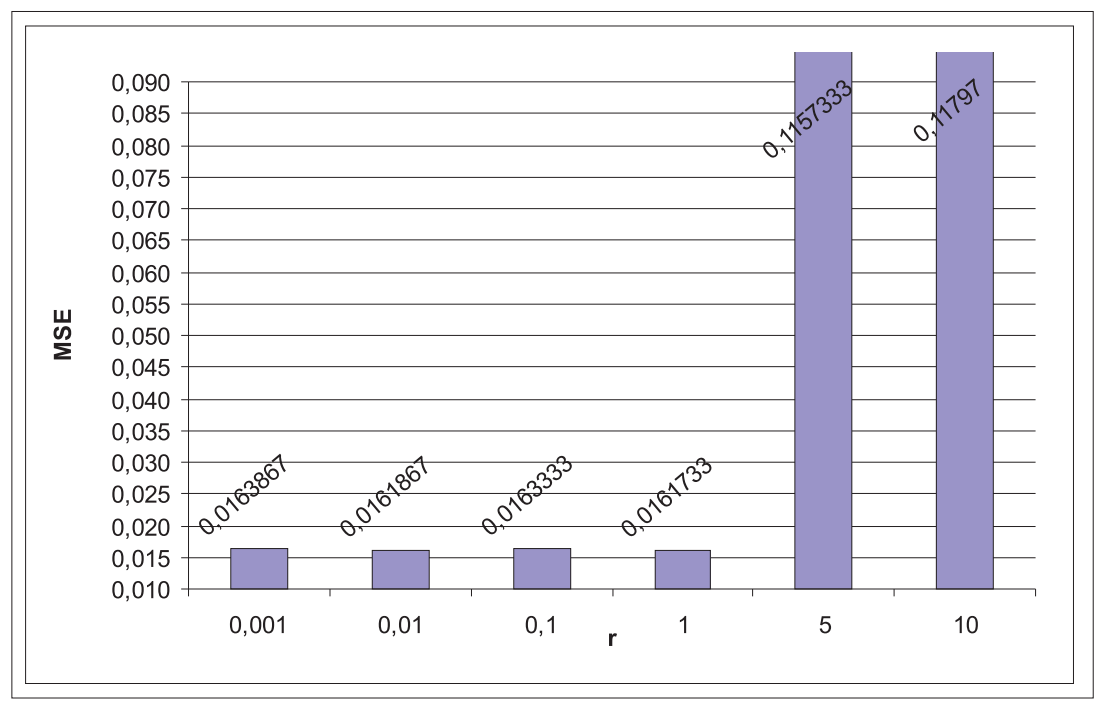

Figura 6.15: MSE para diferentes valores de $r$.

determinados. 
O gráfico da Figura 6.16 mostra o MSE obtido para os melhores modelos gerados para cada kernel. Os valores dos erros podem ser observados na Tabela 6.6. As barras no gráfico representam a média do MSE para as três partições e as linhas sobre as barras representam o desvio padrão. Nesse caso, pode ser observado que o kernel que forneceu um modelo com melhor desempenho foi o gaussiano, embora o kernel polinomial também tenha apresentado bons resultados.

\begin{tabular}{|l|c|c|}
\hline Kernel & Treinamento & Teste \\
\hline \hline gaussian & $\mathbf{0 , 0 0 5 1 2 0} \pm \mathbf{0 , 0 1 5 8}$ & $\mathbf{0 , 0 0 6 7 3 3} \pm \mathbf{0 , 0 1 6 5}$ \\
\hline sigmoid & $0,019567 \pm 0,1059$ & $0,016173 \pm 0,0416$ \\
\hline polinomial & $0,006207 \pm 0,0187$ & $0,007447 \pm 0,0152$ \\
\hline linear & $0,021857 \pm 0,1257$ & $0,016400 \pm 0,0462$ \\
\hline
\end{tabular}

Tabela 6.6: MSE para o melhor modelo gerado com cada kernel.

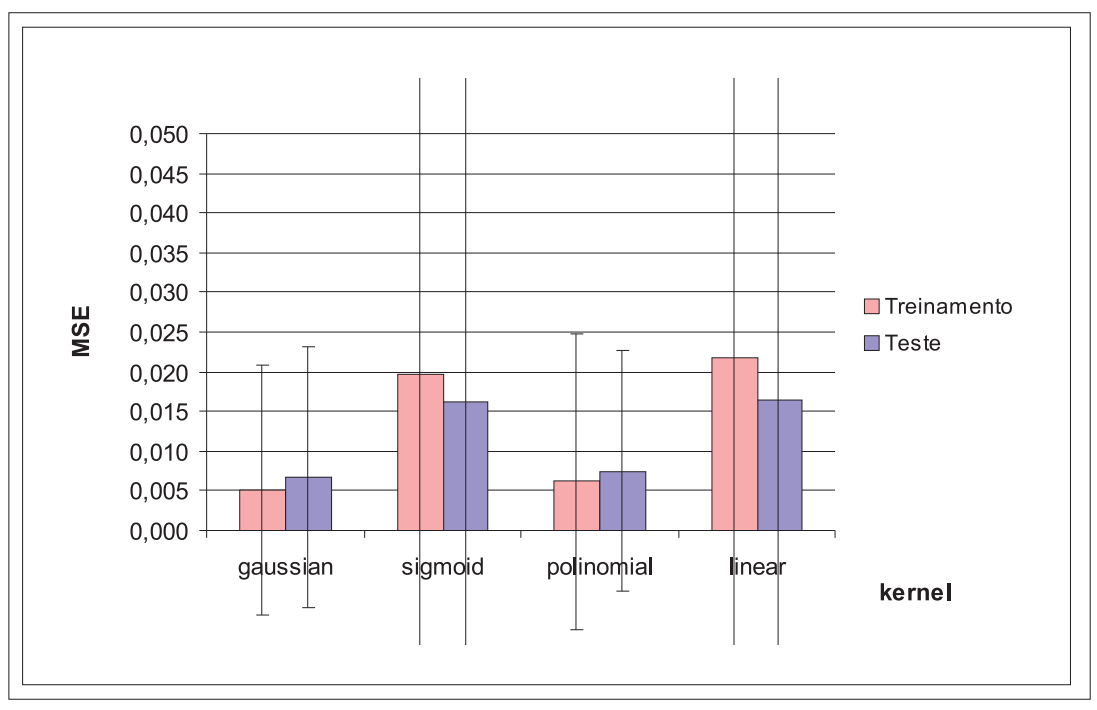

Figura 6.16: MSE para o melhor modelo gerado com cada kernel.

\section{Cubist}

O treinamento do algoritmo Cubist foi realizado utilizando os parâmetros default. A escolha entre instâncias e regras foi deixada por conta do algoritmo. O gráfico da Figura 6.17 mostra o MSE obtido no treinamento com esse algoritmo. O treinamento produziu um erro médio de 0,005537 e o teste de 0,007194. As barras no gráfico representam a 
média do MSE para as três partições e as linhas sobre as barras representam o desvio padrão.

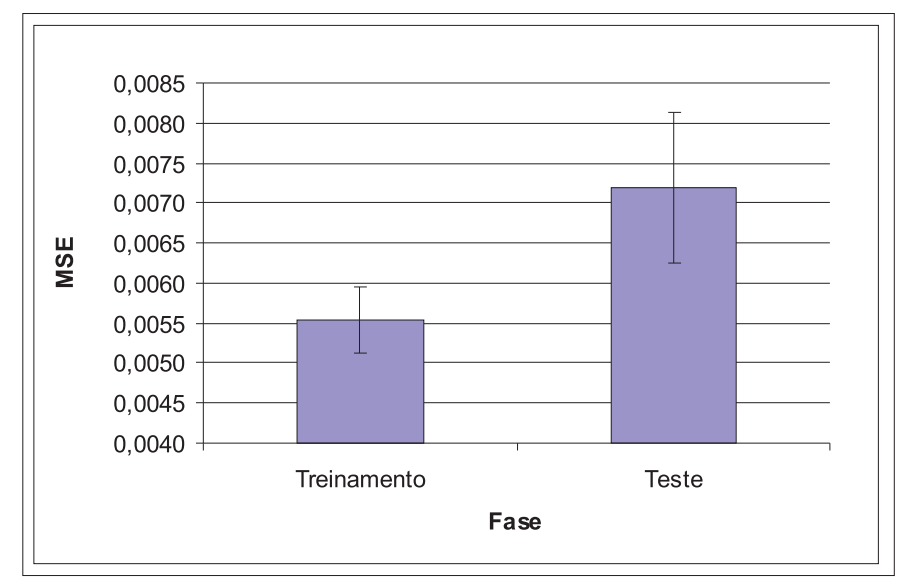

Figura 6.17: MSE do algoritmo Cubist.

M5

O treinamento do algoritmo M5 foi realizado utilizando os parâmetros default. O gráfico da Figura 6.18 mostra o MSE obtido no treinamento com esse algoritmo. O treinamento produziu um erro médio de 0,008326 e o teste de 0,011072. As barras no gráfico representam a média do MSE para as três partições e as linhas sobre as barras representam o desvio padrão.

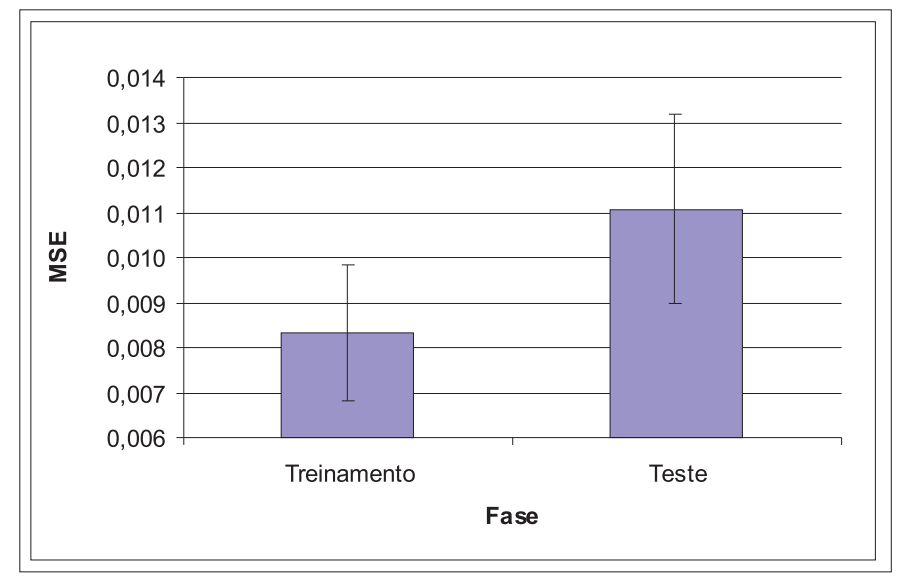

Figura 6.18: MSE do algoritmo M5. 


\section{Comparação entre os métodos}

A Tabela 6.7 mostra um resumo dos resultados obtidos no treinamento e teste dos diversos métodos de aprendizado investigados. Esses resultados correspondem ao melhor estimador gerado por cada algoritmo de aprendizado. Essas informações podem ser mais facilmente interpretadas através do gráfico da Figura 6.19. A partir desse gráfico pode-se observar que o melhor estimador (algoritmo treinado), ou seja, aquele que apresentou menor MSE na fase de teste, foi o SVM. A ordem dos estimadores de acordo com o menor para o maior erro no teste foi: SVM, Cubist, MLPRprop, Cascade, RBF, MLP, M5. Esse resultado era o esperado, uma vez que as características do SVM dão a esse algoritmo uma melhor capacidade de generalização.

\begin{tabular}{|l|l|l|}
\hline Estimador & Treinamento & Teste \\
\hline \hline SVM & $\mathbf{0 , 0 0 5 1 2} \pm \mathbf{0 , 0 0 0 3 8}$ & $\mathbf{0 , 0 0 6 7 3} \pm \mathbf{0 , 0 0 0 8 9}$ \\
\hline Cubist & $0,00554 \pm 0,00041$ & $0,00719 \pm 0,00094$ \\
\hline MLPRprop & $0,00650 \pm 0,00054$ & $0,00841 \pm 0,00136$ \\
\hline Cascade & $0,00275 \pm 0,00079$ & $0,00886 \pm 0,00199$ \\
\hline RBF & $0,01049 \pm 0,00060$ & $0,01022 \pm 0,00145$ \\
\hline MLP & $0,00750 \pm 0,00292$ & $0,01029 \pm 0,00203$ \\
\hline M5 & $0,00833 \pm 0,00150$ & $0,01107 \pm 0,00210$ \\
\hline
\end{tabular}

Tabela 6.7: MSE para o melhor estimador gerado com cada algoritmo investigado. 


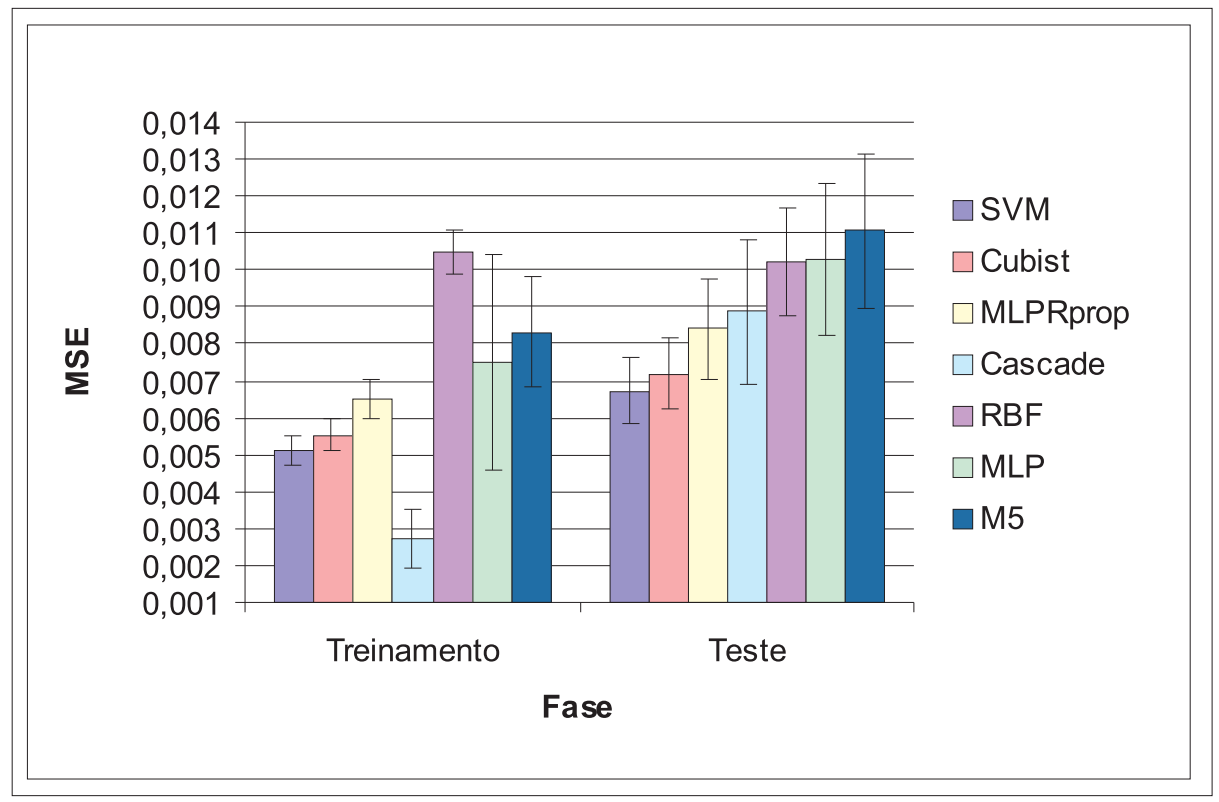

Figura 6.19: Comparação entre os melhores estimadores. 


\subsubsection{Combinação de Estimadores}

Como descrito na Seção 4.6, a combinação de estimadores envolve o ajuste dos estimadores a serem combinados e a combinação em si. O ajuste dos estimadores consistiu do treinamento dos algoritmos de AM escolhidos, com os dados apropriados, já descritos nas seções anteriores.

Quanto à combinação propriamente dita, optou-se por adotar o framework de stacking descrito na Seção 4.6, em que um algoritmo de aprendizado é treinado para combinar as saídas dos estimadores. O algoritmo escolhido para gerar o combinador foi o SVM, devido a sua boa performance como estimador individual.

Quanto aos dados de treinamento para nível 1, foram utilizadas como entradas as predições dos estimadores para os arquivos de treinamento do nível 0. Assim, foram geradas três partições para o treinamento do combinador, com cada arquivo contendo às predições dos estimadores para o arquivo correspondente do nível 0. Por exemplo, o arquivo "treina1" do nível 1 tem como exemplos de treinamento as predições dos estimadores para exatamente os mesmos exemplos do arquivo "treina1" do nível 0.

Com os dados de nível 1, o treinamento do SVM foi feito de forma similar ao descrito para os estimadores, porém com a fase de ajuste dos parâmetros reduzida. Neste caso, foram escolhidos os melhores valores dos parâmetros da fase de treinamento dos estimadores e testadas algumas modificações. Os melhores resultados do treinamento do combinador foram obtidos com os mesmos valores dos parâmetros que se mostraram mais adequados para o treinamento dos algoritmos no nível 0.

Uma questão que sempre surge quando se está combinando estimadores diz respeito a que estimadores combinar. Como este trabalho visa, além de avaliar a combinação de estimadores para fusão de sensores, também investigar a utilização de diferentes algoritmos de AM, escolheu-se, em princípio, um conjunto de algoritmos que englobasse diferentes abordagens para o aprendizado, estrutura e representação de conhecimento. Além disso, existem vários trabalhos que salientam a importância da diferença entre os estimadores 
que serão combinados, ou seja, os estimadores a serem combinados devem ser o mais diferentes possível, devendo também cometer diferentes tipos de erro. Quanto a essa questão, os estimadores empregados neste trabalho são bastante diferentes entre si, uma vez que são baseados em algoritmos de AM bem diferentes, englobando inclusive diversos paradigmas de aprendizado. Portanto, poderia-se simplesmente pensar em combinar todos os estimadore obtidos (7 no total). Porém pode-se questionar se realmente a combinação de todos os estimadores é a melhor solução, uma vez que é a mais cara computacionalmente (requer a predição por todos os estimadores para, em seguida, se obter a predição final pela combinação). Tendo em vista esse questionamento, decidiu-se por tentar avaliar as combinações de apenas alguns dos estimadores.

O processo de avaliar quantos e quais os estimadores possuem melhor potencial de combinação se deu da seguinte maneira. Em primeiro lugar, decidiu-se por avaliar combinações de 3, 5 e 7 (todos) estimadores. Em seguida, com base na forma mais simples de combinação de estimadores, a média aritmética simples, calculou-se um rank para as combinações a serem avaliadas. Para cada exemplo de treinamento foram realizadas todas as combinações possíveis para cada um dos diferentes grupos de estimadores estipulados, através da média simples. Em seguida, foi calculada a diferença entre cada valor obtido por uma combinação e o valor desejado. Ainda para cada exemplo de treinamento, para cada combinação foi atribuída uma classificação (rank) de acordo com a sua diferença para a saída desejada. Assim, a combinação que gerou a menor diferença obteve uma classificação 1 e a que gerou a maior diferença obteve a maior classificação possível. Uma vez que todos os exemplos tiveram as combinações classificadas, foi calculada uma média dos ranks para cada combinação e em seguida uma média dos ranks de cada combinação para as três partições de treinamento. Com isso obteve-se uma classificação geral de todas as possíveis combinações envolvendo um mesmo número de estimadores, e pode-se, para esse número de estimadores, determinar quais estimadores têm maior potencial para gerar uma melhor combinação (com base na menor diferença entre a predição pela combinação e o valor a ser predito).

Os gráficos das Figuras 6.20 e 6.21 mostram o rank para as 21 melhores combinações 
de 3 e 5 estimadores respectivamente. A melhor combinação de 3 estimadores, pela média, envolveu os estimadores Cascade, SVM e Cubist, e a melhor combinação de 5 estimadores envolveu os estimadores MLP, Cascade, SVM, Cubist e MLPRProp.

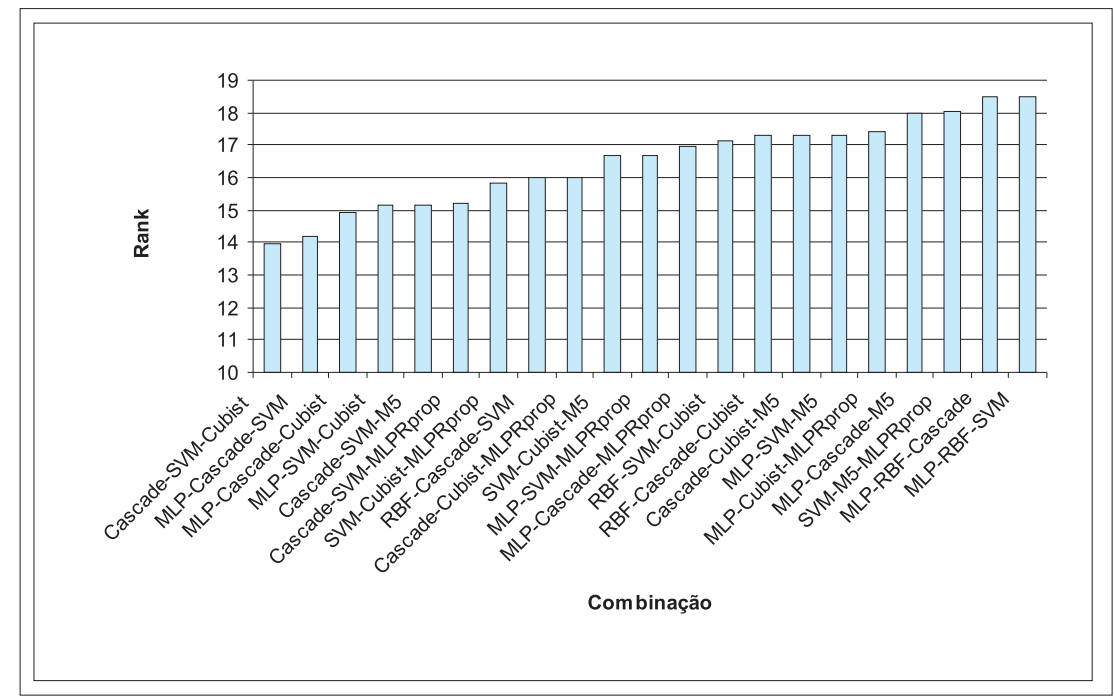

Figura 6.20: Rank das combinações de 3 estimadores.

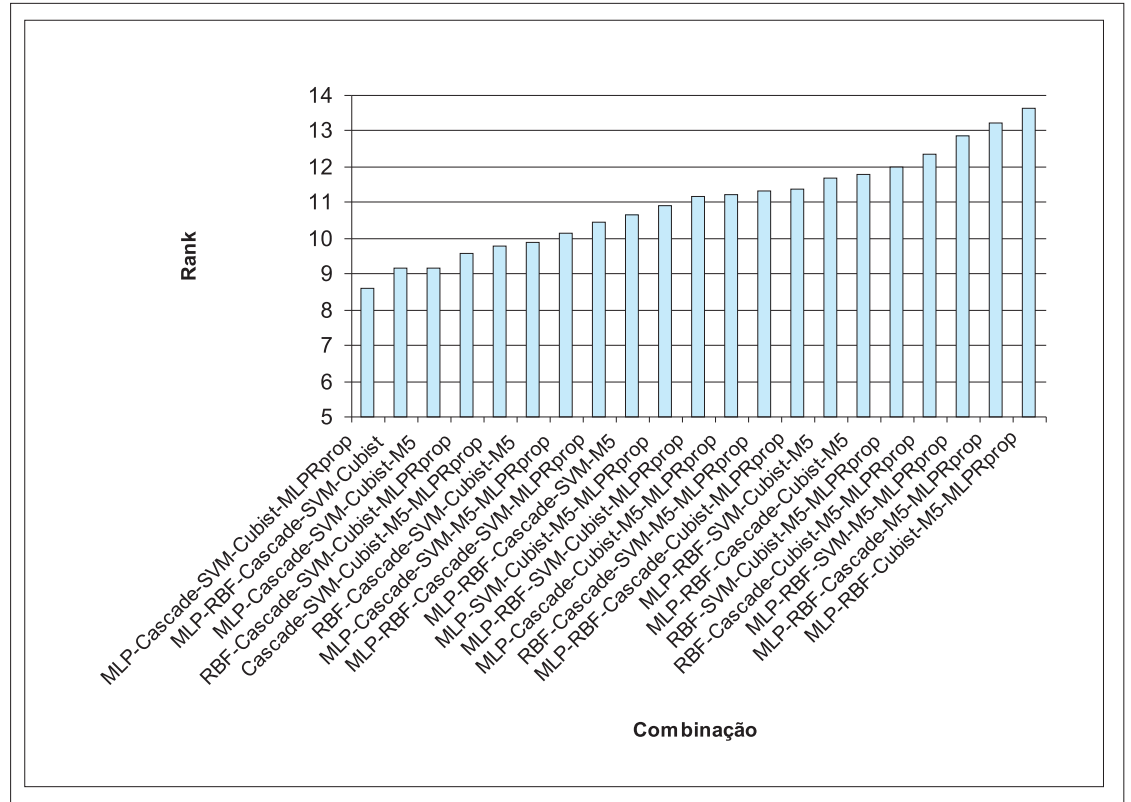

Figura 6.21: Rank das combinações de 5 estimadores. 
Com isso, tomou-se as três melhores combinações de 3 e 5 estimadores e a combinação dos 7 estimadores e preparou-se arquivos para o treinamento e teste dessas mesmas combinações, agora feitas com o algoritmo SVM no lugar da média simples. Feitas as combinações utilizando o SVM, um novo rank foi estabelecido, agora envolvendo as melhores combinações pela média citadas e as combinações pelo SVM. A combinação pela média foi também analisada para se ter uma idéia do quanto um algoritmo mais complexo, treinado para a tarefa específica de combinar as saídas dos diversos estimadores pode melhorar os resultados em comparação com a forma mais simples de combinação (média).

Para facilitar a visualização, nos gráficos daqui para frente os nomes de alguns estimadores foram abreviados da seguinte maneira: Cascade por Cas, Cubist por Cub e MPLRProp por RProp. A combinação de 7 estimadores está representada por "todos"e envolve os estimadores MLP, MLPRProp, Cascade, RBF, SVM, Cubist e M5. A primeira palavra nos rótulos das combinações indica se a combinação foi feita pela média ou com o SVM.

O gráfico da Figura 6.22 mostra o rank geral obtido. As barras no gráfico mostram o rank obtido pela combinação e as linhas sobre as barras mostram a variação do rank da combinação nas três partições de treinamento. A partir do gráfico pode-se notar que embora haja uma diferença entre os ranks das combinações, praticamente todas elas ficaram com uma classificação entre 7 e 8, não havendo uma combinação destacadamente melhor que a outra, o que sugere que para cada exemplo e/ou partição, uma combinação diferente pode ter dado a melhor estimativa.

Vale ainda destacar que, pelo rank, as duas melhores combinações envolveram os algoritmos Cascade, SVM e Cubist, combinados pela média e pelo SVM. Isso reforça a hipótese de que quanto mais diferirem os estimadores, melhor será o resultado da combinação, pois esses três algoritmos pertencem a três paradigmas de aprendizado distintos, cada um realizando a predição de uma maneira completamente diferente do outro.

Esse gráfico mostra ainda que, pelo rank, as 5 melhores combinações envolveram apenas 3 estimadores, dentre os quais encontram-se sempre os estimadores Cascade e SVM 


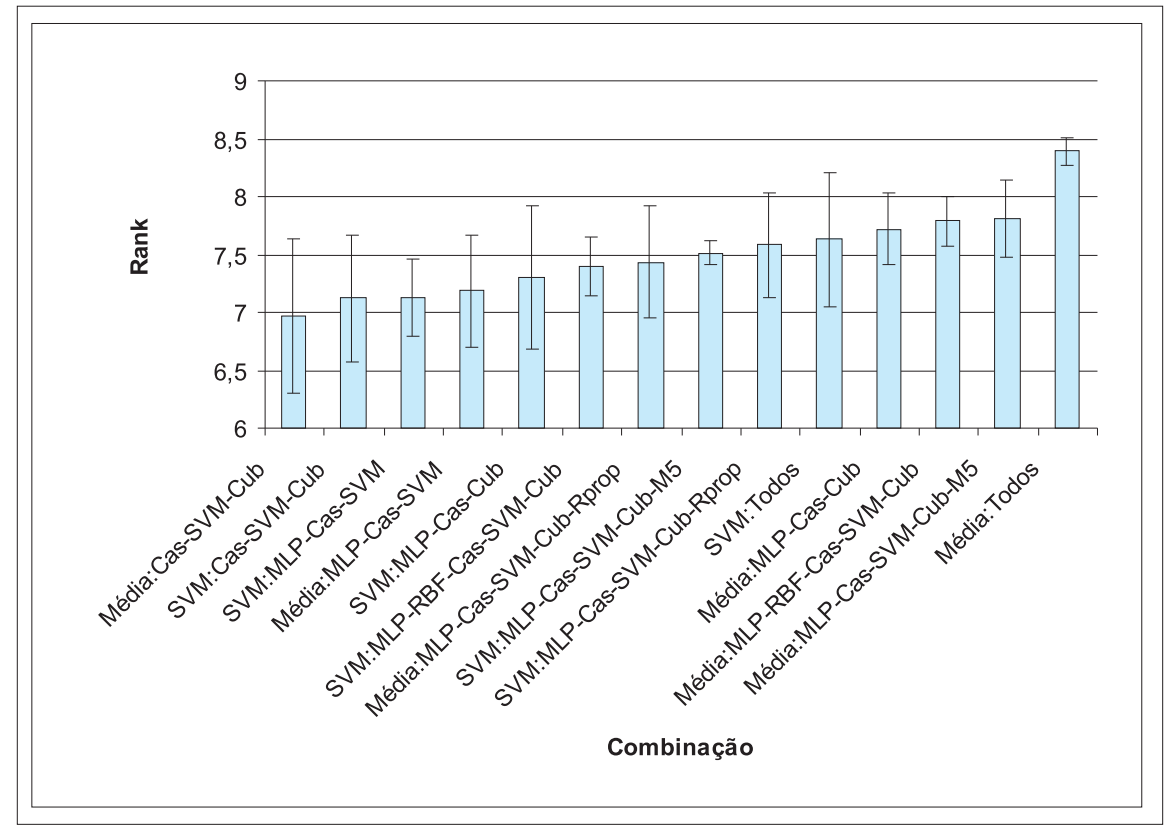

Figura 6.22: Rank final das combinações de 3, 5 e 7 estimadores.

(embora na $5^{a}$ melhor combinação o SVM não esteja como estimador individual, a combinação é feita com esse algoritmo).

Ainda para comparar as combinações, foi calculada a média e o desvio padrão do MSE nas três partições para todas as combinações comparadas no gráfico anterior. A Tabela 6.8 e o gráfico da Figura 6.23 mostram essas informações em ordem crescente de MSE na fase de teste. A primeira coluna na tabela indica a forma como a combinação foi feita (se pela média ou com o SVM) e a segunda indica quais estimadores foram combinados. Observando o MSE no teste das combinações vê-se que a classificação das melhores combinações muda, mas a melhor continua sendo a combinação pela média dos estimadores Cascade, SVM e Cubist. Porém, neste caso, as combinações com maior número de estimadores se apresentaram com melhores resultados (menor MSE). Deve-se notar ainda que as 8 melhores combinações envolveram os estimadores Cascade, SVM e Cubist e que, 5 das 6 melhores combinações foram feitas com o SVM. Porém, o fato da combinação pela média ter fornecido o melhor resultado mostra que, ao menos neste caso, não se faz tão necessário um algoritmo mais complexo para se ter os melhores resultados. Isso pode também levantar a questão de qual seria o algoritmo ideal para 
gerar o combinador. Pode ser que se outro algoritmo fosse empregado, possivelmente um diferente dos utilizados nos estimadores de nível 0 , melhores resultados tivessem sido obtidos.

\begin{tabular}{|l|l|c|c|}
\hline \multicolumn{2}{|c|}{ Combinação } & \multicolumn{2}{c|}{ MSE } \\
\hline Método & Estimadores & Treinamento & Teste \\
\hline \hline Média & Cascade-SVM-Cubist & $\mathbf{0 , 0 0 3 7 1} \pm \mathbf{0 , 0 0 0 2 6}$ & $\mathbf{0 , 0 0 5 9 4} \pm \mathbf{0 , 0 0 1 0 3}$ \\
\hline SVM & MLP-RBF-Cascade-SVM-Cubist & $0,00331 \pm 0,00031$ & $0,00607 \pm 0,00028$ \\
\hline SVM & Todos & $0,00318 \pm 0,00041$ & $0,00608 \pm 0,00055$ \\
\hline SVM & MLP-Cascade-SVM-Cubist-M5 & $0,00328 \pm 0,00031$ & $0,00610 \pm 0,00029$ \\
\hline SVM & MLP-Cascade-SVM-Cubist-MLPRprop & $0,00332 \pm 0,00038$ & $0,00627 \pm 0,00007$ \\
\hline SVM & Cascade-SVM-Cubist & $0,00363 \pm 0,00011$ & $0,00628 \pm 0,00059$ \\
\hline Média & MLP-Cascade-SVM-Cubist-MLPRprop & $0,00426 \pm 0,00035$ & $0,00636 \pm 0,00109$ \\
\hline Média & MLP-RBF-Cascade-SVM-Cubist & $0,00451 \pm 0,00029$ & $0,00653 \pm 0,00134$ \\
\hline SVM & MLP-Cascade-SVM & $0,00367 \pm 0,00032$ & $0,00655 \pm 0,00032$ \\
\hline Média & MLP-Cascade-SVM-Cubist-M5 & $0,00439 \pm 0,00040$ & $0,00665 \pm 0,00128$ \\
\hline Média & MLP-Cascade-Cubist & $0,00432 \pm 0,00037$ & $0,00680 \pm 0,00140$ \\
\hline Média & Todos & $0,00487 \pm 0,00032$ & $0,00681 \pm 0,00124$ \\
\hline Média & MLP-Cascade-SVM & $0,00419 \pm 0,00042$ & $0,00694 \pm 0,00129$ \\
\hline SVM & MLP-Cascade-Cubist & $0,00389 \pm 0,00016$ & $0,00709 \pm 0,00097$ \\
\hline
\end{tabular}

Tabela 6.8: MSE das melhores combinações de 3, 5 e 7 estimadores.

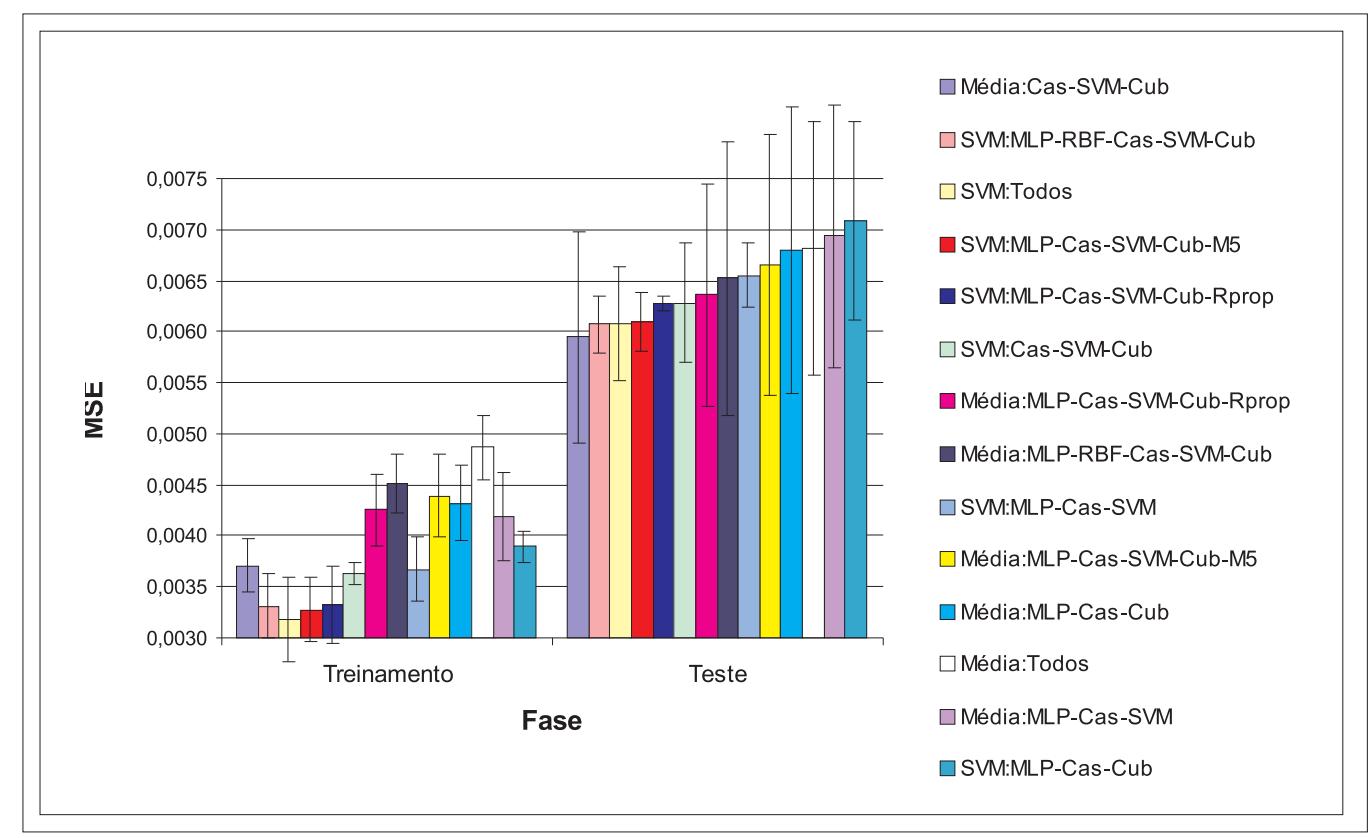

Figura 6.23: MSE das melhores combinações de 3, 5 e 7 estimadores. 


\subsubsection{Comparação entre os métodos}

Com as combinações realizadas, resta comparar os resultados das combinações, dos estimadores e dos sensores. Para isso será analisado o MSE de cada método. As informações em todos os gráficos seguintes desta seção estão ordenadas pelo MSE do teste dos estimadores.

O gráfico da Figura 6.24 mostra o MSE das melhores combinações e dos estimadores. As barras mostram a média para as três partições e as linhas sobre as barras representam o desvio padrão.

Pode-se notar que, em geral, as melhores combinações tiveram um MSE menor no teste do que todos os estimadores, com exceção do SVM, que foi melhor que algumas das combinações.

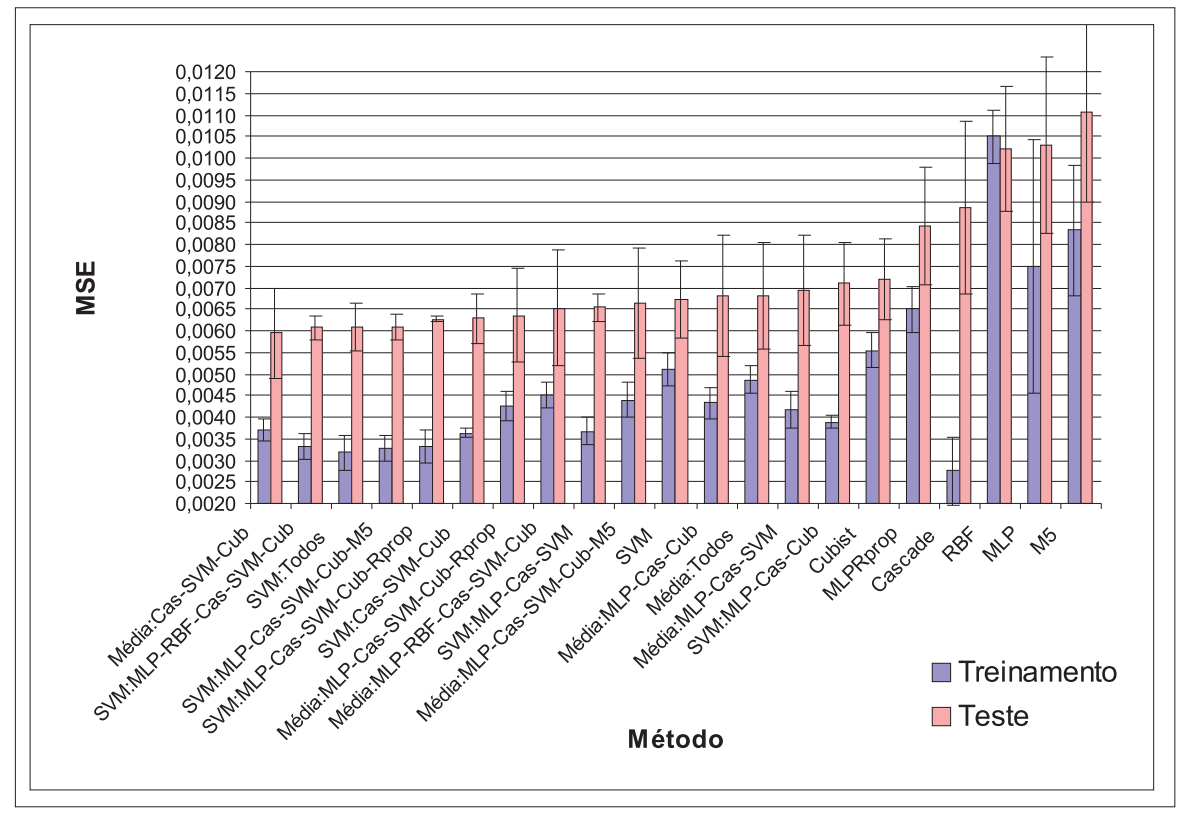

Figura 6.24: Comparação entre o MSE dos estimadores e das combinações.

O gráfico da Figura 6.25 detalha melhor essas informações, mostrando as 3 melhores combinações pela média, as 3 melhores combinações com o SVM e os 3 melhores estimadores. Os valores do MSE para os melhores estimadores, combinações e sensores podem ser observados na Tabela 6.9. Vale ressaltar que as melhores combinações não envolve- 
ram necessariamente os melhores estimadores, como é o caso do MLPRProp. O gráfico da Figura 6.26 mostra o MSE da melhor combinação e do melhor estimador individual em comparação ao obtido com a câmera. Desse gráfico observa-se que do melhor sensor para o melhor estimador e combinador houve uma redução drástica no MSE, porém do melhor estimador para o melhor combinador a redução do erro foi pequena. A diferença entre o MSE do melhor estimador e do melhor sensor foi de 0,04906, a diferença entre o MSE do melhor combinador e do melhor sensor foi de 0,04985 e a diferença da melhor combinação para o melhor estimador individual foi de 0,00079 . Isso mostra que a fusão de sensores com a aplicação do SVM diminuiu o erro apresentado pelo melhor sensor em 87,93\% e a aplicação da combinação diminuiu esse erro em 89,35\%, o que representa uma redução de 11,74\% em relação ao erro do SVM. Embora 11,74\% possa parecer pouco se comparado aos $87,93 \%$ de redução obtido com o SVM, deve ser observado que, cada vez que o erro diminui por causa da utilização de um método, uma nova redução se torna mais difícil, mas ainda assim, essa redução pode levar a ganhos importantes na estimativa de distâncias.

\begin{tabular}{|l|c|c|}
\hline \multirow{2}{*}{ Método } & \multicolumn{2}{c|}{ MSE } \\
\cline { 2 - 3 } & Treinamento & Teste \\
\hline \hline Média:Cas-SVM-Cub & $\mathbf{0 , 0 0 3 7 1} \pm \mathbf{0 , 0 0 0 2 6}$ & $\mathbf{0 , 0 0 5 9 4} \pm \mathbf{0 , 0 0 1 0 3}$ \\
\hline SVM:MLP-RBF-Cas-SVM-Cub & $0,00331 \pm 0,00031$ & $0,00607 \pm 0,00028$ \\
\hline SVM:Todos & $0,00318 \pm 0,00041$ & $0,00608 \pm 0,00055$ \\
\hline SVM:MLP-Cas-SVM-Cub-M5 & $0,00328 \pm 0,00031$ & $0,00610 \pm 0,00029$ \\
\hline Média:MLP-Cas-SVM-Cub-Rprop & $0,00426 \pm 0,00035$ & $0,00636 \pm 0,00109$ \\
\hline Média:MLP-RBF-Cas-SVM-Cub & $0,00451 \pm 0,00029$ & $0,00653 \pm 0,00134$ \\
\hline \hline SVM & $\mathbf{0 , 0 0 5 1 2} \pm \mathbf{0 , 0 0 0 3 8}$ & $\mathbf{0 , 0 0 6 7 3} \pm \mathbf{0 , 0 0 0 8 9}$ \\
\hline Cubist & $0,00554 \pm 0,00041$ & $0,00719 \pm 0,00094$ \\
\hline MLPRprop & $0,00650 \pm 0,00054$ & $0,00841 \pm 0,00136$ \\
\hline \hline Câmera & $\mathbf{0 , 0 7 9 4 7} \pm \mathbf{0 , 0 0 6 7 6}$ & $\mathbf{0 , 0 5 5 7 9} \pm \mathbf{0 , 0 2 0 2 1}$ \\
\hline
\end{tabular}

Tabela 6.9: MSE dos melhores sensor, estimadores e combinadores. 


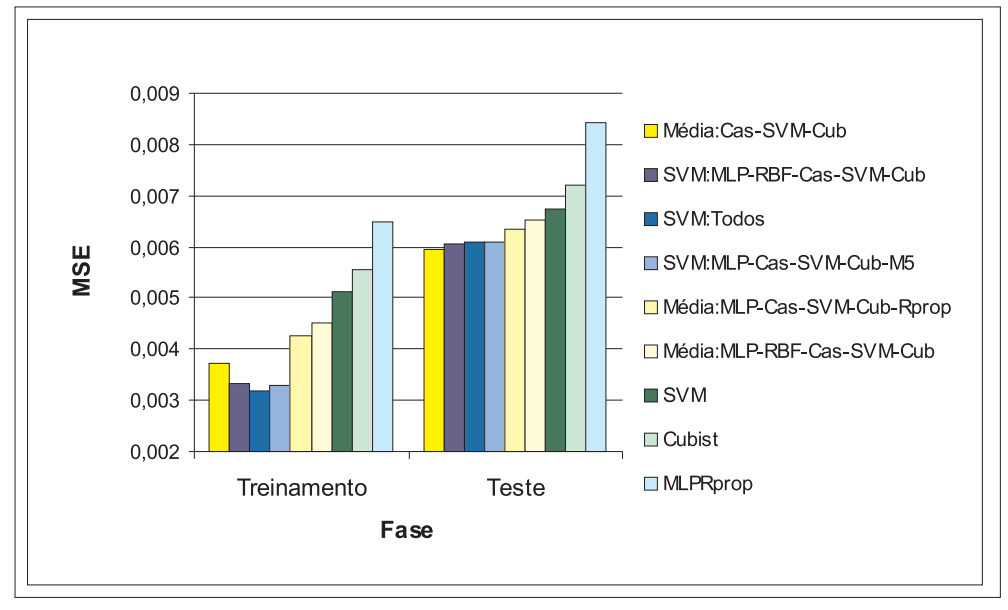

Figura 6.25: Comparação entre o MSE dos melhores estimadores e combinações.

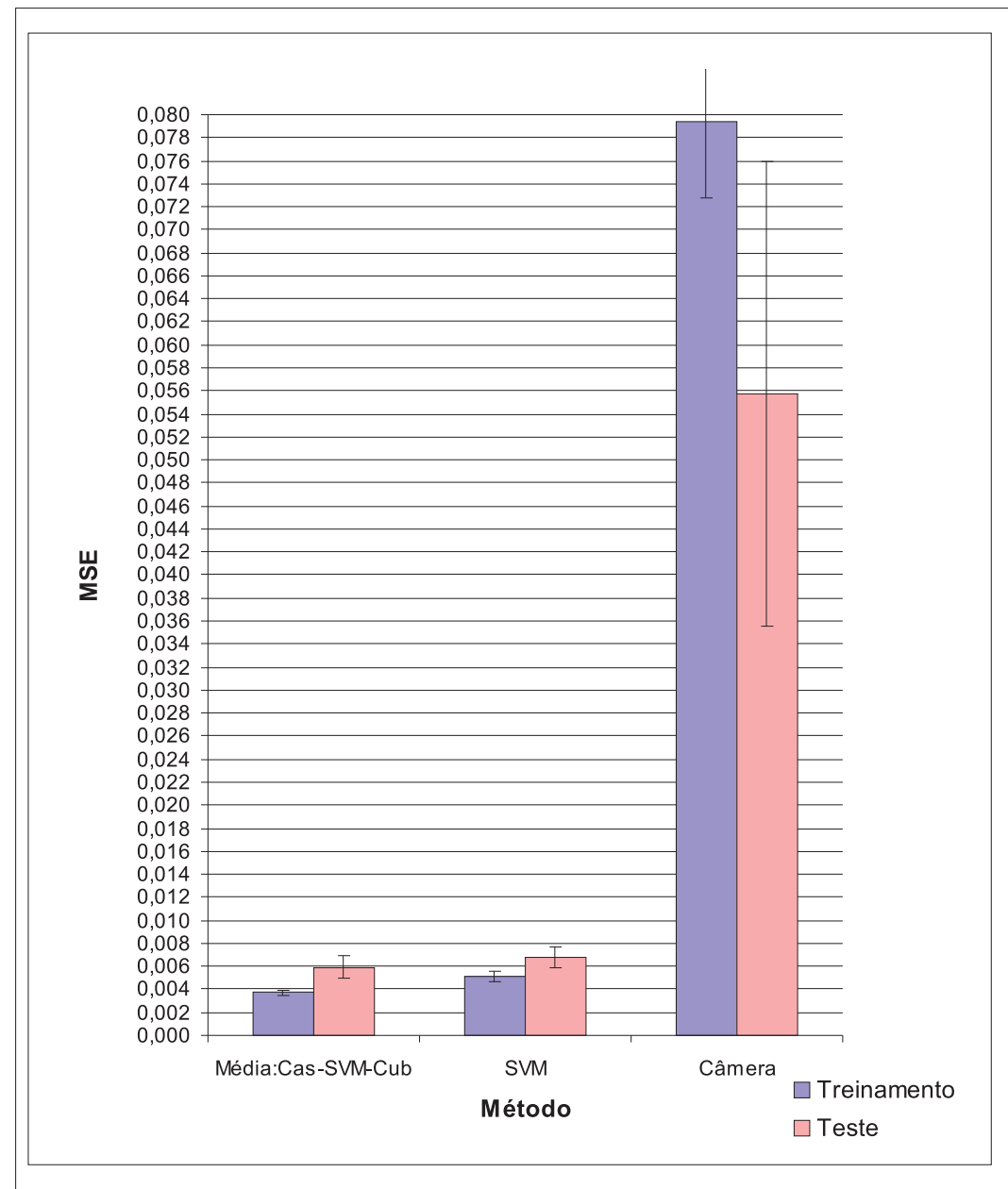

Figura 6.26: Comparação entre o MSE do melhor sensor, do melhor estimador e da melhor combinação. 
A grande redução no erro com relação aos sensores, observada com a aplicação dos métodos, é claramente significativa. Porém, algumas questões ainda permanecem. É possível afirmar o mesmo quanto a redução do erro obtida com os combinadores, em relação aos estimadores? E quanto aos diversos estimadores? O melhor estimador é significativamente melhor do que os demais? Assim, para comparar o desempenho dos diversos estimadores e combinadores, foi aplicado um teste estatístico, comparando-se a diferença entre os erros dos métodos. O teste aplicado foi o t para dados emparelhados (Johnson, 2000; Morettin, 2000), testando-se a diferença de duas médias (MSE). Esse teste foi aplicado aos seguintes pares de métodos/sensores, com um nível de significância $\alpha=5 \%$ :

- Câmera e SVM;

- Câmera e Média:Cas-SVM-Cub;

- SVM e Média:Cas-SVM-Cub;

- Cubist e SVM (dois melhores estimadores);

- SVM:MLP-RBF-Cas-SVM-Cub e Média:Cas-SVM-Cub (dois melhores combinadores).

Para cada caso estabeleceu-se as hipóteses $\mathrm{H}_{0}$ e $\mathrm{H}_{1}$ como segue:

$$
\left\{\begin{array}{l}
H_{0}: M S E_{1}-M S E_{2}=0 \\
H_{1}: M S E_{1}-M S E_{2} \neq 0
\end{array}\right.
$$

Neste caso $M S E_{1}$ e $M S E_{2}$ são as médias dos erros cometidos pelos métodos que estão sendo comparados. A Tabela 6.10 mostra o valor obtido para a estatística t nos vários casos. Com $\alpha=5 \%$ e $\phi=236$ (graus de liberdade), $\mathrm{t}_{5 \%}=1,645(\phi=\infty)$ (Johnson, 2000).

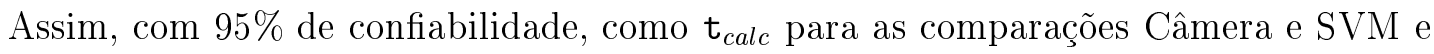
Câmera e Média:Cas-SVM-Cub são ambas maiores do que $t_{5 \%}$, rejeita-se $H_{0}$, aceitandose a hipótese alternativa $H_{1}$ de que $M S E_{1} \neq M S E_{2}$. Com isso, pode-se concluir que a redução do erro, em relação à câmera, com a aplicação dos estimadores e combinadores 


\begin{tabular}{|l|c|}
\hline Métodos & $\mathrm{t}_{\text {calc }}$ \\
\hline \hline Câmera e SVM & 3,026037912 \\
\hline Câmera e Média:Cas-SVM-Cub & 3,050851754 \\
\hline SVM e Média:Cas-SVM-Cub & 1,563190939 \\
\hline Cubist e SVM & 0,545185048 \\
\hline SVM:MLP-RBF-Cas-SVM-Cub e Média:Cas-SVM-Cub & 0,449740166 \\
\hline
\end{tabular}

Tabela 6.10: Valor de $t_{\text {calc }}$ para o teste das várias comparações.

(SVM e Média:Cas-SVM-Cub) foi realmente significativa, o que já era esperado em função do grande percentual de redução destacado anteriormente.

Por outro lado, com a mesma confiabilidade, pode-se notar que a diferença no erro entre os diversos métodos investigados não foram significativas, ao menos quando são considerados os melhores estimadores e combinadores. Isso pode ser concluído uma vez que $\mathrm{t}_{\text {calc }}$ para as comparações SVM e Média:Cas-SVM-Cub (1,563190939), Cubist e SVM (0,545185048) e SVM:MLP-RBF-Cas-SVM-Cub e Média:Cas-SVM-Cub (0,449740166) foi menor do que $\mathrm{t}_{5 \%}$, o que faz com que a hipótese $H_{0}$ seja aceita, ou seja, $M S E_{1}=M S E_{2}$.

Se entretanto for considerado um nível de significância de $10 \%$, tem-se $t_{5 \%}=1,282$. Neste caso, $\mathrm{t}_{\text {calc }}$ para SVM e Média:Cas-SVM-Cub (1,563190939) é maior do que $\mathrm{t}_{5 \%}$, e $H_{0}$ é rejeitada. Então, com $90 \%$ de confiabilidade, a aplicação da combinação (no melhor caso), reduz significativamente o erro em relação ao melhor estimador.

\subsubsection{Avaliação dos Resultados}

Uma análise mais detalhada do comportamento dos algoritmos pode ser realizada observando-se os erros e seus desvios-padrão em alguns dos ângulos medidos. Essa avaliação permite analisar a melhora propiciada pelos diversos métodos em termos de precisão e acurácia das medidas. Para essa análise estão sendo considerados, individualmente, três dos ângulos em que foram coletados os dados (o menor ângulo, 22,5 $5^{\circ}$ o ângulo médio, $45^{\circ}$, e o maior ângulo, $90^{\circ}$ ). Além disso, o conjunto de todos os ângulos também está sendo mostrado para uma comparação dos erros em cada ângulo com o erro geral. 
Os gráficos das Figuras 6.27, 6.28, 6.29 6.30 mostram o erro (MSE) e o desvio padrão do erro apresentado pelos do erro apresentado pelos sensores/métodos empregados. Nesses gráficos, as informações estão ordenadas pelo MSE de todos os ângulos. As barras representam o MSE e as linhas sobre as barras representam o desvio-padrão do erro, que indica o quanto o erro $\left((x-y)^{2}\right)$ variou. O MSE representa a precisão das medições e o desvio padrão a sua acurácia Para se conhecer melhor o comportamento dos sensores, o erro cometido por cada um é mostrado no gráfico da Figura 6.27. A partir desse gráfico, vê-se que a câmera foi o sensor que teve o comportamento mais uniforme para os diversos ângulos, apresentando sempre melhor precisão e maior estabilidade. A câmera apresentou melhores resultados mesmo no caso em que o sonar obtém sua melhor performance (sonar 4 a $\left.90^{\circ}\right)$.

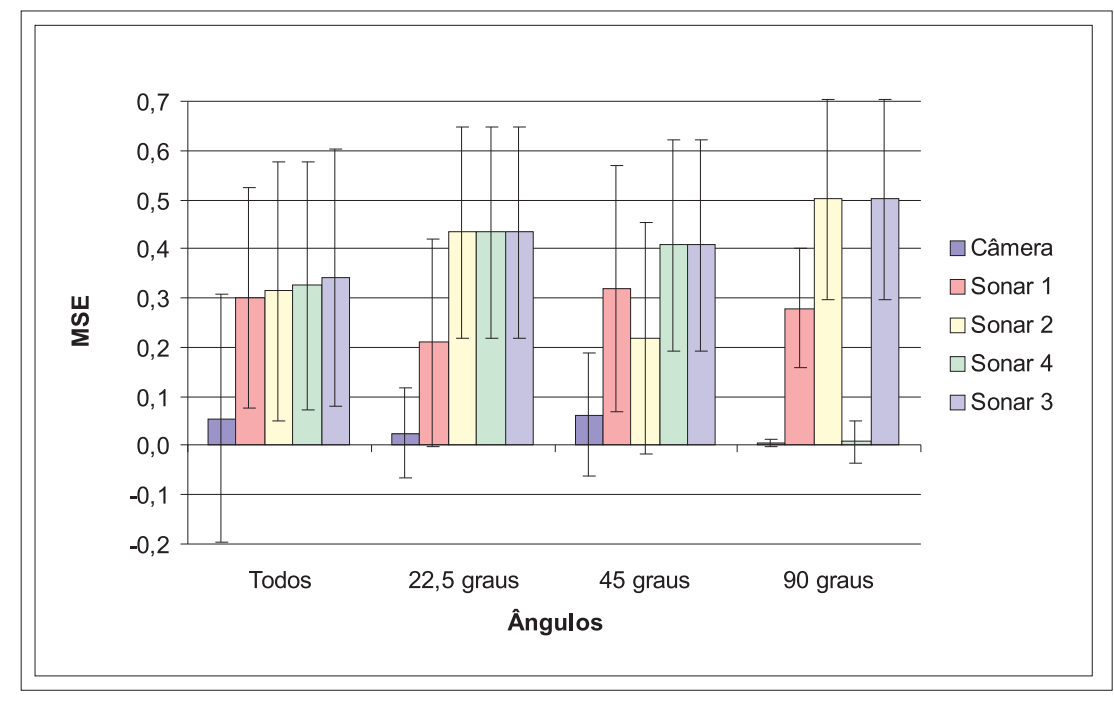

Figura 6.27: Comparação dos erros dos sensores.

O comportamento dos diversos estimadores pode ser observado no gráfico da Figura 6.28. Por esse gráfico, pode-se observar que na maioria dos casos, exceto no ângulo de $45^{\circ}$, o SVM apresentou menor erro, ou seja maior precisão. No ângulo de $45^{\circ}$, o Cubist e MLPRprop tiveram a maior precisão. Isto ilustra as diferentes habilidades de cada estimador, que fazem com que, para cada situação, um estimador diferente seja o mais apropriado. Quanto à questão da estabilidade das medidas, também observa-se uma grande variação no comportamento dos estimadores. No cálculo com todos os ângulos, os estimadores mais estáveis foram o Cubist, o MLPRprop e o SVM. Já a 90², por exemplo, 
o MLP e o SVM foram os mais estáveis. Apesar da grande variação do comportamento dos estimadores nos diferentes ângulos, nota-se uma uniformidade no comportamento dos diversos estimadores dentro de um mesmo ângulo, ou seja, para um mesmo ângulo, os erros (e os desvios) permanecem dentro de uma faixa de valores que, de um ângulo para outro, pode variar bastante. A grande variação no comportamento dos estimadores para os diversos ângulos sugere que a precisão e acurácia podem ainda ser melhoradas com a combinação do estimadores, como proposto neste trabalho.

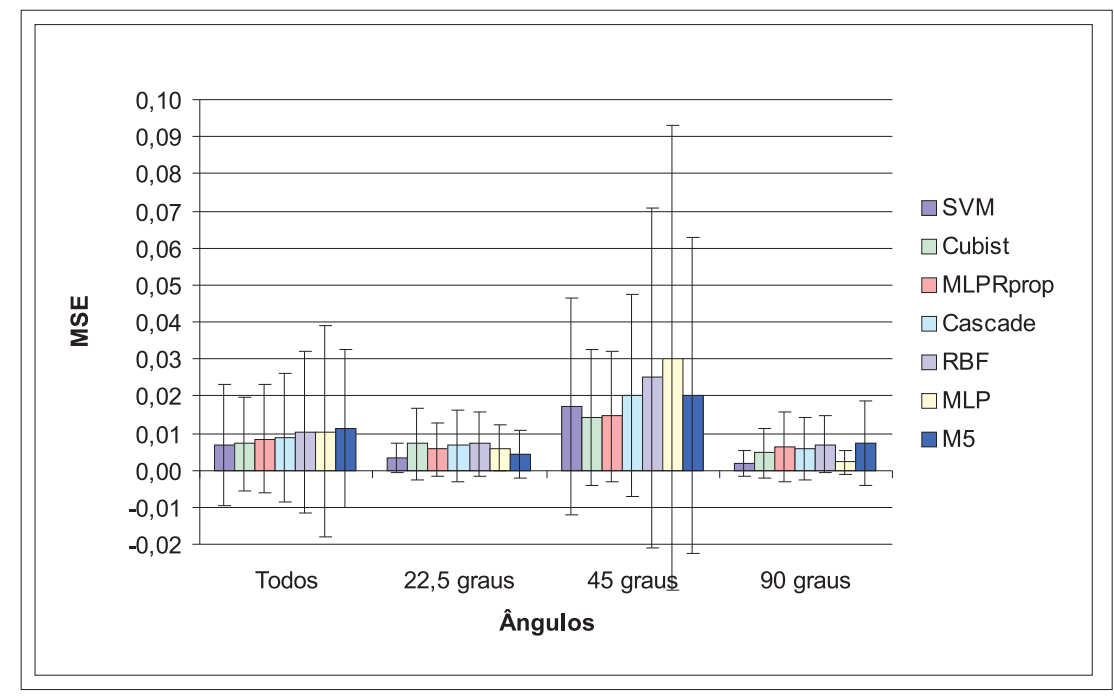

Figura 6.28: Comparação dos erros dos estimadores.

Para os combinadores, como ilustrado pelo gráfico da Figura 6.29, a uniformidade dentro de um mesmo ângulo é ainda maior. Apesar disso, nos diversos ângulos também pode ser observada uma variação do comportamento dos diversos combinadores. Por exemplo, o combinador Média:Cas-SVM-Cub, que foi o mais preciso e estável no cálculo para todos os ângulos, teve um dos piores desempenhos se considerado só o ângulo de $90^{\circ}$.

Para uma comparação entre as precisões dos sensores, estimadores e combinadores, foram selecionados os dois melhores sensores (câmera e sonar 4 - melhor à $90^{\circ}$ ), os dois melhores estimadores e as duas melhores combinações (uma pela média e uma com o SVM). Vale ressaltar que melhor aqui se refere ao método que apresentou menor MSE na fase de testes. A Tabela 6.11 e o gráfico da Figura 6.30 mostram o erro e o desvio padrão para esses casos. Por esse gráfico pode-se observar que, em todos os casos, todos 


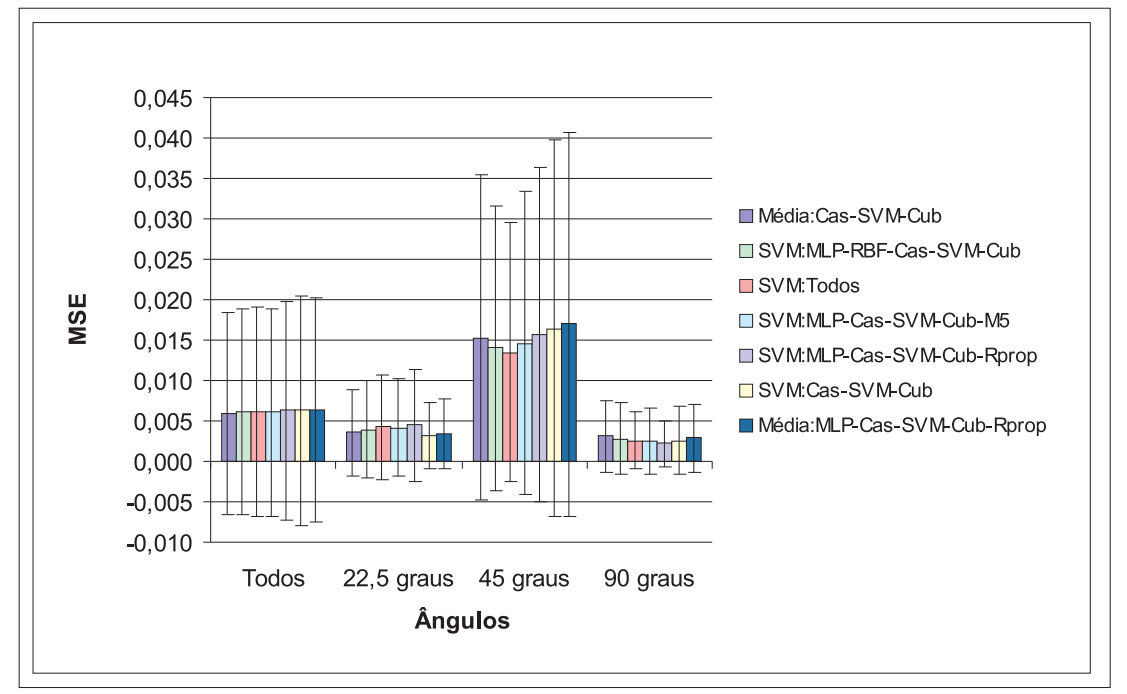

Figura 6.29: Comparação dos erros dos combinadores.

os métodos empregados tiveram um sensores, tanto no que se refere à precisão quanto no que se refere à acurácia. A maior precisão pode ser observada pelo tamanho das barras no gráfico (MSE), que é sempre menor nos métodos do que nos sensores. A acurácia das medidas é representada pelas linhas sobre as barras (desvios dos erros), também menores para os métodos do que para os sensores. No caso do sonar 4, devido ao erro ser muito grande, o desvio padrão nem aparece no gráfico, pois as informações estão representadas numa escala que permite uma melhor visualização dos erros dos métodos, bem menores do que os do sonar 4 e da câmera, em alguns casos. Pode-se observar ainda que, mesmo em ângulos em que nenhum dos sensores está apto a fornecer medidas adequadas, os métodos empregados foram capazes de fornecê-las.

Um fato que merece nota é que, comparando-se os diversos gráficos, vê-se que o comportamento dos diversos métodos seguiu o comportamento da câmera, o que sugere que o sensor que mais contribuiu no processo de fusão foi a câmera. Isso era de se esperar, uma vez que a câmera foi o sensor que apresentou melhor desempenho.

Comparando-se os estimadores com os combinadores, vê-se que, no caso geral (todos os ângulos), os combinadores melhoraram ainda mais os resultados, como já destacado na Seção 6.3.3. Porém, se forem observados cada ângulo separadamente, nota-se que, em 
alguns casos, os estimadores tiveram um erro menor do que os combinadores. Assim, não se pode estabelecer, com rigor, que um método é melhor que o outro, ou que a combinação dos estimadores sempre melhora ainda mais a qualidade das medidas em relação aos estimadores, se considerados individualmente, quando os métodos são aplicados ao problema em questão. O que vê-se claramente é que a aplicação da fusão de sensores, utilizando as técnicas de inteligência artificial propostas, melhora a qualidade das medidas dos sensores.

\begin{tabular}{|l|c|c|c|c|}
\hline \multirow{2}{*}{ Método } & \multicolumn{3}{c|}{ MSE \pm desvio padrão } \\
\cline { 2 - 5 } & Todos & $\mathbf{2 2 , \mathbf { 5 } ^ { \circ }}$ & $\mathbf{4 5}^{\circ}$ & $\mathbf{9 0}^{\circ}$ \\
\hline \hline Média:Cas-SVM-Cub & $0,00594 \pm 0,01257$ & $0,00361 \pm 0,00533$ & $0,01531 \pm 0,02014$ & $0,00308 \pm 0,00442$ \\
\hline SVM:MLP-RBF-Cas-SVM-Cub & $0,00607 \pm 0,01270$ & $0,00389 \pm 0,00602$ & $0,01399 \pm 0,01771$ & $0,00281 \pm 0,00445$ \\
\hline SVM & $0,00673 \pm 0,01655$ & $0,00329 \pm 0,00415$ & $0,01735 \pm 0,02920$ & $0,00170 \pm 0,00345$ \\
\hline Cubist & $0,00719 \pm 0,01271$ & $0,00715 \pm 0,00962$ & $0,01411 \pm 0,01845$ & $0,00460 \pm 0,00661$ \\
\hline Câmera & $0,05579 \pm 0,25280$ & $0,02535 \pm 0,09175$ & $0,06299 \pm 0,12612$ & $0,00606 \pm 0,00784$ \\
\hline Sonar 4 & $0,32504 \pm 0,25059$ & $0,43303 \pm 0,21602$ & $0,40768 \pm 0,21575$ & $0,00749 \pm 0,04369$ \\
\hline
\end{tabular}

Tabela 6.11: Comparação do MSE e desvio padrão do erro entre os melhores sensores, estimadores e combinadores.

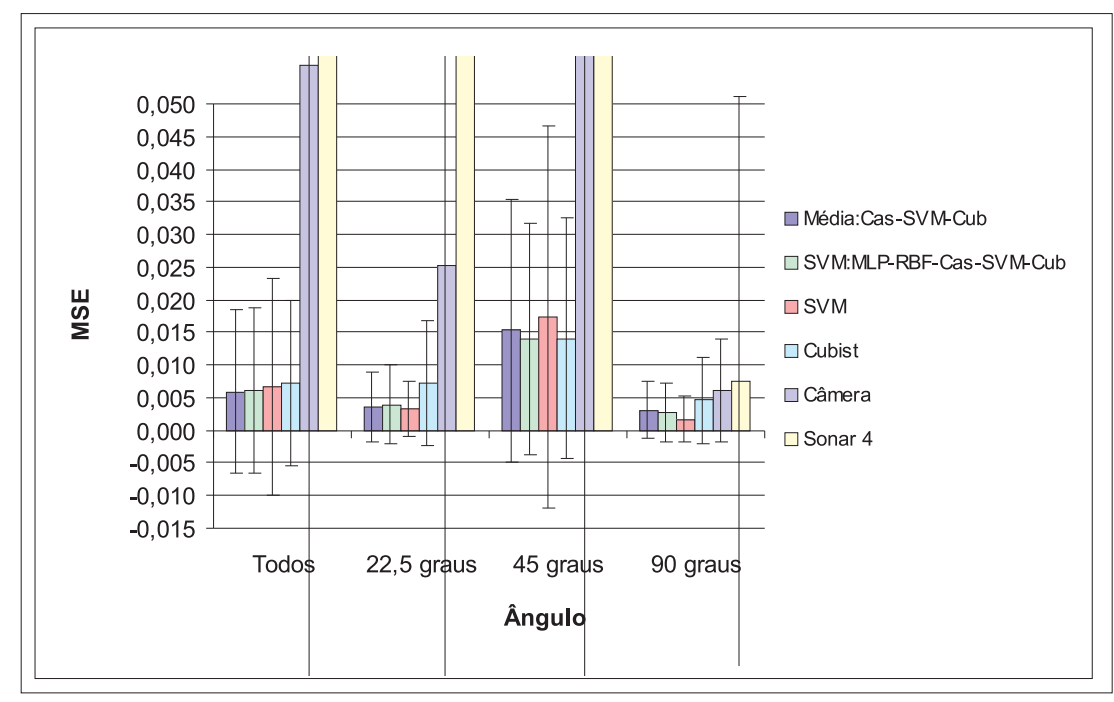

Figura 6.30: Comparação entre o MSE e o desvio padrão dos melhores sensores, estimadores e combinadores. 
Pela análise dos gráficos anteriores, fica destacado que a aplicação dos diversos métodos reduz o erro com relação aos sensores. Mas também é importante dimensionar essa redução. Para isso, algumas tabelas e gráficos foram traçados, considerando os dois melhores estimadores e combinadores. A Tabela 6.12 e o gráfico da Figura 6.31 mostram a porcentagem de redução dos erros obtidas com os melhores métodos em relação à câmera, ou seja, o quanto esses métodos reduziram o erro das medidas feitas pela câmera. A Tabela 6.13 e o gráfico da Figura Figura 6.32 mostram a mesma informação com relação ao sonar 4 medidas dos sonares, que foram obtidas a $90^{\circ}$ ).

\begin{tabular}{|l|c|c|c|c|}
\hline \multirow{2}{*}{\multicolumn{1}{|c|}{ Método }} & \multicolumn{4}{|c|}{ Redução do Erro (\%) } \\
\cline { 2 - 5 } & Todos & $\mathbf{2 2 , 5}^{\mathbf{}}$ & $\mathbf{4 5}^{\boldsymbol{o}}$ & $\mathbf{9 0}^{\boldsymbol{}}$ \\
\hline \hline Média:Cas-SVM-Cub & 89,35 & 85,75 & 75,70 & 49,11 \\
\hline SVM:MLP-RBF-Cas-SVM-Cub & 89,12 & 84,66 & 77,80 & 53,69 \\
\hline SVM & 87,93 & 87,00 & 72,46 & 72,01 \\
\hline Cubist & 87,11 & 71,79 & 77,60 & 24,03 \\
\hline
\end{tabular}

Tabela 6.12: Redução do erro com relação à câmera.

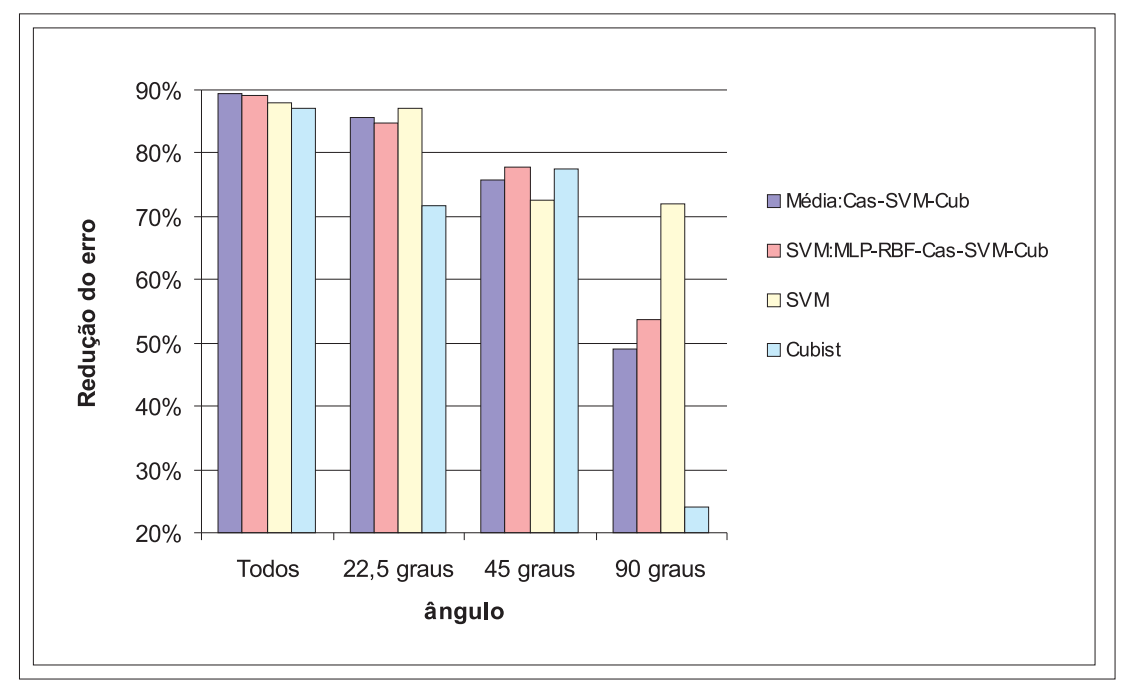

Figura 6.31: Redução do erro com relação à câmera.

Com relação à câmera, em todos os ângulos mostrados obteve-se, com pelo menos um método, uma redução do erro superior a 70\%. Em alguns casos essa redução chegou a um valor próximo de $90 \%$. No pior caso ilustrado, obteve-se uma redução de 24,03\% com o algoritmo Cubist no ângulo de $90^{\circ}$. Como já descrito na Seção 6.3.3, a redução alcançada 
pelo melhor método, se comparados todos os ângulos (rótulo Todos no gráfico), foi de $89,35 \%$.

\begin{tabular}{|l|c|c|c|c|}
\hline \multirow{2}{*}{\multicolumn{1}{|c|}{ Método }} & \multicolumn{4}{|c|}{ Redução do Erro (\%) } \\
\cline { 2 - 5 } & Todos & $\mathbf{2 2 , \mathbf { 5 } ^ { \circ }}$ & $\mathbf{4 5}^{\circ}$ & $\mathbf{9 0}^{\boldsymbol{}}$ \\
\hline \hline Média:Cas-SVM-Cub & 98,17 & 99,17 & 96,24 & 58,80 \\
\hline SVM:MLP-RBF-Cas-SVM-Cub & 98,13 & 99,10 & 96,57 & 62,51 \\
\hline SVM & 97,93 & 99,24 & 95,74 & 77,34 \\
\hline Cubist & 97,79 & 98,35 & 96,54 & 38,50 \\
\hline
\end{tabular}

Tabela 6.13: Redução do erro com relação ao sonar 4 .

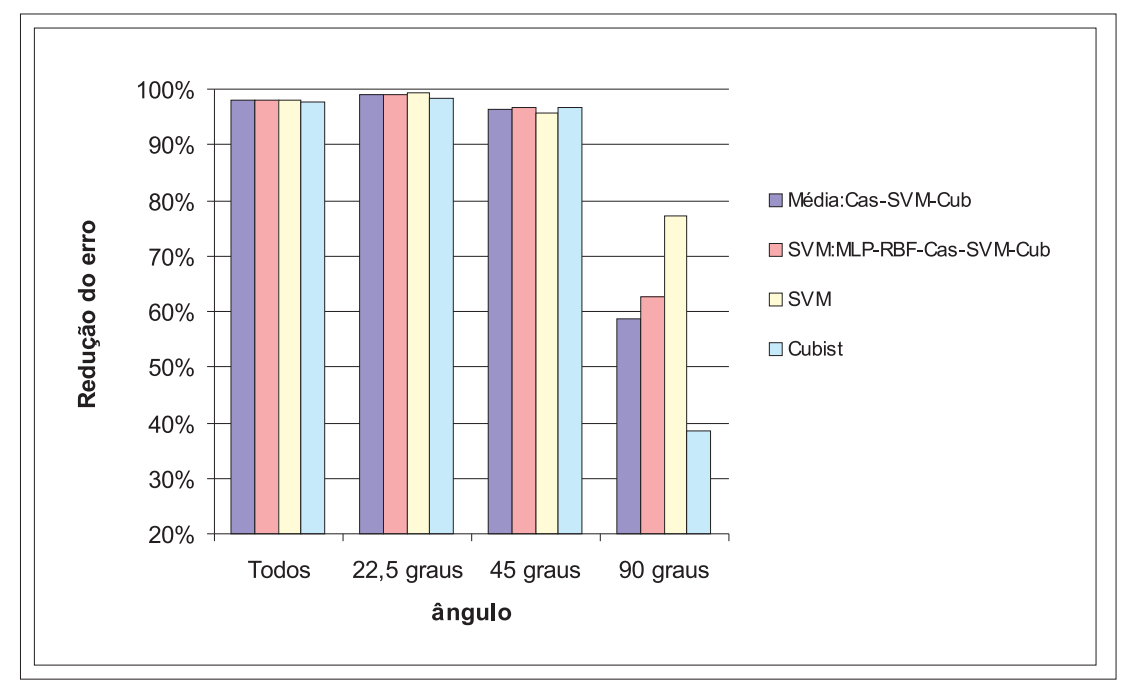

Figura 6.32: Redução do erro com relação ao sonar 4.

Com relação ao sonar 4, observa-se que a redução no erro foi ainda maior, no geral, ficando entre $95 \%$ e $100 \%$. Mesmo no ângulo de $90^{\circ}$, em que esse sensor apresenta o melhor desempenho possível, as reduções no erro foram significativas, chegando a uma redução de mais de $70 \%$ no caso do SVM.

Outro aspecto a se ressaltar é que as menores reduções nos erros observadas a $90^{\circ}$ observadas nos gráficos das Figuras 6.13 e 6.12 se devem ao fato de que as medidas dos sensores ilustrados nesses gráficos já são mais precisas nesse ângulo do que nos demais.

A grande redução no erro com relação ao sonar 4 observada nos ângulos de $22,45^{\circ} \mathrm{e}$ $45^{\circ}$ se explica pelo fato de que esse sonar praticamente não "alcança"o alvo, cometendo 
os maiores erros que o sonar pode cometer (como pode ser observado no gráfico da Figura 6.27). Assim, com grandes erros do sonar, pode-se ainda obter uma grande redução no erro, mesmo que o erro obtido com a fusão seja grande. O que se está querendo destacar com isso é que as reduções mostradas para esse ângulo não dizem respeito a melhoras nas medidas do sonar em questão, e sim a correções na sua capacidade de obter medidas nesse ângulo. Já com relação à câmera, as reduções mostradas se referem aos erros realmente cometidos pelo sensor, e não simplesmente à má condição de leitura causada pelo posicionamento do sensor (observar o gráfico da Figura 6.27). 


\subsection{Base B14}

Para a base B14, foram realizados os mesmos experimentos previamente realizados com a base Pioneer1. Assim, nesta seção serão descritos apenas os resultados obtidos, e não todo o processo de treinamento dos diversos algoritmos, uma vez que esse processo é semelhante ao já descrito na Seção 6.2 .

\subsubsection{Estimadores}

Os mesmos algoritmos empregados com a base Pioneer1, exceto as redes Cascade Correlation, foram utilizados para a fusão dos dados da base B14. A seguir, se encontram descritos os resultados obtidos com esses algoritmos. Vale observar que o treinamento das redes Cascade Correlation e MLP treinada com o algoritmo de aprendizado Quickprop não puderam ser concluídos até a impressão deste trabalho devido à grande lentidão demonstrada no seu treinamento. O mesmo ocorreu com as redes MLP com 100 e 150 neurônios intermediários treinadas com o algoritmo Backpropagation padrão.

\section{MLP}

O gráfico da Figura 6.33 mostra o MSE para as diversas topologias treinadas com a variação de $\eta$. Nesse caso, cada grupo de barras representa os erros obtidos com diferentes taxas de aprendizado para uma topologia. Por esse gráfico, observa-se que a rede que teve o melhor desempenho para cada topologia foi treinada com uma taxa de aprendizado diferente, como o ocorrido com a base Pioneer1. A rede que apresentou melhor desempenho possuía 50 neurônios na camada intermediária (17-50-1) e foi treinada com $\eta=0,9$.

Uma observação a ser feita é que os experimentos com as topologias de 100 e 150 neurônios intermediários não puderam ser concluídos, devido a grande lentidão do treinamento das redes. Entretanto, com base em resultados parciais, pôde-se observar que o comportamento das redes com essas topologias não diferem muito do comportamento das 
redes com 50 neurônios intermediários. Assim, para o prosseguimento dos experimentos apenas as topologias mostradas no gráfico foram consideradas.

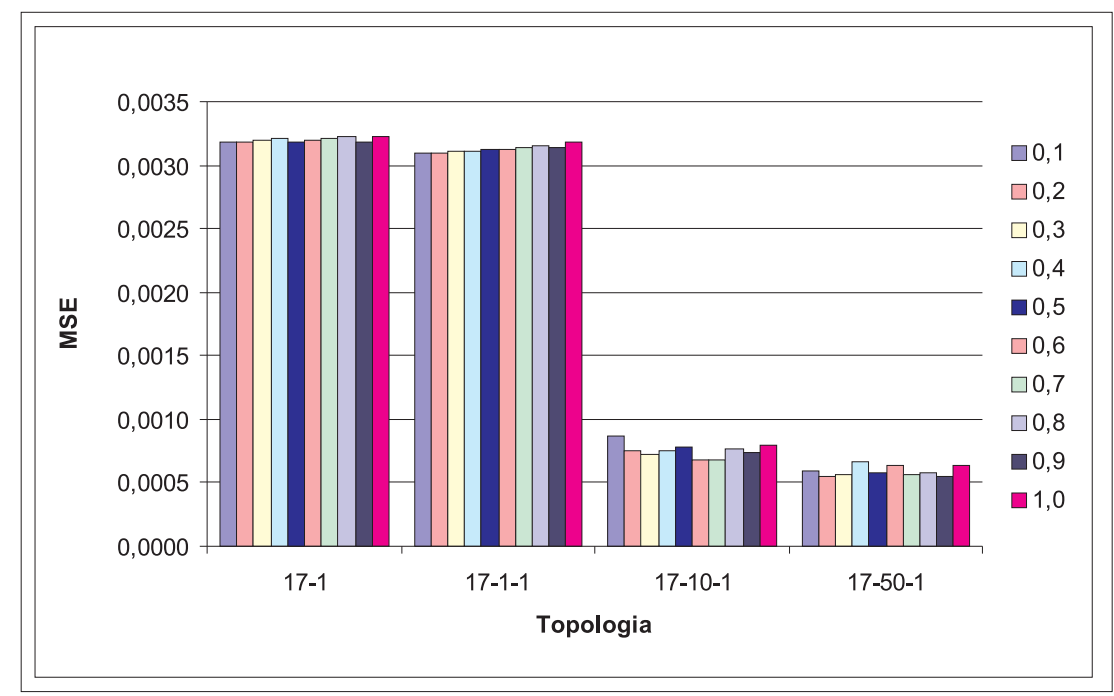

Figura 6.33: MSE para redes MLP treinadas com diferentes $\eta$ (base B14).

Os resultados podem ser melhor visualizados na Tabela 6.14 e no gráfico da Figura 6.34. A Tabela 6.14 mostra o MSE no treinamento, validação e teste da melhor rede treinada para cada topologia, bem como a taxa de aprendizado com que foi treinada essa rede. Essas mesmas informações estão representadas no gráfico da Figura 6.34. Nesse gráfico, as barras representam a média do MSE das três partições e as linhas sobre as barras representam o desvio padrão.

\begin{tabular}{|l|c|c|c|c|}
\hline Topologia & $\eta$ & Treinamento & Validação & Teste \\
\hline \hline $17-1$ & 0,5 & $0,00337 \pm 0,00006$ & $0,00322 \pm 0,00013$ & $0,00318 \pm 0,00007$ \\
\hline $17-1-1$ & 0,1 & $0,00305 \pm 0,00004$ & $0,00314 \pm 0,00010$ & $0,00309 \pm 0,00005$ \\
\hline $17-10-1$ & 0,6 & $0,00056 \pm 0,00003$ & $0,00066 \pm 0,00006$ & $0,00067 \pm 0,00003$ \\
\hline $\mathbf{1 7 - 5 0 - 1}$ & $\mathbf{0 , 9}$ & $\mathbf{0 , 0 0 0 3 3} \pm \mathbf{0 , 0 0 0 0 8}$ & $\mathbf{0 , 0 0 0 5 6} \pm \mathbf{0 , 0 0 0 0 6}$ & $\mathbf{0 , 0 0 0 5 5} \pm \mathbf{0 , 0 0 0 0 3}$ \\
\hline
\end{tabular}

Tabela 6.14: MSE da melhor rede MLP treinada para cada topologia (base B14).

Além da visualização do melhor resultado, esse gráfico permite uma comparação dos erros obtidos nas fases de treinamento, validação e teste, e também o quão parecido foi o treinamento das três partições (desvio padrão).

O gráfico da Figura 6.35 mostra o MSE obtido no treinamento com o algoritmo Rprop. 


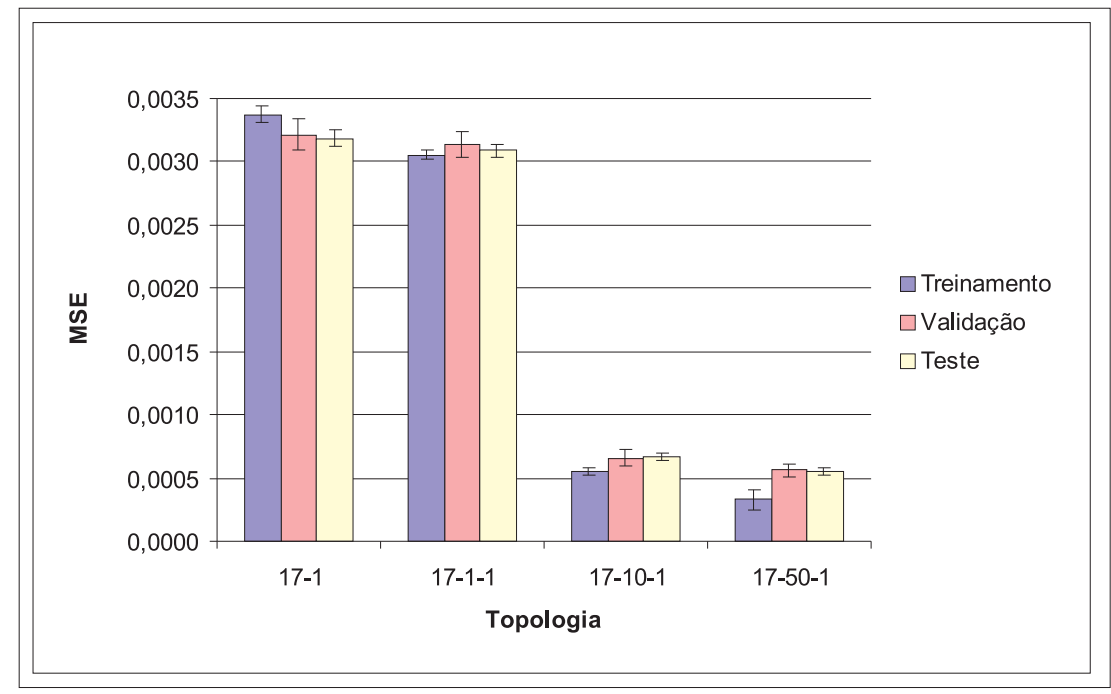

Figura 6.34: MSE da melhor rede MLP treinada para cada topologia (base B14).

O treinamento esse algoritmo produziu um erro médio de 0,00036, a validação de 0,00067 e o teste de 0,00066. As barras nos gráficos representam a média do MSE para as três partições e as linhas sobre as barras representam o desvio padrão.

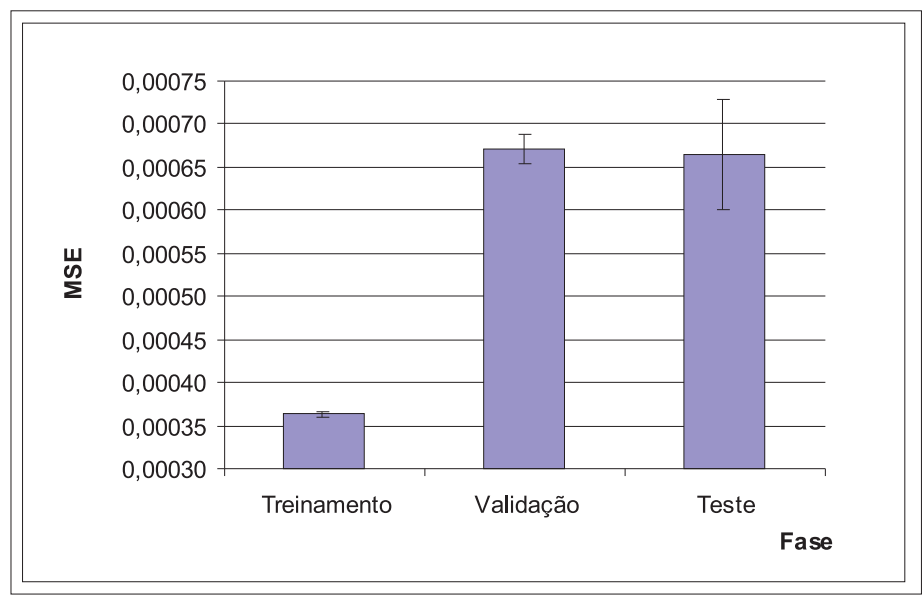

Figura 6.35: MSE da rede MLP treinada com o algoritmo Rprop (base B14).

\section{RBF}

A Tabela 6.15 mostra os valores de cada parâmetro que forneceu o melhor resultado em cada partição com que foi realizado o treinamento. 


\begin{tabular}{|c|c|c|c|}
\hline Partição & $\eta_{1}$ (centros) & $\eta_{2}$ (bias) & $\eta_{3}$ (pesos) \\
\hline \hline 1 & 0,000005 & 0,000005 & 0,00001 \\
\hline 2 & 0,00009 & 0,000005 & 0,0007 \\
\hline 3 & 0,00005 & 0,000005 & 0,000005 \\
\hline
\end{tabular}

Tabela 6.15: Parâmetros do treinamento das redes RBF (base B14).

O gráfico da Figura 6.36 mostra o MSE obtido no treinamento das redes RBF. O treinamento produziu um erro médio de 0,00383 e o teste de 0,00401. As barras no gráfico representam a média do MSE para as três partições e as linhas sobre as barras representam o desvio padrão.

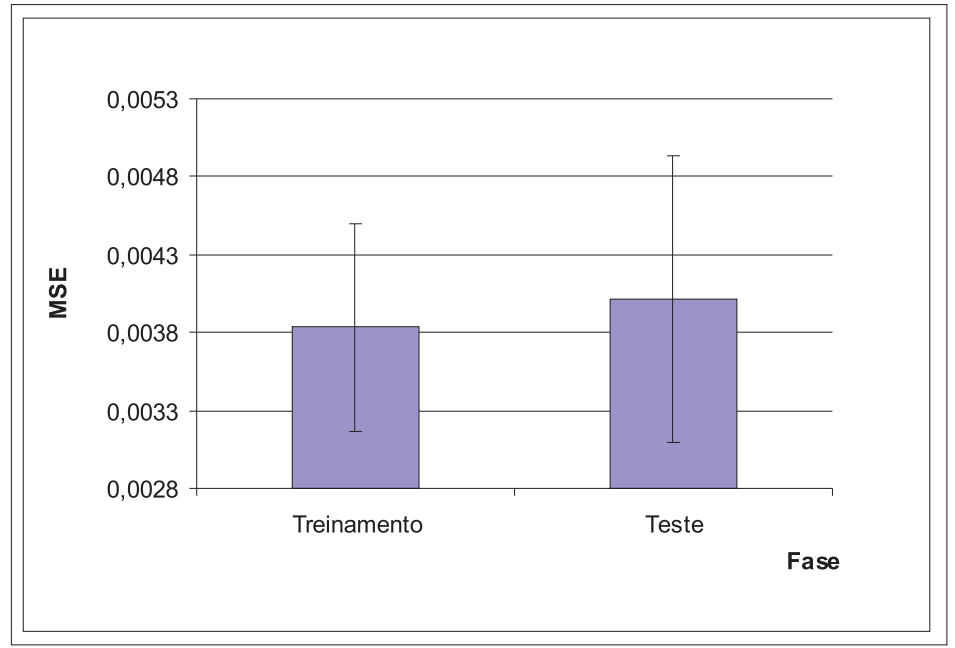

Figura 6.36: MSE das redes RBF (base B14).

\section{SVM}

Para o treinamento com o algoritmo SVM, foi empregado somente o kernel gaussiano, pois esse kernel apresentou melhor desempenho com a base Pioneer1. Experimentos com os demais kernels não foram realizados devido ao reduzido tempo para finalização dos experimentos. Com a base B14, não foi realizada a fase de determinação dos parâmetros eps e c, como para a base Pioneer1. Neste caso, os melhores valores obtidos com a base Pioneer1 foram utilizados. Alguns poucos testes com outros valores foram feitos, causando sempre uma piora nos resultados. 
No gráfico da Figura 6.37 pode-se observar os resultados obtidos com diferentes valores para o parâmetro st. O valor desse parâmetro que forneceu o melhor resultado foi 1.

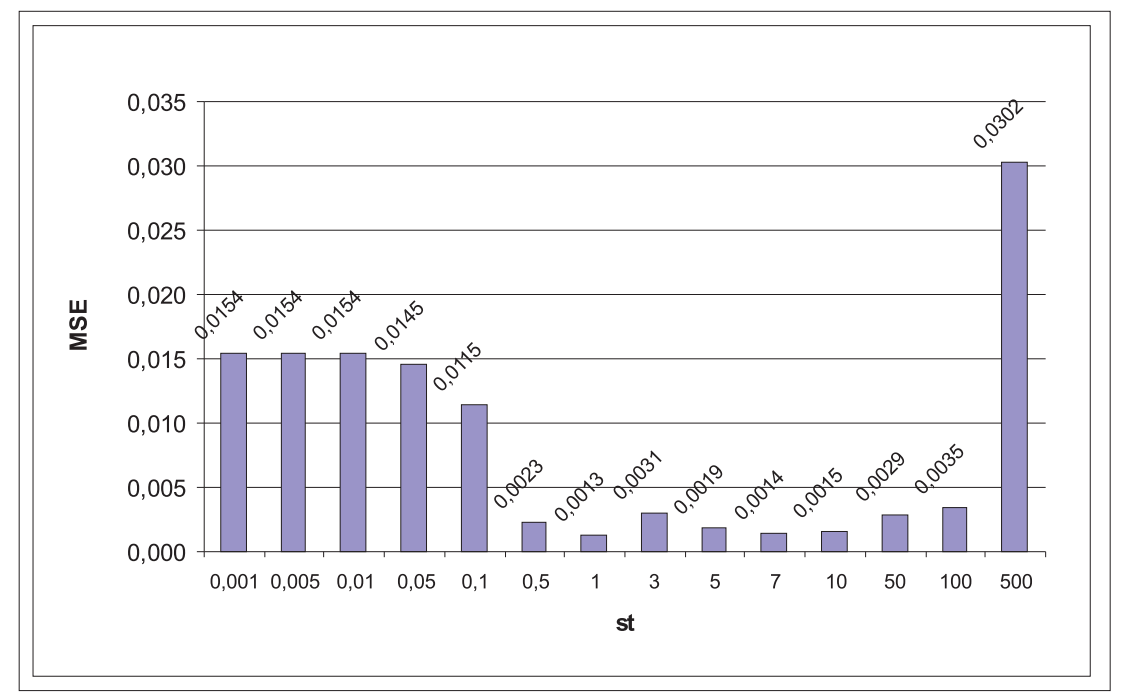

Figura 6.37: MSE para diferentes valores de st (base B14).

O gráfico da Figura 6.38 mostra o MSE obtido no treinamento e teste do melhor caso. O treinamento produziu um erro médio de 0,00086 e o teste de 0,00133. As barras no gráfico representam a média do MSE para as três partições e as linhas sobre as barras representam o desvio padrão.

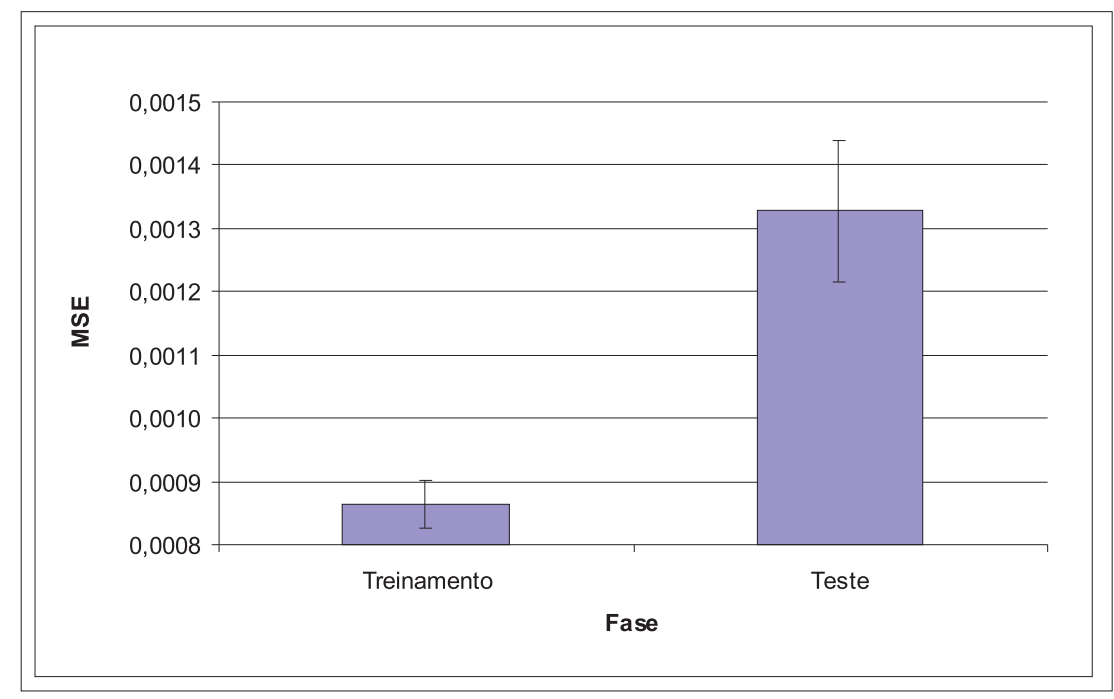

Figura 6.38: MSE do algoritmo SVM (base B14). 


\section{Cubist}

O gráfico da Figura 6.39 mostra o MSE obtido no treinamento com o algoritmo Cubist. O treinamento produziu um erro médio de 0,00024 e o teste de 0,00071. As barras no gráfico representam a média do MSE para as três partições e as linhas sobre as barras representam o desvio padrão.

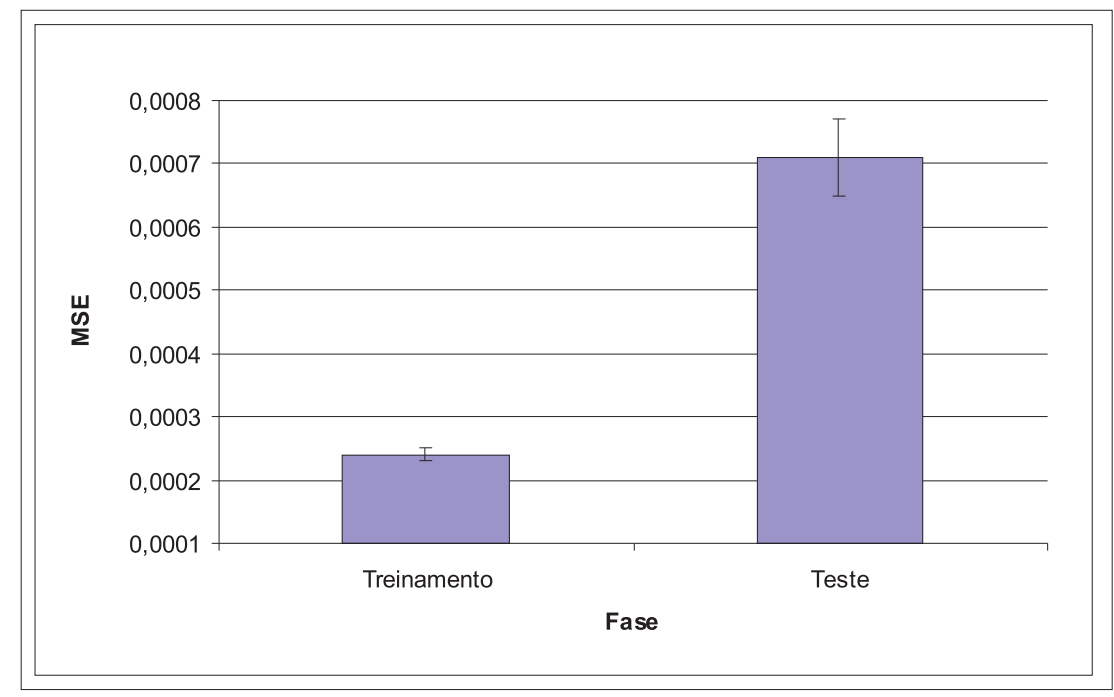

Figura 6.39: MSE do algoritmo Cubist (base B14).

M5

O gráfico da Figura 6.40 mostra o MSE obtido no treinamento com o algoritmo M5. O treinamento produziu um erro médio de 0,00058 e o teste de 0,00169. As barras no gráfico representam a média do MSE para as três partições e as linhas sobre as barras representam o desvio padrão. 


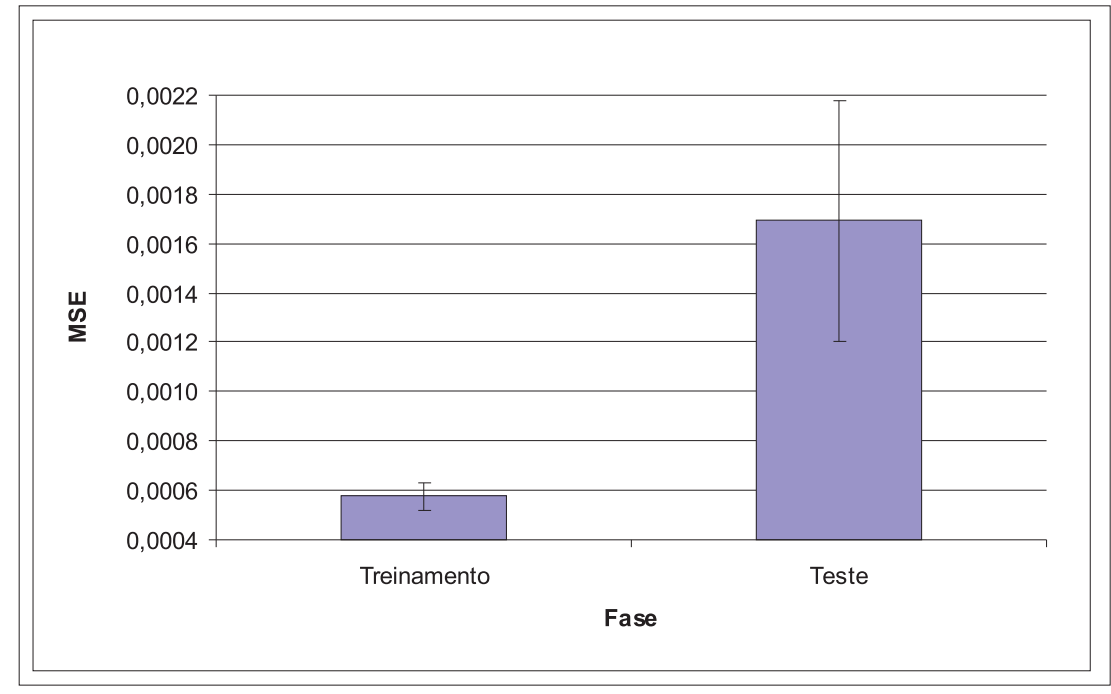

Figura 6.40: MSE do algoritmo M5 (base B14). 


\section{Comparação entre os métodos}

A Tabela 6.16 mostra um resumo dos resultados obtidos no treinamento e teste dos diversos métodos de aprendizado investigados com a base B14. Esses resultados correspondem ao melhor estimador gerado por cada algoritmo de aprendizado. Essas informações podem ser mais facilmente interpretadas através do gráfico da Figura 6.41. A partir desse gráfico pode-se observar que o melhor estimador, ou seja, aquele que apresentou menor MSE na fase de teste, foi o MLP, seguido do MLPRprop e do Cubist.

\begin{tabular}{|l|l|l|}
\hline Estimador & Treinamento & Teste \\
\hline \hline MLP & $\mathbf{0 , 0 0 0 3 3} \pm \mathbf{0 , 0 0 0 0 8}$ & $\mathbf{0 , 0 0 0 5 5} \pm \mathbf{0 , 0 0 0 0 3}$ \\
\hline MLPRprop & $0,00036 \pm 0,00003$ & $0,00066 \pm 0,00011$ \\
\hline Cubist & $0,00024 \pm 0,00001$ & $0,00071 \pm 0,00006$ \\
\hline SVM & $0,00086 \pm 0,00004$ & $0,00133 \pm 0,00011$ \\
\hline M5 & $0,00058 \pm 0,00006$ & $0,00169 \pm 0,00048$ \\
\hline RBF & $0,00383 \pm 0,00073$ & $0,00401 \pm 0,00090$ \\
\hline
\end{tabular}

Tabela 6.16: MSE para o melhor estimador gerado com cada algoritmo investigado (base B14).

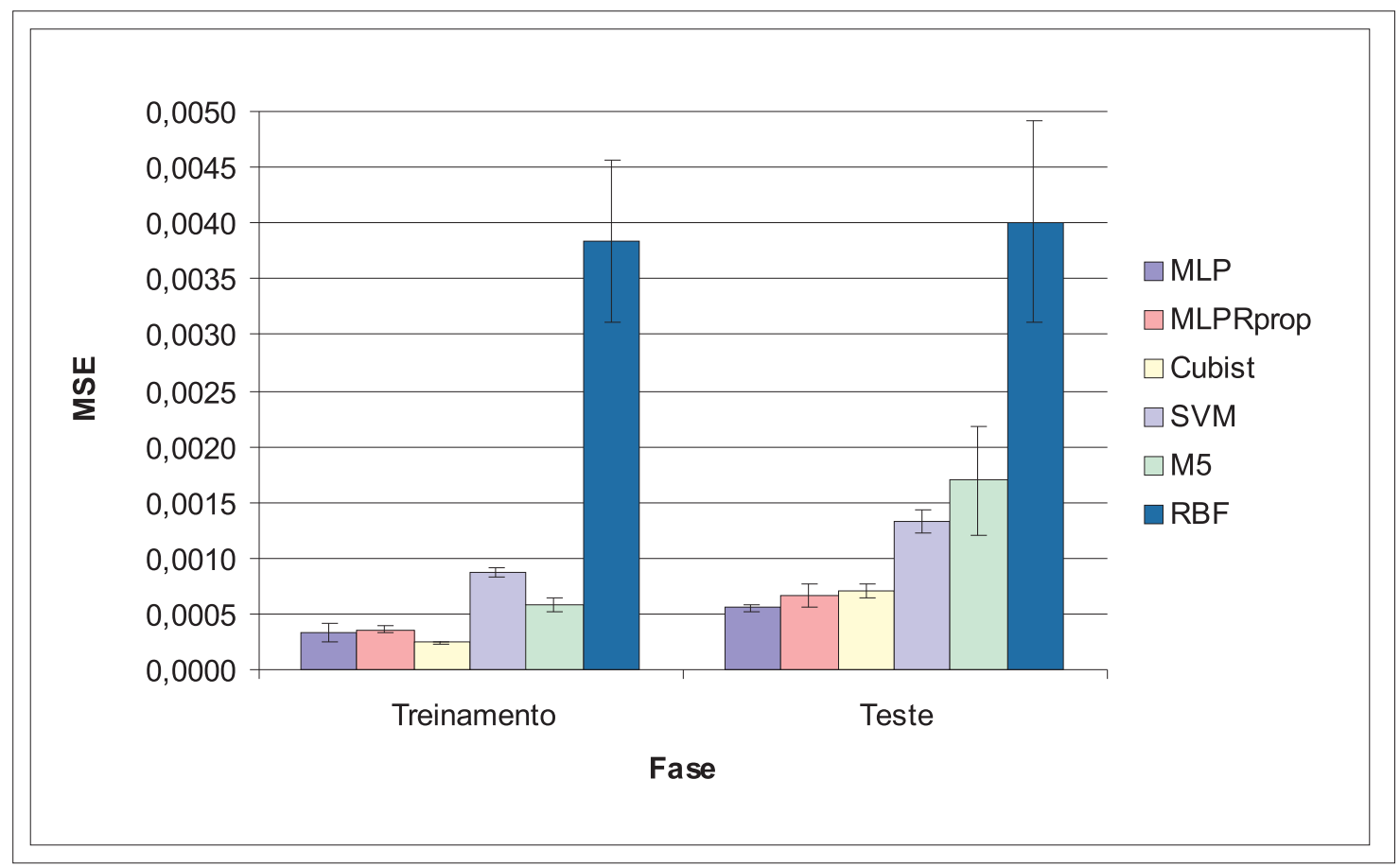

Figura 6.41: Comparação entre os melhores estimadores (base B14). 


\subsubsection{Combinação de Estimadores}

Os gráficos das Figuras 6.42 e 6.43 mostram o rank para as combinações de 3 e 5 estimadores respectivamente. A melhor combinação de 3 estimadores, pela média, envolveu os estimadores MLP, Cubist e M5, e a melhor combinação de 5 estimadores envolveu os estimadores MLP, SVM, Cubist, M5 e MLPRprop.

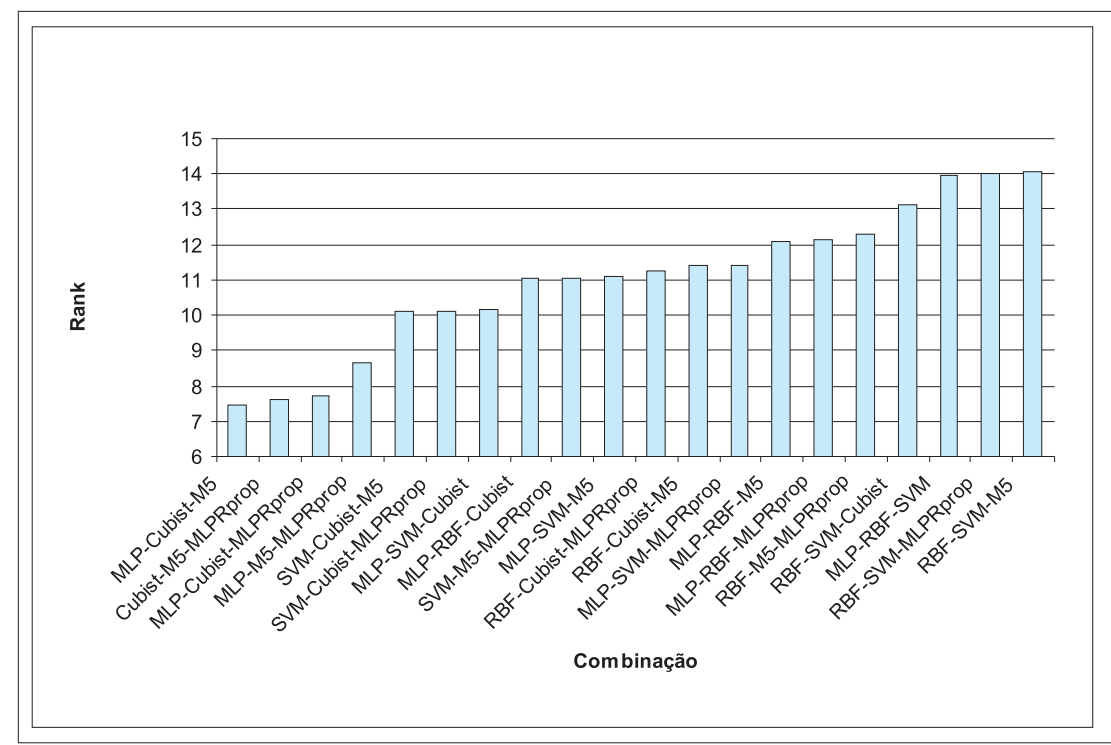

Figura 6.42: Rank das combinações de 3 estimadores (base B14).

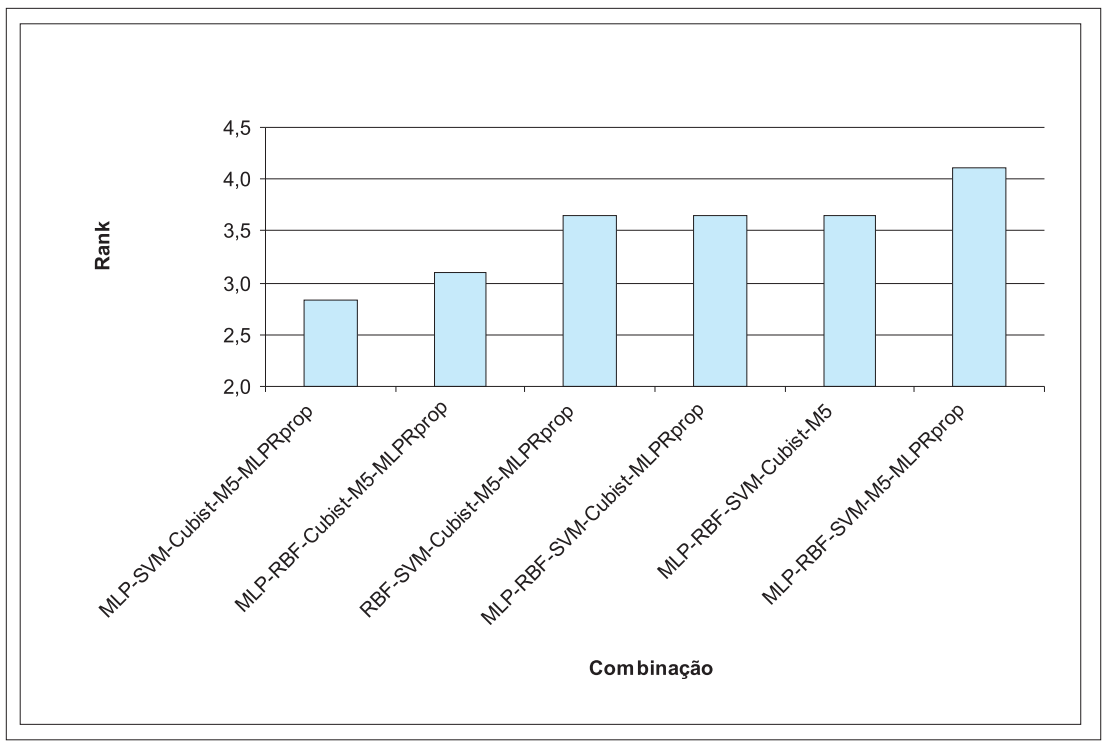

Figura 6.43: Rank das combinações de 5 estimadores (base B14) . 
O gráfico da Figura 6.44 mostra o rank geral obtido. As barras no gráfico mostram o rank obtido pela combinação e as linhas sobre as barras mostram a variação do rank da combinação nas três partições de treinamento. A partir do gráfico pode-se notar que, pelo rank, as três melhores combinações envolveram o algoritmo Cubist e foram realizadas pela média. Vale destacar que as melhores combinações envolveram, em geral, os melhores estimadores (quando se observa o rank). Esse gráfico mostra ainda que, pelo rank, as 5 melhores combinações envolveram apenas 3 estimadores, como no caso da base Pioneer1.

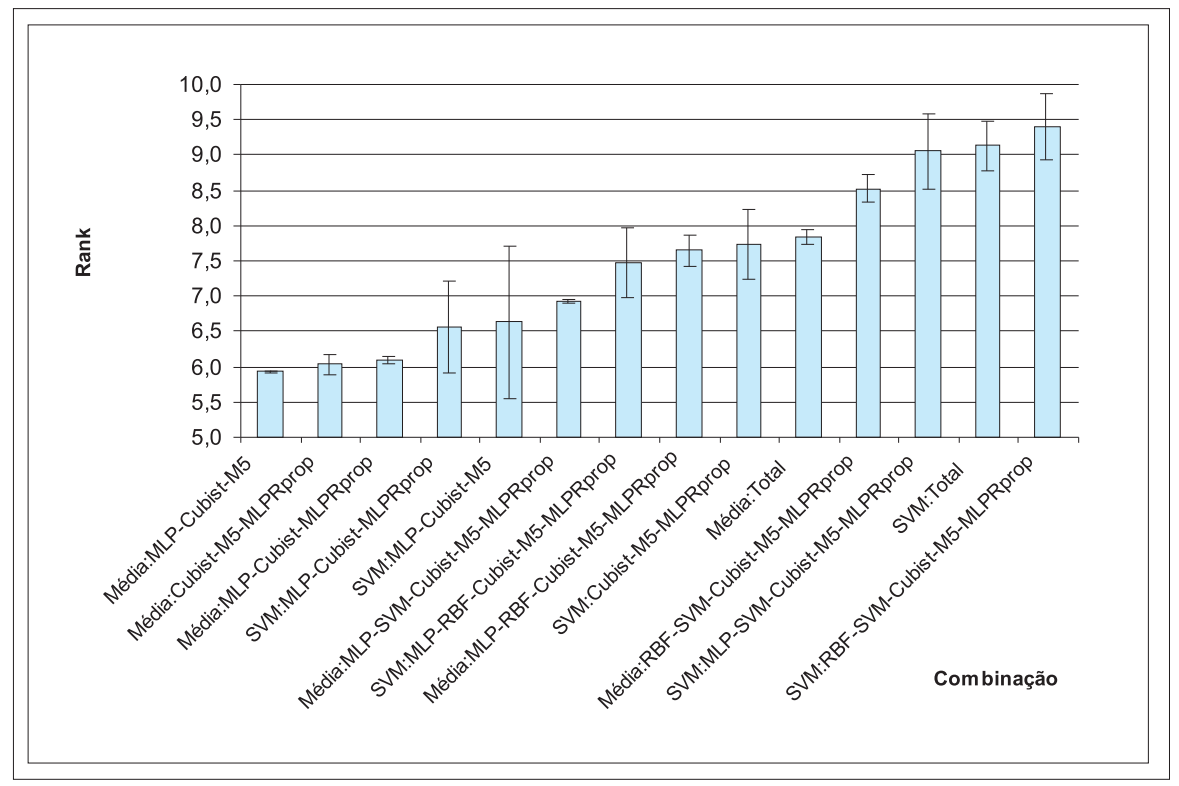

Figura 6.44: Rank final das combinações de 3, 5 e 7 estimadores (base B14).

Ainda para comparar as combinações, foi calculada a média e o desvio padrão do MSE nas três partições para todas as combinações comparadas no gráfico anterior. A Tabela 6.17 e o gráfico da Figura 6.45 mostram essas informações em ordem crescente de MSE na fase de teste. A primeira coluna na tabela indica a forma como a combinação foi feita (se pela média ou com o SVM) e a segunda indica quais estimadores foram combinados. Observando o MSE no teste das combinações vê-se que a classificação das melhores combinações muda. As duas melhores combinações envolveram os estimadores MLP, Cubist e MLPRprop, combinados pela média e com o SVM. 


\begin{tabular}{|l|l|c|c|}
\hline \multicolumn{2}{|c|}{ Combinação } & \multicolumn{2}{c|}{ MSE } \\
\hline Método & Estimadores & Treinamento & Teste \\
\hline \hline Média & MLP-Cubist-MLPRprop & $\mathbf{0 , 0 0 0 2 4} \pm \mathbf{0 , 0 0 0 0 2}$ & $\mathbf{0 , 0 0 0 4 4} \pm \mathbf{0 , 0 0 0 0 9}$ \\
\hline SVM & MLP-Cubist-MLPRprop & $0,00023 \pm 0,00004$ & $0,00050 \pm 0,00007$ \\
\hline Média & MLP-SVM-Cubist-M5-MLPRprop & $0,00027 \pm 0,00001$ & $0,00058 \pm 0,00020$ \\
\hline Média & Cubist-M5-MLPRprop & $0,00027 \pm 0,00002$ & $0,00062 \pm 0,00014$ \\
\hline Média & MLP-Cubist-M5 & $0,00025 \pm 0,00002$ & $0,00064 \pm 0,00020$ \\
\hline SVM & Cubist-M5-MLPRprop & $0,00028 \pm 0,00003$ & $0,00069 \pm 0,00010$ \\
\hline Média & Total & $0,00042 \pm 0,00002$ & $0,00070 \pm 0,00011$ \\
\hline SVM & MLP-Cubist-M5 & $0,00024 \pm 0,00004$ & $0,00070 \pm 0,00015$ \\
\hline Média & RBF-SVM-Cubist-M5-MLPRprop & $0,00049 \pm 0,00002$ & $0,00077 \pm 0,00006$ \\
\hline SVM & MLP-SVM-Cubist-M5-MLPRprop & $0,00043 \pm 0,00007$ & $0,00081 \pm 0,00016$ \\
\hline SVM & MLP-RBF-Cubist-M5-MLPRprop & $0,00031 \pm 0,00006$ & $0,00104 \pm 0,00069$ \\
\hline Média & MLP-RBF-Cubist-M5-MLPRprop & $0,00045 \pm 0,00003$ & $0,00105 \pm 0,00068$ \\
\hline SVM & Total & $0,00043 \pm 0,00004$ & $0,00351 \pm 0,00477$ \\
\hline SVM & RBF-SVM-Cubist-M5-MLPRprop & $0,00045 \pm 0,00006$ & $0,02309 \pm 0,03465$ \\
\hline
\end{tabular}

Tabela 6.17: MSE das melhores combinações de 3, 5 e 7 estimadores (base B14).

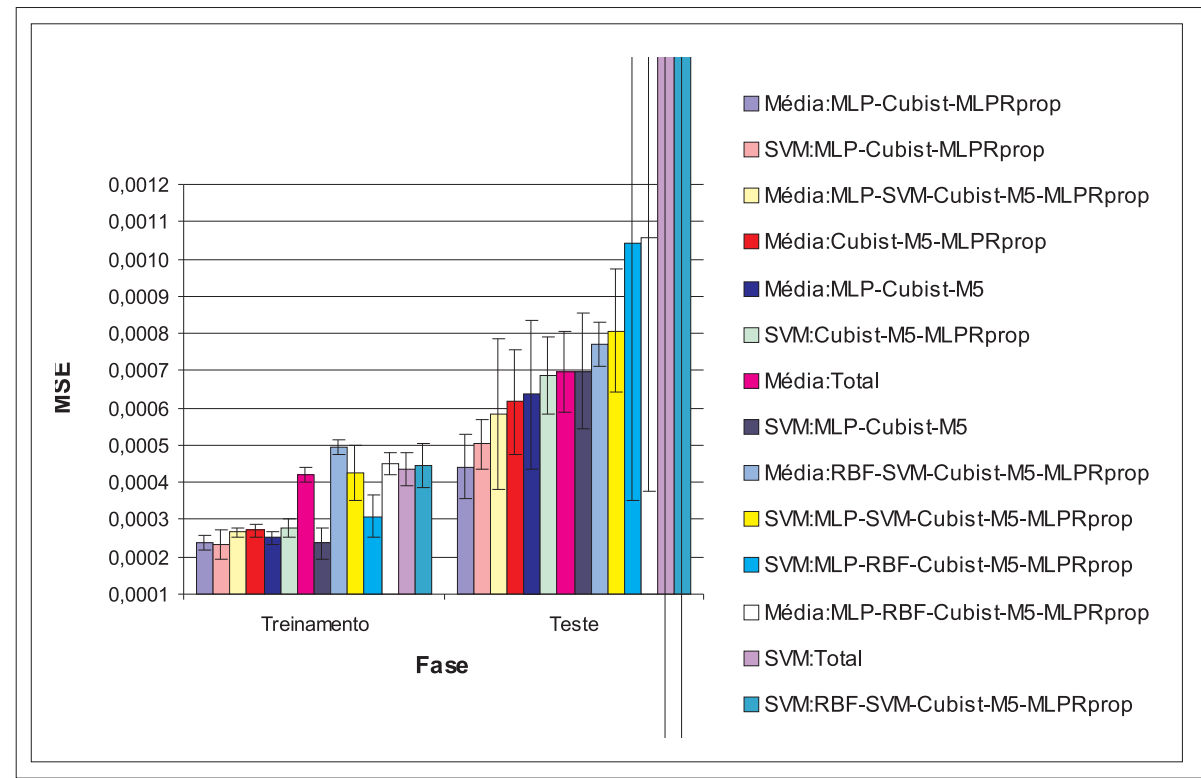

Figura 6.45: MSE das melhores combinações de 3, 5 e 7 estimadores (base B14). 


\subsubsection{Comparação entre os métodos}

Com as combinações realizadas, resta comparar os resultados das combinações, dos estimadores e dos sensores. Para isso será analisado o MSE de cada método. As informações em todos os gráficos seguintes desta seção estão ordenadas pelo MSE do teste dos estimadores.

O gráfico da Figura 6.46 mostra o MSE das melhores combinações e dos estimadores. As barras mostram a média para as três partições e as linhas sobre as barras representam o desvio padrão. Por esse gráfico, pode-se observar que o estimador MLP obteve um bom resultado, comparado às combinações, só sendo superado pelas duas melhores combinações. Pode-se observar também que outros estimadores obtiveram resultados melhores do que algumas combinações (MLPRprop e Cubist).

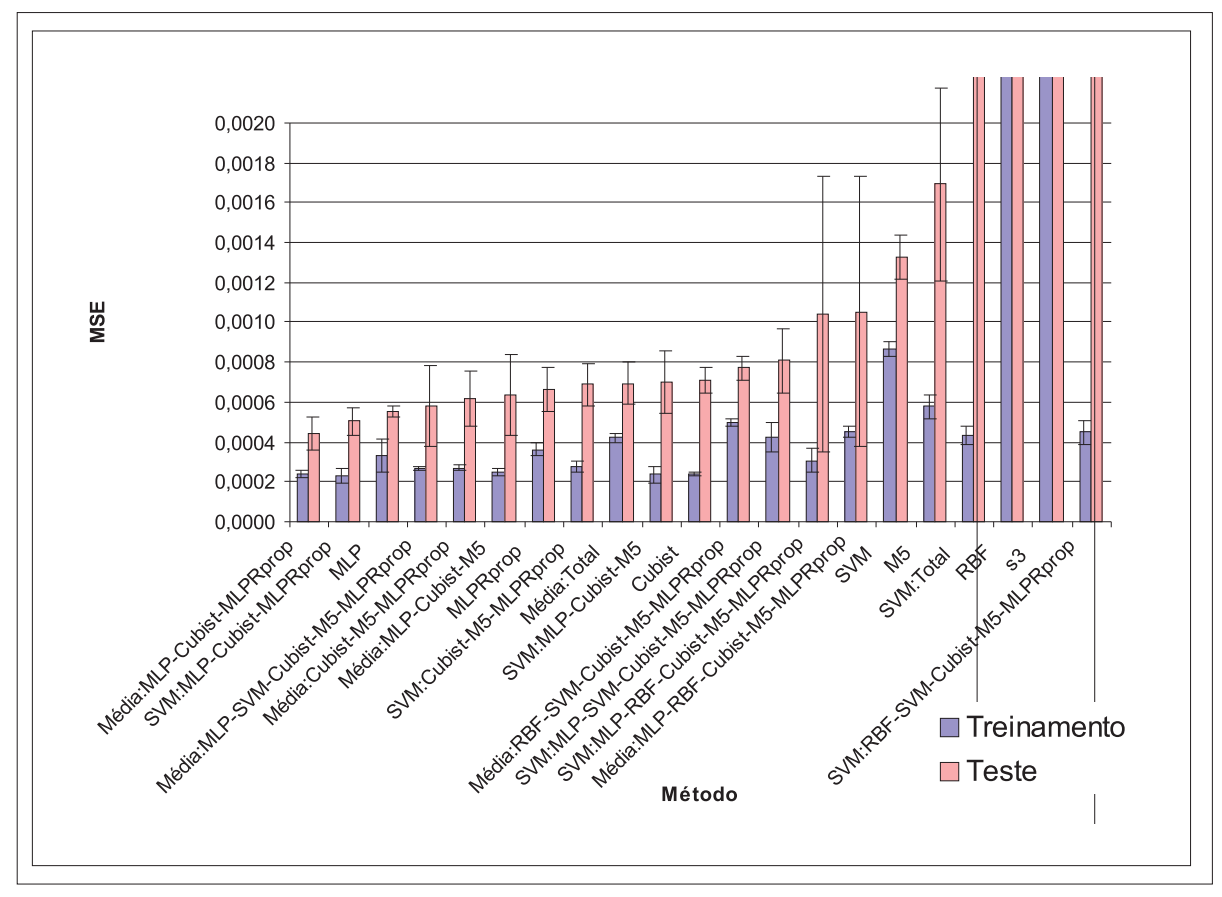

Figura 6.46: Comparação entre o MSE dos estimadores e das combinações (base B14).

O gráfico da Figura 6.47 detalha melhor essas informações, mostrando as 3 melhores combinações pela média, as 3 melhores combinações com o SVM e os 3 melhores estimadores. Os valores do MSE para os melhores estimadores, combinações e sensores podem 
ser observados na Tabela 6.18. Neste caso, ao contrário do ocorrido com a base Pioneer1, as melhores combinações envolveram os três melhores estimadores.

O gráfico da Figura 6.48 mostra o MSE da melhor combinação e do melhor estimador individual (MLP) em comparação ao obtido com o Sonar 3 (sensor com menor erro) . Desse gráfico observa-se que do melhor sensor para o melhor estimador e combinador houve uma redução drástica no MSE, porém do melhor estimador para o melhor combinador a redução do erro foi pequena. A diferença entre o MSE do melhor estimador e do melhor sensor foi de 0,01921, a diferença entre o MSE do melhor combinador e do melhor sensor foi de 0,01932 e a diferença da melhor combinação para o melhor estimador individual foi de 0,00011 .

Isso mostra que a fusão de sensores com a aplicação do estimador MLP diminuiu o erro apresentado pelo melhor sensor em $97,22 \%$ e a aplicação da combinação diminuiu esse erro em $97,77 \%$, o que representa uma redução de $20 \%$ em relação ao erro do melhor estimador. Embora $20 \%$ possa parecer pouco se comparado aos $97,22 \%$ de redução obtido com a MLP, deve ser observado que, cada vez que o erro diminui por causa da utilização de um método, uma nova redução se torna mais difícil, mas ainda assim, essa redução pode levar a ganhos importantes na estimativa de distâncias. Pode-se destacar ainda que as reduções nos erros da base B14 foram maiores do que as reduções da base Pioneer1.

\begin{tabular}{|l|c|c|}
\hline \multirow{2}{*}{ Método } & \multicolumn{2}{c|}{ MSE } \\
\cline { 2 - 3 } & Treinamento & Teste \\
\hline \hline Média:MLP-Cubist-MLPRprop & $\mathbf{0 , 0 0 0 2 4} \pm \mathbf{0 , 0 0 0 0 2}$ & $\mathbf{0 , 0 0 0 4 4} \pm \mathbf{0 , 0 0 0 0 9}$ \\
\hline SVM:MLP-Cubist-MLPRprop & $0,00023 \pm 0,00004$ & $0,00050 \pm 0,00007$ \\
\hline Média:MLP-SVM-Cubist-M5-MLPRprop & $0,00027 \pm 0,00001$ & $0,00058 \pm 0,00020$ \\
\hline Média:Cubist-M5-MLPRprop & $0,00027 \pm 0,00002$ & $0,00062 \pm 0,00014$ \\
\hline SVM:Cubist-M5-MLPRprop & $0,00028 \pm 0,00003$ & $0,00069 \pm 0,00010$ \\
\hline SVM:MLP-Cubist-M5 & $0,00024 \pm 0,00004$ & $0,00070 \pm 0,00015$ \\
\hline \hline MLP & $\mathbf{0 , 0 0 0 3 3} \pm \mathbf{0 , 0 0 0 0 8}$ & $\mathbf{0 , 0 0 0 5 5} \pm \mathbf{0 , 0 0 0 0 3}$ \\
\hline MLPRprop & $0,00036 \pm 0,00003$ & $0,00066 \pm 0,00011$ \\
\hline Cubist & $0,00024 \pm 0,00001$ & $0,00071 \pm 0,00006$ \\
\hline \hline Sonar 3 & $\mathbf{0 , 0 2 0 2 5} \pm \mathbf{0 , 0 0 0 2 0}$ & $\mathbf{0 , 0 1 9 7 6} \pm \mathbf{0 , 0 0 0 6 1}$ \\
\hline
\end{tabular}

Tabela 6.18: MSE dos melhores sensor, estimadores e combinadores (base B14). 


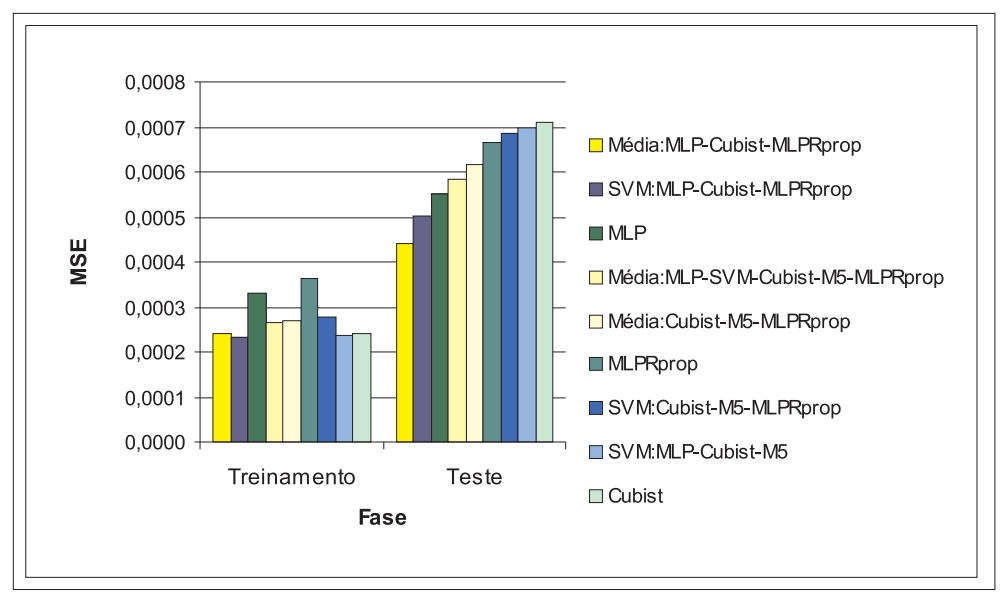

Figura 6.47: Comparação entre o MSE dos melhores estimadores e combinações (base B14).

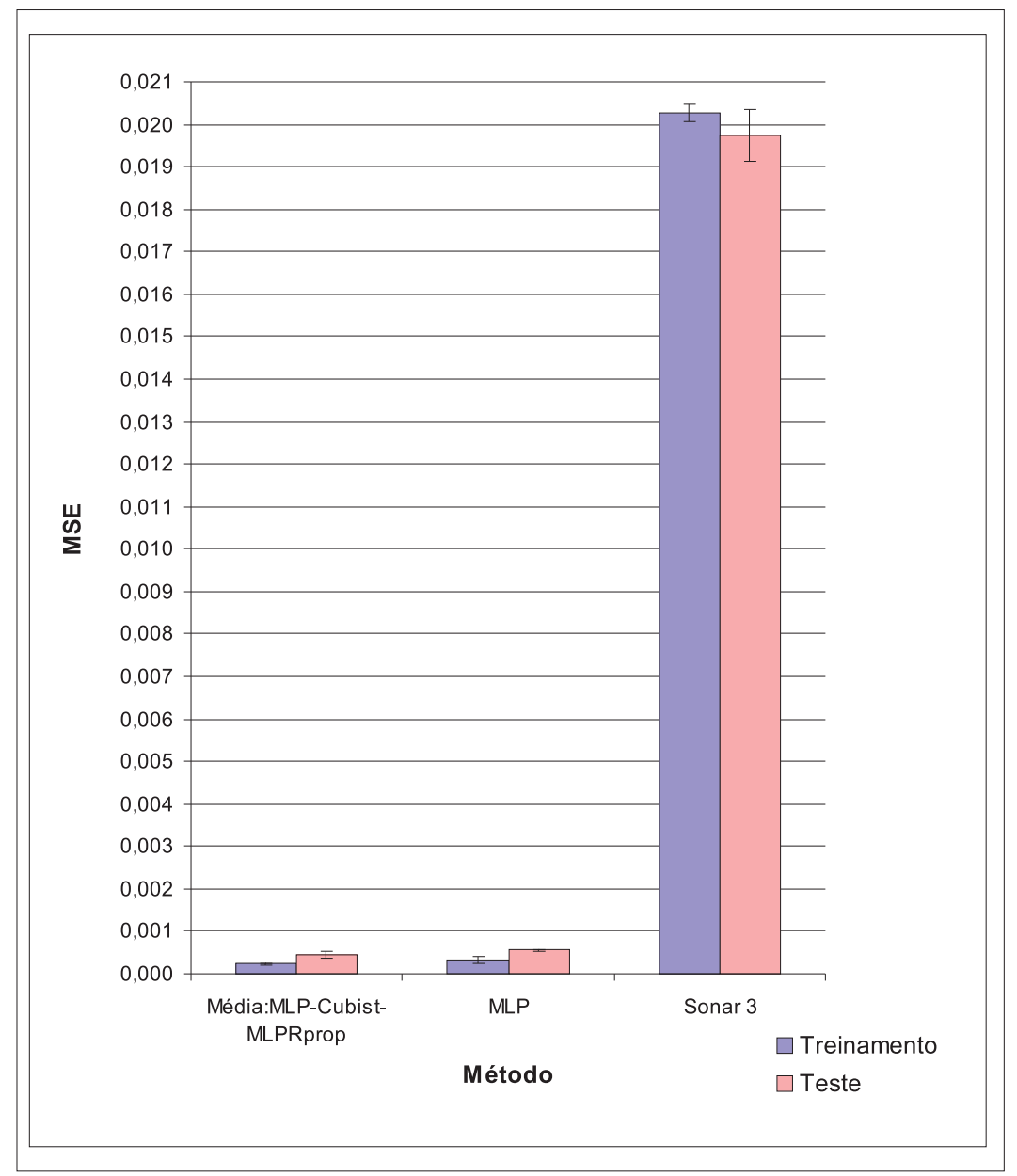

Figura 6.48: Comparação entre o MSE do melhor sensor, do melhor estimador e da melhor combinação (base B14). 
O teste estatístico t para dados emparelhados também foi aplicado aos dados desta base. Esse teste foi aplicado aos seguintes pares de métodos/sensores, com um nível de significância $\alpha=5 \%$ :

- Sonar 3 e MLP;

- Sonar 3 e Média:MLP-Cubist-MLPRprop;

- MLP e Média:MLP-Cubist-MLPRprop;

- MLPRprop e MLP (dois melhores estimadores);

- SVM:MLP-Cubist-MLPRprop e Média:MLP-Cubist-MLPRprop (dois melhores combinadores).

A Tabela 6.19 mostra o valor obtido para a estatística t nos vários casos. Com $\alpha=$ $5 \%$ e $\phi=7628$ (graus de liberdade), $\mathrm{t}_{5 \%}=1,645(\phi=\infty)$ (Johnson, 2000).

\begin{tabular}{|l|c|}
\hline Métodos & $\mathrm{t}_{\text {calc }}$ \\
\hline \hline Sonar 3 e MLP & 32,75076199 \\
\hline Sonar 3 e Média:MLP-Cubist-MLPRprop & 32,89950739 \\
\hline MLP e Média:MLP-Cubist-MLPRprop & 4,166810939 \\
\hline MLPRprop e MLP & 4,444415718 \\
\hline SVM:MLP-Cubist-MLPRprop e Média:MLP-Cubist-MLPRprop & 5,183199172 \\
\hline
\end{tabular}

Tabela 6.19: Valor de $\mathrm{t}_{\text {calc }}$ para o teste das várias comparações (base B14).

Com $95 \%$ de confiabilidade, $\mathrm{t}_{\text {calc }}$ é maior do que $\mathrm{t}_{5 \%}$ para todas as comparações. Neste caso, rejeita-se $H_{0}$, aceitando-se a hipótese alternativa $H_{1}$ de que $M S E_{1} \neq M S E_{2}$. Com isso, pode-se concluir que a redução do erro, em todos os casos foi realmente significativa.

\subsection{Considerações Finais}

Neste capítulo foram descritos os experimentos realizados para a determinação dos melhores estimadores e combinadores a partir dos diversos algoritmos investigados. Para os experimentos, foram utilizadas duas bases de dados: Pioneer1 e B14. Análises detalhadas e comparações dos resultados obtidos também foram realizadas, destacando-se as melhorias na precisão e acurácia obtidas com a aplicação de cada método investigado. 
No próximo capítulo serão traçadas as conclusões do trabalho realizado, ressaltando os principais resultados obtidos. As contribuições e limitações deste trabalho também serão discutidas. Ao final, serão apresentadas algumas possibilidades promissoras de trabalhos futuros. 


\section{Capítulo 7}

\section{Conclusões}

Os experimentos descritos neste trabalho tiveram como objetivo verificar se as técnicas de aprendizado de máquina descritas e a combinação de estimadores podem oferecer bons resultados quando aplicadas à problemas de fusão de sensores. Por bons resultados entenda-se uma melhora da precisão e acurácia das informações obtidas com os sensores.

Os objetivos foram atingidos na medida em que mostrou-se que a aplicação das diversas técnicas de inteligência artificial para fusão de sensores, aplicadas nas bases de dados utilizadas, resultou em significativa redução do erro cometido pelos sensores e aumento da estabilidade das medidas (acurácia).

Para fusão foram utilizados os seguintes sensores: uma câmera e sete sonares, no caso da base Pioneer1, e oito sonares, oito "sonares visuais"e oito sensores de proximidade infravermelho, no caso da base B14. Na construção dos estimadores foram utilizados redes neurais (MLP, RBF e Cascade Correlation), SVM, Cubist e M5. A combinação dos estimadores foi feita com a média simples e SVM.

Nos experimentos realizados, obteve-se reduções de até 89,35\% no erro cometido pelo melhor sensor da base Pioneer1 e reduções de até 97,77\% no erro cometido pelo melhor sensor da base B14. Assim, as análises realizadas sugerem que a aplicação de técnicas 
de inteligência artificial para a fusão de sensores com o objetivo de melhorar a precisão e acurácia das medidas obtidas por sensores individuais é uma abordagem promissora.

Ainda que não se tenha obtido significativas diferenças nos erros cometidos com os diversos métodos, no caso da base Pioneer1, outras investigações que considerem questões de custo podem levar a uma definição mais clara de quais métodos são mais adequados para cada situação.

\subsection{Contribuições}

Neste trabalho, foram empregados algoritmos de aprendizado de máquina diferentes dos até agora propostos para fusão de sensores, juntamente com alguns algoritmos já empregados largamente. Isso permitiu uma comparação entre os diversos algoritmos investigados.

Outra contribuição deste trabalho foi a proposição da combinação de estimadores para fusão de sensores, como uma forma de melhorar as medições de sensores.

Além disso, foi feita uma investigação de uma forma de se determinar potenciais combinações de estimadores através do estabelecimento de ranks a partir da forma mais simples de combinação, a média simples.

\subsection{Limitações e Trabalhos Futuros}

Uma das limitações deste trabalho diz respeito aos dados utilizados para testar as possibilidades de métodos para fusão. A base principal utilizada é composta por informações de distâncias referentes a poucos ângulos de abordagem e distâncias, apresentando assim, um pequeno subconjunto das possíveis distâncias e ângulos. A segunda base se aproxima mais de uma situação real, uma vez que não se restringe apenas a algumas distâncias escolhidas. Porém, essa base toma como referência para as medições (distância real), 
distâncias obtidas através de odometria, que também apresentam erros na medição.

Uma outra limitação é que as investigações neste trabalho tratam das questões de precisão e acurácia, porém, não levam em consideração o custo de implementação e utilização dos diversos métodos. Assim, uma possibilidade para futuros trabalhos envolve a investigação dos custos associados a implementação e utilização dos diversos métodos para fusão. Restrições de custo podem ser decisivas, uma vez que os problemas que requerem fusão de sensores, geralmente exigem as informações em tempo real.

Uma outra possibilidade para trabalhos futuros diz respeito a utilização de outros algoritmos bem como outros paradigmas para a combinação dos estimadores. Neste trabalho obteve-se pouca diferença nos resultados obtidos com os combinadores em relação aos estimadores. Porém, é possível que, se a combinação fosse realizada com a aplicação de outros algoritmos (possivelmente diferentes dos utilizados nos estimadores), reduções nos erros mais significativas fossem obtidas.

Outra abordagem possível é a utilização das técnicas investigadas em outros problemas na área de fusão de sensores.

A implantação dos métodos investigados em um robô para testes em situações reais também constitui uma possibilidade de extensão deste trabalho.

Além disso, a utilização de outros tipos de sensores, além dos já utilizados, também se mostra uma extensão interessante deste trabalho. 


\section{Referências}

Abidi, M. A. and Gonzalez, R. C., editors (1992). Data Fusion in Robotics and Machine Intelligence. Academic Press.

Allen, P. K. (1995). Integrating Vision and Touch for Object Recognition Tasks, chapter 18, pages 407-440. In (Luo and Kay, 1995).

Baranauskas, J. A. and Monard, M. C. (2000). Reviewing some machine learning concepts and methods. Technical Report 102, Instituto de Ciências Matemáticas e de Computação; Universidade de São Paulo. ftp://ftp.icmc.sc.usp.br/pub/BIBLIOTECA/rel_tec/Rt_102.ps.zip.

Berler, A. and Shimony, S. E. (1997). Bayes networks for sensor fusion. Proceedings of the 13th Conference on Uncertainty in AI.

Bower, T. G. R. (1974). The evolution of sensory systems. Perception: Essays in Honor of James J. Gibson, pages 141-153. ed. by R. B. MacLeod and H. L. Pick, Jr.

Braga, A. P., Carvalho, A. C. P. L. F., and Ludermir, T. B. (2000). Redes Neurais Artificiais: Teoria e Aplicações. Livros Técnicos e Científicos (LTC).

Brooks, R. R. and Iyengar, S. S. (1998). Multi-Sensor Fusion: Fundamentals and Applications with Software. Prentice Hall.

Broomhead, D. S. and Lowe, D. (1988). Multivariable funcional interpolation and adaptative networks. Complex Systems, 2:321-355.

Collobert, R. (2000). A small user guide for svmtorch. http://www.idiap.ch/learning/SVMTorch.html [10/08/2000].

Collobert, R. and Bengio, S. (2000). Support vector machines for 
large-scale regression problems. Research Report IDIAP-RR-00-17. http://www.idiap.ch/learning/SVMTorch.html [10/08/2000].

Dasarathy, B. V. (1997). Sensor fusion potential exploitation - innovative architectures and illustrative applications. Proceedings of the IEEE, 85(1):24-38.

Diniz, H., Filho, E. F. M., and Carvalho, A. C. P. L. F. (1997). SNNS - Stuttgart Neural Network Simulator. Manual de Referência Rápida.

Everett, H. R. (1995). Sensors for Mobile Robots: Theory and Application. A. K. Peters, Wellesley, MA.

Faceli, K. and Carvalho, A. C. P. L. F. (1998). Treinamento de uma rede neural artificial para fusão de sensores para previsão de distâncias em um robô móvel. Monografia apresentada para o exame final da disciplina SCE-191 - Projeto Supervisionado.

Faceli, K., Carvalho, A. C. P. L. F., Rezende, S. O., and Melfi, F. R. (1999). Sistemas inteligentes para fusão de sensores. Anais do XIX Congresso Nacional da Sociedade Brasileira de Computação (II Encontro Nacional de Inteligência Artificial), 4:163175.

Fahlman, S. E. (1988). Faster-learning variations on back-propagation: An empirical study. Connectionist Models Summer School.

Fahlman, S. E. and Lebiere, C. (1988). The cascade-correlation learning architecture. Advances in Neural Information Processing Systems, 2.

Ferworn, A. (1997). Cps607 - autonomous mobile robotics. http://www.scs.ryerson.ca/ aferworn/courses/CPS607/INDEX.HTML.

Frank, E., Wang, Y., Inglis, S., Holmes, G., and Witten, I. H. (1998). Using model trees for classification. Machine Learning, 32:63-76.

Gama, J. M. P. (1999). Combining Classification Algorithms. PhD thesis, Departamento de Ciência de Computadores, Faculdade de Ciências da Universidade do Porto. http://www.ncc.up.pt/ jgama/tese.ps.gz.

Goodridge, S. G. (1997). Multimedia Sensor Fusion for Intelligent Camera Control and Human-Computer Interaction. PhD thesis, Department of Electrical and Computer 
Engineering, North Carolina State University, Raleigh, NC.

Groover, M. P., Weiss, M., Nagel, R. N., and Odrey, N. G. (1989). Robótica: Tecnologia e Programação. McGraw-Hill.

Hall, D. (1992). Mathematical Techniques for Multisensor Data Fusion. Artech House Inc.

Horswill, I. (1993). Visual support for navigation in the polly system. Algorithmic Foundation of Robotics, pages 62-67.

Horswill, I. (1994). Collision avoidance by segmentation. Proceedings of the 1994 International Conference on Intelligent Robots and Systems (IROS-94).

Huttenlocher, D. P., Leventon, M. E., and Rucklidge, W. J. (1995). Visually-guided navigation by comparing edge images. Algorithmic Foundation of Robotics, pages $85-96$.

Iovine, J. (1998). Robots, Androids and Animatrons: 12 Incredible Projects You Can Build. McGraw-Hill.

Johnson, R. A. (2000). Miller and Freund's Probability and statistics for engineers. Prentice Hall.

Jones, J. L. and Flynn, A. M. (1993). Mobile Robots. A. K. Peters.

Joshi, R. and Sanderson, A. C. (1999). Multisensor Fusion: A Minimal Representation Framework. World Scientific.

Klein, L. A. (1999). Sensor and Data Fusion Concepts and Applications. SPIE Press.

Kokar, M. M. and Tomasik, J. (1994). Towards a formal theory of sensor/data fusion. Technical Report COE-ECE-MMK-1/94, Northeastern University, Boston, MA. http://www.coe.neu.edu/ kokar/publications/koktom.ps.

Kokar, M. M., Tomasik, J. A., and Weyman, J. (1999). A formal approach to information fusion. Proceedings of the Second International Conference on Information Fusion (Fusion-99), 1:133-140. http://www.coe.neu.edu/ kokar/publications/f99mjj.ps. 
Krogh, A. and Vedelsby, J. (1995). Neural network ensembles, cross validation, and active learning. Advances in Neural Information Processing Systems, 7.

Krotov, E. and Martin, J. (1986). Range from focus. IEEE International Conference on Robotics and Automation, pages 1093-1098.

Kwok, T. Y. and Yeung, D. Y. (1995). Constructive feedforward neural networks for regression problems: A survey. Technical Report HKUST-CS95-43, Department of Computer Science, Hong Kong University of Science and Technology, Kowloon, Hong Kong. http://info.cs.ust.hk/faculty/dyyeung/paper/cnn.html.

Kwok, T. Y. and Yeung, D. Y. (1999). Constructive algorithms for structure learning in feedforward neural networks for regression problems. IEEE Transactions on Neural Networks, pages 630-645. http://info.cs.ust.hk/faculty/dyyeung/paper/cnn.html.

LeBlanc, M. and Tibshirani, R. (1993). Combining estimates in regression and classification. Technical Report 9318, Department of Statistics, University of Toronto.

Lee, D. (1978). The functions of vision. Modes of Perceiving and Processing Information, pages 159-170. ed. by H. L. Pick and E. Saltzman.

Luo, R. C. and Kay, M. G. (1992). Data Fusion and Sensor Integration: State-of-the-art 1990s, chapter 2, pages 7-135. In (Abidi and Gonzalez, 1992).

Luo, R. C. and Kay, M. G., editors (1995). Multisensor Integration and Fusion for Intelligent Machine and Systems. Ablex Publishing Corporation.

Marks, L. E. (1978). The Unity of the Senses: Interrelations among the Modalities. Academic Press, New York.

Martens, S., Gaudiano, P., and Carpenter, A. (1998). Mobile robot sensor integration with fuzzy ARTMAP. Technical Report CAS/CNS-TR-98-011, Boston University. http://cns-web.bu.edu/ gaudiano/Publications.html.

McKerrow, P. J. (1995). Introduction to Robotics. Addison-Wesley.

Merz, C. and Pazzani, M. (1997). Combining neural network regression estimates with regularized linear weights. Advances in Neural Information Processing Systems, 9. 
Merz, C. J. (1998). Classification and Regression by Combining Models. PhD thesis, University of California, Irvine. http://www.ics.uci.edu/ cmerz/thesis.ps.

Morettin, L. G. (2000). Estatística Básica, volume 2 - Inferência. Makron Books.

Murphy, R. R. (1996). Biological and cognitive foundations of intelligent sensor fusion. IEEE Transactions on Systems, Man and Cybernetics, 26(1):42-51.

Nagai, W. A. (1999). Modelos de previsão no processo de data mining. Mini Dissertação apresentada para o exame de qualificação.

Nakauchi, Y. and Mori, Y. (1998). Emergent behavior based sensor fusion for mobile robot navigation system. IEICE Trans. Inf. and Syst., E81-D(9):959-967.

Nguyen, H. G. and Blackburn, M. R. (1995). A simple method for range finding via laser triangulation. Technical Report 2737, Naval Command, Control and Ocean Surveillance Center, San Diego, CA. www.spawar.navy.mil/sti/publications/pubs/td/2734/nradtd2734txtok.html.

Nilsson, A. and Holmberg, P. (1993). Robot-sensor system integration by means of 2-D vision and ultrasonic sensing for localization and recognition of objects. Proceedings of the 1993 IEEE/RSJ International Conference on Intelligent Robots and Systems, pages $1793-1799$.

Parekh, R., Yang, J., and Honavar, V. (1997). Constructive neural network learning algorithms for multi-category real-valued pattern classification. Technical Report 97-06, Department of Computer Science, Iowa State University of Science and Technology, Iowa, USA.

Parekh, R., Yang, J., and Honavar, V. (1998). Constructive neural network learning algorithms for pattern classification.

Pasika, H. J. C. (1999). Neural Network Sensor Fusion Engines for Remote Sensing. PhD thesis, McMaster University. http://soma.crl.mcmaster.ca/ pasika/pubs.html.

Pick, H. L. and Saltzman, E. (1978). Modes of perceiving and processing information. Modes of Perceiving and Processing Information, pages 1-20. ed. by H. L. Pick and E. Saltzman. 
Prampero, P. C. (1998). Combinação de classificadores para reconhecimento de padrões. Master's thesis, Instituto de Ciências Matemáticas e de Computação, Universidade de São Paulo.

Prechelt, L. (1994). Proben1 - a set of neural network benchmark problems and benchmarking rules. Technical Report 21, University of Karlsruhe, Germany.

Riedmiller, M. and Braun, H. (1993). A direct adaptative method for faster backpropagation learning: The RPROP algorithm. Proceedings of the IEEE International Conference on Neural Networks 1993 (ICNN 93).

Rulequest-Research (2000). Rulequest Research - Data Mining Tools. http://www.rulequest.com.

Rumelhart, D. E. and McClelland, J. L. (1986). Parallel Distributed Processing, volume 1: Fondations. MIT Press.

Rüping, S. (2000). mysvm -manual. http://www-ai.cs.unidortmund.de/SOFTWARE/MYSVM/ [10/08/2000].

Sahin, E. and Gaudiano, P. (1998). Visual looming as a range sensor for mobile robots. Fifth International Conference on Simulation of Behavior.

Saunders, C., Stitson, M. O., Weston, J., Bottou, L., Schölkopf, and Smola, A. (1998). Support vector machine - reference manual. Technical Report CSD-TR-98-03, Royal Holloway, University of London. http://svm.dcs.rhbnc.ac.uk/ [26/06/2000].

Schölkopf, B., Sung, K., Burges, C., Girosi, F., Niyogi, P., Poggio, T., and Vapnik, V. (1996). Comparing support vector machines with gaussian kernels to radial basis functiun classifiers. http://www.kernel-machine.org/publications.html $[23 / 08 / 2000]$.

Sebastiani, F. (1999). Machine learning in automated text categorization. $A C M$ Computing Surveys. Submitted for publication. http://faure.iei.pi.cnr.it/ fabrizio/ $[10 / 03 / 00]$.

Sharkey, A. J. C. (1999). Combining Artificial Neural Nets : Ensemble and Modular Multi-Net Systems(Perspectives in Neural Computing). Springer Verlag. 
Sousa, H. C. (1999). Utilização de redes neurais construtivas para reconhecimento de padrões. Mini Dissertação apresentada para o exame de qualificação.

Stein, B. and Meredith, M. A. (1993). The Merging of the Senses. MIT Press, Cambridge, MA.

Tumer, K. and Ghosh, J. (1996). Classifier combining: Analytical results and implications. working notes from the Workshop Integrating Multiple Learned Models National Conference on Artificial Intelligence.

Vapnik, V. (1995). The Nature of Statistical Learning Theory. Springer-Verlag, New York.

Vargas, E. C. (1998). Kipu: Um simulador para redes neurais construtivas. Master's thesis, Instituto de Ciências Matemáticas e de Computação, Universidade de São Paulo.

Walker, R. J. (1993). Multi Sensor Data Fusion Applied to a Class of Autonomous Land Vehicles. PhD thesis, University of Southampton, Faculty of Engineering and Applied Science.

Wang, Y. and Witten, I. H. (1997). Induction of model trees for predicting continuous classes. In Proceedings of the Poster Papers of the European Conference on Machine Learning, University of Economics, Faculty of Informatics and Statistics, Prague.

Wei, S. C., Yagi, Y., and Yachida, M. (1998). Building a local floor map by use of ultrasonic and omni-directional vision sensors. Advanced Robotics, 12(4):433-453.

Witten, I. H. and Frank, E. (1999). Data Mining: Practical Machine Learning Tools and Techniques with Java Implementations. Morgan Kaufmann. http://www.cs.waikato.ac.nz/ ml/weka/book.html.

Wolpert, D. H. (1992). Stacked generalization. Neural Networks, 5:241-259.

Zell, A., Mamier, G., Vogt, M., Mache, N., Hübner, R., Döring, S., Herrmann, K., Soyez, T., Schmalzl, M., Sommer, T., Hatzigeorgiou, A., Posselt, D., Schreiner, T., Kett, B., Clemente, G., and Wieland, J. (1995). SNNS - Stuttgart Neural Network Simulator - User Manual, Version 4.1. Report No. 6/95. 


\section{Apêndice A}

\section{Exemplos de Arquivo de Entrada para o Treinamento dos diversos algoritmos}

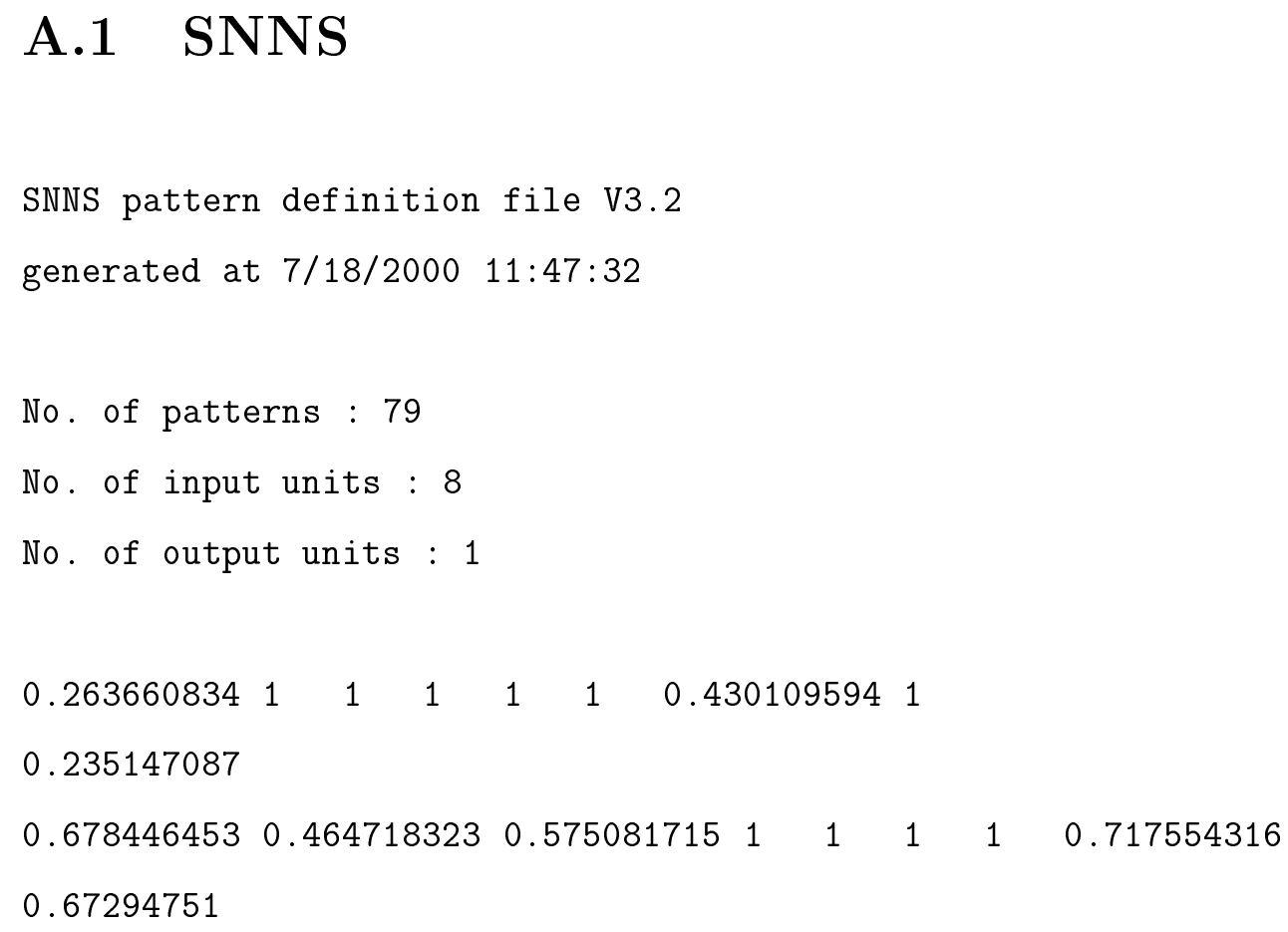




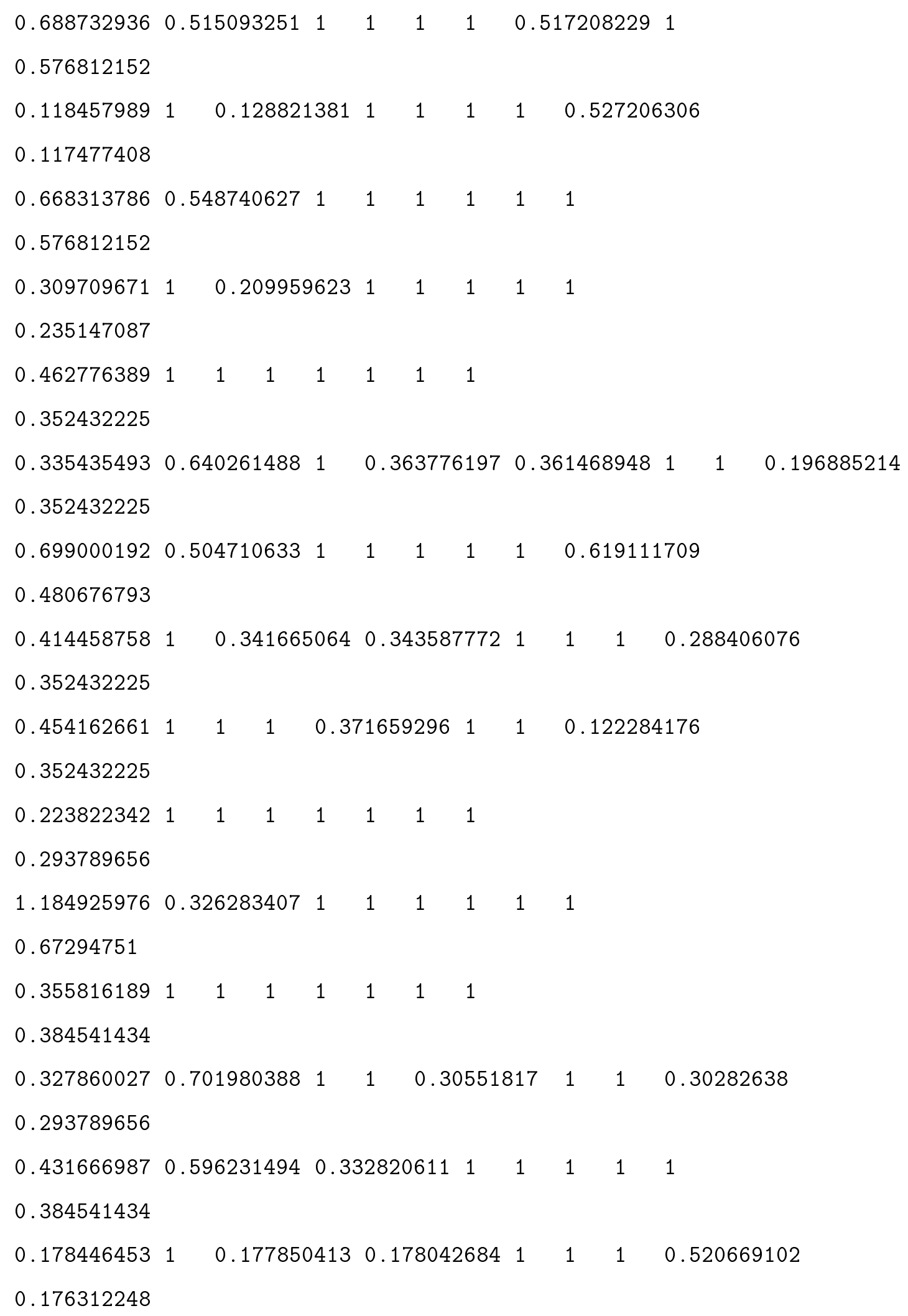




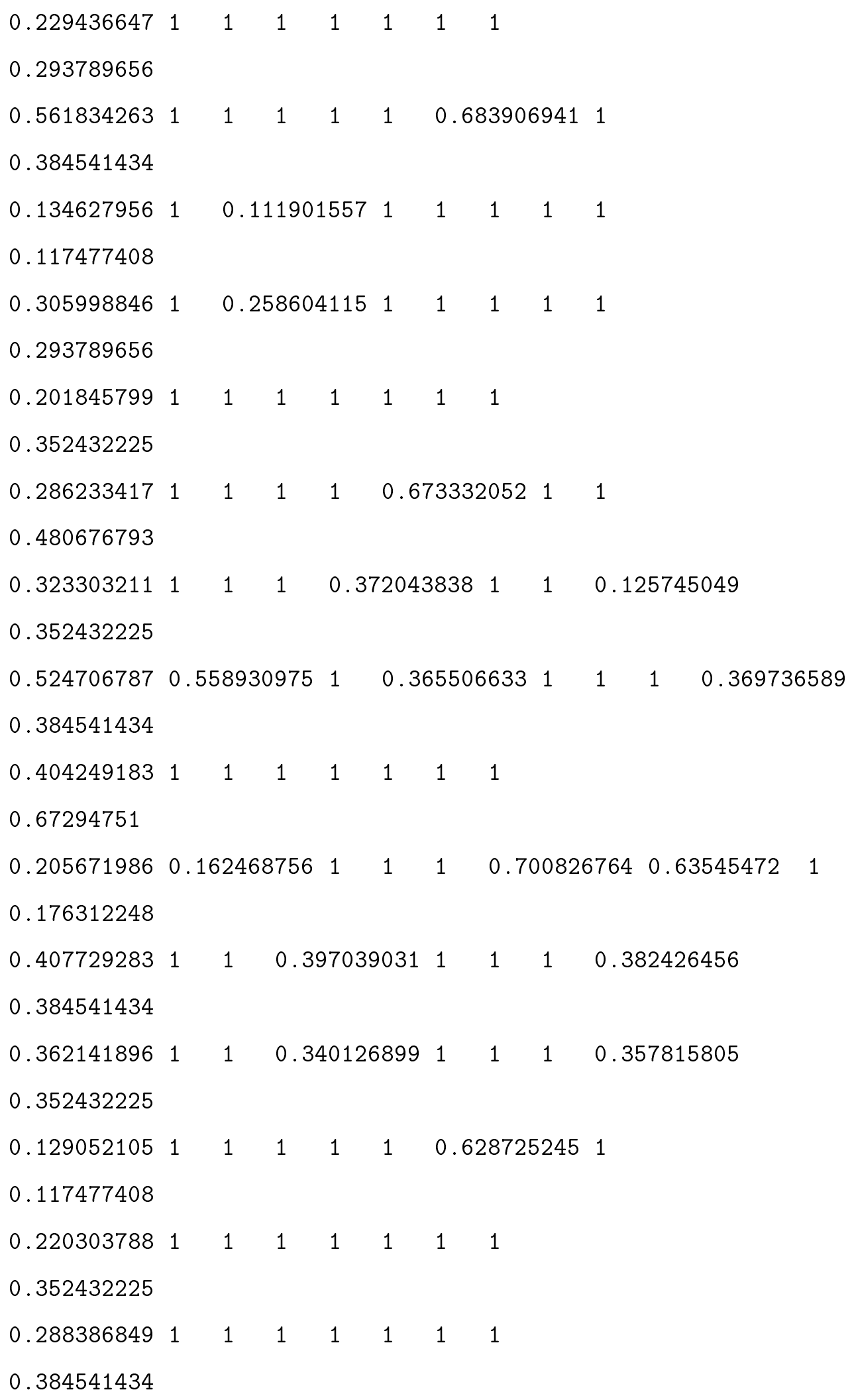




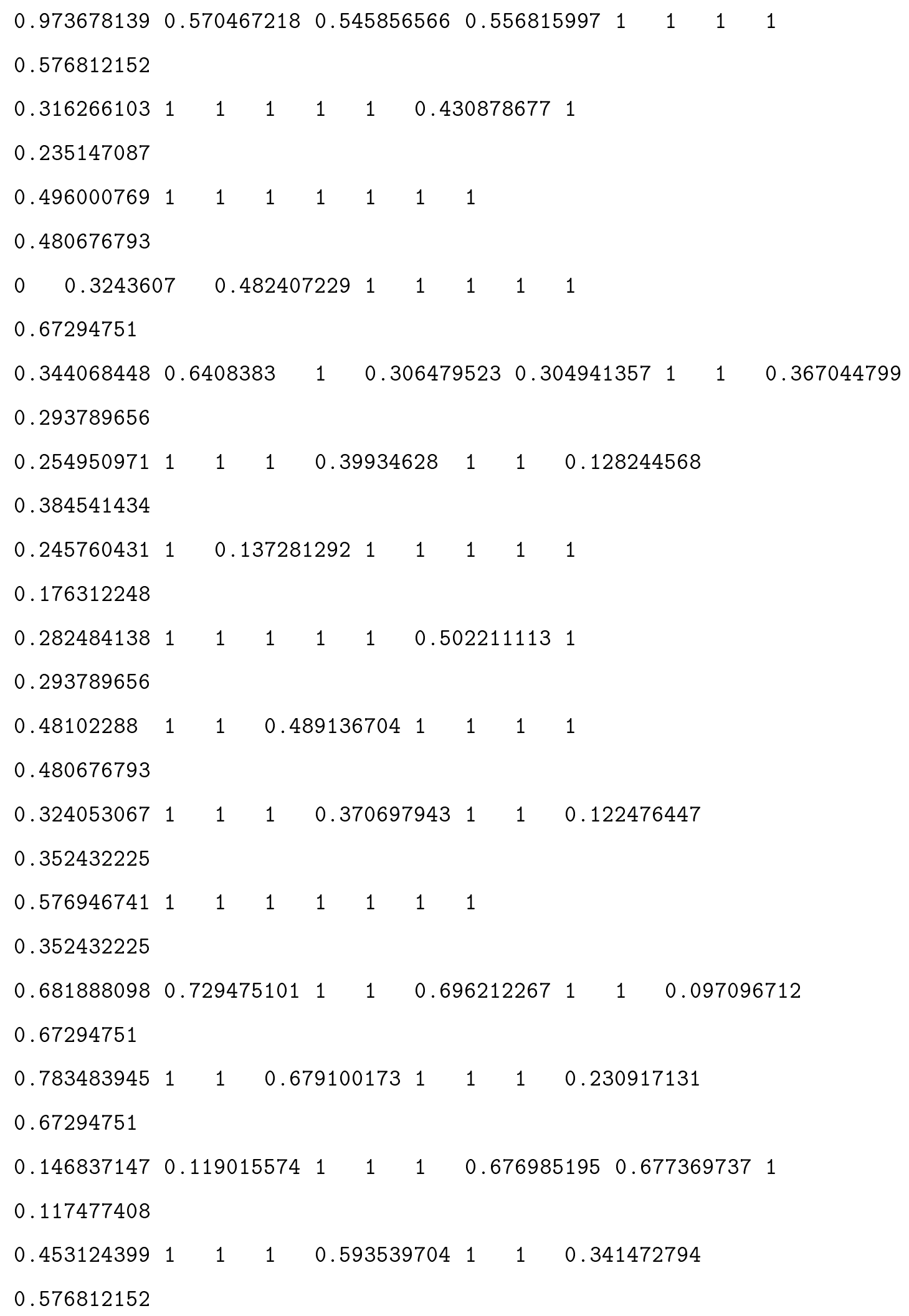




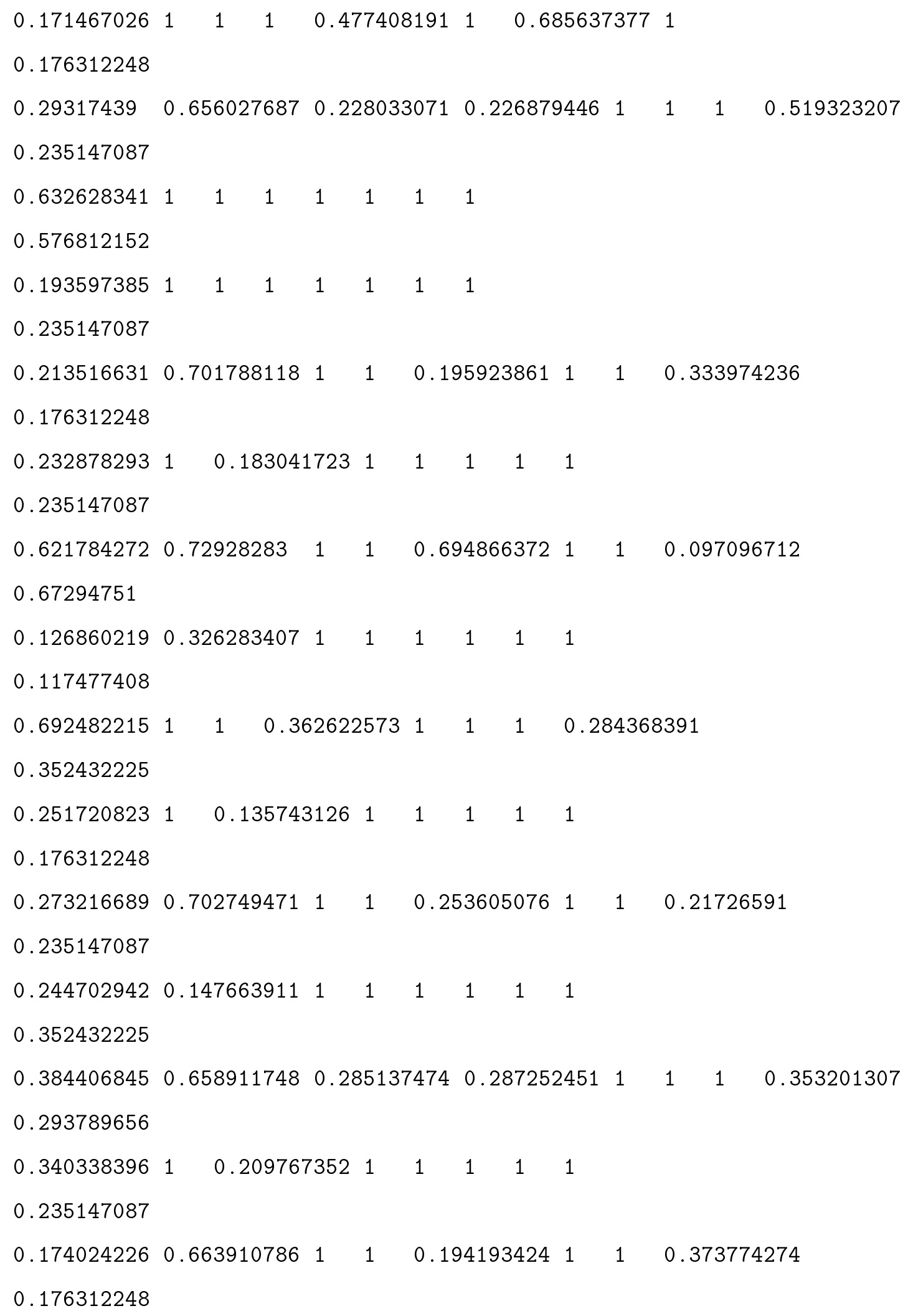




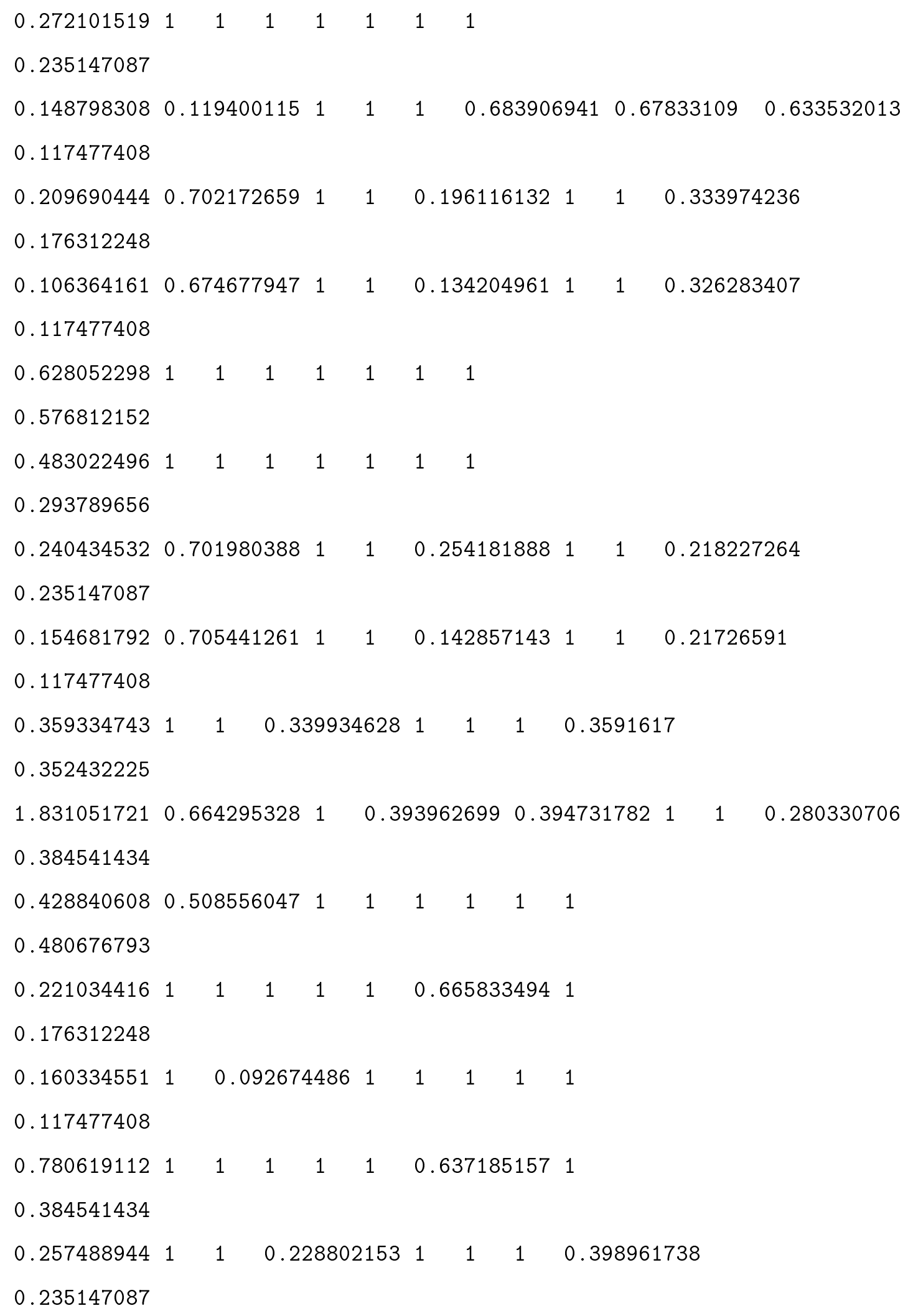




$\begin{array}{lllllllllll}0.616362238 & 1 & 1 & 1 & 1 & 1 & 0.566621803 & 1 & & \\ 0.352432225 & & & & & & & & & \\ 0.190732551 & 1 & 0.16073832 & 1 & 1 & 0.474139589 & 1 & 1 \\ 0.176312248 & & & & & & & & & \end{array}$




\section{A.2 SVM}

799

0.2636611111111110 .43011110 .235147

$\begin{array}{lllllllll}0.678446 & 0.464718 & 0.575082 & 1 & 1 & 1 & 1 & 0.717554 & 0.672948\end{array}$

$\begin{array}{llllllllll}0.688733 & 0.515093 & 1 & 1 & 1 & 1 & 0.517208 & 1 & 0.576812\end{array}$

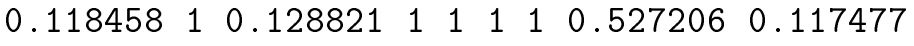

$0.668314 \quad 0.54874111111111110 .576812$

$\begin{array}{lllllllllll}0.30971 & 1 & 0.20996 & 1 & 1 & 1 & 1 & 1 & 0.235147\end{array}$

0.46277611111111111110 .352432

$\begin{array}{llllllllll}0.335435 & 0.640261 & 1 & 0.363776 & 0.361469 & 1 & 1 & 0.196885 & 0.352432\end{array}$

$\begin{array}{llllllllll}0.699 & 0.504711 & 1 & 1 & 1 & 1 & 1 & 0.619112 & 0.480677\end{array}$

$\begin{array}{llllllllll}0.414459 & 1 & 0.341665 & 0.343588 & 1 & 1 & 1 & 0.288406 & 0.352432\end{array}$

$\begin{array}{llllllllllll}0.454163 & 1 & 1 & 1 & 0.371659 & 1 & 1 & 0.122284 & 0.352432\end{array}$

0.2238221111111111110 .29379

$\begin{array}{lllllllllll}1.184926 & 0.326283 & 1 & 1 & 1 & 1 & 1 & 1 & 0.672948\end{array}$

0.3558161111111111110 .384541

$\begin{array}{lllllllllll}0.32786 & 0.70198 & 1 & 1 & 0.305518 & 1 & 1 & 0.302826 & 0.29379\end{array}$

$\begin{array}{lllllllll}0.431667 & 0.596231 & 0.332821 & 1 & 1 & 1 & 1 & 1 & 0.384541\end{array}$

$\begin{array}{lllllllll}0.178446 & 1 & 0.17785 & 0.178043 & 1 & 1 & 1 & 0.520669 & 0.176312\end{array}$

0.229437111111111110 .29379

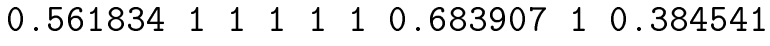

0.13462810 .111902111111110 .117477

0.305999110 .258604111111110 .29379

0.2018461111111111110 .352432

0.28623311111110 .6733321110 .480677

$\begin{array}{llllllllllll}0.323303 & 1 & 1 & 1 & 0.372044 & 1 & 1 & 0.125745 & 0.352432\end{array}$

$\begin{array}{llllllllll}0.524707 & 0.558931 & 1 & 0.365507 & 1 & 1 & 1 & 0.369737 & 0.384541\end{array}$

0.404249111111111110 .672948

$\begin{array}{llllllllll}0.205672 & 0.162469 & 1 & 1 & 1 & 0.700827 & 0.635455 & 1 & 0.176312\end{array}$ 
0.4077291110 .397039111110 .3824260 .384541

$\begin{array}{llllllllll}0.362142 & 1 & 1 & 0.340127 & 1 & 1 & 1 & 0.357816 & 0.352432\end{array}$

$\begin{array}{llllllllllll}0.129052 & 1 & 1 & 1 & 1 & 1 & 0.628725 & 1 & 0.117477\end{array}$

0.220304111111111110 .352432

0.2883871111111111110 .384541

$\begin{array}{llllllllll}0.973678 & 0.570467 & 0.545857 & 0.556816 & 1 & 1 & 1 & 1 & 0.576812\end{array}$

$\begin{array}{lllllllllll}0.316266 & 1 & 1 & 1 & 1 & 1 & 0.430879 & 1 & 0.235147\end{array}$

0.49600111111111110 .480677

$\begin{array}{lllllllll}0 & 0.324361 & 0.482407 & 1 & 1 & 1 & 1 & 1 & 0.672948\end{array}$

$\begin{array}{llllllllll}0.344068 & 0.640838 & 1 & 0.30648 & 0.304941 & 1 & 1 & 0.367045 & 0.29379\end{array}$

$\begin{array}{lllllllllll}0.254951 & 1 & 1 & 1 & 0.399346 & 1 & 1 & 0.128245 & 0.384541\end{array}$

0.24576110 .137281111111110 .176312

$\begin{array}{llllllllll}0.282484 & 1 & 1 & 1 & 1 & 1 & 0.502211 & 1 & 0.29379\end{array}$

0.4810231110 .4891371111110 .480677

$\begin{array}{lllllllllll}0.324053 & 1 & 1 & 1 & 0.370698 & 1 & 1 & 0.122476 & 0.352432\end{array}$

0.57694711111111110 .352432

$\begin{array}{llllllllll}0.681888 & 0.729475 & 1 & 1 & 0.696212 & 1 & 1 & 0.097097 & 0.672948\end{array}$

$\begin{array}{lllllllll}0.783484 & 1 & 1 & 0.6791 & 1 & 1 & 1 & 0.230917 & 0.672948\end{array}$

$\begin{array}{lllllllllll}0.146837 & 0.119016 & 1 & 1 & 1 & 0.676985 & 0.67737 & 1 & 0.117477\end{array}$

$\begin{array}{lllllllllll}0.453124 & 1 & 1 & 1 & 0.59354 & 1 & 1 & 0.341473 & 0.576812\end{array}$

$\begin{array}{llllllllllll}0.171467 & 1 & 1 & 1 & 0.477408 & 1 & 0.685637 & 1 & 0.176312\end{array}$

$\begin{array}{llllllllll}0.293174 & 0.656028 & 0.228033 & 0.226879 & 1 & 1 & 1 & 0.519323 & 0.235147\end{array}$

0.63262811111111110 .576812

0.19359711111111110 .235147

$\begin{array}{llllllllll}0.213517 & 0.701788 & 1 & 1 & 0.195924 & 1 & 1 & 0.333974 & 0.176312\end{array}$

0.232878110 .183042111111110 .235147

$\begin{array}{llllllllll}0.621784 & 0.729283 & 1 & 1 & 0.694866 & 1 & 1 & 0.097097 & 0.672948\end{array}$

0.126860 .3262831111111110 .117477

$\begin{array}{lllllllllll}0.692482 & 1 & 1 & 0.362623 & 1 & 1 & 1 & 0.284368 & 0.352432\end{array}$

$\begin{array}{llllllllll}0.251721 & 1 & 0.135743 & 1 & 1 & 1 & 1 & 1 & 0.176312\end{array}$ 


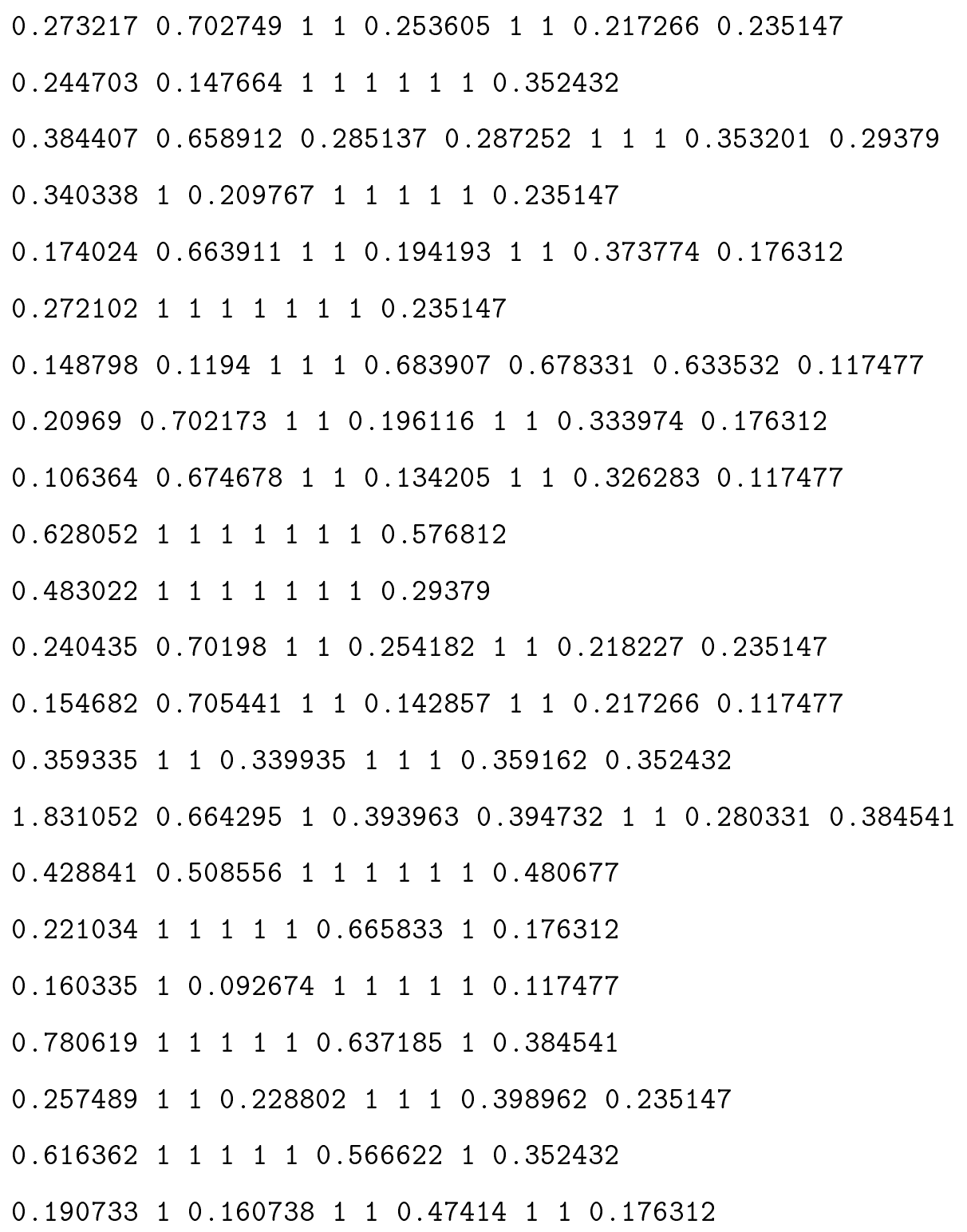




\section{A.3 Cubist}

\section{Arquivo nomearq.names}

| Comment: Fusao de sensores

\begin{tabular}{lll} 
dreal. & \multicolumn{1}{c}{ | class names } \\
& & \\
dcamera: & continuous. & $\mid$ distancia obtida das imagens \\
ds1: & continuous. & $\mid$ distancia do sensor 1 \\
ds2: & continuous. & $\mid$ distancia do sensor 2 \\
ds3: & continuous. & $\mid$ distancia do sensor 3 \\
ds4: & continuous. & $\mid$ distancia do sensor 4 \\
ds5: & continuous. & $\mid$ distancia do sensor 5 \\
ds6: & continuous. & $\mid$ distancia do sensor 6 \\
ds7: & continuous. & $\mid$ distancia do sensor 7 \\
dreal: continuous. & $\mid$ distancia real
\end{tabular}

\section{Arquivo nomearq.data}

$$
\begin{aligned}
& 0.263661,1,1,1,1,1,0.43011,1,0.235147 \\
& 0.678446,0.464718,0.575082,1,1,1,1,0.717554,0.672948 \\
& 0.688733,0.515093,1,1,1,1,0.517208,1,0.576812 \\
& 0.118458,1,0.128821,1,1,1,1,0.527206,0.117477 \\
& 0.668314,0.548741,1,1,1,1,1,1,0.576812 \\
& 0.30971,1,0.20996,1,1,1,1,1,0.235147 \\
& 0.462776,1,1,1,1,1,1,1,0.352432 \\
& 0.335435,0.640261,1,0.363776,0.361469,1,1,0.196885,0.352432 \\
& 0.699,0.504711,1,1,1,1,1,0.619112,0.480677 \\
& 0.414459,1,0.341665,0.343588,1,1,1,0.288406,0.352432
\end{aligned}
$$


$0.454163,1,1,1,0.371659,1,1,0.122284,0.352432$

$0.223822,1,1,1,1,1,1,1,0.29379$

$1.184926,0.326283,1,1,1,1,1,1,0.672948$

$0.355816,1,1,1,1,1,1,1,0.384541$

$0.32786,0.70198,1,1,0.305518,1,1,0.302826,0.29379$

$0.431667,0.596231,0.332821,1,1,1,1,1,0.384541$

$0.178446,1,0.17785,0.178043,1,1,1,0.520669,0.176312$

$0.229437,1,1,1,1,1,1,1,0.29379$

$0.561834,1,1,1,1,1,0.683907,1,0.384541$

$0.134628,1,0.111902,1,1,1,1,1,0.117477$

$0.305999,1,0.258604,1,1,1,1,1,0.29379$

$0.201846,1,1,1,1,1,1,1,0.352432$

$0.286233,1,1,1,1,0.673332,1,1,0.480677$

$0.323303,1,1,1,0.372044,1,1,0.125745,0.352432$

$0.524707,0.558931,1,0.365507,1,1,1,0.369737,0.384541$

$0.404249,1,1,1,1,1,1,1,0.672948$

$0.205672,0.162469,1,1,1,0.700827,0.635455,1,0.176312$

$0.407729,1,1,0.397039,1,1,1,0.382426,0.384541$

$0.362142,1,1,0.340127,1,1,1,0.357816,0.352432$

$0.129052,1,1,1,1,1,0.628725,1,0.117477$

$0.220304,1,1,1,1,1,1,1,0.352432$

$0.288387,1,1,1,1,1,1,1,0.384541$

$0.973678,0.570467,0.545857,0.556816,1,1,1,1,0.576812$

$0.316266,1,1,1,1,1,0.430879,1,0.235147$

$0.496001,1,1,1,1,1,1,1,0.480677$

$0,0.324361,0.482407,1,1,1,1,1,0.672948$

$0.344068,0.640838,1,0.30648,0.304941,1,1,0.367045,0.29379$

$0.254951,1,1,1,0.399346,1,1,0.128245,0.384541$

$0.24576,1,0.137281,1,1,1,1,1,0.176312$

$0.282484,1,1,1,1,1,0.502211,1,0.29379$ 


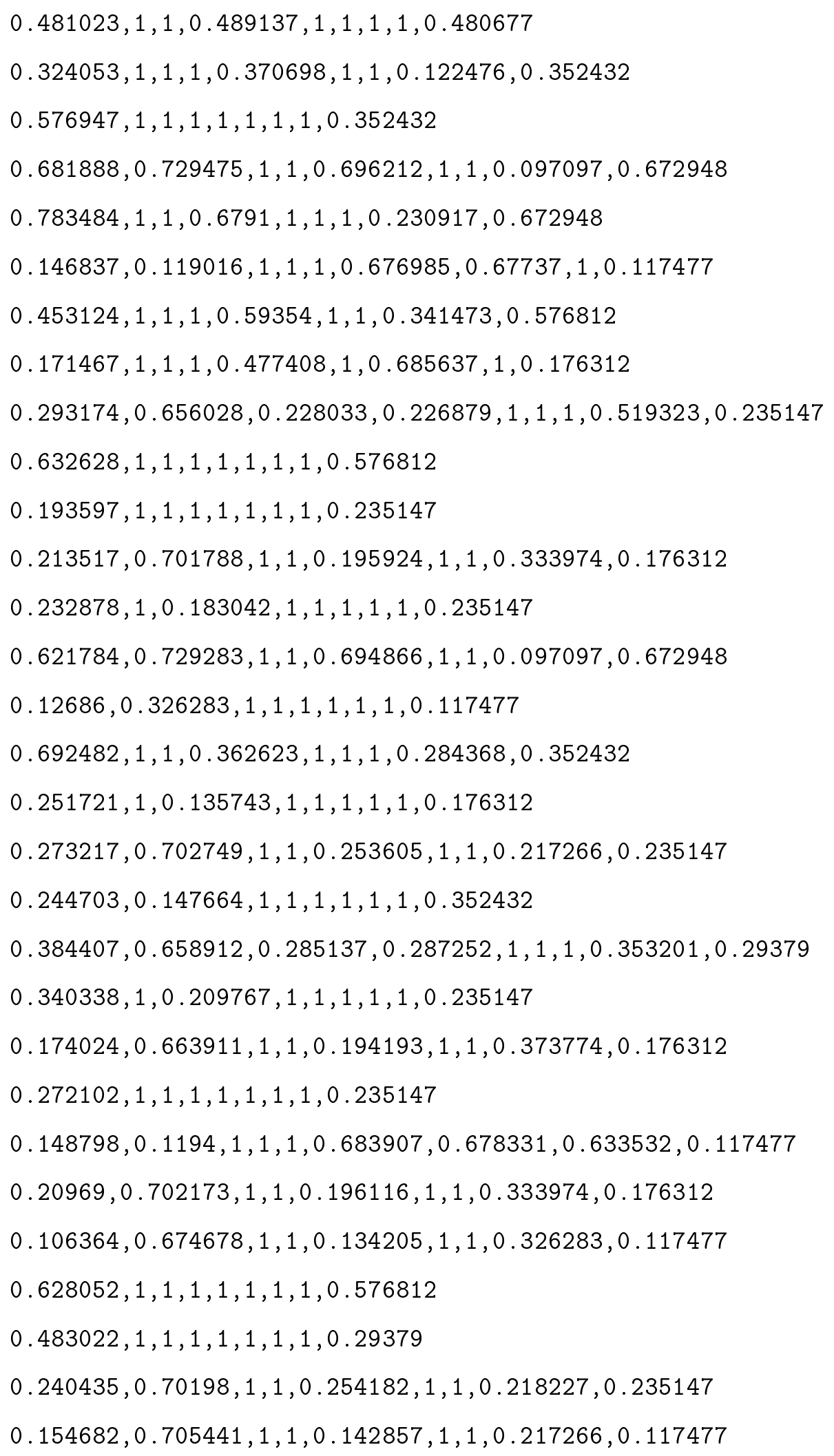




$$
\begin{aligned}
& 0.359335,1,1,0.339935,1,1,1,0.359162,0.352432 \\
& 1.831052,0.664295,1,0.393963,0.394732,1,1,0.280331,0.384541 \\
& 0.428841,0.508556,1,1,1,1,1,1,0.480677 \\
& 0.221034,1,1,1,1,1,0.665833,1,0.176312 \\
& 0.160335,1,0.092674,1,1,1,1,1,0.117477 \\
& 0.780619,1,1,1,1,1,0.637185,1,0.384541 \\
& 0.257489,1,1,0.228802,1,1,1,0.398962,0.235147 \\
& 0.616362,1,1,1,1,1,0.566622,1,0.352432 \\
& 0.190733,1,0.160738,1,1,0.47414,1,1,0.176312
\end{aligned}
$$



A.4 M5
Orelation, 'testa1'
Qattribute, dcamera real
Qattribute,ds1 real
Qattribute,ds2 real
Qattribute, ds3 real
Qattribute, ds4 real
Qattribute,ds5 real
Qattribute,ds6 real
Qattribute,ds7 real
Qattribute,dreal real

\section{Qdata}

$0.263661,1,1,1,1,1,0.43011,1,0.235147$

$0.678446,0.464718,0.575082,1,1,1,1,0.717554,0.672948$

$0.688733,0.515093,1,1,1,1,0.517208,1,0.576812$

$0.118458,1,0.128821,1,1,1,1,0.527206,0.117477$

$0.668314,0.548741,1,1,1,1,1,1,0.576812$

$0.30971,1,0.20996,1,1,1,1,1,0.235147$

$0.462776,1,1,1,1,1,1,1,0.352432$

$0.335435,0.640261,1,0.363776,0.361469,1,1,0.196885,0.352432$

$0.699,0.504711,1,1,1,1,1,0.619112,0.480677$

$0.414459,1,0.341665,0.343588,1,1,1,0.288406,0.352432$

$0.454163,1,1,1,0.371659,1,1,0.122284,0.352432$

$0.223822,1,1,1,1,1,1,1,0.29379$

$1.184926,0.326283,1,1,1,1,1,1,0.672948$

$0.355816,1,1,1,1,1,1,1,0.384541$

$0.32786,0.70198,1,1,0.305518,1,1,0.302826,0.29379$ 


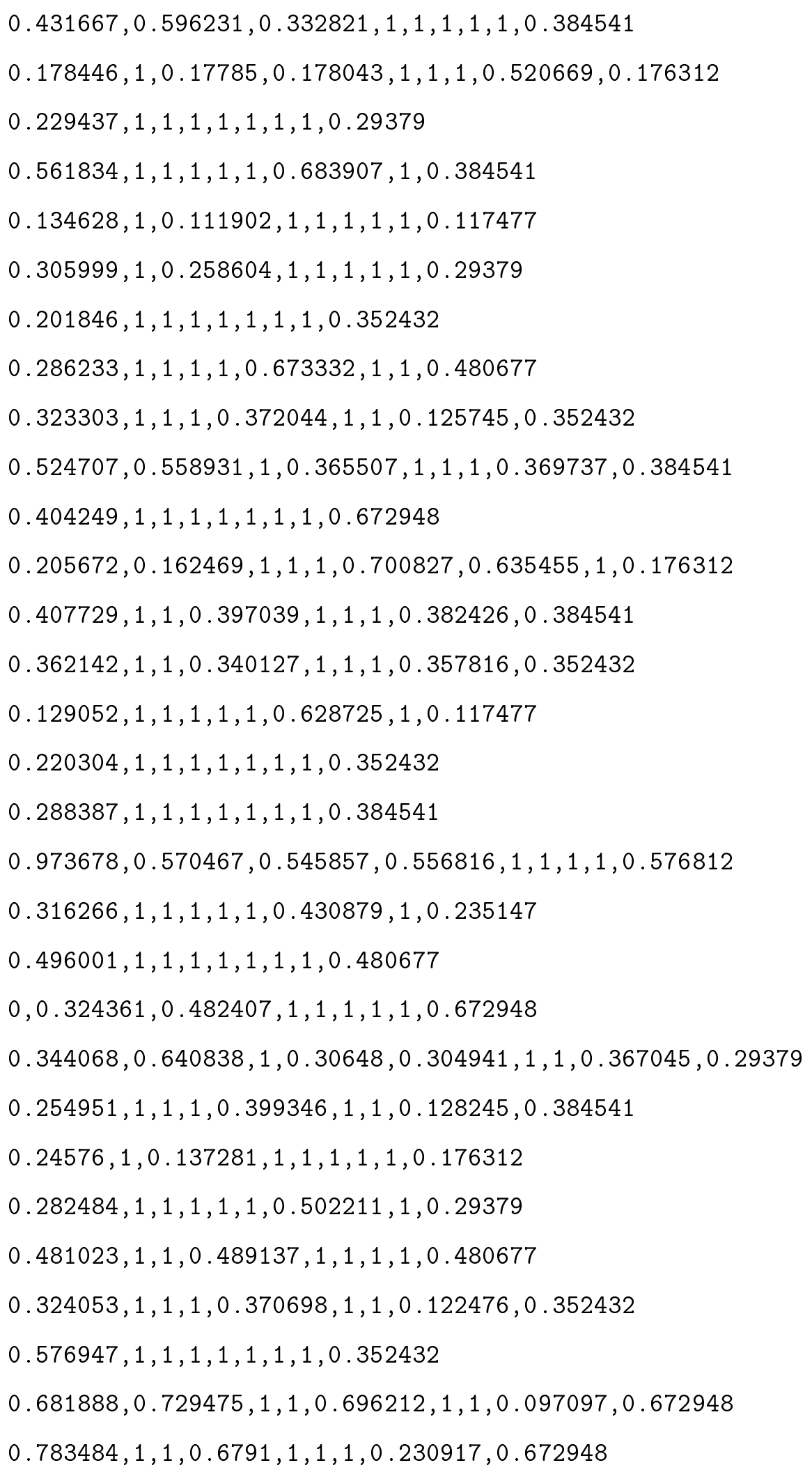


$0.146837,0.119016,1,1,1,0.676985,0.67737,1,0.117477$

$0.453124,1,1,1,0.59354,1,1,0.341473,0.576812$

$0.171467,1,1,1,0.477408,1,0.685637,1,0.176312$

$0.293174,0.656028,0.228033,0.226879,1,1,1,0.519323,0.235147$

$0.632628,1,1,1,1,1,1,1,0.576812$

$0.193597,1,1,1,1,1,1,1,0.235147$

$0.213517,0.701788,1,1,0.195924,1,1,0.333974,0.176312$

$0.232878,1,0.183042,1,1,1,1,1,0.235147$

$0.621784,0.729283,1,1,0.694866,1,1,0.097097,0.672948$

$0.12686,0.326283,1,1,1,1,1,1,0.117477$

$0.692482,1,1,0.362623,1,1,1,0.284368,0.352432$

$0.251721,1,0.135743,1,1,1,1,1,0.176312$

$0.273217,0.702749,1,1,0.253605,1,1,0.217266,0.235147$

$0.244703,0.147664,1,1,1,1,1,1,0.352432$

$0.384407,0.658912,0.285137,0.287252,1,1,1,0.353201,0.29379$

$0.340338,1,0.209767,1,1,1,1,1,0.235147$

$0.174024,0.663911,1,1,0.194193,1,1,0.373774,0.176312$

$0.272102,1,1,1,1,1,1,1,0.235147$

$0.148798,0.1194,1,1,1,0.683907,0.678331,0.633532,0.117477$

$0.20969,0.702173,1,1,0.196116,1,1,0.333974,0.176312$

$0.106364,0.674678,1,1,0.134205,1,1,0.326283,0.117477$

$0.628052,1,1,1,1,1,1,1,0.576812$

$0.483022,1,1,1,1,1,1,1,0.29379$

$0.240435,0.70198,1,1,0.254182,1,1,0.218227,0.235147$

$0.154682,0.705441,1,1,0.142857,1,1,0.217266,0.117477$

$0.359335,1,1,0.339935,1,1,1,0.359162,0.352432$

$1.831052,0.664295,1,0.393963,0.394732,1,1,0.280331,0.384541$

$0.428841,0.508556,1,1,1,1,1,1,0.480677$

$0.221034,1,1,1,1,1,0.665833,1,0.176312$

$0.160335,1,0.092674,1,1,1,1,1,0.117477$ 
$0.780619,1,1,1,1,1,0.637185,1,0.384541$

$0.257489,1,1,0.228802,1,1,1,0.398962,0.235147$

$0.616362,1,1,1,1,1,0.566622,1,0.352432$

$0.190733,1,0.160738,1,1,0.47414,1,1,0.176312$ 


\section{Apêndice B}

\section{Arquivo batch para treinamento das redes MLP}

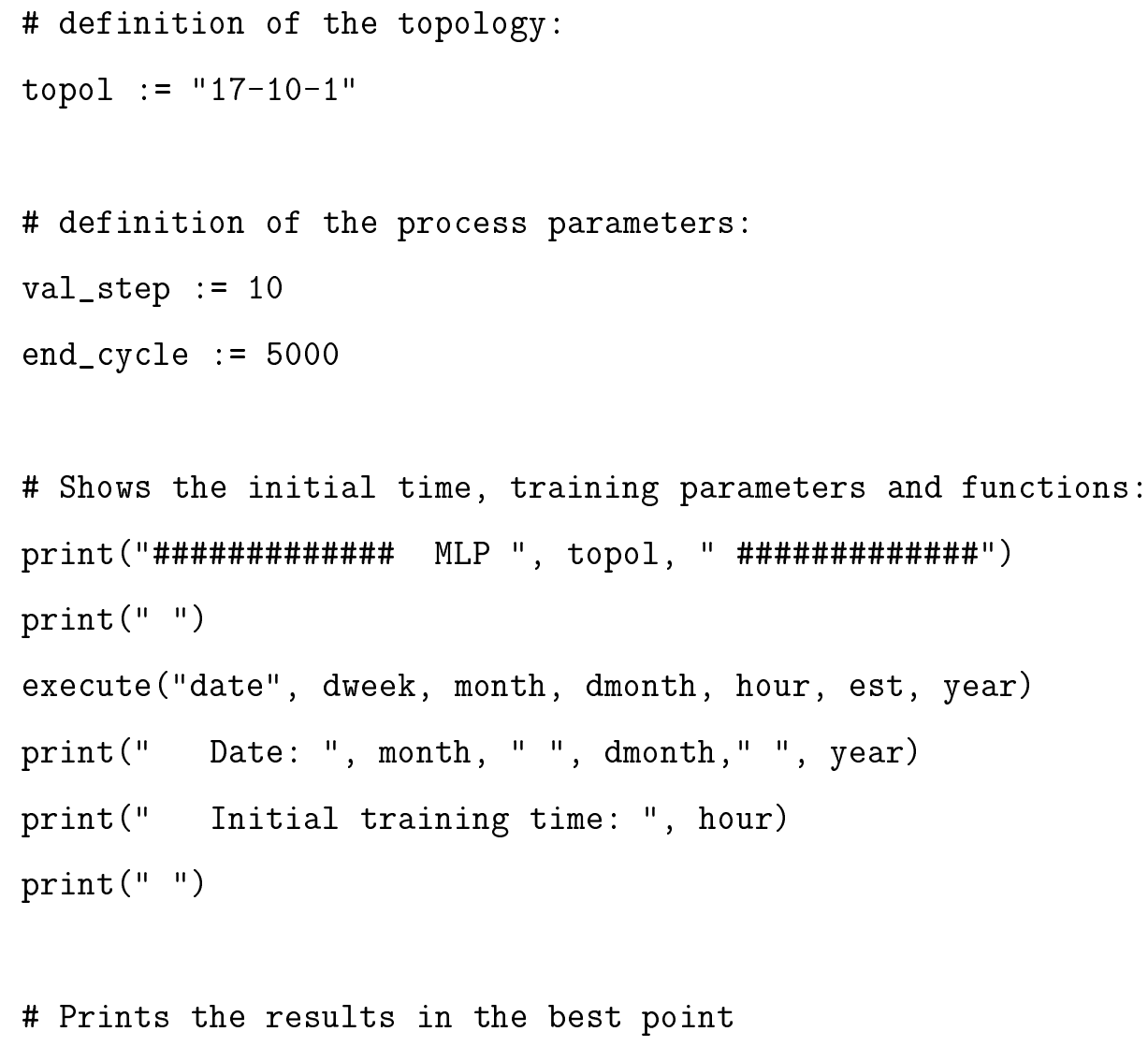




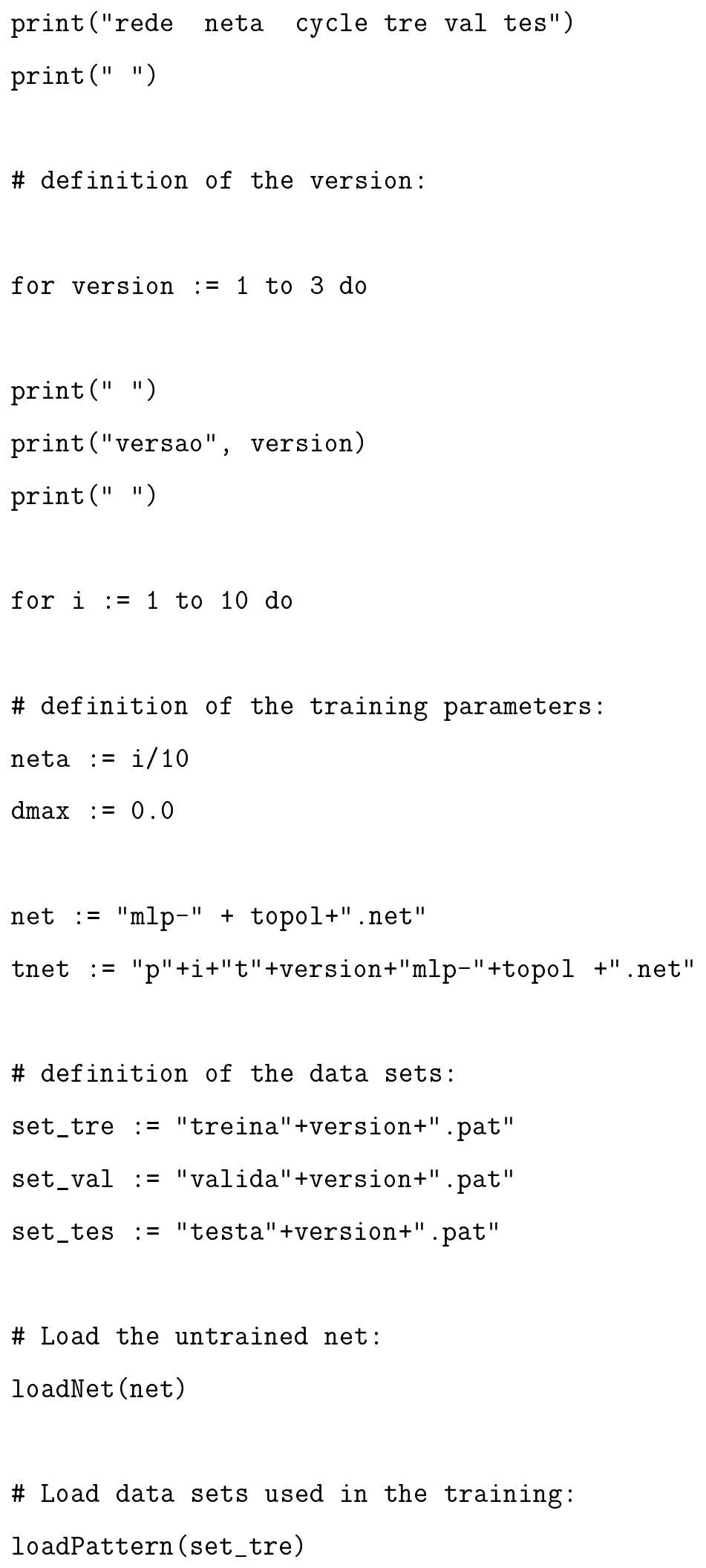




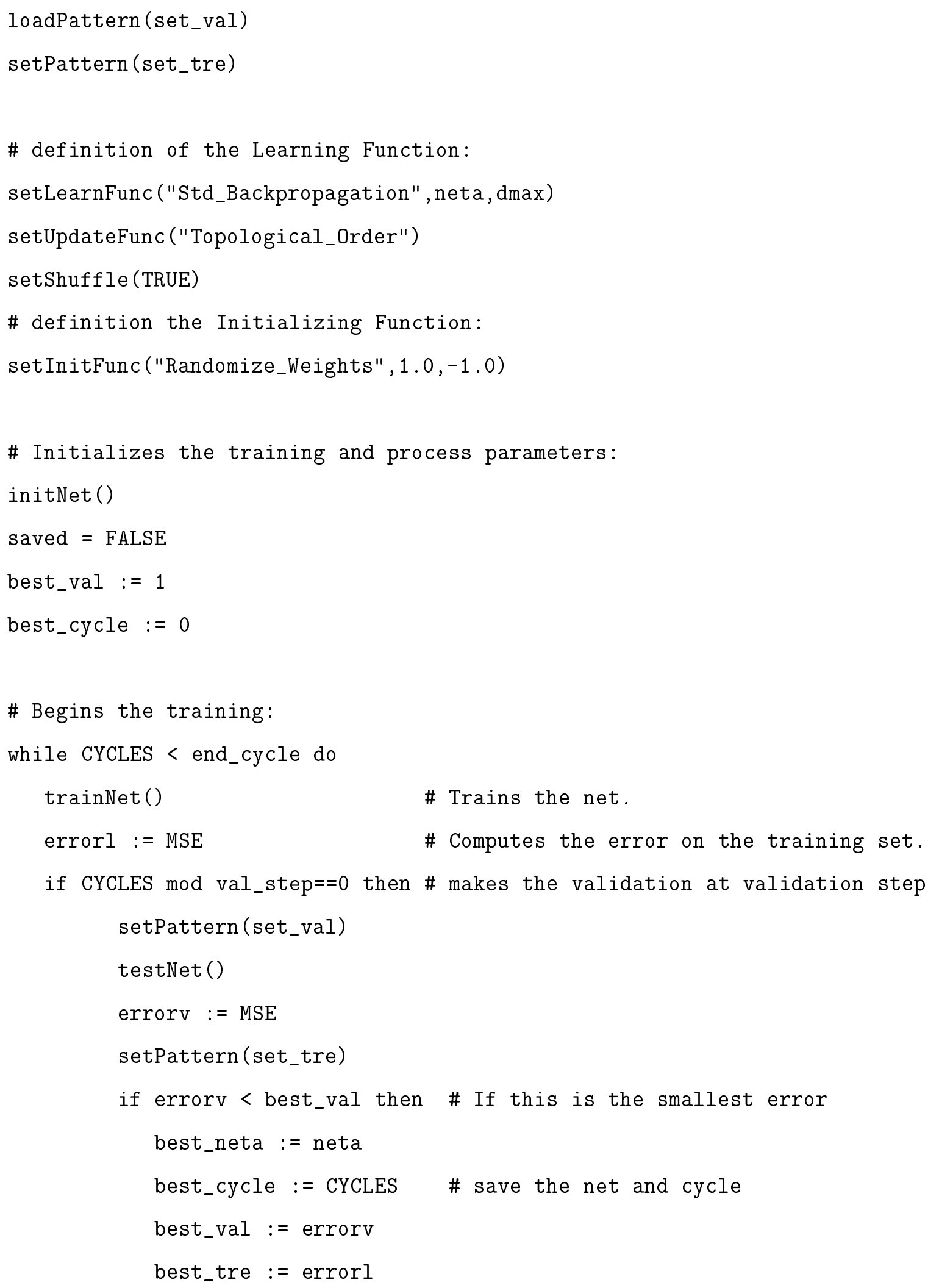




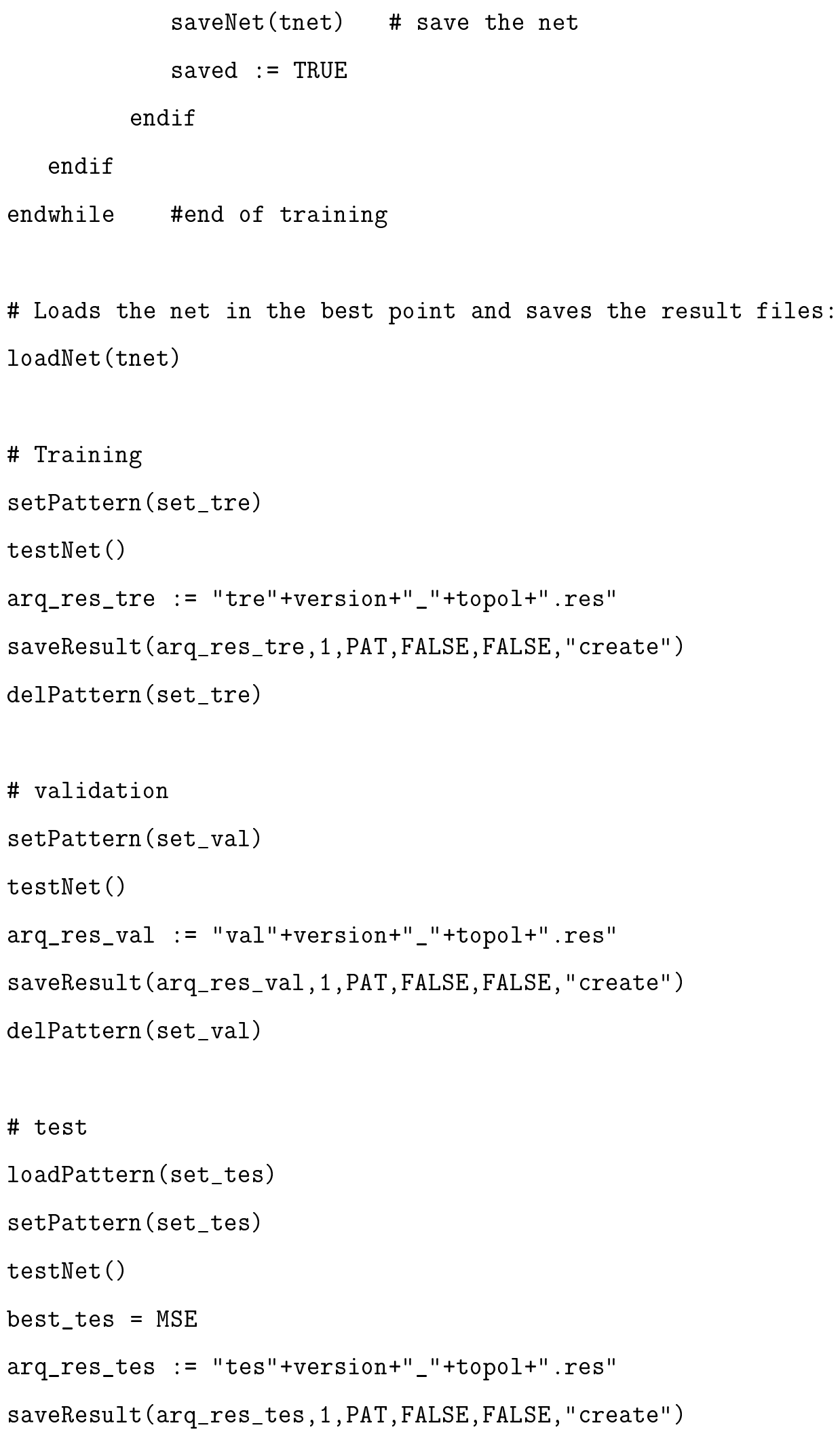




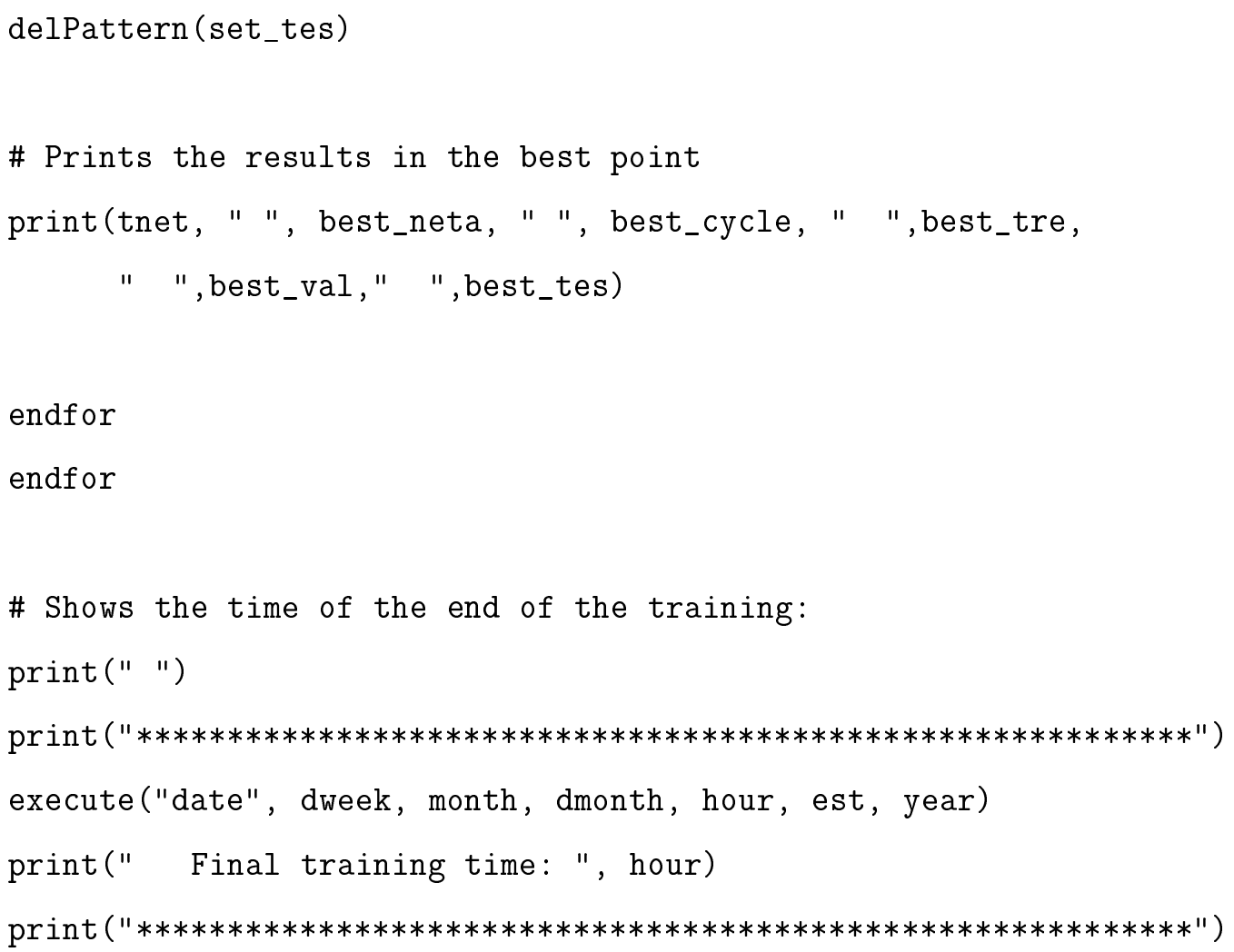

